\title{
Life-span development and myocardial infarction : an epidemiological study
}

Citation for published version (APA):

Falger, P. R. J. (1989). Life-span development and myocardial infarction : an epidemiological study.

[Doctoral Thesis, Maastricht University]. Rijksuniversiteit Limburg. https://doi.org/10.26481/dis.19891116pf

Document status and date:

Published: 01/01/1989

DOI:

10.26481/dis.19891116pf

Document Version:

Publisher's PDF, also known as Version of record

\section{Please check the document version of this publication:}

- A submitted manuscript is the version of the article upon submission and before peer-review. There can be important differences between the submitted version and the official published version of record.

People interested in the research are advised to contact the author for the final version of the publication, or visit the DOI to the publisher's website.

- The final author version and the galley proof are versions of the publication after peer review.

- The final published version features the final layout of the paper including the volume, issue and page numbers.

Link to publication

\footnotetext{
General rights rights.

- You may freely distribute the URL identifying the publication in the public portal. please follow below link for the End User Agreement:

www.umlib.nl/taverne-license

Take down policy

If you believe that this document breaches copyright please contact us at:

repository@maastrichtuniversity.nl

providing details and we will investigate your claim.
}

Copyright and moral rights for the publications made accessible in the public portal are retained by the authors and/or other copyright owners and it is a condition of accessing publications that users recognise and abide by the legal requirements associated with these

- Users may download and print one copy of any publication from the public portal for the purpose of private study or research.

- You may not further distribute the material or use it for any profit-making activity or commercial gain

If the publication is distributed under the terms of Article $25 \mathrm{fa}$ of the Dutch Copyright Act, indicated by the "Taverne" license above, 


\title{
LIFE-SPAN DEVELOPMENT AND MYOCARDIAL INFARCTION: AN EPIDEMIOLOGICAL STUDY
}

\author{
Paul R.J. Falger
}




\title{
LIFE-SPAN DEVELOPMENT AND MYOCARDIAL INFARCTION: AN EPIDEMIOLOGICAL STUDY
}

\author{
Proefschrift
}

ter verkrijging van de graad van doctor aan de Rijksuniversiteit Limburg te Maastricht,

op gezag van de Rector Magnificus Prof. Dr. F.I.M. Bonke, volgens het besluit van het College van Dekanen, in het openbaar te verdedigen

op

donderdag, 16 november 1989 om 14.00 uur

door

Paul Raymond Joseph Falger

geboren te Utrecht in 1944 


\section{Promotores:}

Prof, Dr. A.P.W.M. Appels

Prof. Dr. J.M.A. Munnichs (Katholieke Universiteit Nijmegen)

\section{Beoordelingscommissie:}

Prof. Dr. F. Sturmans, voorzitter

Dr. F.W.H.M. Băr

Prof. Dr. M.A. van den Hout

Prof. Dr. J.A. Knotnerus

Prof. Dr. J.A.M. Winnubst (Rijksuniversiteit Utrecht)

This research was supported in part by Grant 31.010h/1981 from the Dutch Heart Foundation; financial support by the Dutch Heart Foundation for the publication of this thesis is also gratefully acknowledged. 
"... Der Mensch als ganzer lebt sein Leben in teilweiser unbewusster, teilweise bewusster Regulierung seines Systems. Er versucht, indem er dauernd Vergangenheit, Gegenwart und Zukunft in individuell verschiedenem Grade im Auge zu behalten trachtet, sein Leben zu lenken und die Umstände zu bemeistern. Er erlebt das Resultat seiner Bestrebungen zu verschiedenen Zeiten seines Lebens als gelingend oder als misslingend, je nach Einsatz, Umständen und Zielen" 1 .

(Charlotte Bühler, 'Der menschliche Lebenslauf als psychologisches Problem", 1959).

Dedicated to the memory of my father for Mischa, Marije, and Jeremy 
Taalkundige adviezen:

Pamela Falger-Cohen, M.A.

Manuscript en vormgeving:

Isel van Noppen

Omslag en druk:

Hub Scheyen

Paranimfen:

Yolande Nalissen-de Vos

Erik Schouten 


\section{TABLE OF CONTENTS}

pag.

Voorwoord

Chapter 1. Life-Span Developmental Aspects of and Psychosocial Risk Indicators in the Etiology of Myocardial Infarction . . . . 13

1.1. Introduction: Approaching the Problem . . . . . . . . 13

1.2. Life-Span Developmental Psychology as Theoretical and Methodological Orientation ......... . . . 14

1.3. Some Origins of Life-Span Developmental Psychology . . . 16

1.4. Psychosocial Risk Indicators in the Etiology of Myocardial Infarction .............. . 19

1.5. Integration: The Role of Psychosocial Risk Indicators in the Etiology of Myocardial Infarction from a Life-Span Developmental Perspective . . . . . . . . . . . . 31

1.6. Some Hypotheses and Explorations about Psychosocial Risk Indicators in the Etiology of Myocardial Infarction from a Life-Span Developmental Perspective . . . . . . . . 38

Chapter 2. Design and Methods of the Study: A Life-Span Developmental Approach . . . . . . . . . . . 41

2.1. Introduction . . . . . . . . . . . . . 41

2.2. Subjects .................... 42

2.3. Age Distribution . . . . . . . . . . . . . 48

2.4. Instruments . . . . . . . . . . . . 51

Chapter 3. Results: Relationships between the Type A CoronaryProne Behavior Pattern and First Myocardial Infarction . . 67

3.1. Introduction \& Hypotheses ............. 67

3.2. Hypothesis 1: Occurrence of the Type A Coronary-Prone Behavior Pattern .......... 68

3.3. Hypothesis 2: The Type A Coronary-Prone Behavior Pattern as an Independent Risk Indicator for First Myocardial Infarction

3.4. The Type A Coronary-Prone Behavior Pattern and its Association with Reported Stressful Life Events over the Life-Span 
Chapter 4. Results: Relationships between Manifestations of Vital Exhaustion and First Myocardial Infarction . . . . . . . 75

4.1. Introduction \& Hypotheses . . . . . . . . . .75

4.2. Hypothesis 1: Occurrence of Manifestations of Vital

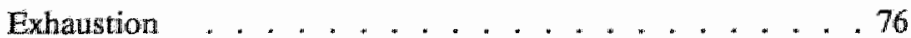

43. Hypothesis 2: Manifestations of Vital Exhaustion as an Independent Risk Indicator for First Myocardial Infarction $\quad .77$

4.4. Hypothesis 3: Type A Subjects are at an Elevated Risk of Becoming Vitally Exhausted . . . . . . . . . 83

4.5. Hypothesis 4: Vitally Exhausted Type A Subjects are at Greater Risk of Suffering First Myocardial Infarction than Vital Type A Subjects . . . . . . . . . . . . . . . .83

4.6. Hypothesis 5: Type A Subjects are More at Risk of Suffering First Myocardial Infarction than Type B Subjects When Controlling for Manifestations of Vital Exhaustion . . 84

4.7. Manifestations of Vital Exhaustion and their Association with Reported Stressful Life Events over the Life-Span . . . 86

Chapter 5. Results: Relationships between Reported Stressful Life Events over the Life-Span and First Myocardial Infarction . . 89

5.1. Introduction, Hypotheses \& Explorations . . . . . . . . 89

5.2. Hypothesis 1: Occurrence of Reported Stressful Life Events over the Life-Span . . . . . . . . . . . . . . . . . . 92

5.3. Hypothesis 2: Reported Stressful Life Events over the Life-Span as Independent Risk Indicators for First Myocardial Infarction . . . . . . . . . . . . . . . . . 95

5.4. Exploration 1: Type A Coronary-Prone Behavior Pattern as a Moderating Factor Regarding Risk for First Myocardial Infarction Associated with Reported Stressful Life Events . . 96

5.5. Exploration 2: Manifestations of Vital Exhaustion as Moderating Factors Regarding Risk for First Myocardial Infarction Associated with Reported Stressful Life Events . . 99

5.6. Reported Stressful Life Events over the Life-Span, Type A Coronary-Prone Behavior Pattern, Manifestations of Vital Exhaustion, and Other Factors as Risk Indicators for First Myocardial Infarction: Multiple Logistic Regression Analyses 102

5.7. Summary 
Chapter 6. Discussion I: Life-Span Development and First Myocardial Infarction: Some Epidemiological Considerations . . . . 107

6.1. The Type A Coronary-Prone Behavior Pattern and its Association with First Myocardial Infarction . . . . . 107

6.2. Reported Stressful Life Events and their Association with First Myocardial Infarction

6.3. Manifestations of Vital Exhaustion and Their Association with First Myocardial Infarction . . . . . . . . . . . . 116

6.4. The Type A Coronary-Prone Behavior Pattern, Reported Stressful Life Events, and their Associations with First Myocardial Infarction . . . . . . . . . . . . . . . . 122

6.5. The Type A Coronary-Prone Behavior Pattern, Manifestations of Vital Exhaustion, and their Common Association with First Myocardial Infarction . . . . . . . . . . . . . 125

6.6. Manifestations of Vital Exhaustion, Reported Stressful Life Events, and their Associations with First Myocardial Infarction

Chapter 7. Discussion II: Life-Span Development and First Myocardial Infarction: Some Psychological Considerations

7.1. Intraduction . . . . . . . . . . . . . 135

7.2. The Psychological Impact of Reported Stressful Life Events over the Life-Span of Three Sellected Cases with First Myocardial Infarction . . . . . . . . . . . . . 135

7.3. Occurrence and Psychological Impact of Reported Stressful Life Events over the Life-Span of Three Cases with First Myocardial Infarction: Some Similarities and Differences

7.4. The Life-Span Development of Cases with First Myocardial Infarction and Bühler's Theory of "Self-Determination" . . 158

Chapter 8. Summary .................. 169

List of Abbreviations . . . . . . . . . . . . . . 183

Notes $\ldots \ldots \ldots \ldots . \ldots . \ldots . \ldots 184$

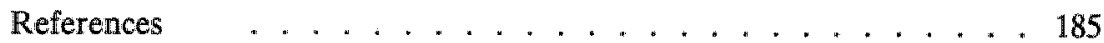

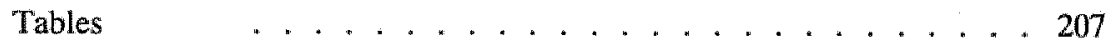

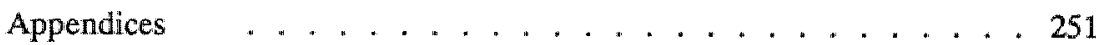

List of Publications and Abstracts . . . . . . . . . . . . 293

Curriculum Vitae . . . . . . . . . . . . . . . . . . . . . 299 


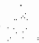

.

$\therefore$ 


\section{Voorwoord}

Tien jaar liggen er tussen het opzetten van het onderzoek, waarover in dit proefschrift verslag wordt gedaan, en het schrijven van dit voorwoord. In die lange tijd zijn er bijna 500 mensen - enkele onderzoekers, interviewers, en verpleegkundigen/afdelingshoofden, maar bovenal vele hartpatiënten, en overige personen, hier slechts aangeduid als "controles" - bij dit onderzoek betrokken geweest. Van de hartpatiënten, destijds opgenomen in Ziekenhuis St. Annadal (Maastricht) of het De Wewer Ziekenhuis (Heerlen) kan ik hier helaas niet meer allen bedanken. Zonder hun onvoorwaardelijke medewerking aan de levensloopinterviews, die vaak buitengewoon openhartig en bijna altijd indringend waren en de kern van hun levensverhaal blootlegden, zou dit proefschrift niet geschreven zijn. Ook de levensgeschiedenis van de buurt- of ziekenhuiscontroles was onmisbaar on de vele analyses over de centrale vraagstelling zin te geven en te doen slagen.

De verschillende bijdragen van de onderzoekers, interviewers en verpleegkundigen komen bij een gelegenheid als deze nu eenmaal onvermijdelijk op naam van de promovendus, maar toch wil ik enkele van hen hier in het bijzonder noemen.

Martha Moonen en Ime Bressers, jullie hebben, net afgestudeerd, mede aan de wieg van deze studie gestaan. Zonder jullie wekelijkse gang naar het ziekenhuis om de eerste contacten met patiënten te leggen, die de schrik van hun infarct nog nauwelijks te boven waren, zouden niet zovelen hebben meegewerkt. Vervolgens hebben jullie ervaren, hoe ingewikkeld de geografie van Zuid Limburg is, toen deze patiënten ook nog eens thuis werden bezocht om hun leven in kaart te brengen. Jullie moeilijke taak is later overgenomen door Jos Bekkers, ook verantwoordelijk voor de eerste invoer en "cleaning" van alle interviews. Ook wil ik hierbij de dames Bonfrère, Kentgens, Lugger, Satijn en Van Valkenburg van onderzoeksbureau "Research \& Marketing" te Heerlen bedanken voor het begrip waarmee zij de voor hen niet alledaagse vraaggesprekken met patiënten en controles uit dit onderzoek hebben gevoerd. Naar Theo Bergmans, afdeling cardiologie 3 West, De Wever Ziekenhuis, gaat mijn dank uit voor zijn grote inzet om gedurende drie jaar zoveel mogelijk patiënten bij dit onderzoek te betrekken, en daarbij steeds blijmoedig tijd voor mij vrij te maken. Zonder de welwillende medewerking van de cardiologen van dit ziekenhuis, en van St. Annadal, zouden alle hartpatiënten echter nooit gezien zijn. 
Tenslotte hierbij een bijzonder woord wan dank aan Erik Schouten, die vanaf de afsluiting van het onderzoek alle analyses op de computer verrichtte, en nooit moe werd nog weer elegantere oplossingen uit te voeren.

Hooggeleerde Appels, beste Ad, onze samenwerking om dit proefschrift tot een goed einde te brengen is niet altijd even gemakkelijk verlopen, al was je immer een trouwe toeverlaat bij moeilijke analyseproblemen. Van jou heb ik niet alleen geleerd om de hoofdzaken van dit onderzoek van de vele interessante bijzaken te scheiden, maar ook dat het mogelijk is om zulks kort en bondig op te schrijven. De artikelen die na dit proefschrift zullen verschijnen, mogen daarvan getuigen.

Hooggeleerde Munnichs, beste Joep, gedurende de vele jaren waarin dit proefschrift langzaam gestalte kreeg, ben je een grotere persoonlijke steun voor mij geweest, dan je wellicht beseft hebt. Je rotswaste wertrouwen in de mogelijkheden om beschrijvende levenslooppsychologie en epidemiologie in een onderzoek als dit bij elkaar te brengen, zall voor mij een kompas voor toekomstige studies blijven wormen.

Hóggeleerde Bremer, beste Joost, hoewel je niet direct bij dit onderzoek betrokken was, wil ik je bedanken voor de mogelijkheden die je me als voorzitter van de vakgroep van begin af aan hebt geboden om datgene te onderzoeken, waardoor ik gegrepen was.

Beste Isel, zonder jouw aanstekelijke werklust, en je schier oneindig geduld voor mijn onophoudelijke wijzigingen, zou dit proefschrift nooit zijn uiteindelijke fraaie vorm hebben gekregen. Daarvoor wil ik je heel hartelijk bedanken.

De afgelopen tien jaar hebben ook mijn persoonlijk leven niet onberoerd gelaten. Mijn vader heeft het voltooien van dit proefschrift niet mogen meemaken; hij overleed, midden in dit onderzoek, plotseling aan een hartinfarct, te jong nog om al afscheid te nenen.

Pamela; zonder jouw niet aflatende steun en begrip in de moeilijke jaren die nu achter ons liggen, je nuchtere afstandelijkheid, aanstekelijke humor, en niet op de laatste plaats je strenge toepassing van de soms onbegrijpelijke regels wan je moedertaal zou dit proefschrift niet op deze manier, en zeker nooit in deze vorm, tot stand zijn gekomen. Je was daarmee de meest kritische referent die men zich kan wensen.

Tenslotte, Mischa, Marije, en Jeremy, jullie vader zou nu meer tijd voor jullie moeten hebben, zoals hij all jaren beloofde. Houdt hem daar aan! 


\section{Chapter 1: Life-Span Developmental Aspects of and Psychosocial Risk Indicators in the Etiology of Myocardial Infarction.}

\subsection{Introduction: Approaching the Problem.}

Throughout this thesis, first myocardial infarction (MI) in adulthood will be considered as the outcome of a protracted developmental process that covers several stages of the human life-span. During this developmental process, a multitude of biological, behavioral, psychic, and social factors interact continuously in ever-changing configurations to bring about the life-threatening event of first MI in early, middle, or late adulthood.

At first sight, these statements may appear to be perfectly self-evident. However, this does not necessarily mean that the following study will yield any easy answers. On the contrary, these statements pose some rather serious problems with regard to the appropriate theoretical model and methodology that will be necessary and sufficient to study the occurrence of first MI in adulthood from this particular vantage point.

More specifically, one first needs to decide whether it is appropriate to adopt a primarily biologically-oriented model that focuses on molecular psychophysiological determinants. If so, should one study the intricate interactions between these determinants (e.g., systolic blood pressure reactivity, plasma-norepinephrine output and platelet aggregation following exposure to acute "stress") through thoroughly controlled laboratory manipulations, using young, healthy subjects or older individuals who may be slightly at risk? Or should one adhere instead to a contextualistic model that separates individual contributions [e.g., the Type A coronary-prone behavior pattern (TABP)] from ecological determinants (e.g., upward accupational mobility or social network structures), knowing that both are embedded in a rapidly changing culturalhistorical setting ? Should one also investigate this enticing epidemiological puzzle by means of a sequential design with repeated measurements, following three similar cohorts through ten years of their respective life-histories? Such a strategy would most 
likely appeal to any interested scientist, although obtaining some unparalleled results would take a long time indeed.

Both paradigms have produced meaningful results. However, they may not be optimally suited to depicting the particular devellopmental course (i.e., the behavioral, psychological, and social life history) that might be conducive to premature breakdown due to MI. Therefore, it will be proposed here that a life-span developmental orientation - both in theory construction and methodology - may solve some of the problems that arise with respect to the developmental description and explanation of particular behavioral and psychosocial factors that lead to coronary heart disease (CHD) and first MI.

\subsection{Life-Span Developmental Psychology as Theoretical and Methodological Orientation.}

\section{A. Theoretical Orientation.}

Almost two decades ago, life-span developmental psychology became established as a comprehensive theoretical and methodological orientation in studying the development of human behavior. In its broadest sense, it deals with the description and explanation of ontogenetic, age-related behavioral change from birth to death (Baltes Goulet, 1970). Studying intraindividual change in behavior across the lifespan and interindividual differences and similarities in intraindividual change thus became the primary frame of reference (Baltes et al., 1977).

The adjective "life-span developmental" has become generally accepted as denoting the entire range of problems that can be studied. It has been argued, however, that conceptually speaking, it may be more accurate to place the emphasis instead on the manifold processes involved in behavioral change. Thus, the term "ontogenetic" is perhaps more appropriate (Schroots, 1982; Munnichs \& Ollbrich, 1985). In this thesis, the terms "life-span developmental" and "ontogenetic" will be used interchangeably.

Given this theoretical orientation, the unequivocal description of, for example, cumulative exposure to psychosocial stress in consecutive developmental phases in the life-span, crucial personality characteristics, and relevant contextual determinants of CHD might delineate, on the one hand, one or several distinct ontogenetic patterns 
that lead to first MI. The observed interactions between particular personality characteristics and contextual variables, which might vary in different developmental phases, could provide, on the other hand, some psychological explanations for the development of premature $\mathrm{MI}$.

\section{B. Methodological Orientation.}

Renewed interest in the determinants of intra- and interindiwidual differences

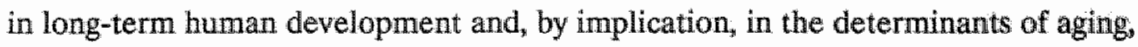
was raised by the ground-breaking paper "A General Model for the Study of Developmental Problems" (Schaie, 1965). This paper dealt with a systematical inquiry into the possible theoretical and methodological explanations for obvious discrepancies and contradictions in conclusions derived from cross-sectional and longitudinal studies on adult development. Schaie concluded that the conventional developmental research strategies were too limited to adequately deal with the crucial issue of confounding with respect to the determinants of development. That is, regardless of the particular research strategy that is adopted, any determinant of human development is a function of the age of the organism, the cohort to which the organism belongs, and the time at which the actual measurement of the variables under study occurs. In this 1965 paper on conceptual principles, and in a later one on research implementations (Schaie, 1973), all possible strategies were spelled out for studying the constituent components of this trifactorial functional equation without confounding. It appeared that the particular model of development that would have to be adopted in any study would depend on the specific determinants of development to be examined. This crucial topic, as it applies to the present study, will be dealt with in more detail later.

In sum, life-span developmental psychology investigates the psychosocial deter. minants of constancy and change in intraindividual development as well as interindividual differences. This is conditional upon the age(s), cohort(s), and environmentalhistorical context(s) of the subjects being investigated. In terms of the present study, this means focusing attention on similarities and differences in cumulative exposure patterns with regard to behavioral and psychosocial factors in different developmental phases or domains. These might be conditional upon such variables as age when $\mathrm{MI}$ occurred, distinct behavioral and psychosocial risk profiles (e.g., the presence or ab- 
sence of TABP), and different sacio-econiomic contexts in which future MII-cases grew up, began working, started their own families, etc.

In other words, an ontogenetic perspective allows one to answer such questions as" Is the vast majority of MI-cases characterized by TABP, irrespective of the age at which they suffered their first $\mathrm{MI}_{\text {" }}$ or is TABP most prominent in early adulthood? Does every MI-case report, in general, the same stressful life events (SLE) prior to first MI, despite different childhood experiences, working conditions and career patterns, and family situations, or are such SLE clearly associated with age, TABP, or adverse life styles?

Before discussing these behavioral and psychosocial factors, some historical precursors to the current ontogenetic orientation will be discussed.

\section{Some Origins of Life-Span Developmental Psychology.}

Although the current interest in determinants of ontogenetic development gathered momentum in the United States, the original notions about life-long human development as a meaningful and prolific unit of psychological analysis can be traced back to the German developmental psychology of the last two centuries (Baltes, 1979; Reinert, 1979; Baltes et al., 1980). A thorough scrutiny of the historical sources of lifespan developmental psychology would be beyond the scope of this thesis. However, the crucial work of Charlotte Bühler, which represents the beginning of contemporary ontogenetic psychology and which sparked the author's interest in the present study, will be discussed here (Charles, 1970; Groffmann, 1970).

\section{The Work of Charlotte Buhler.}

In 1933, Charlotte Bühler published a thorough developmental analysis of some 200 biographiles of contemporary and historical characters (Bühler, 1933; 1959; 1968) ${ }^{2}$. In her investigation, empirical evidence was presented for a distinct structure of consecutive developmental phases with respect to personal striving for psychic integration and fulfillment throughout the life-span. These phases were seen as: "... (1) before self-determination of life-goals sets in; (2) a tentative and preparatory self-determination of life-goals; (3) self-determination of life-goals becomes more 
specified and definitive; (4) assessment of the foregoing life and the attained or failed fulfillment; (5) a phase in which either more or less complete fulfillment is acknowledged, and a post-self-determination life sets in with rest and memories, sometimes illness and decline; or elsewhere partial fulfillment and partial fallure motivate the individual to return to previous forms of striving, sometimes also to resignation; or elsewhere the feeling of more or less complete failure ends in depression or despair" (Bühler, 1968).

In discussing these biographies, particular emphasis was placed on intra- and interindividual differences in life-span patterns of self-determination, leading either to psychic integration and fulfillment or to partial or complete failure.

According to Bühler, self-determination throughout various phases of the lifespan could be achieved through the thoughtful application of different constellations of four motivational and developmental processes, namely, "schöpferische Expansion" (creative expansion), "adaptive Selbst-beschränkung" (self-limiting adaptation), "Aufrechterhaltung der inneren Ordnung" (upholding internal order), and "Bedürfnisbefriedigung" (satisfaction of needs; Bühler, 1959). The psychological outcome of each developmental phase was considered to be largely dependent upon the particular constellation of processes contingent upon self-determination in antecedent developmental stages. These predominant patterns were denoted as "healthy", "problematic", or "neurotic" (Bühler, 1968). The relative success or failure of a dominant self-determination pattern within a specific developmental phase appeared to be contingent upon the niature of personal fulfillment in the antecedent stages.

Thus, in many respects, this "early" formulation of a contemporary ontogenetic psychological theory is important for the present study about life-span developmental determinants of first MI.

First, biological development as a normative model is distinct from psychological and social development throughout the course of an individual's life. That is , biological development, in general, is conceived of as irreversible, linear development, reaching an early maturational apex, but then gradually declining, or, in other words, representing an "irrewersible decrement" model (Schaie, 1973). 
Second, psychological and social development over the life-span is conceptualized as a reversible, cyclical developmental process, unfolding in clearly discernable stagess, it is "superimposed" upon, and in continuous interchange with, biological development and aging. In current thinking on adult development, this means that "competence" - with all of its different individual outcomes - rather than "decrement" is the key concept (Albee, 1980). Psychological outcomes in one stage are considered to be partly dependent upon the degree of fulfillment in antecedent stages and to partly emerge from hitherto unique, motivational constellations that are predominant during a certain episode in the life-span. Thus, the nature of psychic and social development is, in essence, discontinuous (Kagan, 1980). As such, the Bühler model of ontogenetic development clearly fits into the framework of an organismic and dialectical developmental orientation rather than into the prevailing mechanistic mode for biological development (Reese \& Overton, 1970; Owerton \& Reese, 1973; Riegel, 1979a,b).

Third, ontogenetic development serves as a comprehensive model for describing, explaining and evaluating human motivation to pursue certain universal objectives throughout consecutive stages of the life-span. That is like any organismic model, the Bühler theory is teleological in nature. It presupposes, in part, conscious, reasoned striving - often against odds - for meaningful fulfillment throughout life, as may be apparent from her terminology:

In summing up the merits of this study for life-span developmental psychology, it was concluded: "... Here, probably for the first time, an attempt was made at a comprehensive, descriptive, longitudinal analysis of behavior" (Groffmano, 1970). In Chapter 7, the merits of Bühler's theory will be discussed with respect to the results of the present study, that is, to an ontogenetic orientation in the psychosocial etiology of first MI.

\section{B. Some Current Successors.}

This comprehensive study by Bühler represented the culmination of a much older continental European tradition of interest in human development as an effervescent process from birth to death (Groffman, 1970; Reinert, 1979). 
The delayed impact of this original work can be recognized in the scholarly response towards a number of biographical investigations published in the United States at the end of the 1970 "s. Through highly readable accounts like "Adaptation to Life" (Vaillant, 1977), "Transformations" (Gould, 1978), and "The Seasons of a Man's Life (Levinson et all, 1979), the multi-faceted evidence for wastly different routes that aduit human development in modern Western society can take became widespread. The results of these biographical studies; most of them longitudinal, could be challenged on several methodological grounds. These include bias in sample composition, absence or inadequate selection of reference subjects, and claims of universality with respect to particular developmental structures also found, to some extent, in the Bühler study. Yet, those accounts and the psychiatric studies upon which they were based (e.g., Gould, 1972; Vaillant, 1974; Levinson, 1977), have stimulated interest in broad scientific questions pertaining to psychosocial determinants of ontogenetic development, as well as in specific investigations like the present one in which first MI in adulthood serves as the endpoint.

\subsection{Psychosocial Risk Indicators in the Etiology of Myocardial Infarction.}

In this section, the role of three distinct categories of bebavioral and psychosocial risk indicators in the development of $\mathrm{MI}$ in adulthood will be discussed. These categories are: (1) the Type A coronary-prone behavior pattern (TABP), (2) stressful life events (SLE), and (3) manifestations of vital exhaustion. In the concluding section. of this chapter, attention will be paid to the implications of these risk indicators for behavioral and psychosocial development from a life-span developmental perspective. These sections are based to a large extent upon a number of thorough earlier reviews (Jenkins, 1971; 1976; 1978a; 1988; Jenkins \& Zyzanski, 1980; Matteson \& Ivarncevich, 1980; Rosenman \& Chesney, 1980; Matthews, 1982; Siegel, 1984; Matthews \& Haynes, 1986; Booth-Kewley \& Friedman, 1987; Haynes \& Matthews, 1988). 
A. The Type A Coronary-Prone Behavior Pattern and the Development of Myocardial linfarction.

At the end of the $1950^{\prime}$ 's, the American cardiologists M. Friedman and R. Rosenman reported on a specific, owert behavioral disposition - Type $\mathbb{A}$ - that appeared to be associated with the prevalence of $\mathrm{CHD}$ and $\mathrm{MI}$ in middle-aged men and women (Friedman \& Rosenman, 1959; Rosenman \& Friedman, 1961). TABP was described as: "... An action-emotion complex that can be observed in any person who is aggressively involved in a chronic, incessant struggle to achieve more and more in less and less time, and if required to do so, against the opposing efforts of other things or other persons, (...) stemming from a fundamentai, and irretrievable sense of insecurity about the intrinsic value of the personality involved" (Friedman \& Rosenman, 1959).

Before describing the epidemiollogical evidence and some psychological components of this pathogenic behavior pattern, the established assessment procedures in adults will be reviewed here briefly since this evidence appears to be largely dependent upon the manner in which TABP is measured (Siegel, 1984; Matthews \& Haynes, 1986; Haynes \& Matthews, 1988).

\section{A.1. The Assessment of the Type A Coronary-Prone Behavior Pattern.}

A. Interview procedure: The Structured Interview (SI) method was first employed in the Western Collaborative Group Study (WCGS). It contains some 25 questions in which subjects are asked how they usually respond to everydlay situations, ones that should elicit impatience, hostility, and competitiveness from Type A individuals (Rosenman, 1978). During the interview, observable behavior, such as particular speech and psychomotor characteristics, is also assessed (Dembroski \& MacDougall, 1983; Dembroski \& Costa, 1988). Together, the answers and observations allow the interviewer to classify the subject as "Type A" (A1 or A2) or "Type B" (B3 or B4). These classifications represent a continuous scale in which A1 refers to a "fully developed" behavior pattern and B4 refers to one in which this pattern is "absent, the opposite of Al". This distribution is, by definition, bimodal, that is, it contains roughly equal percentages of Type A's and Type B's. The intermediate position, $\mathrm{X}$, is used in case of strong doubt. 
B. Questiomnaire procedures. The other established instruments used for the assessment of TABP are self-report questionnaires, which, by nature, do not allow for the assessment of observable behavioral characteristics. These questionnaires are:

(a) the Jenkins Activity Survey (JAS), which was also developed and employed in the WCGS, consisting of some 50 items similar to those represented in the SI. These items assess overall TABP, as well as three separate components that may underlie this behavior pattern, namely, competitive drive, speed and impatience, and job involvement (Jenkins $s_{n}$ 1978b);

(b) the Framingham Type A Scale (FTA), containing only 10 iterns that assess individual competitive drive, sense of time urgency, and perception of job pressure (Haynes et al., 1978a,b), and

(c) two other short measurement dewices that were developed by Bortner, natmely, the Performance Battery (Bortner \& Rosenman, 1967) and the Short Ratting Scale (Bortner, 1969). These latter instruments have not been widely employed.

All established instruments for measuring TABP, however disparate they may seem, appear to be reliable (Matthews, 1982). However, they do not assess the same aspects of the broad construct of TABP (e.g., Jenkins, 1978b; Matthews et al., 1982; Matthews \& Haynes; 1986; Haynes \& Matthews, 1988). Moreover, it should be noted that of those subjects exhibiting TABP, only a small fraction actually develops CHD and MI (Matthews, 1982; Siegel, 1984; Matthews \& Haynes, 1986; Haynes \& Matthews, 1988).

\section{A.2. Epidemiological Evidence.}

The epidemiological evidence for a positive relationship between TABP and manifestations of CHD in adult subjects is based on a number of retrospective studies and on two longitudinal investigations. The latter will be discussed first.

A. Prospective Studies. The role of TABP in the subsequent development of CHD was initially established in two longitudinal studies in large American populations. These are the WCGS, mentioned earlier, and the Framingham Heart Study (FHS). It was demonstrated that over periods of about eight years, initially healthy, middle-aged subjects exhibiting TABP suffered MI at least twice as often in the 
WCGS, and between two and three times as often in the FHS, as subjects not characterized by this particular behavioral disposition (Rosenman et al., 1975; Brand et als, 1976: Haynes et al., 1980). In both studies TABP proved to constitute an independent behavioral risk indicator in the development of CHD and MI. That is, it contributed to the subsequent development of CHD (i.e., angina pectoris, ML, and sudden cardiac death), independent from hypertension, smoking, hypercholesterolemia, weight, or other established clinical risk indicators (Cooper et al., 1981; Matthews \& Haynes, 1986: Haynes \& Matthews, 1988).

More recent longitudinal studies, however, have cast doubts on the predictive power of the original concept of TABP (Kittel, 1984; Appels \& Mulder, 1985; Shekelle et al., 1985; Appels et al., 1986; 1987b; Ragland \& Brand, 1988a,b). That is, in a sixyear follow-up study conducted in Belgium, TABP, as assessed by the JAS, was only marginally successful in predicting future MI-cases (Kittel, 1984). In one such study from the Netherlands, with a follow-up period of nine-and-a-half years, the JAS did not predict future cases of fatal or non-fatal MI (Appels et al., 1987b). However, in a small sample $(N=243)$ from this large study $(N=3171)$, TABP had also been assessed by using the SI. It appeared that all four cases who suffered coronary death in this subsample had previously been assessed as Type A. No coronary death was reported in Type B cases, a small, but significant, difference (Appels et al., 1986). In the United States, however, in the MRFIT study, TABP, as assessed by the SI, was not found to be associated with future CHD, including MI (Shekelle et al, 1985). Finally, and perhaps most disconcertingly, in a recent analysis of the current twenty-two year follow-up of the original WCGS, a significant inverse relationship was found to exist between TABP and survival after $\mathrm{MI}$, after controlling for variable follow-up time, type of initial coronary event, and established clinical risk indicators (Ragland \& Brand, 1988a,b).

It could be argued that this apparent failure in some recent prospective studies to establish an association between TABP and risk of future $C H D$, including $M I$, does not necessarily imply that the existing body of knowledge about TABP is false (Matthews \& Haynes, 1986; Dimsdalle, 1988; Haynes \& Matthews, 1988). These investigations do not refute the original evidence from the WCGS and the FHS, reported above, or from numerous case-referent studies. Rather, these recent findings suggest 
(1) that the theoretical concepts of Type A behavior and coronary-prone behavior should be more clearly defined and distinguished, (2) that the theoretical scrutiny of TABP may be narrowed to eliminate those components that the accumulated evidence has demonstrated to be unimportant, and (3) that TABP theory, at the same time, should be broadened to encompass additional psychological attributes that may be associated with TABP (Matthews \& Haymes, 1986; Booth-Kewley \& Friedman, 1987; Haynes \& Matthews, 1988).

With regard to the latter, it has been noted that clinical manifestations of anxiety and depression appear to be particularly important variables since they are associated with MI, independently from TABP (Booth-Kewley \& Friedman, 1987; Friedman \& Booth-Kewley, 1987). In another section of this chapter, the role of manifestations of vital exhaustion, which bears a close resemblance to these psychological attributes, will be discussed.

Since the present study was begun in 1980, before the disappointing results of the above-mentioned studies became known, TABP, as measured by means of the SI, was included as one of the major independent variables. In addition, the recent critical analyses of most of the studies about TABP indicate rather unequivocally that the SI assessment appears to be superior by far to the JAS and other, less often used, instruments in establishing associations between TABP and CHD, including first MI (Siegel, 1984; Matthews \& Haynes, 1986; Booth-Kewley \& Friedman, 1987; Haynes \& Matthews, 1988).

B. Retrospective Studies. A substantial number of case-referent studies from the United States and Western and Eastern Europe have further confirmed the crucial role of TABP in the development of CHD. These studies, employing either the SI, JAS, or components of TABP, are summarized elsewhere (Jenkins \& Zyzanski, 1980; Matteson \& Ivancevich, 1980; Rosenman \& Chesney, 1980; Siegel, 1984; BoothKewley \& Friedman, 1987).

In brief, these retrospective studies reveal clear associations between TABP and manifestations of CHD (i.e., degree of atherosclerosis, anamnestic history, angina pectoris, and MI). Furthermore, these associations appear to remain constant in socioeconomic and national contexts that are quite different from the Southern Californian middle-class cultural setting of the late 1950's in which the concept was originally developed (Friedman \& Rosenman, 1959; Rosemman \& Friedman, 1961). 


\section{A.3. Some Psychological Aspects and Components.}

At about the same time these epidemiological studies were being conducted, psychollogists began to explore the psychological components underlying particular characteristics of TABP. These studies, for the most part small-scale laboratory experiments, were conducted in much younger and considerably smaller populations, however. These explorations dealt primarily with various, isolated personality characteristícs in relation to particular enwironmental demands. A full-scale review of these studies (e.g., Matthews, 1982; Baker et al, 1984; Booth-Kewley \& Friedman, 1987; for authoritative reviews) would be beyond the scope of this thesis since the present study focuses exclusively on adult subjects. Therefore, only those components and the developmental concomitants most important in middle-aged subjects will be mentioned here. These include competitive drive, impatience, and, perhaps most important, overt hostility and anger. These psychological components appear to be most consistentlyrrelated to the onset and further development of CHD and MI (Matthews et al,s 1977; Jenkins \& Zyzanski, 1980; Matthews, 1982; Booth-Kewley \& Friedman, 1987; Dembroski \& Costa, 1988).

A. Developmental Aspects. The few experiments that have been performed on the development of TABP in childhood indicate that this pattern is probably induced by specific mother-child interactions (Matthews, 1977, 1979; Matthews \& Angulo, 1980; Matthews \& Valkin, 1981). That is, it is hypothesized that ever increasing parental standards of performance, in particular with respect to striving for achievement, when mediated by high parental expectations and aspirations, frequent approval and disapproval, a competitive and involved attitude, and authoritative discipline techniques, may play a decisive role in the onset and subsequent reinforcement of TABP in childhood (Emmelkamp \& Karsdorp, 1987; McCranie \& Simpson, 1987).

In adolescents, striving to achieve roles that are, as yet, ill-defined or not readily attainable, may have a crucial impact on the development of the pathogenic components of TABP (Butensky et al., 1976). Another study demonstrated that the major components of TABP in adults (i.e., competitive drive, impatience, and overt hostility and anger) could already be identified reliably in adolescents (Siegel \& Leitch, 1981). In a different study it was found that a masculine sex role orientation in adolescence (i.e., a role geared towards displaying aggressiveness) was associated with TABP 
correlates (De Gregorio \& Carver, 1980). Finally, it could be argued that particullar SLE associated with adverse or highly competitive living conditions and situations in childhood and adolescence might contribute both to the development of TABP and, in later phases of adult life, to CHD (Arnesen \& Forsdahl, 1985; Steinberg, 1985; VegaLahr \& Field, 1986).

In sum, it appears that TABP may already be firmly established when a susceptible individual reaches early adulthood. It is, therefore, relevant to examine which specific characteristics may constitute the psychological core of this behavior pattern. In this respect, the concept of "controllability", first suggested by Glass (1977), appears to be consonant with a life-span developmental perspective.

B. "Controllability". Initial studies of the psychological characteristics of TABP focused to a large extent on the dimension of "controllability" (Glass, 1977). The results of a series of experimental studies - mainly with college-aged subjects - on various aspects of "controllability" suggest that TABP may reflect a specific, pathogenic inclination to cope with stressful characteristics of the environment by exerting as much control as possible over other individuals and over the physical environment, regardless of actual necessity.

The experimentally established indicators of "controllability" include:

(a) threats to self-esteem, imposed by a lack of environmental control (Krantz et al., 1974; Pittner \& Houston, 1980; Brunson \& Matthews, 1981);

(b) performing at near maximum capacity, irrespective of the presence or absence of deadlines (Glass et al., 1974; Burnam et al., 1975);

(c) the suppression of fatigue and related physical symptoms (Carver et all., 1976; Matthews \& Brunson ${ }_{n}$ 1979); and

(d) interpersonal aggression, induced by social insecurity (Carver \& Glass; 1978;

Gastorf et al, 1980; Smith \& Brehm, 1981).

Thus, "controllability" may be central to the developmental and psychological aspects of TABP. (For a more extensive appraisal, see Matthews, 1982; Booth-Kewley \& Friedman, 1987; Friedman \& Booth-Kewley, 1987). 
B. Stressful Life Events and the Development of Myocardial Infarction.

Mast of the studies relating the occurrence of stressful life events (SLE) to MI have been performed in Sweden and Finland by Theorell et al. and by Rahe et al., respectively. Since an extensive review of the main Theorell studies has been published previously (Falger, 1983a), those findings will just be summarized here, supplemented when necessary by the Finnish investigations.

\section{B.1. Retrospective Studies.}

Except for two longitudinal surveys to be discussed later, all studies employed a case-referent design (Theorell \& Rahe, 1970; 1971; 1972; Lind \& Theorell, 1973; Lundberg et all., 1975; Lundberg \& Theorell, 1976). Subjects were middle-aged male cases from Stockholm, mostly from upper occupational strata, who had survived MI (first or reinfarction), and healthy malle referents, usually matched for age. The number of participants in both groups varied between 27 and 104. A modified version of the Social Readjustment Rating Scale (SRRS), a self-report questionnaire most often used in "early" SLE research (Holmes \& Rahe, 1967), was always employed. In addition, a questionnaire about CHD behavior resembling TABP, a sociological history survey, and several measurements of work-load - all constructed by the investigators - were alternately included. As a rule, the time intervals studied, covered a period of two years before MI, thus emphasizing the role of SLE as intermediate-term phenomena, as opposed to the long-term impact of TABP.

In most instances, a significant accumulation of SLE prior to MI was demonstrated in the lives of cases; but not in those of referents. Most SLE occurred in association with conflicts at work or involved coping with increased responsibilities. MIcases were significantly less satisfied with their jobs than referents. It also appeared that cases evaluated these particular SLE as psychologically more upsetting or distressing, or requiring more readjustment, than referents did (Romo et al., 1974). In general, the results from the retrospective studies in Finland, which also employed a modified SRRS, corroborated these findings (Rahe et al., 1973; 1974). 


\section{B.2. Prospective Studies.}

In the first short-term prospective study on SLE over a four-month period, exposure to SLE in $21 \mathrm{MI}$-cases who had resumed working after their first MI was linked to changes in catecholamine output and in other stress-related biochemical parameters (Theorell et al., 1972). Measurements of those parameters and exposure to SLE were repeated every two weeks. Once again, the SLE that were reported most often involved conflicts at work or changes in circumstances under which work had to be performed. These SLE were correlated with significantl y elevated levels of catecholamines and uric acid.

In two later studies, continuous psychophysiological measurements were taken. while MI-cases were being interviewed about previously experienced SLE (Theorell et al., 1977b; Theorell, 1980). It was demonstrated that blood pressure and heart rates increased when certain emotional aspects of these SLE were mentioned during the interview. In some instances, even ventricular arrhythmias were evoked. This also occurred later on in the interview, when the same SLE were brought up again.

The last prospective study, of some 6,500 middle-aged building construction workers who were followed up for more than a year and a half, measured non-fatal MI and cardiac dleath due to prior exposure to SLE and to other manifestations of psychosacial distress (Theorell et al., 1975; Theorell; 1976; Theorell \& Floderus-Myrhed, 1977; Theorell et al., 1977a). During follow-up, 51 cases with first MI could be identified. At the beginning of the study, they reported a significantly higher mean score on a workload index, consisting of combined SLE and distress indices, than referents. The single items that discriminated the best between cases and referents were: "Increased or too much responsibility at work", "Extensive periods of overwork", and "Prior episodes of unemployment". Not only was irregularity of work a significant factor, but also the occupational lewel of the majority of MI-cases. In the sub-group of concrete workers, the building construction workers laboring the hardest under rather harsh working conditions, the incidence of MI was about twice as high as in all other occupations combined. Moreover, it was found that MI-cases who survived had reported more neurotic complaints at the onset of the study than referents.

In sum, these results clearly underscore the importance of work-related stressors in the development of MI in adulthood. Unfortunately, none of the established TABP 
assessment procedures was included in any of these studies. They might have clarified the complex interrelationships among TABP, specific job demands, and ensuing dissatisfaction both in higher occupational strata, as investigated in the retrospective studies, and annong blue-collar workers, as studied in the latter prospective survey.

\section{Manifestations of Vital Exhaustion and the Development of Myocardial Infarction.}

Attempts to understand short-term psychosocial risk indicators in the development of $\mathrm{MI}$ invariably lead one to some rather astonishing findings regarding the determinants of the illness history in the months prior to MI or sudden cardiac death (SCD). It appears that a relatively large number of the patients who later suffer MI or SCD visit a physician two or three months before their coronary event or untimely death. Their complaints, possibly of cardiovascular origin, cannot be recognized unequivocally as such at the time they are reported. Thus, one may wonder what peculiar "psychic and/or physical phenomena those patients may have experienced that urged them to consult their physician. In other words, how might the ominous precursors of imminent MI or SCD be recognized in their psychosocial and life-span developmental contexts? Since these phenomena constituted a major impetus for the present investigation and represent a relatively novel field for exploration, the literature on this subject will be discussed in detail here.

\section{C.1. Retrospective Studies.}

In order to answer the above questions, several investigators began interviewing patients and/or their relatives. They tried to discover which particular phenomena the patients had experienced in the months before the MI or SCD. It was observed that not only cardiac symptoms but also feelings of extreme tiredness and general malaise were reported by substantial numbers of the middle-aged cases, male and female alike.

One retrospective study focusing on psychosocial aspects in $26 \mathrm{SCD}$-cases from a healthy, industrial population of 44,000 adult subjects found that all cases had suffered from increasing fatigue in the weeks prior to death (Greene et al., 1972). A prevalence study by Kuller et al. (1972) demonstrated that $56 \%$ of 208 SCD-cases had suf- 
fered from "undue flatigue and $28 \%$ had reported difficulty sleeping in the last weeks prior to death, whille $42 \%$ had experienced breathlessness and $37 \%$ chest pain. In many cases, these symptoms were also noted to increase more and more in frequency or severity. In a retrospective study by Alonzo et al. (1975), it was found that of the 112 hospitalized cases who had survived MI, $38 \%$ had previously reported feelings of fatigue or weakness, $16 \%$ general malaise, and $14 \%$ emotional changes. Chest pain was reported by $67 \%$ of these cases and breathlessness by $36 \%$. After interviewing the relatives of a referent group, consisting of 88 cases who had suffered SCD before hospitalization, it appeared that $42 \%$ of those cases had experienced feelings of fatigue or weakness, $20 \%$ had gone through emotional changes, and $17 \%$ had suffered from general malaise. Significantly fewer of these cases $(35 \%)$ had apparently experienced chest pain. In a prevalence study by Rissanen al. (1978), feelings of "undue" fatigue were ascribed to $32 \%$ of 118 cases suffering untimely SCD, while cardiac symptoms, including altered or recent angina pectoris, dysrhythmia, and breathlessness, were ascribed to 33\%. In a review of some other studies of prodromata of SCD and MI, Kuller (1978) consistently reported that "fatigue" ranked highest among prodromal symptoms in middle-aged men and women in the two weeks before SCD. In most instances, difficulty sleeping was reported second, with chest pain being ranked as the third most common symptom. The latter symptoms usually occurred with greater frequency in MI-cases than in SCD-cases.

All of the above symptoms, manifestations of a phenomenon referred to as "vital exhaustion", were studied by Verhagen et al. (1980) using the Maastricht Questionnaire (MQ). This particular questionnaire, which serves as a major instrument also in the present study, will be described in detail later. In the Verhagen et al. case-referent study, the MQ scores of 58 men with first MI were compared with those of 58 healthy referents matched for socio-economic status and age. TABP, just one of a number of other behavioral and psychosocial determinants, was also included and assessed by means of the SI. The $\mathrm{MQ}$, rather than the SI, proved to be the best discriminating instrument among cases with first MI and referents, thus underscoring the importance of these short-term psychosocial determinants in the onset of MI. 


\section{C.2. Prospective Studies.}

The results from the few longitudinal studies employing established clinical psychological assessment procedures place particular emphasis upon manifestations of depression and on symptoms of exhaustion. In one such study over a 14-year follow-up period, it was found that high scores on the Hypochondriasis Scale of the Minnesota Multiphasic Personality Inventory diseriminated positively between 31 middle-aged cases with newly emerging CHD (including MI) and 138 healthy referents (Brozek et al., 1966). Another prospective study, of 1046 male medical students, over a 20-year period (Thomas \& Greenstreet, 1973; Thomas, 1976), followed their "habits of nervous tension" as precursors of five serious diseases in middle adulthood. It was demonstrated that a significantly higher score on a depression scale devised for this purpose and administered to students while they were attending school and in comparatively good health would predict the onset of coronary occlusion and mental illness two decades later. This particular scale included items about exhaustion or excessive fatigue, depressive feelings, increased urge to sleep, and concern about physical health. The 12 cases in the coronary occlusion group appeared to have reported being tired on awakening more often than the total healthy referent group of 123 subjects, matched for age. These "early" studies, however, did not specifically assess the prodromal symptoms of first Ml, something which occurred explicitly in the following series of studies employing the MQ.

The first version of the MQ (Form A) was included in the Imminent Myocardial Infarction Rotterdam (MMR) study, a 10-month prospective investigation. The main clinical objective of this study was to develop some reliable instrument for use in general practice that would identify middle-aged patients at high risk of developing an acute coronary event in the near future. Patients who consulted their general practitioner about complaints of possible cardiac origin were referred to this study for closer pliysical examination and were subsequently followed up. Patients filled out the MQ at the beginning of the follow-up. It was found that the 37 men (mean age 50 yrs.) who suffered a new cononary event (including MI and SCD) within this 10-month period had a significantly higher mean MQ score than the remaining patient group of 405 men (mean age $49 \mathrm{yrs}$; Appels, 1980). In addition, the mean MQ score of these 37 cases was also compared with the MQ scores of a healthy referent group of 317 men (mean 
age 46 yrs.) participating in another screening study. In this instance, the mean MQ score in cases was about two standard deviations higher (Appels, 1980).

The MQ items that discriminated between the cases and both referent groups were subsequently analyzed twice by a hierarchical cluster analysis. The similar patterns that were identified by this procedure indicated that the MQ consisted of item groupings denoting feelings of tiredness, helplessness and hopelessness, loss of vitality, depression and hypochondriasis, sleep disturbances, and exhaustion (Appels, 1980).

The second version of the MQ (Form B) was subsequently tested in another prospective study. This form, as well as the main results of this study, will be discussed later.

\subsection{Integration: The Role of Psychosocial Risk Indicators in the Etiology of Myocardial Infarction from a Life-Span Developmental Perspective.}

When the role of psychosocial risk indicators and the ways in which they may interact in the etiology of MI are considered from the life-span developmental perspective described in section 1.2., several questions may be raised.

\section{A. The Type A Coronary-Prone Behavior Pattern.}

The first question that may be raised with respect to $\mathrm{TABP}$ concerns the specific historical context in which this particular behavioral disposition emerged. The second one involves the current environmental characteristics that might elicit TABP.

\section{A.l. Historical Conteit.}

It may be argued that the emergence of TABP, as defined in the original studies, is, above all, the outcome of particular psychological and social experiences of certain cohorts in the general population of the United States (Elder \& Rockwell, 1979). That is, when, at the end of the 1950's, the original WCGS-cohorts were selected, the male participants were between 39 and 59 years of age. Thus, a substantial segment of this sample of Southern Californians was born and raised in the 1920's and 1930 's, right before or during the Great Depression. This historic decade of social disruption 
was followed by World War II, equally traumatic in rature with regard to social fragmentation. This, in turn, was followed by unsurpassed psychosociall and physical adjustments to the most massive long-cycle economic upswing in the history of the United States" or any other economy (Eyer, 1977a,b; 1980).

If "controllability" is, in fact, the core psychological dimension of TABP, one could argue that the unprecedented exposure to prolonged environmental stressors during the Great Depression facilitated the emergence of Type A-like behavior as an appropriate social response pattern for exerting personal control over these hardships (Elder, 1979). Onie could further argue that the psychological and social readjustment, in both men and women, to the extraordinary demands of a nation braced for warfare at the beginning of the 1940 's might subsequently have reinforced TABP as a fully adequate social response pattern. Finally, the period of rapid economic growth in the two decades after World War II, growth that clearly offered ample opportunity for sustained competitiveness among individuals, might have fostered the general development of TABP to the actual proportions observed at the onset of the WCGS. Thus, the rapidly expanding series of unprecedented life experiences in particular cohorts in which "lard work" becane instrumental in securing upward social mobility may very well have created almost prototypical incentives to exert control over one's constantly changing environment. As a result, individuals tended to respond to these and future challenges with a set behavioral pattern, namely TABP. However, they wound up paying for this with their health, as evidenced by an equally unprecedented increase in CHD, MI and SCD.

Having analyzed these specific historical circumstances, which most probably have many parallels in European countries like the Netherlands, some attention will be paid to the second question, namely, that regarding current environmental characteristics that may sustain TABP.

\section{A.2. Current Enwironmental Characteristics.}

It may be argued that large, modern, industrial organizations are optimally suited to elicit and further perpetuate TABP both because of the bureaucratic complexity and ambiguity of the organizational structures involved and because of the increasingly abstract nature of the actual work to be performed in most modern enterprises 
(Chesney \& Rosenman, 1980). These organizational aspects result in a high degree of interdependence among employees and, thus, in a chromic need for control This fosters TABP not only in relatively stable, predictable, corporate environments but also, and especially, in organizations undergoing thorough and rapid change. Both expan* sion and decline elicit severe job stress in the susceptible Type A individual who perceives such potentially destabilizing changes as a threat to an established sense of control over the work environment. Circumstances likely to trigger occupational distress in susceptible Type A subjects include changes in job decision latitude and job demands. If these are habitually associated with repeated structural reorganizations that bear upon the content of the work to be performed or upon blocked opportunities for further promotions, they will result in status inconsistency (Karasek et al., 1981). This latter threat to one's sense of personal identity has, in fact, been demonstrated to induce increased TABP (Siegrist \& Weber, 1983).

In sum, TABP may have evolved as an adequate social response pattern to sustained and ever-increasing and expanding changes in personal environments. This exertion of contimuous environmental control, which is perceived as necessary for adequate personal functioning, is, however, associated with progressively damaging psychophysiological processes, conducive to CHD.

\section{B. Stressful Life Events.}

As with TABP, the role of SLE in the long-term development of Ml can be considered from a life-span developmental perspective. This raises three questions. The first involves the possible build-up of stressful episodes over the entire human lifespan, the second the seemingly different cognitive appraisals of SLE in MI-cases and referents; and the third the issue of social support systerns in relation to the appraisal of SLE,

\section{B.1. Build-up of Stressful Life Events over the Life-Span.}

Almost all of the studies that have been discussed thus far have focused on the occurrence of SLE in the last two years before first MI or reinfarction. However, from an ontogenetic perspective, one could logically argue that clusters of SLE occur together also during earlier stages of an individual's life course (Antonovsky \& Kats, 
1967. Hinkle, 1974; Lehr, 1976; Hultsch \& Plemons, 1979; Brim \& Ryff, 1980; Vossel, 1987). A gradual accumulation of SLE during these early phases may contribute to the development of CHD and MI in later stages of life (Arnesen \& Forsdahl, 1985; Steinberg, 1985). This important issue will be discussed in more detail later.

\section{B.2. Cognitive Apprausal of Stressful Life Events.}

Turning to the second question, involving cognitive appraisal of SLE, it was already noted that the MI-cases in the Theorell et al. studies described each SLE they had encountered either as being psychologically more upsetting or distressing, or as requiring more social readjustment, than healthy referents did (Lundberg et al., 1975). The same was true for SLE that MI-cases had not experienced but still were asked to rate in the same manner (Lundberg \& Theorell, 1976).

Only a few other studies have included aspects of cognitive appraisal of SLE in MI-cases, with, in general, similar results. In a series of retrospective Australian studies, different scales, representing idiosyncratic interpretations of the emotional impact of SLE, discriminated significantly between cases with first MI and age-matched referents with severe angina pectoris (Byrne, 1980, 1983; Byrne \& Whyte, 1980). That is, MI-cases scored significantly higher on dimensions of emotional upset, depression, and helplessness than the other patients did. This latter characteristic in particular is thought to be closely linked to the dimension of "controllability" of TABP (Glass \& Carver, 1980, Matthews \& Glass, 1984), as well as to life-span development (Elder \& Seligman, 1986).

In this context ${ }_{n}$ it is conjectured that individuals who have experienced an episode of helplessness in relation to the occurrence of particular SLE at some phase in their life-span development will be more susceptible to experiencing helplessness again when similar SLE are encountered in later developmental phases. In particular, it may be said that when the idiosyncratic attributions made with respect to the occurrence of a specific event are internal, global, and stable, the ensuing helplessness will most likely occur across similar situations and may, thus, become chronic (Abramson et al., 1980; 1989). Since adult subjects exhibiting TABP are thought both to encounter more SLE than Type B subjects (Matthews \& Glass, 1984) and to exert more effort to control these events than their counterparts (Glass \& Carver, 1980), they may be 
particularly susceptible to experiencing helplessness if, despite repeated physical and mental efforts, an event appears to be uncontrollable.

It is unfortunate that no established measurements of TABP were included in most of the studies mentioned above. Only one such study about MI-cases included a self-constructed measure of TABP (Byrne, 1981). A different study of healthy males who were screened for CHD risk indicators included both TABP, assessed by means of the SI, JAS, and Bortner Rating Scale, and a modified version of the SRRS (Byrne \& Rosenman, 1986). In both studies there appeared to be positive associations between TABP, in general, and the occurrence of SLE. Thus, the associations between TABP, SLE, and future CHD and MI deserve more attention (Byrne, 1987).

One should, however, be careful not to overgeneralize these findings on "controllability" and helplessness in relationship to SLE, which occur in different developmental phases, and CHD. That is, the little comparative literature on the relationships between exposure to SLE and developmental stages suggests that particular loss-re lated SLE associated with social role changes are perceived as less stressful in late adulthood and early old age than in younger ages (Sands \& Parker, 1979; Brim \& Ryff, 1980; Silver \& Wortman, 1980).

\section{B.3. Stressful Life Events as Transitions.}

The latter findings point to the intriguing sociological notion of the human lifespan as a succession of social role transitions that are superimposed upon the biological timetable (Neugarten \& Datan, 1973; Elder, 1975; Elder \& Rockwell, 1979; Elder \& Caspi, 1986). These transitions, and the SLE that are generally associated with them, occur either "on time" (i.e., in accordance with the social timetable that is contingent in a specific cohort from the general population) or "off time". "Offtime" transitions and/or SLE can constitute major stressors if they disrupt the expected sequences and rhythms of life (Bortner, 1979). Thus, it can be argued that certain psychological adjustment problems in MI-cases may stem from the fact that the SLE they had to cope with occurred "off time". 


\section{B.4. Social Support and Stressful Life Events.}

The last question to be dealt with here involves the social networks of individuals and the ways in which social support from these networks might moderate idiosyncratic perceptions of, and coping strategies for, SLE (Cassel, 1976; Cobb, 1976; Berkman, 1982; 1986). In the Jatter comprehensive analyses of the relationship between specific social network characteristics and CHD, it was concluded that network configurations in the work and home domains are likely to directly influence the incidence of major SLE and that many such adwerse events may seriously disrupt, or otherwise impair, the supportive characteristics of existing network relationships.

It could be argued that a substantial build-up of SLE in the years or months prior to MI might put such a strain on the limited "buffering" capabilities of the social networks of the prospective MI-case that the perception of actual support would diminish, or perhaps disappear completely. It could further be argued that if the majority of the SLE were associated with the work domain and if the individual's perception of the supportive qualities of his social network there were questionable, any and all potential support would have to come from the home domain. If the latter were characterized by chronic marital or relational frictions, the individual concerned would have few places left to turn to for social support. It is conceivable that the breakdown in those social networks might hamper psychosocial adaptation.

In sum, it can be concluded that SLE constitute pivotal psychological and social parameters in any study on life-span characteristics and associated health outcomes. Not only does the occurrence of SLE need to be examined, but also idiosyncratic strategies for perceiving and coping with SLE. TABP may exert a significant modifying influence on all of these aspects of SLE, as may the quality and extent of social support networks.

\section{Manifestations of Vital Exhaustion.}

As with the empirical evidence concerning TABP and the presumably catalytic role of SLE, questions arise when the precursory symptoms of vital exhaustion are considered from a life-span developmental perspective. The only one that will be dealt with here, however, concerns the psychosocial pathways along which these symptoms of vital exhaustion might develop and eventually result in first MI. The crucial issue of 
the long, intermediate-, and short-term pathophysiological mechanisms that may first be conducive to vital exhaustion and subsequently to $M T$ is beyond the scope of this thesis:

Strictly speaking, the symptoms of vital exhaustion are both endpoints and precursors. That is, manifestations of vital exhaustion can be thought of as the psychological endpoint of an antecedent developmental process in which long-term behavioral determinants, such as TABP, and long-, intermediate-, and short-term psychosocial determinants, such as SLE, combine to produce symptoms of physical and psychological breakdown in adaptive resources. As such, vital exhaustion is an important phemomenon in its own right, regardless of its presumed association with imminent $\mathrm{MI}_{\text {, }}$ SCD, or other clinically relevant parameters of cardiac malfunctioning ${ }^{3}$.

When regarded as short-term psychological determinants of first MI, these symptoms add a new dimension to the array of already existing behavioral and psychosocial risk indicators since they focus exclusively on "downstream" precursors. From the above reviews of TABP and SLE, it can be concluded that most investigations thus far have focused on long-term and/or intermediate-term determinants, the latter depending on the chronological period over which SLE were being measured.

Since the manifestations of vital exhaustion referred to above do not reveal their developmental origins, it seems pertinent to investigate whether exposure to, and subsequent coping with, particular SLE, in conjunction with TABP, might bring about those precursory symptoms. Unfortunately, however, what little evidence there is pertains primarily to SCD and, therefore, will not be discussed here. Nevertheless, when one considers vital exhaustion together with the TABP and SLE from a life-span developmental perspective, the image emerges of an increasingly vulnerable individual who becomes witally exhausted because of his inability to deal with the different categories of SLE that he experiences over his life-span and that conflict with his idiosyncratic "expected life history" (Bortner, 1979). At some moments in his life he is only" able to influence these SLE arid at other moments to control them completely: In other instances, he will merely succumb to the inexorable course of those SLE. Depending on the support he receives from his social networks, he may be able to meet these challenges successfully. In the absence of such support, however, he may eventually give up and develop manifestations of vital exhaustion. 
This conjecture about the particular dynamics of a life-span conducive to vital exhaustion and to subsequent first MI may be said to constitute a reformulation of a particular outcome of the developmental process of striving for "psychic integration and fulfillment" that was proposed by Buhler. There, it was noted that unsuccessful "self-determination" over the life course would lead to exhaustion, depression, and despair. Unsuccessful "self-determination" was defined as the experience of more or less complete failure to achieve psychic integration and fulfillment, contingent upon antecedent developmental stages. The methodology for assessing the parallel, and probably interactive, contributions of TABP, SLE, and vital exhaustion to the development of first MI that will be described next may provide an empirical basis for testing this important Buhler conjecture about the consequences of life-span development gone awry.

\subsection{Some Hypotheses and Explorations about Psychosocial Risk Indicators in the Etiology of Myocardial Infarction from a Life-Span Developmental Perspective.}

The previous reviews about the role of particular psychosocial risk indicators in the etiology of MI suggest a number of hypotheses, some of which will be tested in the present study. They also suggest some interesting interrelationships that deserve further exploration before these can be formulated as testable hypotheses. These hypotheses and explorations will be tested and performed in the context of a case-referent study, the methodology of which will be described in Chapter 2 .

A. The Type A Coronary Prone Behavior Pattern: Hypotheses \& Explorations.

In the present study it is hypothesized that: (1) the Type A coronary-prone behavior pattern in general occurs more often in MI-cases than in referents; and that (2) the Type A coronary-prone behavior pattern constitutes an independent behavioral risk indicator for first $\mathrm{MI}$ when controlling for other risk indicators for $\mathrm{CHD}$.

The questions of whether the Type A coronary-prone behavior pattern occurs at a higher rate in young MI-cases than in older ones and whether this behavioral dis- 
position is associated with SLE in "Childhood \& Adolescence" "Work Career", and "Family \& Sociall Life" will also be explored.

B. Manifestations of Vital Exhaustion: Hypotheses \& Explorations.

In the present study it is hypothesized that: 1) vital exhaustion, in general, occurs more often in MI-cases than in referents; 2) vital exhaustion, in general, constitutes an independent psychosocial risk indicator for first MI when controlling separately for age, AP, and current smoking; 3) subjects who are assessed as being Type $A$ are at an elevated risk of becoming vitally exhausted; 4) Type A subjects who are vitally exhausted are at a more elevated risk of suffering first MI than Type A subjects who are not vitally exhausted; and 5) when controlling for vital exhaustion, Type A subjects are at a more elevated risk of suffering first MI than Type B subjects.

The question of whether manifestations of vital exhaustion are associated with SLE in "Childhood \& Adolescence", "Work \& Career", and "Family \& Social Life" will also be explored.

\section{Stressful Life Events: Hypotheses \& Explorations.}

In the present study it is hypothesized that: (1) in general, SLE in the domains of "Childhood \& Adolescence", "Work \& Career", and "Family \& Social Life" occur more ofter in MI-cases than in referents; and that (2) in general, SLE in the domains of "Childhood \& Adolescence", "Work \& Career", and "Family \& Social Life" constitute psychosocial risk indicators for first MI.

The questions of whether TABP exerts a moderating influence on the associations of SLE in the domains of "Childhood \& Adolescence", "Work \& Career", and "Family \& Social Life" with first MI and whether SLE in these same domains exert a moderating influence on the association of vital exhaustion with first MI will also be explored. 
$-40$ 


\section{Chapter 2: Design and Methods of the Study: \\ A Life-Span Developmental Approach.}

\subsection{Introduction.}

This chapter will describe the study design. A total of 133 male cases who sur vived first MI (MI-cases) were compared with 133 male neighborhood referents (NR) and 192 male hospital referents (HR). There were a number of reasons for including two referent groups.

First, by selecting a "healthy" referent from the same neighborhood as an MLcase, differences in the subjects' socioeconomic backgrounds are presumably kept to a minimum (Kleinbaum et al., 1982; Rothman, 1986). This is quite important since different levels of socioeconomic status appear to be associated with different rates of CHD-morbidity (Marmot, 1982). In addition, such a strategy allows social and economic factors to exert a similar influence on the life-span developmental patterns of MI-cases and referents (Baltes \& Schaie, 1973; Neugarten \& Datan, 1973). Second, by independently selecting referents with diseases other than CHD from the same hospital as the MI-cases, morbidity patterns will most likely be more similar between MIcases and HR, than between MI-cases and NR, since the prevalence of disease is not distributed randomly in the general population (Kleinbaum et al, 1982; Pearce \& Checkoway, 1988). Furthermore, by including HR, one can study the possible effects of hospitalization on the perception and/or recall of the risk indicators of interest, something which would be impossible if only NR were included (Rothman, 1986). Thus, if analyses with respect to exposure to behavioral and psychosocial risk indicators yield significant differences for MI-cases compared to both NR and HR, one will be able to conclude that these differences specifically contributed to the development of first MI, since the possible associations of these indicators with other diseases will already have been analyzed as well.

Both referent groups were free of MI. MI-cases and referent groups were distributed similarly among seven age groups, each spanning five years, and ranging from age 35 to age 69 . In this manner, specific age group differences in constellations of psychosocial determinants conducive to first MI could be identified. 
This chapter will also describe the methods and instruments that were used to assess the psychosocial determinants included in this study. They consisted of a structur-ed biographical interview and a number of self-report questionnaires designed to assess:

(1) stressful life events (SLE), and the perception, coping strategies, and social support networks that are associated with the occurrence of SLE, by means of a self-developed Structured Biographical Interview (SBI);

(2) the Type A coronary-prone behavior pattern (TABP), by means of the Structured Interview (SI);

(3) vital exhaustion, by means of the self-report Maastricht Questionnaire (MQ);

(4) symptoms of angina pectoris and chest pain prior to MI, by means of the selfreport London School of Hygiene Cardiovascular Questionnaire (LSHCQ) ("Rose Questionnaire");

(5) habitual life styles that may constitute elevated risks for the development of CHD and MI, by means of a self-report life styles questionnaire (LSQ); and

(6) selected demographic parameters, as included in the SBI.

Finally, this chapter will describe the scoring systems with regard to the various instruments and the univariate and multivariate statistical procedures employed to bring about the results.

\subsection{Subjects.}

In all, data were collected from three groups of Caucasian males, aged 35 to 69, from the South Limburg region of the Netherlands. These groups included MI-cases, $\mathrm{NR}$, and $H R$.

A. MI-Cases: Criteria, Selection \& Selection Bias.

\section{A.l. Criteria.}

The patient group comprised 133 cases with first documented MI who had been hospitalized between June 1980 and September 1983 in the cardiology wards of the two largest regional hospitals, that in Heerlen and the university hospital in Maastricht. Only patients from the actual catchment areas of these hospitals were included in the 
study in order to awoid possible selection bias due to the outstanding reputation of the university hospital (Miettinen, 1985a,b).

The diagnosis "first MI" was based on:

(1) the clinical history taken by a cardiologist from the hospital,

(2) the standard ECG-readings regarding MI, and

(3) the maximum plasma enzyme assessments.

\section{A.2. Selection \& Procedure.}

Once a week, all new male cases with the diagnosis of first MI were visited by the author and an assistant. These patients had been recently released from the coronary care unit, and their names and diagnosis were provided by the heads of the two hospital wards. Once each case had been told the purpose of the study and had agreed to participate in it, a set of questionnaires containing the MQ, LSHCQ and LSQ (cf. 2.4. Instruments) was left behind. Also, a tentative appointment was made for an extensive interview including the SBI and SI after discharge from the hospital.

All MI-cases were to be assigned to one of seven consecutive age strata, each spanning five years, ranging from age 35 to age 69 (see 2.3. Age Distribution). Sampling was to continue until at least 15 cases per stratum could be included in the final analyses. Since first MI constitutes a very rare event in young adults but increases with age, a consecutive series of cases with first MI would have resulted in the quotas for the older strata being reached much sooner than those for the younger strata. Thus, while an overall consecutive series was not used, efforts were made to obtain consecutive series of cases with first MI within each separate age stratum. These MI-cases would represent those in the source population at large, insofar as these patients would normally seek treatment in the two largest regional hospitals in the catchment area (Miettinen, 1985a,b).

In all, 220 MI-cases were approached in the hospitals; the final refusal rate was $25 \%$ (see Appendix I). 


\section{A.3. Selection Bias.}

The selection bias (and, hence, the confounding of results) that may have resulted from this refusal rate was studied as follows. As shown in Appendix I, 55 MI-cases who initially agreed to participate in the study while in the hospital later refused to do so when approached to make an appointment for the SBI at home. No further attempts were made to have them participate, as this might have created information bias on the part of MI-cases, that is, they might have distorted or withheld information as a result of being obliged to participate (Miettinen, 1985a,b).

Of these 55 non-participating MI-cases, 20 had returned a fully completed set of the above-mentioned questionnaires. Thus, comparisons of the scores on their questionnaires with those of the 133 participating MI-cases may indicate a possible selection bias on the part of the latter. Table 2.1. (p. 207) shows these comparisons with respect to mean age, vital exhaustion (MQ), angina pectoris (LSHCQ), current smoking, coffee consumption, use of sleeping pills, and sleep complaints (LSQ) within the last half year prior to first MI. Since TABP was to be assessed as part of the SBI at home, no such assessments are available for the MI-cases who refused to participate. It has recently been argued that surviving MI-cases who exhibit TABP to an extreme degree may be unwilling to comply with psychological testing after MI and they may deny their disease and the behaviors they think are associated with it (Abbott et al., 1985; Halperin \& Littman, 1985; Oakes, 1985). Thus, the actual prevalence of TABP in the participating MI-cases may have been underestimated.

Since none of the comparisons in Table 2.1. appear to be significant, it seems reasonable to assume that the present findings about MII-cases (with the possible exception of the occurrence of TABP) are representative of the source population at large (Miettinen, 1985a,b).

\section{B. Neighborhood Referents: Criteria, Selection \& Selection Bias.}

\section{B.1. Criteria.}

The first referent series consisted of $133 \mathrm{NR}$, living on the same or adjacent street as MI-cases at the time of the latter's coronary event and thus representing the source population at large (Miettinen, 1985a,b). NR were only to be included if they had no self-reported history of MI. 


\section{B.2. Selection \& Procedure.}

NR were selected between August 1980 and December 1983 to match MI-cases who had completed the SBI. Suitable NR were sought in the following manner.

First, a complete list of NR was compiled from the most current telephone directory, which is published annually, in such a way that randomization of NR was maximized. That is, for ech MI-case with an even identification number in our filles, a NR was selected by going through the current telephone directory from $A$ to $Z$; for each odd-numbered MI-case, a NR was selected by going from $\mathrm{Z}$ to $\mathrm{A}$.

Second, for each MI-case, five subjects were randomly selected from this list.

Third, the first NR was mailed a short questionnaire indicating the purpose of the study. This was done in the same manner as had been done with the MI-cases. The NR was encouraged to participate in the study if he was, in fact, male, between 35 and 69 years of age, and had not suffered an MI. The NR was requested to return a reply form indicating interest in participation within two weeks of receipt of the questionnaire.

Fourth, if no response was received within these two weeks, the second NR was sent the questionnaire, and so on, until a suitable NR had been found. As with MIcases and HR, no attempts were made to persuade non-responding NR to participate because time-consuming as this process was, this might have created inequality of information on the part of NR (Miettinen, 1985a,b).

\section{B.3. Selection Bias.}

In all, 532 potential NR were approached in this manner; the final participation rate was $48 \%$ (see Appendix $I$ ).

The possible selection bias that may have resulted from this relatively high percentage of refusalls could only be studied to a limited extent. As shown in Appendix I, $278 \mathrm{NR}$ refused to participate. That is to say, either they did not return the reply form within two weeks of receipt of the questionnaire or they returned the form but indicated in some way that they were either too busy or feeling too old to participate.

Since no further information is available about NR who refused to participate, it cannot be unequivocally assumed that there was no selection bias in the findings about NR who did participate. However, on the basis of the little information pro- 
vi-ded in the reply forms that were returned, it appears that older subjects were less willing to participate than younger, most likely healthier, ones.

\section{Hospital Referents: Criteria, Selection \& Selection Bias. \\ C.1. Criteria:}

The second referent group consisted of $192 \mathrm{HR}$, admitted to the departments of general surgery, neurology, opthalmology, and urology of the same hospitals as the MIcases between March 1982 and March 1985. These dates only coincide in part with the time that the MI-cases were selected. The reason for this difference is that originally only NR were to be included in this study. During the course of the study, a grant ${ }^{1}$ was obtained that permitted the inclusion of a second referent group. As with, and for the same reasons as MI-cases, only patients from the actual catchment areas of both hospitals were included. As mentioned earlier, HR were specifically chosen so that the possible effects of hospitalization on the perception and/or the recall of SLE, vital exhaustion, and habitual life styles prior to admission to the hospital could be studied, something which would have been impossible with NR alone (Rothman, 1986). Moreover, from a life-span developmental perspective, it seemed worth studying whether the life-span pattens of HR would differ in any important respect from those of NR, since conceptually both referent groups are thought to be representative of the source population at large (Miettinen, 1985a,b).

\section{C.2. Selection \& Procedure.}

HR were only to be included if, on the basis of hospital records, they had not suffered a documented MI and if they had been hospitalized for a non-life-threatening, commonly occurring ailment that was thought to be unrelated to current SLE. Table 2.2. (p. 208) shows the various primary reasons for hospitalization and indicates that the afflictions of HR represent the same non-life-threatening physical conditions that occur in the source population at large (Miettinen, 1985a,b). In all, 252 potential HR were approached. As with MI-cases, their names were provided by the heads of the cooperating departments. The final refusal rate was $16 \%$ (see Appendix $I$ ). 


\section{C.3. Selection Bias.}

The possible selection bias (and, hence, confounding of results) that may thave resulted from this refusal rate, was studied as follows. As shown in Appendix $I_{4} 1 \mathrm{HR}$ who initially agreed to participate in the study later refused. As with MI-cases and NR, no attempts were made to persuade those HR to participate. Only two of these $41 \mathrm{HR}$ had returned a fully completed set of MQ, LSHCQ, and LSQ, too few to allow any meaningful comparisons to be made between non-participating and participating HR. The mean age of the former was 51.6 years (S.D. $=10.6$ years), that of the latter 51.1 years (S.D. $=9.7$ years; $t=0.32, \mathrm{NS}$ ). As illustrated in Table 2.2, the primary reasons for hospitalization of the non-participating HR did not differ from those of participating HR. Thus, there is no reason to assume that the findings about HR have been biased by age or primary reasons for hospitalization. Rather, it may be thought that the findings about HR, which will be presented later, are in fact representative of the source population at large (Miettinen, 1985a,b).

One other possible source of selection bias, due to the later inclusion of $\mathrm{HR}$, should be mentioned here. Most HR were sampled later in the course of the ongoing study than both MI-cases and NR. Therefore, those HR may have been exposed to different environmental risk indicators that occurred later (e.g., particular SLE associated with rapid economic changes) or they may have changed their life styles to a different extent (e.g., quit smoking more often) than MI-cases and HR who were included much earlier in the study. Thus, it cannot be stated unequivocally that some of the differences between MI-cases and HR were not due, in part, to the differences in time of measurement between both groups of participants (see also 2.3.A.1.).

Finally, it should be noted here that the above-mentioned selection criterion regarding the absence of MI in both NR and HR allowed, in principle, for a referent to become included in the group of MI-cases later (Miettinen, 1985a, b; Rothman, 1986). This was, in fact, the case with one subject, who participated first as a NR and, about a year later, as an MI-case. 


\subsection{Age Distribution.}

The present study was designed to sample all subjects in such a way that both MIcases and referenis would be distributed among seven consecutive age strata of about equal size (i.e, at least $15 \mathrm{MI}$-cases, $15 \mathrm{NR}$, and $25 \mathrm{HR}$, aged 35-39, 40-44, etc. up to ages 65-69) in order to match for age. Given this age distribution and the fact that first MI appears to be a very rare event in young adults, it follows that a substantial amount of time - more than three years - was needed to collect all the youngest MI-cases.

Table 2.3. ( $\mathrm{p}$. 209) shows the actual age distribution of MI-cases, NR, and HR, and all subjects were, indeed, distributed about equally over the seven age strata in this cross-sectional study. It should be noted here that within a life-span developmental context the term "cross-sectional" signifies a design in which a constellation of single observations about different age groups is made at one particular point in time (Schaie, 1965; Baltes, 1968). The present case-referent study, which employs some fundamen-t-all life-span developmental notions within an epidemiological framework, may, therefore, be said to constitute a cross-sectional study in which such observations are performed in three distinct groups with presumably different life-span developmental histories.

The rationale behind this particular and very time-consuming sampling procedure with respect to age was that any study on the determinants of human development has to take into account the problem of confounding with respect to the age and cohort membership of the subject under examination and to the time of measurement (Schaie, 1965; Baltes, 1968; Schaie \& Gribbin, 1975; Baltes et al., 1977; 1978).

\section{A. Confounding.}

\section{A.1. "Time of Measurement" Effects.}

Given the nature of the present study, time of measurement could not be limited to a few weeks or months. Since occurrence of first MI still constitutes a rare event in young adults, it took considerably longer to sample all MI-cases and referents that needed to be included. That is, while it took less than five months to collect a sufficient number of eligible MI-cases for the age stratum 55-59, it took more than three years to collect those for the two youngest strata. In order to understand the mechanisms 
that may be involved in this particular source of confounding, it is necessary to know something about the historical circumstances surrounding the subjects.

Since the beginning of this century, the economy of the eastern part of the South Limburg region of the Netherlands bas been completely dominated by coal mining and related industrial development, which have provided the major source of income for a vastly expanding population. During the fifties, this part of South Limburg became one of the nation's most prosperous areas. In 1965, however, the Dutch government decided it would close down all twelve, mostly state-owned, mines over a period of about ten years. This meant that about 60,000 jobs, mostly well-paid, would be eliminated and that completely new industrial sources of employment would have to be created. Older mine workers were allowed to retire early with a special pension, while younger ones were guaranteed new jobs. It later appeared that the better educated and better skilled young workers, who also took an active role in searching lor new jobs, fared much better than those who remained with their former employer and waited until the coal mines were actually closed down. These young men had to choose from a much more limited and much lower paid range of jobs, mainly due to the area's rapidly declining economic climate in the second half of the seventies. In fact, the region as a whole has since remained one of the nation's most problematic areas. As was shown in a preliminary analysis of the mine workers from the present study (about one-third of all participating subjects), remaining with the former employer and having less of an opportunity to find adequate job replacement placed these subjects at a significantly elevated risk for first MI (Falger, 1984). Since it took more than three years to collect the youngest MI-cases in the present study, it may very well be that those cases included towards the very end of the study were exposed to the abovementioned adverse economic conditions much longer than those included at the beginning. Thus, time of measurement, especially with respect to the socioeconomic parameters that may directly influence individual psychosocial development, may constitute a confounder in younger cohorts of MI-cases. 


\section{A.2. "Age and Cahor-Membership" Effects.}

Although time of measurement constitutes an important variable in developmental research, it has been argued that distinguishing meaningfully between age effects and cohort effects [the latter originally meaning year(s) of birth (Schaie, 1965)] is the major challenge in cross-sectional studies in life-span developmental psycho-logy (Battes, 1968; Schaie \& Gribbin, 1975; Baltes et all, 1977; 1978). That is, when subjects who differ widely in age are observed at about the same point in time, the differences observed do not only reflect age changes but also "cultural differentials", in particular differences in the conditions under which subjects belonging to clearly different cohorts were brought up (Baltes, 1968).

In order to distinguish as precisely as possible between age effects and cohort effects in the analyses of the occurrence of SLE that will be reported in Chapter 5, it would have been necessary to take both year of birth and year in which first SLE occurred into account. This would have necessitated the collection of a substantially larger number of ML-cases and referents, given the rather rare occurrence of some SLE. In that case, the influence of possible time of measurement effects might have become an unacceptable source of confounding. Therefore, the chronological years in which SLE first occurred in different age strata of both MI-cases and referents have been omitted deliberately, and cohorts have been defined in such a way as to include five consecutive years of birth instead of one.

One important consequence of this strategy is that alleged "cohort effects" that may be found with respect to the occurrence of SLE may actually constitute "age by cohort" effects. Most of the life-span developmental data thus far collected in crosssectional studies, while possibly confounded by age and cohort effects, have been construed to entail cohort effects (Baltes et al,; 1977; 1978), assuming that age has been strictly controlled for. The rationale behind this reasoning is that "age", as an explanatory factor in hurnan development, is, by definition, irreversible and, as such, does not appear to be the most important initial variable for the exploratory analysis of life-span developmental patterns (Baltes et al., 1978).

The present study will, therefore, focus on cohort-membership and the various ways in which this membership may influence developmental histories conducive to premature MI in consecutive stages of adulthood. Because of this particular emphasis 
on cohort effects, it follows that age, as a major risk indicator, should be matched as closely as possible in all three groups of participating subjects. Table 2.3. shows that this is, in fact, the case. This particular cross-sectional study is designed in such a way as to allow for the analysis of hypothesized changes in the associations of different psychosocial risk indicators with first MI within warious cohorts.

\subsection{Instruments.}

A. The Structured Biographical Interview Assessment of Sireasful Life Events.

About two months after being discharged from the hospital, MI-cases and HR were interviewed at home regarding the occurrence of, and their appraisal of and coping strategies for, SLE over the entire life-span prior to first MI or hospitalization. The Structured Biographical Interview (SBI) was used to assess these SLE. NR were also interviewed at home using the SBI.

\section{A.1. Construction.}

The reasons for constructing the SBI have been described previously (Falger, 1983b). In sum, it could be said that the SBI consists of 47 SLE: 11 about "Childhood \& Adolescence", 16 about "Work \& Career", and 20 about "Family \& Social Life". These SLE were selected after a review of the literature that was followed by a pilot study with about 30 Dutch MI-cases (Falger, 1983b; 1987). The SLE that were included under "Work \& Career" were based almost exclusively upon the work of Theorell et al. The potential impact of those SLE on life-span development, both shortly after the event and in the long run, was first discussed in the pilot study before these SLE were included in the SBI. The SLE that were included under "Childhood \& Adolescence" and "Family \& Social Life" were based primarily on the interviews from the pilot study. That is, at the time the SBI was constructed, no studies had yet been published on the formative role of critical events during childhood and adolescence in the subsequent development of CHD in later phases of the life-span. Yet, during the pilot study, most MI-cases repeatedly emphasized the importance of some of the events from this domain, in particular "Prolonged illness" and "Loss of one/both parents". They described the ways in which these events had influenced their lives, mainly by 
obliging them to take over the parent's role, which affected their performance in school. Other crucial events were "Prolonged familial conflicts" and "Prolonged financial problems", mainly due to the father's unemployment during the Great Depression, and "Disruption of one's educational career", due to World War II. Important events in "Family \& Social Life" were also tapped, among them "Prolonged/serious educational problems with children", "Conflicts with in-laws" (mostly at the beginning of one's marriage, when it was common to live with an extended family due to the severe housing shortage after World War II), "Prolonged marital conflicts", and "Prolonged/serious financial problems" over extended periods of one's marriage. In general, the events from "Family \& Social Life" were regarded as being the most difficult ones to cope with.

However, not all events that were discussed in the pilot study were included in the final form of the SBI. Some events (e.g., "Performing forced labor in German captivity during World War I" and "Emigration after World War $\mathrm{I}^{\prime \prime}$ ), which undoubtedly played an important role in structuring subsequent life-span development, appeared to have occurred too infrequently to be meaningfully included in future statistical analyses. Only those SLE that were expected to have occurred in at least $10 \%$ of the MIcases from all combined age strata were included in the SBI.

In constructing the SBI, the following theoretical and methodological arguments were taken into consideration. Because the SBI was used here for the first time and constitutes by far the largest instrument in this study, these arguments will be discussed in some detail. The complete SBI (in Dutch) is included as Appendix II.

\section{A.2. An Intenview Schedule Instead of a Questionnaire to Assess Stressful Life}

\section{Events in Life-Span Development.}

Most case-referent studies about the occurrence of SLE prior to MI have used adapted versions of the Social Readjustment Rating Scale, a self-report questionnaire that is predominantly situation-centered (Holmes \& Rahe, 1967; Vossel, 1987). The present study, however, employed a structured interview schedule, for a number of reasons. 
A. "Sleeper" Effects. Almost all studies using questionnaires bave investigated the occurrence of SLE in the last two years - or during shorter periods of time - prior to first MI (or reinfarction) only. However, it was concluded before that from a person-centered vantage point, earlier stages of an individual's life may also contain highly relevant SLE that may influence physical and mental health in later developmental phases (Antonovsky \& Kats, 1967; Hinkle, 1974; Hultsch \& Plemons, 1979; Brim \& Ryff, 1980; Vossel, 1987). Moreover, these early events may very well contribute to the subsequent development of pathogenic behavior, $\mathrm{CHD}$, and MI in later stages of life (Arnesen \& Forsdahl, 1985; Steinberg, 1985). In other words, certain SLE from early developmental stages may have constituted "sleeper effects". They may have influenced the course of individual development in a critical manner, although at the actual time of occurrence they did not appear to have that potential. Examples of SLE that might have produced such effects include the loss of a parent during childhood or the (cohort-specific) disnuption of one's educational career due to particular circumstances during World War II.

B. Emciency. In order to map SLE from previous developmental stages, a number of rather tedious, and very long, questionnaires may be required. That is, not only does the actual occurrence of SLE of each participating subject have to be registered, but also the associated appraisal and coping strategies, all in standardized questionand-an-swer form. Yet, those replies, which may include incomplete and/or inconsistent information, cannot be immediately verified. The major advantage of a structured interview schedule is that the actual occurrence of each SLE in chronological time may be assessed as precisely as possible by a trained interviewer. Moreover, all relevant information regarding idiosyncratic anticipating, appraising, and coping strategies for each SLE may be included after the interviewer has discussed them with the subject (Brown, 1974; 1984).

C. Protection Against Retrospective Bias. Finally, an interview is better suited than a questionnaire for controlling "retrospective bias" associated with case-referent studies since an interview enables the interviewer to directly check the replies given and to reformulate questions, when nec-essary. Moreover, a strong advantage of an interview is that it can provide information on exposure at different times in the past probably much more accurately than a long, tedious series of questionnaire items 
(Rothman, 1986). Beffore discussing the issue of retrospective bias, however, some attention sthould be paid to the interviewer characteristics that may have influenced the information obtained in the SBI:

\section{A.3. Inteniewer Characteristics.}

The SBI were conducted by nine different interviewers. Table 2:4. (p. 210) shows the distribution of all the interviews with MI-cases, NR, and HR conducted from July 1980 - Augustus 1985 by the respective interwiewers. Only one interviewer (i.e., C, the author) conducted interviews throughout the entire period of data collection. Interviewers A and B, wo female students from the Department of Medical Psychology, participated from the very start of the study until the beginning of 1982. Together, they interviewed more than half of the MI-cases ( $54 \%$ ). The author himself interviewed an additional $18 \%$ of the MI-cases. Thus, these three interviewers conducted more than two-thirds of all SBI with MI-cases. Interviewers A and B also conducted almost onethird of all the interviews with NR (29\%) since, at first, NR were the only referents. Interviewers $\mathrm{D}$ through $\mathrm{H}$, also female, became involved in the study after receiving a grant from the Dutch Heart Foundation in the beginning of 1982 . Although initially contracted only to conduct all of the interviews with HR, but in fact completing $91 \%$ of them, these interviewers were also assigned to conduct interwiews with a number of MI-cases and NR, in order to distribute these interviews as much as was still possible among all interviewers. These were well-trained interviewers from a professional research agency, who did not, however, have any clinical background. Interviewer I, like A and B, was a student from the Department of Medical Psychology, who conducted the very last interviews with MI-cases and HR, most of whom were young.

All interviewers had been trained by the author to properly conduct the SBI as well as the Structured Interview assessment of TABP.

Given this number of interviewers, whose knowledge regarding the purpose and the hypotheses of the study differed widely, the results from the SBI may have been confounded by intra- and/or inter-interviewer differences. Table 2.5. (p. 211) shows the mean number of reported SLE recorded by the nine interviewers during the SBI with MI-cases, NR, and HR. With the exception of interviewer $E$, there were no intrainterviewer differences with respect to the assessment of SLE in the three groups of 
participating subjects. This was also true when the reported SLE in the domains of "Childhood \& Adolescence", "Work \& Career", and "Family \& Social Lfe" were analyzed separately (not shown here).

Testing for possible inter-interviewer differences would have been more difficult since it would have necessitated controlling for the age of the subjects interviewed, using several age strata. That is, younger subjects most likely would have reported fewer SLE than older ones. Due to the relatively small number of SBI conducted by most of the interviewers within each group of subjects (cf. Table 2.4.), no such test was carried out.

\section{A.4. Retrospective Bias.}

When employing a structured interview schedule in a case-referent study, the methodological pitfall of "retrospective bias" always has to be taken into account (Jenkins et al., 1979; Miettinen, 1985a). This bias may be caused by an idiosyncratic "search for meaning" on the part of the MI-cases under study, which may lead to overreporting, and/or by "selective forgetting", which may lead to underreporting.

A. "Search for Meaning". According to some sources, "search for meaning"t may be specific to studies about MI (Connoly, 1976; De Faire \& Theorell, 1976; Totman, 1979). That is, the retrospective assessment of the impact of critical SLE by the interviewer may be seriously affected by the subject's attempt to explain his first $\mathrm{MI}$ in terms of the events that precedled it. However, a person-centered, structured interview like the SBI, in which SLE are firmly anchored within the context of the individual life-span and which focuses exclusively on SLE that can be verified objectively, may effectively reduce such bias (Cohler, 1982; Laux \& Weber, 1987; Thomae, 1987).

Indeed, the fixed structure of the SBI follows the chronological order of the lifespan in such a way that SLE from "Childhood \& Adolescence", including the subject"s full educational career, are discussed first. These events are followed by SLE that pertain to "Work \& Career"; SLE from "Family \& Social Life" are discussed last. This sequence was chosen as a result of the findings from the pilot study, in which different arrangements of SLE (e.g., beginning with the SLE from the period immediately preceding first MI and continuing back in time) were presented (Falger, 1983b). 
In principle, retrospective bias due to "search for meaning" associated ith SLE varies, depending on how much time has elapsed between first $\mathrm{MI}$ and actual interviewing. It could be argued that the longer the time interval, the greater is the number of SLE reported by the patient to have contributed to the onset of first MI. In order to assess this particular aspect of the recall of SLE in MI-cases in the present study, the following analysis was performed.

The mean time between receipt of completed questionnaires (i.e., MQ, LSHCQ, and LSQ, filled out in the hospital) and actual interviewing at home was 64 days (S.D. $=39$ days). In order to assess bias due to "search for meaning", all MI-cases were assigned to one of three categories, according to when they were interviewed: within one month, between one and three months, or more than three months after returning the completed questionnaires. Then, the mean number of reported SLE from the SBI and the SI-assessments regarding TABP (see below) were compared.

Table 2.6. (p. 212) shows that there were no significant differences whatsoever regarding the mean age, occurrence of TABP, or number of reported SLE in the three respective domains of the SBI; or in the total number of reported SLE in these three categories. It may thus be concluded that the results with respect to the biographical parameters inchuded in the SBI were not biased by age or TABP. Nor were they influenced by the different timing of the interviews.

B. "Selective Forgetting". In the previous paragraph, the chronological sequence of the SBI was mentioned. A chronological structure not only facilitates the establishment of a trusting relationship between the individual under study and the interviewer, but also provides the best opportunity to check the actual occurrence of SLE in the different domains of the SBI. That is, the results from the pilot study (Falger, 1983b) clearly indicated that SLE from "Childhood \& Adolescence", even when rather traumatic, were relatively the easiest to discuss. It also appeared that equally sensitive SLE from "Work \& Career" and, in particular, from "Family \& Social Life" in most instances elicited much more emotional" reactions. Moreover, the same study demonstrated that a fixed chronological arrangement allowed the occurrence of major SLE to be brought up more than once in the course of the interview because of the overlap in domains. Such a strict chronological arrangement reduces the likelihood of the sub- 
jects' simply "forgetting" an event. This, at least, was one of the major conclusions from the pilot study, in which the order of questions and domains varied.

\section{A.5. Interviewer Bias.}

The nine interviewers who conducted the SBI and made the TABP-assessments were all aware of the status of the MI-cases and the referents, prior to interviewing them. Moreover, interviewers A, B, C, and I were aware of the various hypotheses put forward in the present study, due to their prolonged involvement with the study and their clinical backgrounds. Interviewers $\mathrm{D}$ through $\mathrm{H}$ were told the purpose of the study when being trained to conduct the SBI and SI. Thus, a different form of retrospective distortion, namely, interviewer bias, may have influenced the results of the SBI.

From a methodological point of view, blind interviewing with respect to the interviewee's status would most probably have precluded any bias on the part of the interviewer. However, ethical and practical considerations made it necessary to inform the interviewer about this status prior to interviewing. As a result, the biographies of the MI-cases may have been assessed more thoroughly than those of referents. It should be mentioned here that the remaining information about most of the other risk indicators (e.g., angina pectoris, current smoking, and manifestations of vital exhaustion) obtained in the present study was collected by means of questionnaires completed by the participants, independently of the interviewer (see $C_{*}, D_{\text {s, and }} E_{*}$ ). Therefore, possible interviewer bias may not apply to all collected information about the life histories of MI-cases, $\mathrm{NR}$, and $\mathrm{HR}$.

In the present study, this issue cannot be resolved unequivocally, as mentioned previously with respect to interviewer characteristics. That is, even if it would have been shown that there were no significant inter-interviewer differences regarding the number of reported SLE in MI-cases, one might have still found a larger prevalence of SLE in cases than in referents, as a result of more meticulous recording of SLE in MI-cases. Only by repeating the SBI with all 458 subjects with different interviewers would insight into the inter-interviewer reliability have been provided. Then again, the chronological arrangement of the SBI and the clear phrasing of each SLE make it improbable that either interviewer or interviewee misinterpreted anything in the SBI. 
B. The Structured Interview Assessment of the Type A Coronary-Prone Behavior Pattern.

\section{B.1. Selection.}

After completing the SBI, TABP was assessed by means of the Dutch version of the Structured Interview (SI; Rosenman, 1978), which was first employed in the Russian/Dutch Kaunas-Rotterdam Intervention Study (KRIS) (Appels et al., 1982, 1987b; Glasunov et al, 1981 ).

The author was trained in the assessment of TABP, first, by using a selection of the original tapes and classifications from the WCGS, made by Dr. Rosenman, and then, by using a selection of the original tapes and classifications from the Dutch part of the KRIS. The author later trained the other eight interviewers, using the same tapes and procedures.

\section{B.2. Retrospective Bias.}

In most longitudinal studies about TABP it has been demonstrated that this overt behavioral disposition is stable and clearly recognizable in the adult phases of the human life-span (Matthews, 1982; Matthews \& Haynes, 1986; Haynes \& Matthews, 1988). However, the characteristics of TABP in recent MI-cases tend to be more manifest before the coronary event than after (Powell et al., 1984; Matthews \& Haynes, 1986; Haynes \& Matthews, 1988). Since in the present study the assessment of TABP occurred, on the average, about two months after discharge from the hospital, and since extreme Type A MI-cases in other studies have reportedly been unwilling to participate in psychological testing (Abbott et al., 1985; Halperin \& Litiman, 1985; Oakes, 1985), it is likely that the prevalence of TABP, as measured in the present MI-cases, represents an underestimation of the actual occurrence of this behavior pattern in the source population.

\section{B.3. Intenviewer Bias.}

A particular form of interviewer bias may have further influenced the assessment of TABP. That is, prior to interviewing all interviewers were aware of the status of the MI-cases and referents. This may have resulted in a more critical assessment of TABP in MI-cases than in referents. Ideally, the SI-assessments should have been audio or 
wideotaped so that an independent expert who was blind to the status of the subjects under study could have classified them (Dembroski \& MacDougall, 1983; Dembroski \& Costa, 1988). However, because it might have affected the trusting relationship between interviewee and interviewer thought necessary for properly conducting the SBI, this procedure was not followed.

\section{The Maastricht Questionnaire Assessment of Vital Exhaustion. \\ C.1. Selection.}

Manifestations of vital exhaustion were assessed by means of the Maastricht Questionnaire (MQ). An earlier form of this self-administered questionnaire, consisting of 37 items (Form A), was developed in a follow-up study over a period of ten months among 415 middle-aged men. They had all recently gone to a general practitioner with complaints of possible cardiac origin (Appels, 1980). The predictive potential of Form $\mathrm{A}$ of the $\mathrm{MQ}$ was subsequently tested in another prospective study, namely, the Rotterdam Civil Servant Study (RCSS) among 3877 middle-aged subjects, originally free of $\mathrm{CHD}$, who were followed up for an average period of 4.2 years (Appels et al., 1987a, 1989). All 37 items on this form were completed at the beginning of the study. An item anallysis later showed that 21 of them predicted non-fatal and fatal MI. These items make up Form B.

The present study, which was begun at about the same time as the $\mathrm{RCSS}_{\text {" }} \mathrm{em}-$ ployed an intermediate item pool, consisting of the 37 on Form A plus 21 additional items that were based on a recent series of elinical interviews with middle-aged MIcases. All 58 of these items were phrased in the past tense, asking MI-cases and referents alike how they had felt within the last half year prior to hospitalization or to interviewing. MI-cases and HR were asked to complete the MQ in the hospital; NR filled out the MQ at home prior to the SBI.

\section{C.2. Retrospectrve Blias.}

As mentioned previously with respect to the SBI, retrospective bias due to "search for meaning" on the part of MI-cases (and possibly also of HR who might recently have gained knowledge about their prior illness in the hospital) may have in- 
fluenced the results of the MQ. In order to reduce the likelihood of this happening the following strategy was adopted.

In computing the final score with respect to the occurrence of vital exhaustion within the last half year prior to MI, hospitalization, or interviewing, only the 21 items of Form B of the MQ were considered. These items were the ones that had predicted MI over an average follow-up period of 4.2. years in the RCSS (Appels et al., 1987a, Appendix 2; Appels et al.; 1989). For these particular items, the minimum score was 0 and the maximum score 42 ; Cronbach's alpha was 0.89 , indicating good internal consistency, while the mean inter-item correlation was 0.31 . Thus, by selecting only those items that were found to be predictive of MI in a follow-up study, the likelihood of any difference between MI-cases and referents with regard to mean MQ-scores being fully attributed to retrospective bias alone is reduced. However, a consequence of this rather conservative strategy is that the risk associated with vital exhaustion may be underestimated in the present study. The complete $\mathrm{MQ}$, as used in the present study, will be presented in Table 4.2.

\section{The London School of Hygiene Assessment of Angina Pectoris. \\ D.1. Selection \& Retrospective Bias.}

In the hospital, MI-cases and HR were also asked to complete the London School of Hygiene Cardiovascular Questionnaire (LSHCQ), better known as the "Rose Questionnaire", for the assessment of angina pectoris within the last half year prior to hospitalization (Rose et al., 1982). NR filled out the LSHCQ at home prior to the SBI.

In the present study, no particular attention was paid to possible retrospective bias in the reporting of angina pectoris since the "Rose Questionnaire" has been widely used as an indicator of CHD in many large-scale, epidemiological studies explicitly designed to compare the questionnaire assessments with those of clinicians (e.g., Heyden et al., 1971; Lundman et al., 1971; Rose et al., 1982). This questionnaire is known to adequately reflect the natural history of the disease and it is acknowledged as a standard, valid, unbiased measure. In the Netherlands, the LSHCQ has been validated within the context of the KRIS (Glasunov et al., 1981), the same study in which the Dutch version of the SI for the assessment of TABP was first employed (Appels et al., $1982,1987 b)$. 


\section{E. Life Styles Questionnaire.}

\section{E.1. Selection \& Retraspective Bias.}

Finally, MI-cases and HR were asked to complete a self-developed Life Styles Questionnaire (LSQ) for the assessment of sleep complaints, current smoking; alcohol and coffee consumption, and eating habits within the last half year prior to hospitalization. NR filled out the LSQ at home before beginning the SBI.

As was argued previously with respect to TABP, it may be assumed that healthrelated habits like those included in the LSQ constitute rather stable phenomenona over the adult life-span. Furthermore, with the possible exception of sleep complaints that have been discussed elsewhere (Falger et al., 1988), the frequency of such daily habits as smoking and coffee and alcohol consumption can be reported rather unequivocally. In fact, however, epidemiological studies have repeatedly demonstrated that most categories of patients tend to underreport behavioral habits that they think have adverse health consequences (Miettinen, 1985b).

\section{F. Some Demographic Parameters.}

Finally, it should be noted that a number of demographic parameters were recorded in the SBI. These included age, place of birth, highest level of formal education, employment status and marital status prior to Ml, hospitalization, or interviewing, and number of children.

\subsection{Scoring \& Statistics.}

A. The Structured Biographical Inteniew Assessment of Stressful Life Events.

A.1. Scoring.

Each of the 47 SLE included in the SBI could be answered with "yes" or "no". After each affirmative reply, the interviewer also usually assessed the following aspects of that particular SLE:

(a) year(s) in which it occurred;

(b) whether the event had been anticipated (to be answered "yes", "no", or "?"); 
(c) how the event had been appraised (to be answered "predominantly positive", "predominantly negative", "predominantly ambiguous", or "?"), both at the time the event actually occurred and at the time of the interview;

(d) whether the subject had gotten any kind of social support at the time of the event (to be answered "yes", "no", or "?");

(e) if there had been social support, who had provided it; and finally,

(f) how this support had been appraised (to be answered "predominantly positive"; "predominantly negative", "predominantly ambiguous", or "?").

\section{A.2. Statistics.}

The following analyses were performed with regard to the actual occurrence of SLE in "Childhood \& Adolescence", "Work \& Career", and "Family \& Social Life" in the biographies of MI-cases, NR, and HR;

(a) whether SLE, in general, occurred more often over the life-span of MII-cases than of $\mathrm{NR}$ and $\mathrm{HR}$;

(b) whether particular SLE occurred more often in MI-cases than in either refer-ent group;

(c) whether particular SLE occurred more often over the life-span of Type A than Type B subjects;

(d) whether particular SLE occurred more often in Type A MI-cases than in Type A referents, and whether SLE occurred more often in Type B MI-cases than in Type B referents;

(e) whether particular SLE were associated more often with the life-span of subjects who had been characterized as being "vitally exhausted" than with those who were not; and

(f) whether particular SLE occurred more often in "vitally exhausted" MI-cases than referents, and whether particular SLE occurred more often in "vital" MIcases than referents.

In general, differences in overall and cohort-specific occurrences of SLE between MI-cases and referents, which will be specified later in the respective chapters, were tested using univariate $\mathrm{F}$ - and t-tests (SPSS-X, 1986) and $\mathrm{Chi}^{2}{ }^{2}$-tests (Mantel \& Haenszel, 1959; Mantel, 1963). In addition, estimated relative risks (i.e., the maximum like- 
lihood pooled point estimates that are based on the odds ratios) and $95 \%$ test-based confidence intervals around the maximum likelihood estimate associated with SLE

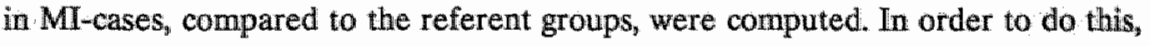
crude relative risks and $95 \%$ confidence intervals were calculated first. Relative risks and $95 \%$ confidence intervals that were adjusted simultaneously for age and for Type A and Type B behavior, or for age and vital exhaustion, respectively, as potential confounders, were calculated second (Miettinen, 1976, 1985b). The latter statistical analyses were performed employing Program 1 from Rothman \& Boice (1982). More detailed descriptions of the multivariate statistical analyses will be given, as needed, in the respective chapters.

In most instances, the latter computations were performed using stepwise multiple logistic regression analyses. This particular method of anal-ysis constitutes a mathematical modelling procedure for controlling and/or adjusting for the potential confounding and/or modifying effects of extraneous factors that may impinge on the relationship between exposure to these factors and the disease under study (Kleinbaum et al., 1982). In terms of the present study this means that a step-wise multiple logistic regression analysis allows one, first, to investigate all concurrent associations between first $\mathrm{MI}$ and the various independent variables - in particular, age, angina pectoris, current smoking, TABP, and vital exhaustion - that were previ-ously subject to univariate analyses. Such a regression analysis allows one, second, to express the results as estimated relative risks and $95 \%$ confidence intervals based on the regression coefficients and their standard errors after the last step of the analysis has been completed (BMDP, 1985). The results of these multivariate analyses can, therefore, be compared directly to those from the previous analyses.

\section{B. The Structured Interview Assessment of Type A Coronary-Prone Behavior} Pattern.

\section{B.1. Scoring \& Statistics.}

On the basis of the SI, each subject was originally designated as being "A1", "A2", "X" $\mathrm{X}$, "B3", or "B4", according to the original criteria used in the WCGS. The actual occurrence of TABP in MI-cases, NR, and HR was summarized using a dichotomy, namely, "Type A" (including A1 and A2) or "Type B" (including X, B3, and B4). 
In general, differences in overall occurtence of TABP between MI-cases and referents were tested using Chi ${ }^{2}$-tests (SPSS-X, 1986). Differences in the rate of occurrence between Type $\mathrm{A}$ and Type $\mathrm{B}$ behavior in all seven age strata and in the three groups under study were also calculated in order to describe the possible variability in the association of TABP with age in MI-cases, as opposed to NR and HR (Miettinen, 1985b). Finally, age-adjusted relative risks and $95 \%$ confidence intervals were computed. More detalled descriptions of the multivariate statistical analyses will be given, as needed, in the respective chapters.

\section{The Maastricht Questionnaire Assessment of Vital Exhaustion. \\ C.1. Scoring \& Statistics.}

Each of the 58 items of the intermediate form of the MQ could be answered with "yes", "?", or "no". Affirmative replies were coded as 2, question marks as 1, and negative replies as 0 . As mentioned earlier, in computing the final score regarding the occurrence of vital exhaustion within the last half year prior to $\mathrm{MI}$, interviewing, or hospitalization, only 21 of these items were considered.

In general, mean MQ scores (i.e., computed as either univariate F- or t-tests), age-adjusted and standardized relative risks, and multiple logistic regression functions were computed for the various analyses pertaining to vital exhaustion. All univariate analyses were performed using the programs from SPSS-X (1986); the stratified analyses employed either program 1 or 3 from Rothman \& Boice (1982), and the multivariate analyses were computed using program $L R$ from BMDP (1985). More detailed descriptions of the multivariate statistical analyses will be given, as needed, in the respective chapters.

D. The London School of Hygiene Assessment of Angina Pectoris.

\section{D.1. Scoring \& Statistics.}

The scores of MI-cases, NR, and HR on the LSHCQ with respect to the occurrence of angina pectoris within the last half year prior to $\mathrm{MI}$, interviewing, or hospitalization were classified as: "No complaints", "Aspecific complaints", or "Probably angina pectorisis". 
Only the differences in overall occurrence of "Probably angina pectoris" in MIcases and referents were calculated using $\mathrm{Chi}^{2}$-tests (SPSS-X, 1986).

\section{E. The Life Styles Questionnaire. \\ E.1. Scoring \& Statistics.}

E.1.A. Current Smoking. Of all the questions from the LSQ with respect to smoking in MI-cases, NR, and HR, only the replies to current smoking (i.e., "yes"/"no") within the last half year prior to MI, interviewing, or hospitalization were analyzed. These differences were calculated using $\mathrm{Chi}^{2}$-tests (SPSS-X, 1986).

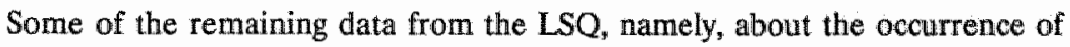
sleep complaints, current smoking, and coffee consumption, will not be included in the analyses presented here, but have been published separately (Falger et al., 1988).

\section{F. Demographic Parameters.}

Of the demographic parameters included in the SBI, only age was analyzed and will be included frequently in most of the above analyses as a criterion for stratification. The other parameters, in particular highest level of formal education, employment status, and marital status, will only be included in the analyses regarding the occurrence of SLE over the life-span of MI-cases and referents. 
$-66$ 


\section{Chapter 3: Resuits: \\ Relationships Between the Type A \\ Coronary-Prone Behavior Pattern \\ and First Myocardial Infarction.}

\subsection{Introduction \& Hypotheses.}

\section{A. Introduction.}

This chapter will primarily address the occurrence of TABP in cases with first MI, in NR, and in HR. It will include an exploratory analysis of the relationship between TABP, in general, and the occurrence of SLE over the life-span. The associations of TABP with the other major psychosocial determinants that were included in this study will be reported in detai] in Chapters 4 and 5 .

It was concluded in Chapter 1 that TABP, as assessed by the SI, should be considered an independent behavioral risk indicator for $\mathrm{MI}$ in the adult American population (Brand, 1978; Siegel, 1984; Matthews \& Haynes, 1986; Booth-Kewley \& Friedman, 1987; Haynes \& Matthews, 1988). The same appears to be true - albeit to a more limited extent - for the adult populations in other industrialized societies in both Western and Eastern Europe. In the Netherlands, the relationships between TABP and both CHD in general and first MI in particular bave thus far only been assessed in three studies with contradictory results (cf. Verhagen et al., 1980; Appels et al., 1982; 1986; 1987b).

Since the focus of the present study is on life-span developmental patterns that may be conducive to MI in different stages of adulthood, it seems pertinent to ask whether the majority of the MI-cases studied exhibited TABP, regardless of the age at which they suffered their first MI, or whether TABP constitutes a distinct behavioral risk indicator in early developmental stages only. That is, both the original epidemiological evidence about TABP (e.g., Rosenman et al., 1964; 1975; Brand, 1978; Zyzanski, 1978) and some recent reviews (Siegel, 1984; Matthews \& Haynes, 1986; BoothKewley \& Friedman, 1987; Haynes \& Matthews, 1988)) suggest that TABP may play a much more decisive role in young CHD cases than in older ones. Therefore, in the analyses to follow, the occurrence of TABP will be assessed both for the entire age 
range under study (i.e., ages 35-69) and for three distinct age strata (i.e., ages 35-44, 45-59, and 60-69). Those particular strata were selected because they correspond well with the distinctions that are generally made in life-span developmental research with respect to adulthood and beginning old age, namely, "young adulthood", "middle-age", and "beginning old age" (e.g., Schaie, 1977; Vaillant, 1977; Gould, 1978; Levinson et al., 1979).

In Chapter 1 it was further concluded from some American studies that in adult populations TABP may generally be associated with SLE that pertain to conflicts at work and in the family (Burke \& Weir, 1980; Margolis et al., 1983). In the Netherlands, such relationships have thus far only been assessed, by means of questionnaires, in one study in young men and women (Dorreboom \& Snel, 1988), and in another in men, aged 40-44 (Falger, 1988).

\section{B. Hypotheses.}

In the present study it was hypothesized that:

(1) the Type A coronary-prone behavior pattern in generall occurs more often in MI-cases than in referents; and that

(2) the Type A coronary-prone behavior pattern constitutes an independent behavioral risk indicator for first MI when controlling for some other risk indicators for CHD.

The questions of whether the Type A coronary-prone behavior pattern would occur at a higher rate in young MI-cases than in older ones and whether this behavioral disposition would be associated with SLE in "Childhood \& Adolescence", "Work \& Career", and "Family \& Social Life" were also explored.

\subsection{Hypothesis 1: Occurrence of the Type A Coronary-Prone Behavior Pattern.}

Table 3.1. (p. 213) shows that according to the SI assessments, 89 MI-cases (67\%), $65 \mathrm{NR}(49 \%)$, and $93 \mathrm{HR}(48 \%)$ were designated as being Type $\mathrm{A}\left(\mathrm{Chi}^{2}=12.72 ; \mathrm{df}=2\right.$, $p<.01)$. Thus, TABP occurred significantly more often in these male MI-cases than in both referent groups. Hence, the first hypothesis was corroborated. 
The mean age of the 89 Type A cases was 51.7 years (S.D. $=9.6$ years) and that of the 44 Type B cases was 55.9 years $(S . D .=8.7$ years; $t=2.47 ; \mathrm{df}=1,131, \mathrm{p}<.01)$. This finding indicates that Type A cases in this study suffered their first MIIs at a significantIy younger age than Type $B$ cases. Furthermore, it indicates that the age distribution in Type A cases may be skewed towards the younger age strata (cf. Table 2.3.).

Table 3.1. also indicates that in the youngest age stratum of MI-cases, every case but one was assessed as being Type $\mathrm{A}(93 \%)$. In the oldest stratum, on the other hand, only $50 \%$ of the MI-cases were designated as being Type A, a situation similar to the general distribution characteristics of TABP in NR and HR. This also indicates that TABP no longer exhibits discriminating power in this particular stratum.

Table 3.2. (p. 214) and Figure 3.1. show the ratios between Type A and Type B behavior (i.e., the number of Type A subjects divided by the number of Type B subjects) in MI-cases, NR, and HR in seven age strata. In MI-cases, this ratio appeared to be exceptionally high in the youngest stratum, as was to be expected on the basis of the occurrence shown in Table 3.1.. In this stratum of "young" adults, nine cases (60\%) were designated as fully developed Type A1 and five cases (33\%) as Type A2; there was only one Type B3 case (7\%). This particular finding represents a general tendency in most epidemiological research about risk indicators for chronic disease of early onset. That is, their single effects are the strongest and the most clearly recognized in the youngest age stratum being studied (Miettinen, 1985b; Rothman, 1986).

In MT-cases in the four age strata from 40 to 59 years ("middle-age"), TABP shows occurrence rates similar to those found in most other case-referent studies (Jenkins \& Zyzanski, 1980; Siegel, 1984). This does not appear to be the case in the two oldest age strata representing "beginning old age".

\section{Hypothesis 2: The Type A Coronary-Prone Behavior Pattern as an} Independent Risk Indicator for First Myocardial Infarction.

\section{A. Relative Risk.}

Given the above-mentioned occurrence of TABP in MI-cases, NR, and HR, the estimated relative risks and $95 \%$ confidence intervals for first MI that may be associated with TABP were computed. In order to both control for age and enhance statis- 
tical power, the original seven age strata were combined into the three strata that have been mentioned before, namely, ages 35-44, 45-59, and 60-69. As a result, the mean age of MI-cases and that of NR and HR (combined) for the three age strata were: 40.1 $(\mathrm{S} . \mathrm{D} .=2.8)$ years and $39.3(\mathrm{~S} . \mathrm{D} .=3.0)$ years $(\mathrm{t}=1.29, \mathrm{NS}) ; 52.6(\mathrm{S.D} .=4.4)$ years and $51.7(\mathrm{S.D} .=4.1)$ years $(t=1.43, \mathrm{NS})$; and $62.4(\mathrm{S.D}=3.0)$ years and $63.4\left(\mathrm{~S} . \mathrm{D}_{\mathrm{u}}=2.7\right)$ years $(t=1.35, \mathrm{NS})$, respectively.

Table 3.3. (p. 215) shows the overall age-adjusted relative risks and 95\% confidence intervals associated with TABP in MI-cases, compared to NR and HR, and in the three combined age strata. The overall relative risks are clearly and significantly elevated (i.e, 237 in the NR-series and 2.29 in the HR-series). As such, these general results are in accordance with those of most other case-referent studies (Jenkins \& Zyzanski, 1980; Siegel, 1984). These relative risks are also of the same magnitude as those in major prospective studies (Matthews \& Haynes, 1986; Haynes \& Matthews, 1988);

The age-adjusted relative risks are clearly and significantly elevated in "young adulthood" and remain significant in the stratum representing "middle age". In "beginning old age", however, TABP is no longer associated with a significantly elevated risk for first MI.

\section{B. Confounding.}

Although age constitutes the most important risk indicator for CHD and was, therefore, controlled for in the above analyses, other risk indicators, namely angina pectoris, current smoking, and excessive coffee consumption, may have confounded the association between TABP and first MI as well. These particular indicators were chosen because numerous behavioral and psychosocial studies have demonstrated that they are positively associated with both TABP and manifestations of CHD, including MI (e.g.s Jenkins, 1971, 1976, 1978a, 1988; Brand, 1978; Zyzanski, 1978; Matthews \& Haynes, 1986; Haynes \& Matthews, 1988). Furthermore, in the present stu$\mathrm{dy}$, these indicators could be assessed by means of questionnaires, whereas other risk indicators for CHD, such as hypertension, hypercholesterolemia, obesity, and the like, which have a much more ambiguous relationship with TABP, could not. 


\section{Bil. Angina Pectoris.}

According to the LSHCQ assessments, $30 \mathrm{MI}$-cases (23\%) had suffered from angina pectoris within the last half year prior to their $M T$, whereas angina pectoris was reported by $6 \mathrm{NR}(5 \%)$ and by $9 \mathrm{HR}\left(5 \% ; \mathrm{Chi}^{2}=33.99 ; \mathrm{df}=2, \mathrm{p}<, 001\right)$. In other words, angina pectoris occurred significantly more often in MI-cases than in referents and may, therefore, constitute a confounding factor. However, when MI-cases, NR, and HR were combined, angina pectoris did not usually occur more often in Type A subjects than in Type B subjects $\left(\mathrm{Chi}^{2}=0.79 ; \mathrm{df}=1, \mathrm{NS}\right)$.

\section{B.2. Current Smoking.}

According to the responses on the LSQ, $111 \mathrm{MI}$-cases (84\%) reported that they had been smoking cigarettes, cigars, and/or pipes within the last half year prior to their MIs; the same was true for $81 \mathrm{NR}(61 \%)$ and $108 \mathrm{HR}\left(56 \% ; \mathrm{Chi}^{2}=27.50 ; \mathrm{df}=2, \mathrm{p}<\right.$ $.001)$. Thus, current smoking was significantly associated with first MI and may have actually confounded the association between TABP and MI. However, after combining MI-cases, NR, and HR, current smoking was not found to be associated, in general, with TABP $\left(\mathrm{Chi}^{2}=1.63 ; \mathrm{df}=1, \mathrm{NS}\right)$.

\section{B.3. Coffee Consumption.}

Finally, according to the responses on the LSQ, 67 MI-cases (50\%) reported that they had been consuming six or more cups of coffee per day within the last half year prior to their MIs; $48 \mathrm{NR}(36 \%)$ and $74 \mathrm{HR}(39 \%)$ had done the same $\left(\mathrm{Chi}^{2}=6.61\right.$; $\mathrm{df}=2, \mathrm{p}<.05$ ). Because excessive coffee consumption occurred significantly more often in MI-cases than in referents, it may have confounded the relationship between TABP and first MI. However, when MI-cases, NR, and HR were combined, Type A subjects, in general, did not indulge in excessive coffee consumption more often than their Type B counterparts $\left(\mathrm{Chi}^{2}=3.35 ; \mathrm{df}=1, \mathrm{NS}\right)$.

In sum, 'Type A subjects appeared to have at least a twofold risk for first MI compared to Type B subjects. At younger ages, the risk for Type A subjects was three-anda-half to four times greater. This risk declined, however, with increasing age, to a nonsignificant association after age 60. These associations between TABP and elevated 
risk for first MI were not confounded by angina pectoris, current smoking, or excessive coffee consumption.

The possible relationship between TABP and vital exhaustion, another potential confounder, will be discussed in Chapter 4.

\subsection{The Type A Coronary-Prone Behavior Pattern and its Association with} Reported Stressful Life Events over the Life-Span.

Tables 3.4.a - through 3.4.c. (p. 216-218) show the occurrence of SLE in "Childhood \& Adolescence", "Work \& Career", and "Family \& Social Life", as assessed by the Structured Biograph-ical Interview (SBI), in both Type $A(\mathbb{N}=247)$ and Type $B$ subjects $(\mathrm{N}=211)$. In all, 6 of the $47 \mathrm{SLE}(13 \%)$ occurred significantly more often to subjects who had been assessed as being Type A. (When a significance level of p.10 is also taken into consid-eration, the number of significant SLE becomes 7).

In "Childhood \& Adolescence", the event "Prolonged familial conflicts" occurred more often in Type A than Type B subjects; but did not reach statistical significance. Most of the events denoting conflicts in "Work \& Career" and "Family \& Social Life" also occurred more often in Type A than Type B subjects, in most instances to a significant degree.

It is interesting to note that in the domain of "Work \& Career", "Prolonged/serious conflicts with supervisors" apparently did not differentiate between Type A and Type B subjects, whereas both of the other events denoting conflicts at work clearly did. Furthermore, in this domain, Type A subjects reported more often than their counterparts that "Prospects for promotion" had never been realized.

In "Family \& Social Life", "Prolonged/serious conflicts with children away from home" occurred about equally in Type A and Type B subjects. On the other hand, "Prolonged/serious marital conflicts" and "Prolonged/serious conflicts with family members" occurred significantly more often in Type A subjects. Finally, it should be noted that both "Prolonged financial problems" in "Childhood \& Adolescence" and "Prolonged/serious financial problems" in adult "Family \& Social Life" were positively associated with TABP. 
It may, therefore, be concluded that TABP in adult subjects was associated with major conflicts both at work and in family and social life. This is in accordance with the study of Burke \& Weir (1980), who found that TABP was associated more with stressful events at work and less with marital satisfaction, and with the theoretical analysis of Margolis et all. (1983). The possible association of TABP with prolonged or chronic financial problems also deserves attention. Whether these associations apply to Type A MI-cases in particular, given the occurrence of TABP among MII-cases, will be discussed in Chapter 5. 
.74 


\section{Chapter 4: Results: \\ Relationships Between Manifestations of Vital Exhaustion and First Myocardial Infarction.}

\subsection{Introduction \& Hypotheses.}

\section{A. Introduction.}

This chapter will describe the occurrence of manifestations of vital exhaustion in MI-cases, NR, and HR. It will discuss the associations of vital exhaustion with TABP and with the other major risk indicators that were included in this study, and it will explore the relationships between vital exhaustion and SLE over the life-span. In Chapter 1 it was concluded that vital exhaustion may constitute a psychosocial risk indicator for first MI in middle-aged men (Appels, 1980; Appels et al., 1984, 1987a). The unique feature of this risk indicator is that unlike TABP, SLE, or other risk indicators that exert pathogenic influences over major parts of the entire life-span, vital exhaustion may identify subjects at elevated risk for first MI shortly before their coronary event.

Thus far, vital exhaustion and its association with MI has been studied independently from such psychosocial risk indicators as TABP. Recently, the tenacity of the association between TABP and elevated risk for first MI has been challenged by a number of major prospective studies referred to earlier (Kittel, 1984; Appels \& Mulder, 1985; Shekelle et al., 1985; Appels et al., 1986, 1987b; Ragland \& Brand, 1988a,b). The apparent failure to establish an association between TABP and risk for future CHD-mortality, including MI, does not yet warrant the conclusion that the existing theory about TABP is false (Matthews \& Haynes, 1986; Haynes \& Matthews, 1988). Rather, as was concluded earlier, these recent findings suggest that the theory about TABP may be narrowed to eliminate certain components that have been found to be unimportant (Dimsdale, 1988). At the same time, the theory of TABP should be broadened to encompass additional psychological attributes that may be associated both with TABP and with "disease-proneness" in general (Booth-Kewley \& Friedman, 1987; Friedman \& Booth-Kewley, 1987). Vital exhaustion may constitute one such additional attribute and will, therefore, be studied in more detail here. That is, studies 
of wital exhaustion, of the attributes of TABP, and of their respective associations with MI strongly suggest that future MI-cases may experience a period characterized by vital exhaustion before the onset of their coronary events. Given the life-span developmental background of this study, it will be interesting to further explore whether vitall exhaustion constitutes a psychosocial risk indicator of comparable magnitude in each developmental stage under scrutiny or whether associations in "young adulthood" are stronger than those in "middle age" and/or "beginning old age", as appeared to be the case with the pathogenic role of TABP.

A number of interrelated hypotheses could be derived from the above suggestion

\section{B. Hypotheses.}

In the present study it was hypothesized that:

(1) vital exhaustion, in general, occurs more often in MI-cases than in referents;

(2) vital exhaustion, in generall, constitutes an independent psychosocial risk indicator for first MI when controlling separately for age, AP, and current smoking;

(3) subjects who are assessed as being Type A are at an elevated risk of becoming vitally exhausted;

(4) Type A subjects who are vitally exhausted are at a more elevated risk of suffering first MI than Type A subjects who are not vitally exhausted; and (5) when controlling for vital exhaustion, Type A subjects are at a more elevated risk of suffering first MI than Type B subjects.

\subsection{Hypothesis 1: Occurrence of Manifestations of Vital Exhaustion.}

According to the criteria for the occurrence of vital exhaustion that were discussed earlier, the mean scores and standard deviations for the 21 items from the $\mathrm{MQ}$ (Form B) were 18.0 (S.D. $=10.8$ ) in MI-cases, $11.7\left(\right.$ S.D. $\left._{w}=9.8\right)$ in $\mathrm{HR}$, and 9.0 (S.D. $=9.7)$ in NR $(F=28.42 ; \mathrm{df}=2,455, \mathrm{p}<.001)$. In other words, vital exhaustion occurred significantly more often in these male MI-cases than in referents, thus corro- 
borating the first hypothesis. HR reported significantly more manifestations of vital exhaustion than NR $(t=2.41 ; d f=1,323, p<.05)$.

These findings may be interpreted in three different ways.

First, vital exhaustion may be seen, to some extent, as a precursor of diseases other than CHD, such as those included in the present study (cf. Table 2.2.);

Second, vital exhaustion may be seen not as a precursor of those other diseases, but rather as being associated with one or more symptoms that typically present themselves as characteristic of vital exhaustion. On the other hand, those diseases may be associated with particular complaints (e.g, sleep complaints) also represented in the MQ (Falger et al., 1988);

Third, recent hospitalization may have caused some retrospective bias in both MI-cases and HR.

Since there was also a significant difference in mean scores on the MQ between both referent groups, these groups will not be combined in the analyses that follow.

\section{Hypothesis 2: Manifestations of Vital Exhaustion as an Independent Risk Indicator for First Myocardial Infarction.}

\section{A. Relative Risk Associated with The Maastricht Questionnaire.}

Given the above-mentioned occurrence of vital exhaustion in MI-cases $H_{*}$, and $\mathrm{NR}$, the estimated relative risks and $95 \%$ confidence intervals for first MI that may be associated with vital exhaustion as measured by the entire MQ were computed. A distinction was made between "vital" and "vitally exhausted" subjec ts, the latter being those who scored above the median MQ-score (Form B) of the combined HR and NR $(\mathrm{N}=325)$, that is, 8 or more affirmative replies to the 21 items of this form.

Table 4.1. (p. 219) shows the overall age-adjusted estimated relative risks and $95 \%$ confidence intervals associated with vital exhaustion in MI-cases in both the HRand the NR-series. In the NR-series, the estimated relative risk is cleariy and significantly elevated. This result replicates the findings from previous case-referent studies employing the MQ in age-matched, presumably "healthy", referent series (Appels, 1980; Verhagen et al., 1980). In the HR-series, the estimated relative risk is also significantly elevated, but to a much lesser degree than in the NR-series. Thus, it may be 
concluded that vital exhaustion, in general, constitutes a risle indicator for first MI. Possible confounding by other risk indicators will be discussed in sec. $C$.

\section{B. Relative Risk Associated with All Separate Items of The Moastricht}

\section{Questioninaire.}

In the preceding section, the estimated relative risks associated with the total score on the 21 iterns on Form $B$ of the $\mathrm{MQ}$ were presented. However, throughout the entire study, the internediate 58 -item pool was employed (i.e., the 37 items found to discriminate between future cases of CHD and a "heal thy referent group in the IMIRstudy, plus the additional 21 items denwed from clinical interviews), for reasons that were described earlier. Therefore, the estimated relative risks were calculated for each item from the intermediate item pool in order to identify which items distinguished MI-cases from both referent groups. This was also done to prowide insight into which items were common to the intermediate item pool and Form B and which were $\mathrm{a}$ nique.

Table 4.2. (p. 220-230) shows these estimated relative risks and the 95\% confidence intervals after stratifying for the three combined age groups also employed with respect to TABP in both the HR- and the NR-series. For those items for which the heterogeneity $\mathrm{Chi}^{2}$ was significant ( $\mathrm{p} .05$, two-sided, in this instance), indicating a significant age-effect from one or two of the three strata, the estimated relative risks and $95 \%$ confidence intervals are presented separately for each age stratum.

In Table 4.2., the final 21 items on Form $B$ of the $M Q$ are printed in italics and, thus, stand out among the 58 items from the intermediate item pool. Furthermore, all significantly elevated estimated relative risks and $95 \%$ confidence intervals associated with each individual item in both series are printed in bold, regardless of whether they appear in Form B or in the intermediate item pool. Finally, the rank order of each significantly elewated item in both series is indicated. A number of interesting observations can be made regarding the results from Table 4.2 .

First, in the present case-referent study, in both the NR-and HR-series, a positive reply or question mark on 46 out of 58 items (79\%) constituted a significantly elevated risk for first MI. Not all discriminating items from the present study were, however, the same in the two series. This is more than twice the number of items in the prospective RCSS, in which Form B of the MQ was established (Appels et al., 1987a). 
It should be noted here that in the RCSS, rate ratios were calculated, allowing; in general, for more precise risk estimates than the present odds ratios. In most studles about psychosocial risk indicators, odds ratios tend to slightly overestimate the associated risks (Miettinen, 1985b). Moreover, the rate ratios associated with the items on Form $B$ were controlled for angina pectoris at screening, whereas the odds ratios from Table 4.2. were not. (This potential confounder will be discussed in the next section).

For both reasons, the results from the present analyses and from those by $\mathrm{Ap}$ pels et al. (1987a) cannot be compared directly. However, it may be argued that the significantly elevated mean MQ-scores that are based on Form B of the MQ most probably underrepresent the true occurrence of current vital exhaustion in MI-cases. As discussed earlier, retrospective bias may account to some extent for the differences between MI-cases, NR, and HR with respect to vital exhaustion.

Second, and conceptually more important, in both referent series, not all 21 items of Form B were associated with a significantly elevated risk for first MI, as they had been in the RCSS. As mentioned above, direct comparisons should not be made, however. In the NR-series, item 42 was the only one that did not discriminate; in the HRseries, items 35,38 , and $\mathbf{4 2}$ failed to reach significance and item 48 was only marginally associated with risk for first MI.

On the other hand, some items from the intermediate item pool constituted estimated relative risks that were at least as high as those associated with the items on Form B.

\section{B.1. The Neighborhood Series.}

In the NR-series, three items from the intermediate item pool were associated with age-adjusted estimated relative risks of developing first MI within half a year that were similar in magnitude to the risks associated with three items actually included on Form B. These items were: item 05 ["Within the last half year, I seemed to blow up easily at times" (estimated relative risk: 8.66; rank order: 1)], item 19 ["'..., did minor hassles irritate you easily?" (estimated relative risk: 7.66; rank ordler: 3)], and item 36 ["..., did you ever have the feeling 'you hadn't achieved enough, and that you could have achieved more if only you were healthier, not so weak, not so limp' ?" (estimated re- 
Lative risk: 5.24; rank order: 6)], and item 01 ["..., did you often feel tired ?" (estimated relative risk: 7.85 ; rank onder: 2)], item 20 [ [..., did you feel more listless than before ?" (estimated relative risk: 7.04 ; rank order: 4)], and item 07 ["..., did you often feel weak ?" (estimated relative risk: 5.48; rank order: 5)], respectively.

\section{B.2. The Hospital Series.}

In the HR-series, this tendency is even more manifest. Here, item 19 ["..., did minor hassles irritate you easily ?" (estimated relative risk: 7.42; rank order: 1)], item

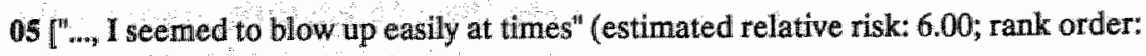
2)], and item 04 [".., did you feel less confident ?" (estimated relative risk: 4.80; rank order: 3)] were all associated with higher risk estimates for first MI than the first item on Form B [i.e. Item 01 "'..., did you often feel tired ?" (estimated relative risk: 4.42; rank order: 4)].

Thus, it may be concluded that certain aspects of vital exhaustion, that is, "irritability" and "demoralization", which clearly distinguished MI-cases from HR and NR in this retrospective study, were represented differently than in the prospective study in which Form B was established (Appels et al, 1987a). This intriguing difference, in particular with respect to "irritability", will be discussed in more detail in Chapter 6.

\section{Confounding.}

The estimated relative risks regarding vital exhaustion that were measured by Form $\mathrm{B}$ of the MQ and are shown in Table 4.1. may have been confounded by the associations of the other risk indicators included in this study with vital exhaustion.

In order to study the possible effects of these confounding factors and still retain sufficient statistical power, the respective distributions of the MQ-scores on Form $B$ were divided into tertiles instead of the halves that were based on the median split employed above. After adjusting separately for the risk indicators age, angina pectoris, and current smoking, this procedure yielded standardized estimated relative risks associated with three progressive degrees of vital exhaustion, instead of the estimated relative risks and $95 \%$ confidence intervals reported in Table 4.1.. With any standardized estimated relative risk, the lowest exposure level will, by definition, be employed as the reference category with value 1.00 , indicating that there is no differ- 
ence whatsoever with respect to risk in cases and referents who have been assigned to this particular category (Miettinen, 1972).

\section{C.1. Age}

The mean scores on the MQ were not found to be associlated with age when all MI-cases, HR, and NR were combined ( $r=0.07$, NS). Yet, since age is the most important risk indicator for CHD and also constitutes an important determinant of lifespan development, this variable was entered in the analyses regarding the standlardized estimated relative risks as described above.

Table 4.3. (p. 224) and Figure 4.1. show both the unadjusted standardized estimat-ed relative risks associated with three progressively increasing degrees of wital exhaustion and the standardized estimated rellative risks after adjusting for age (i.e., the three combined age strata representing "young adulthood", "middle-age", and "beginning old age", respectively).

The unadjusted estimated relative risks, as well as the estimated relative risks that were subsequently adjusted for age, clearly increase with progressive scores on the MQ in both referent series. Moreover, the age-adjusted standardized estimated relative risks yield a higher estimated risk in the third tertile, representing the most serious degree of vital exhaustion, than the corresponding unadjusted estimated relative risk for this tertile. This may indicate that age exerts a modifying influence on vital exhaustion. Finally, both Mantel-Haenszel $\mathrm{Chi}^{2}$ that were derived from the Mantel test for overall trend of significance are highly significant (Mantel \& Haenszel, 1959; Mantel, 1963).

\section{C.2. Angina Pectoris.}

As reported earlier, angina pectoris occurred significantly more often in MIcases than in both referent groups. Thus, in the present standardized estimated relidtive risk analyses, angina pectoris may be a confounding factor. Indeed, when all of the MI-cases, HR, and NR who had reported having suffered from angina pectoris within the last half year prior to completing the LSHCQ were combined $(\mathbb{N}=45 ; 10 \%)$, they scored significantly higher on Form $B$ than the remaining 413 subjects $(90 \%)(t=6.32$; 
$\mathrm{df}=1,456, \mathrm{p} .<001$ ). Thus, vital exhaustion is also positively associated with angina pectoris as assessed by means of the LSHCO.

Table 4.3. and Figure 4.1. show both the unadjusted standardized estimated relative risk associated with three progressively increasing degrees of vital exhaustion and the standardized estimated relative risks after adjusting for angina pectoris. Once again, these adjusted estimated relative risks clearly increase with progressive scores on the MQ, and the overall trend is highly significant in both referent series. Thus, after controlling for angina pectoris within the last hallf year prior to hospitalization, or interviewing, vital exhaustion remains positively associated with elevated risk of first ML.

\section{C.3. Current Smoking.}

As reported earlier, current smoking occurred significantly more often in MIcases than in referents and may, thus, constitute a confounder. Indeed, when all of those M-cases, HR, and NR who had reported smoking cigarettes, cigars, or pipes within the last half year prior to completing the $\mathbb{L S Q}$ were combined $(\mathrm{N}=300 ; 66 \%)$, they had a significantly higher mean MQ-score than the remaining 158 subjects (34\%) $(t=2.70 ; \mathrm{df}=1,456, \mathrm{p}<.01)$. Thus; vital exhaustion is also positively associated with current smoking.

Table 4.3. and Figure 4.1. show both the unadjusted standardized estimated relative risk associated with three progressively increasing degrees of vital exhaustion and the standardized estimated relative risks after adjusting for current smoking. As in the previous analyses involving age and angina pectoris, these adjusted estimated relative risks show a distinct progression over the three consecutive tertiles of the MQ-distribution. "This progression is also represented by the highly significant overall trend in both referent series. Thus, after controlling for current smoking within the last half year prior to hospitalization or interviewing, vital exhaustion remains positively associated with elevated risk of first MI.

Since the above MQ-scores were based exclusively on the 21 items on Form B found to be predictive of future MI in the prospective RCSS (Appels et al., 1987a), it is unlikely that these findings were strongly influenced by retrospective bias on the part of either MI-cases or HR. Furthermore, as discussed earlier, there is little reason to 
assume that these findings are not representative of the source population at large. it may thus be concluded that vital exhaustion precedes the onset of near-future first MI and that manifestations of vital exhaustion are not confounded by age " angina pectoris, or current smoking.

\subsection{Hypothesis 3: Type A Subjects are at an Elevated Risk of Becoming Vitally Exhausted.}

In order to test this particular hypothesis, which may indicate an association between signs and symptoms of vital exhaustion and TABP, and because manifestations of CHD must be omitted from exploratory analyses in order to prevent confounding, all subjects suffering from angina pectoris were excluded from the present analysis. Table 4.4. (p. 225) shows that Type A subjects did, in fact, generally report significantly more symptoms of vital exhaustion than their counterparts. Thus, this hypothesis was also corroborated.

\subsection{Hypothesis 4: Vitally Exhausted Type A Subjects are at Greater Risk of Suffering First Myocardial Infaretion than Vital Type A Subjects.}

The second hypothesis regarding the possible association between vital exhaustion and TABP stated that Type A subjects who are "vitally exhausted" are at a more elevated risk of first MI than Type A subjects who are not. In order to test this hypothesis, all subjects were categorized as either "vital" or "vitally exhausted" in the same manner as they had been when testing hypothesis 2 . That is, the median score on the MQ (a score of 8 or more positive replies on the 21 items on Form B) was used as the cut-off point:

Table 4.5. (p. .226) and Figure 4.2. both show the standardized estimated relative risks associated with first MI in "vital" and "vitally exhausted" Type A and Type B subjects. When "vital" Type B subjects were used as the reference category, the consecutive standardized estimated relative risks increased significantly, from "vital" Type A subjects to "vitally exhausted" Type B subjects to "vitally exhausted" Type A subjects in both referent series. 
Table 4.5. and Figure 4.2. further indicate that the risk for first $M$ is eleven-fold when "vitally exhausted" Type AMI-cases are compared to "vital" Type B NR and more than five-fold when they are compared to "vital" Type B HR. These substantially elevated risks in both referent series suggest a modifying effect of vital exhaustion with respect to the influence of TABP.

In order to explore this possitulity, pairwise comparisons were made between both categories of Type A and Type B subjects. The estimated relative risks, based on the oddls ratio, for first MI in "vital Type A subjects; were actually elewated when compared to "vital" Type B subjects, but not at all significantly so. That is, the estimated relative risks were 1.99 in the NR-series and 1.94 in the HR-series (cf. Table 4.5.), while the corresponding 95\% confidence intervals were 0.79-5.01 and 0.77-4.93, respectively. The estimated relative risks and $95 \%$ confidence intervals for first MI in "vitally exhausted" Type A subjects, compared to "vital" Type A subjects, were 5.53 (2.69$11.36)$ and $5.20(2.52-10.76)$, respectively. Thus, vital exhaustion clearly constitutes an important effect modifier and, in future research, TABP should be considered a risk indicator for first MI only when vital exhaustion is taken into account simultaneouslly. These findings corroborate the fourth hypothesis.

\subsection{Hypothesis 5: Type A Subjects are More at Risk of Suffering First Myocardial Infaretion than Type B Subjects When Controlling for Manifestations of Vital Exhaustion.}

Table 4.5. and Figure 4.2. showed a higher occurrence of TABP in both "vital" and "vitally exhausted" MI-cases. Indeed, the crude estimated relative risks and 95\% confidence intervals associated with TABP were 2.12 (1.29-3.47) in the NR-series and 2.15 (1.36*3.48) in the HR-series, respectively. When adjusted for age (i.e., the three age strata that applied to the analyses regarding TABP), the estimated relative risks and $95 \%$ confidence intervals were $2.57(1.41-3.98)$ and 2.29 (1.43-3.68), respectively.

Given the findings regarding hypothesis 4 , which suggested that TABP might lose its predictive power with respect to the risk for first MI in subjects who have become "vitally exhausted", both risk indicators were controlled for successively. When the estimated relative risk associated with TABP was standardized for vital exhaustion, this 
estimate and the corresponding $95 \%$ confidence interval still reached significance in the HR-series [1.98 (1.24-3.16)], but not in the NR-series [1.62 (0.94-2.80)].

On the other hand, the estimated relative risks and $95 \%$ confidence intervalls for vital exhaustion, after standardizing for TABP, were 2.65 (1.56-4.49) in the HR-series and 6.35 (3.68-10.95) in the NR-series. These results only partly corroborate the fifth hypothesis (i.e., in the HR-series), and the possible synergism (Kleinbaum et al., 1982) between TABP and vital exhaustion may, therefore, need to be investigated further. This would be in accordance with the results of two recent meta-analyses with respect to TABP and "illness proneness", in which it was suggested that psychosocial risk indicators such as anxiety, depression, and exhaustion may be as important predictors of CHD as TABP (Booth-Kewley \& Friedman, 1987; Friedman \& Booth-Kewley, 1987).

In the previous analyses with respect to hypotheses 2 through 5 , the associations between vital exhaustion and risk for first MI were tested while separately adjusting for the risk indicators age, angina pectoris, and current smoking. Another series of such analyses was performed to test possible interactions with TABP. In order to assess the contribution of wital exhaustion together with the respective contributions of the other risk indicators, two stepwise multiple logistic regression analyses were carried out, one for each referent series.

This method of analysis constitutes a mathematical modelling procedure for controlling and/or adjusting for the potential confounding and/or modifying effects of extraneous factors that may impinge on the relationship between exposure to these factors and the disease under study (Kleinbaum et al., 1982). In terms of the present study this means that a stepwise multiple logistic regression analysis allows one, first, to investigate all concurrent associations between first $\mathrm{MI}$ and the various independent variables - in particular, age, angina pectoris, current smoking, TABP, and vital exhaustion - that were previously subject to univariate analyses. Such a regression analysis allows one, second, to express the results as estimated relative risks and $95 \%$ confidence intervals based on the regression coefficients and their standard errors after the last step of the analysis has been completed (BMDP, 1985). The results of these multivariate analyses can, therefore, be compared directly to those from the previous analyses. In these regression equations, age was entered as a categorical variable (i.e., the 
ubiquitous age strata $35-44,45-59$, and 60-69), while angina pectoris, current smoking. $\mathrm{TABP}$, and vitul exhaustion were all entered as dichotomous variables. Those comparisons would not have been possible if vital exhaustion had been entered as a contimuous variable, that is, as scale scores that may have given a more precise estimate of its contribution to the development of first MI.

Table 4.6. (p...) shows the two series of estimated relative risks and 95\% confidence intervals associated with current smoking, angina pectoris, TABP, and vital exhaustion, while simultaneously controlling for age in MI-cases compared to NR and HR.

In the NR-series, vital exhaustion constituted the most powerful discriminating variable between cases and referents and was associated with a more than fivefold estimated risk. Both risk indicators current smoking and angina pectoris were associated with about a threefold risk, while TABP represented only a marginal risk.

In the HR-series, on the other hand, angina pectoris and current smoking distinguíshed the best between MI-cases and HR, while TABP and vital exhaustion both constituted a significantly elevated, more than twofold, risk for MI. In sum, all of the variables included in the analyses described in this chapter were significantly associated with risk of first $\mathrm{MI}$.

\subsection{Manifestations of Vital Exhaustion and their Association with Reported Stressful Life Events over The Life-Span.}

Finally, as with TABP, it was determined whether particular SLE may be associated with vital exhaustion. Tables 4.7.a through 4.7.c (p. 228-230) show the occurrence of SLE in "Childhood \& Adolescence", "Work \& Career", and "Family \& Social Life", as assessed by means of the Structured Biographical Interview, in subjects (MIcases, NR, and HR) categorized as "vitally exhausted" $(\mathrm{N}=280 ; 61 \%)$ and as "vital" $(\mathrm{N}=178 ; 39 \%)$.

In all, 15 of the 47 SLE (32\%) occurred significantly more often over the lifespan of subjects characterized as "vitally exhausted". (When a significance level of p <.10 is considered, three more SLE are added). Only one SLE - "Military service" occurred more often in "vital" subjects. 
In "Childhood \& Adolescence", "Prolonged financial problems", "Prolonged familial conflicts", "Prolonged unemployment (father)", and, to a lesser extent, "Living away from home $\mathrm{e}^{\text {in }}$ were all associated with vital exhaustion in adulthood. It may therefore be concluded that adverse living conditions in the formative phases of childhood and adolescence may exert a long-lasting influence on psychological and physical wellbeïng in later phases of adult life. Since "Prolonged financial problerins" also occurred more often in the formative years of Type A subjects (cf. Table 3.3.), this particular event may be said to have been of crucial importance in the subsequent psychosocial development of the subjects under study.

In "Work \& Career", SLE representing a particular burden on, or the disruption of, one's working pattern and career, namely, "Prolonged overtime", "Prolonged absenteeism", "Present unemployment/disability", "Past unemployment", "Prolonged/serious conflicts with supervisors and/or with subordinates", and, to a lesser extent, "Compulsory search for other job(s)", were associated with vital exhaustion. One of those events - "Prolonged/serious conflicts with subordinates" (cf. Table 3.3.) - also occurred more often in Type A subjects. Thus, this event, in itself, may not have brought about vital exhaustion.

In "Family \& Social Life", almost all SLE associated with prolonged or serious conflicts and problems, that is, "Financial problems", "Marital conflicts", "Educational problems with children", "Conflicts with family members", and, to a lesser extent, "Conflicts with friends/acquaintances" were associated with vital exhaustion in adulthood. This also appeared to be the case with illness-related events, namely, "Prolonged/serious illness or accident (respondent)" and "Prolonged/serious illness/death of family members" "Some of those SLE also occurred more often in Type A subjects, most notably "Prolonged/serious marital conflicts", "Prolonged/serious conflicts with family members", and, to a lesser degree, "Prolonged/serious financial problems".

Thus, it may be concluded, in general, that vital exhaustion is the outcome of a developmental process in which antecedent SLE associated with adverse living conditions during childhood and adolescence, with episodes of overburdening and/or disruption of work, and major problems and conflicts in family and social life have played a key role. The intriguing question of whether such associations occur primarily in 
"vitally exhausted" MI-cases, given the significantly elevated MQ-scores in cases as compared to both referent groups; will be addressed in Chapter 5 .

Hawing examined the relationships between vital exhaustion, TABP, and first MI in this and the previous chapters, attention will now be directed to the independent contribution of SLE over the entire life-span to the development of first MI and to the

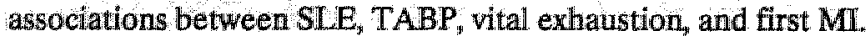




\section{Chapter 5: Results: \\ Relationships between Reported Stressful Life Events over the Life-Span and First Myocardial Infarction.}

\subsection{Introduction, Hypotheses \& Explorations.}

This chapter will describe the occurrence of stressful life events (SLE) over the life-span of MI-cases, NR, and HR in the domains of "Childhood \& Adolescence", "Work \& Career", and "Family \& Social Life", which were included in the Structured Biographical Interview (SBI). A number of associations between TABP, SLE, and first MI, as well as between SLE, vital exhaustion, and first MI, will also be reported.

Chapter 1 concluded that most retrospective studies relating the occurrence of SLE to first and recurrent MI have demonstrated a significant build-up in the number of SLE prior to MI in the lives of cases who survived their coronary events, whereas this did not occur in healthy referents (Theorell \& Rahe, 1970; 1971; 1972; Lind \& Theorel1, 1973; Rahe et al., 1974; Romo et al., 1974). Most SLE that were encountered occurred in association with conflicts at work or with respect to coping with increased responsibilities. Job satisfaction and satisfaction with family life proved to be significantly less in MI-cases than in referents. MI-cases also evaluated these particular SLE as either being psychologically more upsetting or distressing or as requiring more readjustment efforts than referents did (Lundberg et al., 1975; Lundberg \& Theorell, 1976).

In some prospective investigations, the SLE most often reported with regard to MI were, once again, conflicts at work, increased or too much responsibility at work, changes in organizational or physical circumstances under which work was to be performed, extensive periods of overwork, and prior episodes of unemployment (Theorell et al., 1975; Theorell, 1976; Theorell \& Flodérus-Myrhed, 1977; Theorell et al, 1977a). These results clearly underscore the importance of adverse aspects of work in the development of MI in adulthood (Falger, 1983a).

Given this evidence, it is unfortunate that no established procedures for the assessment of TABP were included in any of these studies. This might have clarified the complex interrelationships between TABP, specific job demands, and ensuing dissa- 
tisfaction, both in higher occupational strata, as investigated in most of the above-mentioned retrospective studies, and in blue-collar workers, as studied in the prospective surveys. Similarly, the inclusion of TABP in these particular studies about MI might have elucidated the associations between TABP and SLE that point to conflicts in, and dissatisfaction with, family and social life. Some earlier retrospective investigations in the general population (Burke \& Weir, 1980; Dorreboom \& Snel, 1988; Falger, 1988) have found these associations to be important. Chapter 3 presented the results from the present study that pertain to this issue.

Finally, it may be argued that certain SLE associated with adverse or highly competitive living conditions and situations in childhood and adolescence contribute to the development of both TABP and, in later phases of life, CHD (Matthews, 1982; Arnesen \& Forsdahl, 1985; Steinberg, 1985; Vega-Lahr \& Field, 1986). Chapter 3 already presented some evidence in support of this argument. As mentioned earlier with respect to the Structured Biographical Interview, this may mean that, from a life-span develópmental perspective, adverse SLE in the formative phase of life may constitute crucial "sleeper" effects with regard to the development of MI some decades later (Baltes \& Schaie, 1973).

Chapter 4 pointed to the independent role of manifestations of vital exhaustion in the pathogenesis of first MII. In the same chapter, the general associations between SLE that had occurred previously over the life-span and such manifestations were also presented. It therefore seems appropriate to further study the possible associations between vital exhaustion and SLE in the biographies of MI-cases. Such associations might contribute to a better understanding of the natural history of the development of vital exhaustion as an independent risk indicator for MI.

In light of the above, this chapter will explore:

(1) whether SLE occur more often in MI-cases than in either NR or HR;

(2) which specific SLE associated with "Work \& Career" and "Family \& Social Life", in adulthood, may contribute to the development of first Mr;

(3) which specific SLE associated with "Childhood \& Adolescence" may contribute to the development of first MI in adulthood; 
(4) which particular interactions may exist between TABP and SLE prior to first MI (i.e., given the results regarding the role of TABP in the pathogenesis of first MI and the reported association of TABP with particular SLE, it seems worth investigating whether TABP may also be considered a moderator factor - an effect modifier or a confounder - with respect to the occurrence of SLE prior to first MI); and

(5) which specific SLE may be associated with vital exhaustion prior to first MI (i.e., given the results regarding the role of vital exhaustion in the subsequent development of first $\mathrm{MI}$ and the associations between particular SLE and vital exhaustion, it is worth studying in more detaill whether such manifestations in MI-cases may be moderated - modified or confounded - by the occurrence of previous SLE over the life-span).

\section{B. Hypotheses \& Explorations.}

In the present study it was hypothesized that:

(1) in general, SLE in the domains of "Childhood \& Adolescence" " "Work \& Career", and "Family \& Social Life" occur more often in MI-cases than in referents; and that

(2) in general, SLE in the domains of "Childhood \& Adolescence", "Work \& Career", and "Family \& Social Life" constitute psychosocial risk indicators for first MI.

Two more issues were explored, namely:

(1) whether TABP exerts a moderating influence on the associations of SLE in the domains of "Childhood \& Adolescence", "Work \& Career", and "Family \& Social Life" with first MI; and

(2) whether SLE in these same domains exert a moderating influence on the association of vital exhaustion with first MI. 
5.2. Hypothesis 1: Occurrence of Reported Stressful Life Events over the LifeSpan.

\section{A. Occurrence in General.}

Table 5.1. (p. 231) shows the mean number and standard deviations of reported SLE over the life-span in seven combined age strata of MI-cases, NR, and HR. In all, MI-cases reported a significantly greater exposure to SLE in their biographies than either NR or HR. Thus, in general, the first hypothesis was corroborated. The results regarding the three separate domains indicate that "Family \& Social Life", in particnlar, is characterized by a significantly higher occurrence of SLE in both referent series. On the other hand, in "Work \& Career" and "Childhood \& Adolescence", only the HR-series yielded a significantly higher occurrence of SLE in MI-cases.

\section{B. Occurrence of Separate Events.}

Tables 5.2,a through 5.2.c(p. 232-234) show the occurrence of each separate SLE in the domains of "Childhood \& Adolescence", "Work \& Career", and "Family \& Social Life" in seven combined age strata of MI-cases, NR, and HR. As in Table 5.1., the strata were combined in order to obtain aggregate data about the occurrence of SLE over the entire age range under study. This provides the necessary background for contrasting these data with those about possible (age by) cohort effects in more limited age strata in some of the tables that will follow. The rationale for this strategy was discussed in Chapter 2.

The data from Tables 5.2.a through 5.2.c allow a number of interesting conclusions to be drawn.

First, in the NR-series; 8 out of a total of 47 SLE (17\%) show a significantly higher rate of occurrence in MI-cases. These are: "Prolonged financial problems" ("Childhood \& Adolescence"); "Past unemployment" and "Prolonged overtime" ("Work \& Career"); "Prolonged/serious educational problems with children", "Prolonged/serious conflicts with children away from home", "Prolonged/serious marital conflicts", "Prolonged/serious illness or accident (respondent)", and "Prolonged/serious financiall problems" ("Family \& Social Life"). 
Second, in the HR-series, 18 SLE (38\%) occur significantly more often in MIcases. These are: "Living away from home", "Prolonged familial conflicts", "Prolonged unemployment (father)", and "Prolonged financial problems" ("Childhood \& Adolescence $\left.{ }^{*}\right)$ " "Compulsory search for other job(s)" "Work place closed down", "Increased responsibility at work", "Prolonged/serious conflicts with supervisors", "Prolonged/serous conflicts with subordinates", and "Prolonged/irregular working hours/shiftwork" ("Work \& Career"); "Prolonged/serious educational problems with children", "Prolonged/serious marital conflicts", "Prolonged/serious illness or accident (respondent)", "Living with extended family", and "Prolonged/serious financial problems" ("Family \& Social Life"s).

Third, when a statistical significance level of $\mathrm{p}<.10$ (two-sided) is considered, four additional SLE (9\%) occur more often in the NR-series, namely, "Living away from home" and "Prolonged unemployment (father)" ("Childhood \& Adolescence"); "Pres-ent unemployment/disability" ("Work \& Career"); and "Prolonged/serious illness of children" ("Family \& Social Life"). In the HR-series, one additional SLE occurs, name-ly, "Prolonged/serious conflicts with family members" ("Family \& Social Life"). Thus, those SLE that occur in all realms of the life-span, but predominantly in "Family \& Social Life", may constitute psychosocial indicators for elevated risk of develop-ing first MI.

Fourth, some SLE occur significantly more often in one of the referent groups than in MI-cases. In the NR-series, this is the case with four SLE (9\%). These are: "Military service" ("Childhood \& Adolescence"); "Important organizational/economic changes at work" and "Continuing education to improve one's position" ("Work \& $\mathrm{Ca}$ reer"); and "Spouse working" ("Family \& Social Life"). In the HR-series, this is true for two SLE (4\%), "Military service" ("Childhood \& Adolescence") and "Spouse working" ("Family \& Social Life"). In the HR-series, the higher occurrence may be due to chance alone.

It should be noted in this context that during the actual interviews, MI-cases often asserted that they were very proud they could provide a decent familly income without their spouses having to work. Both NR and HR, on the other hand, said that they found it only natural that their spouses would find work if they wanted to. Thus, the 
event "Spouse working", or rather the absence of it, may constitute an important feature of the life-span developmental patterns of future MI-cases.

Fifth, when a significance level of $\mathrm{p}<.10$ is considered, two additional SLE occur more often in the HR-series, namely, "Relocations" ("Childhood \& Adolescence") and "Prolonged absenteeism" ("Work \& Career"). Statistically speaking, these SLE and the aforementioned "Spouse working" appear to exert a protective influence with respect to the pathogenesis of CHD and first MI over the life-span since they were reported more often by referents.

Sixth, as far as possible differences in occurrence of SLE in both referent groups are concerned, Tables 5.2.a through 5.2.c also show that 8 out of a total of 47 SLE (17\%) occur more often with NR than with HR. These are: "Prolonged parental illness", "Prolonged familial conflicts"; and "Prolonged illness (respondent)" ("Childhood \& Adolescence"); "Important organizational/economic changes at work", "Prospects for promotion (unrealized)", "Increased responsibility at work", and "Prolonged/serious conflicts with supervisors" ("Work \& Career"); and "Prolonged/serious conflicts with family members" ("Family \& Social Life"). When a significance level of $\mathrm{p}<.10$ is considered, a ninth SLE - "Continuing education to improve one's position" ("Work \& Career") can be added. On the other thand, 2 of those 47 SLE (4\%) - or three (6\%) when including $\mathrm{p}<.10$ - show a significantly higher occurrence rate in HR. These are: "Prolonged absenteeism"' ("Work \& Career"); "Prolonged/serious illness/death of family members" ("Family \& Social Life"), and "Childlessness" ("Family \& Social Life"), respectively. One of these two SLE - "Prolonged absenteeism (due to illness)" ("Work \& Career") - appears to indicate that HR, in general, may have experienced one or more episodes of illness prior to their current hospitalization.

In sum, at least 10 of the 47 SLE $(21 \%)$ show a significantly different occurrence rate in the two referent groups. In order to enhance statistical power regarding the testing of the reported occurrence differences in the MI-cases, NR, and HR in the analyses that follow, the latter two groups were combined when possible (i.e, when those SLE distinguish between referent groups only and not between referents and MI-cases). In fact, as shown in Tables 5.2.a through 5.2.c, in only three instances - "Prolonged familial conflicts" ("Childhood \& Adolescence"), "Increased responsibility at work" and "Prolonged/serious conflicts with supervisors" ("Work \& Career") - is the 
significantly higher occurrence of these SLE in one of the referent series attributable to differences between both referent groups. Therefore, with the exception of these three SLE, in the analyses that follow, NRR and HR can, and will, be combined;

\section{Hypothesis 2* Reported Stressful Life Events over the Lifo-Span as} Independent Risk Indicators for First Myocardial Infarction.

\section{A. Relative Risk.}

Based on the above-mentioned rates of occurrence of SLE over the life-span in MI-cases, NR, and HR, the crude estimated relative risks and $95 \%$ confidence intervals for first MI associated with individual SLE were computed separately for each referent series. As before, all seven age strata were combined.

Tables 5.3.a through 5.3.c (p. 235-237) show these relative risks and $95 \%$ confidence intervals in the domains of "Childhood \& Adolescence", "Work \& Career", and "Family \& Social Life" in MI-cases as compared to NR and HR. As may have been expected, the HR-series yielded many more significantly elevated risks for first MI (19 SLE; bold print in Table) than the NR-series (8 SLE). In both series, the occurrence of a number of substantially elevated risks is striking, given the typically "weak" associations between psychosocial risk indicators and CHD (i.e, on the average, a relative risk that is 2.0 ; Miettinen, 1985b). These "high" risiks occur in particular in the domains of "Childhood \& Adolescence" and "Family \& Social Life". That is, in both the NR- and the HR-series, "Prolonged financial problems" during the cases' childhood and/or adolescence represent an almost two-and-a-half-fold risk for first MI in adulthood. Also, in both series, in the domain of "Family \& Social Life", "Prolonged/serious educational problems with children" and "Prolonged/serious conflicts with children away from home ${ }^{\text {th }}$ represent a four-to-seven-fold risk (in the NR-series) and a two-and-a-half-fold risk (in the HR-series) for subsequent MI. In addition, within the same domain, "Prolonged/serious marital conflicts" and "Prolonged/serious financial problems" both represent at least a two-and-a-half-fold risk for first MI in both series. In the remaining domain of "Work \& Career", however, only the HR-series yielded similarly elevated risks with respect to work-related events. That is, previous exposure to "Prolonged/serious conflicts with subordinates", "Prospects for promotion (unrea- 
Hized) "Work place closed down" "Prolonged overtime", and "Prolonged/serious conflicts with supervisors", in this order, were all associated with at least a two-fold risk for first $M I$ in adulthood. As has been argued before, each referent group may, in its own right, be thought to represent the source population at large. Thus, these results may be generalized with respect to the occurrence of SLE in future MI-cases.

The apparent difference between the two referent series may be explained, in part on statistical grounds. That is, comparing MI-cases with different referent groups of unequal size, each of which represent the population at large, generally allows for a more precise estimate of risk in the larger referent series (Miettinen, 1985b). In this instance, this is the HR-series, which is about 1.5 times larger than the NR-series.

\section{B. Confounding.}

Since there was no significant difference in mean age between MI-cases and HR [i.e., 53.1 years (S.D. $=9.5$ ) and 51.1 years $($ S.D. $=9.7$ ) years, respectively], age as such could not have confounded the above results in the HR-series. However, in the NRseries, age might have confounded these results to some extent since NR (mean age 49.2 years; $S . D .=9.3)$ were significantly younger than MI-cases $(t=3.34, p<.001)$. Therefore, in the exploratory analyses that follow, regarding the possible moderating influences of TABP and vital exhaustion on the risks associated with SLE, age will be adjusted for simultaneously in both referent series in order to be able to make direct comparisons between the results from both series (Miettinen, 1985b; Rothman, 1986).

\subsection{Exploration 1: Type A Coronary-Prone Behavior Pattern as a Moderating Factor Regarding Risk for First Myocardial Infaretion Associated with Reported Stressful Life Events.}

\section{A. Occurrence.}

It has already been stated that the age distribution in the present investigation allows for the study of possible cohort effects. Since the findings indicate that the influence of TABP as a risk indicator for MI decreases with increasing age, the analyses that follow with respect to SLE should control for these different levels of TABP. This will be done by simultaneously adjusting for age, according to the three combined age 
strata previously employed (i.e., ages 35-44,45-59, and 60-69). Since there was no difference between NR and HR in the occurrence of TABP, the two groups will be combined in order to enhance statistical power. The only exceptions will be in the analyses of the three SLE mentioned earlier [i.e., "Prolonged familial conflicts" ("Childhood \& Adolescence"), "Increased responsibility at work" and "Prolonged/serious conflicts with supervisors" ("Work \& Career")]. In sum, the present section will further explore the question of whether TABP serves as a moderator - an effect modifier or a confounder - with respect to elevated risk for first MI that is associated with each separate SLE.

\section{B. Relative Risk.}

Tables 5.4.at through 5.4.c (p. 238-240) show both the crude and age-adjusted estimated relative risks that are simultaneously controlled for TABP and the $95 \%$ confidence intervals associated with SLE in MI-cases, as compared to the combined referent groups.

Tables 5.4.a through 5.4.c show that 14 SLE (30\%) were associated with a significantly elevated crude estimated relative risk with respect to first MI in the combined referent series (boll print in Table). These SLE were: "Living away from home", "Prolonged unemployment (father)", and "Prolonged financial problems" ("Childhood \& Adolescence"); "Compulsory search for other job(s)", "Work place closed down", "Prospects for promotion (unrealized)", and "Prolonged overtime" ("Work \& Career"); "Prolonged/serious illness of children", "Prolonged/serious educational problems with children", "Prolonged/serious conflicts with children away from home", "Prolonged/serious marital conflicts", "Prolonged/serious illness or accident (respondent)", "Living with extended family", and "Prolonged/serious financial problems" ("Family \& Social Life"). These significant associations also applied to all three SLE - "Prolonged familial conflicts" ("Childhood \& Adolescence"); "Increased responsibility at work" and "Prolonged/serious conflicts with supervisors" ("Work \& Career") - in the separate HR-series. In the separate NR-series, however, none of these SLE was associated with a significantly elevated crude risk for MI.

After adjusting for age and controlling for TABP, 12 SLE (25\%) retained general and stable significant associations with first MI. This is indicated by the left limit of 
the confidence interval and the corresponding non-significant heterogeneity $\mathrm{Ch}^{2}$ (Mantel et al, 1977). That is, the previously demonstrated associations of "Living away from home" ("Childhood \& Adolescence") and "Compulsory search for other job(s)" ("Work \& Career") with first MI were confounded either by TABP or by age since, after controlling for the former and adjusting for the latter, these events were no longer significantly associated with risk for MI. The same stable associations also applied to all three SLE from the separate HR- series.

The last column in Tables 5.4.a through 5.4.c shows the heterogeneity $\mathrm{Chi}^{2}$ regarding the differences in the distributions of SLE in MI-cases and in the combined NR and HR that might be attributed to either age or TABP. In those analyses in which the heterogeneity $\mathrm{Chi}^{2}$ is significant (i.e. in this instance, $\mathrm{p}<.10$; two-sided), the ageadjusted relative risks and $95 \%$ confidence intervals that are also controlled for TABP should not be considered. In these cases, the crude estimated relative risks and $95 \%$ confidence intervals corresponding to the separate contingency tables (not included here) were used to assess which specific category of Type A/Type B behavior by age, if any, would constitute a significantly elevated risk. In other words, with those SLE it was necessary to assess whether a specific (age by) cohort effect may be assumed.

A number of important conclusions emerged from these particular effect anallyses. First, such cohort effects occurred in particular in young Type A MI-cases, namely, in those in the age stratum 35-44. This was true for "Voluntary search for other job(s)" ("Work \& Career"): crude estimated relative risk and $95 \%$ confidence intervals: $8.00(1.29-49.61$ )" "Increased responsibility at work" ("Work \& Career"): 6.83(2.03-23.02); and "Divorce" ("Family \& Social Life"): 5.14(1.00-26.43). In Type A cases from the middle-aged stratum (45-59), a cohort effect was observed for "Prolonged/serious marital conflicts" ("Family \& Social Life"): crude estimated relative risk and $95 \%$ confidence intervals: $2.96(1.30-6.72)$.

Second, in young Type B MI-cases, significantly elevated crude risks were observed with respect to rather different events. These were: "Prolonged parental illness" ("Childhood \& Adolescence"): crude estimated relative risk and 95\% confidence intervals: 12.86(1.99-83.19) and "Present unemployment/disability" ("Work \& Career"): $18.00(3.63-89.22)$. 
Third, also in Type B cases alone, "Death of children" ("Family \& Social Life"): crude estimated relative risk and 95\% confidence intervals: 6.66(1.92-23.08) only occurred in the stratum 45-59, whereas "Prolonged/serious marital conflicts" ("Family \& Social Life'): 5.21(1.59-17.08) not only occurred in this middle stratum but also in the oldest stratum, 60-69: 6.92(1.39-34.58).

In sum, in Type A MI-cases, (age by) cohort effects occurred primarily in the youngest cohort, which was not the case with Type B MI-cases. Moreover, "Divorce" ("Family \& Social Life") surprisingly occurred exclusively in Type A MI-cases and was associated with a substantially elevated relative risk in each age stratum. Only in the youngest stratum did this risk reach marginal significance, however, due to the small number of occurrences. This resulted in exceptionally wide confidence intervals.

When the age-adjusted results from Tables 5.4.a through $5.4 . \mathrm{c}$ and the (age by) cohort analyses are considered together, it may be concluded, as suggested earlier; that about $40 \%$ of all the relevant SLE do, indeed, constitute an elewated risk for the subsequent occurrence of MI in certain developmental phases in adulthood only. This also applies to most of the elevated risks associated with the (age by) cohort specific occurrence of SLE in Type B cases.

\subsection{Exploration 2: Manifestations of Vital Exhaustion as Moderating}

Factors Regarding Risk for First Myocardial Infarction Associated with Reported Stressful Life Events:

\section{A. Occurrence.}

It was shown earlier that vital exhaustion occurred more often in MI-cases than in either referent group. HR also reported wital exhaustion to a significantly larger extent than NR. In addition, Table 4.6. shows that, over the life-span, certain SLE generally occurred more often in subjects who were "vitally exhausted" than in those who were not. Thus, it can be argued that there is a particular relationship between the occurrence of SLE and vital exhaustion in MI-cases. Unlike TABP, which appears to become established in childhood and adolescence and to remain stable over the subsequent phases of the adult life-span, vital exhaustion most probably only begins to 
appear in the last few years, or months, preceding first MI. Thus, the direction of the latter relationship is diametrically opposed to that with TABP.

The present section, like the previous one, will further explore the question of whether vital exhaustion serves as a moderator - an effect modifier or a confounder regarding elevated risk for first MI associated with separate SLE. In order to do this, MI-cases and referents were designated as "vitally exhausted" when their $\mathrm{MQ}$-scores were equal to or greater than the median score of the combined NR and HR (i.e., 8); all other subjects were designated as "vital". According to this criterion, $109(82 \%)$ of the MI-cases, $118(61 \%)$ of the HR, and $53(40 \%)$ of the NR were "vitally exhausted". Age was adjusted for simultaneously in both referent series as it had been in the previous analyses regarding TABP, that is, in the combined age strata $35-44,45-59$, and 60-69. This strategy allowed for direct comparisons with the crude estimated relative risks and 95\% confidence intervals reported in Tables 5.3.a through 5.3.c.

Tables 5.5.a through 5.5.c (p. 241-243) show the age-adjusted relative risks and 95\% confidence intervals associated with SLE over the life-span in MI-cases, compared to NR and HR separately, after simultaneously controlling for vital exhaustion.

Tables 5.5.a through 5.5.c show that 4 SLE (9\%) in the NR-series retained a significant association with first MI (bold print in Table). These SLE were: "Prolonged financial problems" ("Childhood \& Adolescence"); "Prolonged/serious educational problems with children", "Prolonged/serious conflicts with children away from home", and "Prolonged/serious marital conflicts" ("Family \& Social Life"). This association remained marginal for one work-related SLE, namely, "Prospects for promotion (unrealized)". In the HR-series, 15 SLE (32\%) retained a significant association with first MI (bold print in Table). These SLE were: "Prolonged familial conflicts" and "Prolonged financial problems" ("Childhood \& Adolescence"); "Compulsory search for other job(s)" "Work place closed down", "Prospects for promotion (unrealized)", "Increased responsibility at work", "Prolonged/serious conflicts with supervisors", and "Prollonged overtime" ("Work \& Career"); "Prolonged/serious illness of children", "Prolonged/serious educational problems with children", "Prolonged/serious conflicts with children away from home", "Prolonged/serious marital conflicts", "Prolonged/serious illness or accident (respondent)", "Living with extended family", and "Prolonged/serious financial problems" ("Family \& Social Life"). 
In comparing the results from Tables 5.5. a through 5.5.c with those in Tables 5.3.a through 5.3.c, it appears that, in the NR-series, the associations of 4 SLE with first MI were confounded by vital exhaustion. These were: "Past unemployment" and "Prolonged overtime" ("Work \& Career") and "Prolonged/serious illness or accident (respondent)" and "Prolonged/serious financial problems" "Family \& Social Life"). In other words, the latter SLE were conducive to first MI through their association with vital exhaustion and may, therefore, have only indirectly led to MI.

In the HR-series, 4 other SLE were confounded by vital exhaustion. These were: "Living away from home" and "Prolonged unemployment (father)" ("Childhood \& Adolescence") and "Prolonged/serious conflicts with subordinates" and "Prolonged/irregular working hours/shiftwork" ("Work \& Career"). The last column in Tables 5.5.a through 5.5.c shows the heterogeneity $\mathrm{Chi}^{2}$ with respect to the differences in the distributions of SLE in MI-cases, NR, and HR that might be attributed to either age or wital exhaustion. In those analyses in which the heterogeneity $\mathrm{Chi}^{2}$ for the NR-and/or HR-series is significant (i.e., in this instance, $p<.10$, two-sided), the age-adjusted relative risks and $95 \%$ confidence intervals that are also controlled for vital exhaustion should not be considered. In those cases, the crude estimated relative risks and $95 \%$ confidence intervals corresponding to the separate contingency tables (not shown here) were used to assess what specific category of "vital exhaustion" and/or "vitality" by age, if any, would constitute a significantly elevated risk. In other words, with these specific SLE, it was necessary to assess whether a particular (age by) cohort effect could be assumed.

The following results emerged from these analyses. First, in the NR-series, only one SLE - "Increased responsibility at work" ("Work \& Career"): crude estimated relative risk and $95 \%$ confidence intervals: $5.13(1.42-18.53)$ - constituted a significantly elevated risk in "vitally exhausted" MI-cases in the youngest age stratum.

Second, in the same series, in "vital" MI-cases, "Work place closed down" ("Work \& Career"): crude estimated relative risk: 9.33(2.31-37.77) and "Prolonged/serious illness/death of friends/acquaintances" ("Family \& Social Life"): 18.75(2.64-33.38) were each associated with significantly elevated risk in one particular cohort only (i.e., 45 59 and $35-44$, respectively). 
Third, in the HR-series, 2 SLE - "Prolonged/irregular working hours/shiftwork ("Work \& Career"): crude estimated relative risk: 3.82 (1.12-13.00) and "Prolonged/serious marital conflicts" ("Family \& Social Lfe"): 3.44(1.42-8.36) - constituted signifcantly elevated risks in "exhausted" MI-cases in the oldest and middle age strata, respectively.

Fourth, in the same series, 2 more SLE - "Past unemployment": crude estimated relative risk: 3.59(1.00-13.14) and "Prolonged/irregular working hours/shiftwork" 3.36 (1.00-11.38) (both "Work \& Career") - retained a marginally significant association with first $\mathrm{MI}$ in the youngest stratum.

Finally, also in the HR-series, in "vital" MI-cases, "Work place closed down" ("Work \& Career"): crude estimated relative risk: 9.53 (2.31-37.77) and "Prolonged/serious marital conflicts": 12.00(2.28-63.10) and "Prolonged/serious illness/death of friends/acquaintances": 14.50 (2.26-93.19) (both "Family \& Social Life") were associated with significantly elevated risk for MI, independently of vital exhaustion in the youngest, middle, and youngest strata, respectively.

From these analyses it can be concluded that most of the above-mentioned SLE constituted significantly elevated risks in the youngest age stratum only; this was true of only one SLE in the oldest stratum.

\subsection{Reported Stressful Life Events over the Life-Span, Type A Coronary-} Prone Behavior Pattern, Manifestations of Vital Exhaustion, and Other Factors as Risk Indicators for First Myocardial Infarction: Multiple Logistic Regression Analyses.

Finally, three series of stepwise multiple logistic regression analyses were computed (BMDP, 1985). The general mathematical principle behind this particular multivariate analysis was described earlier. In order to enhance statistical power, both referent groups were combined $(\mathrm{N}=325)$. This was possible since, of the 10 SLE that discriminated significantly between these two groups, only 3 also discriminated between referents and MI-cases (cf. Table 5.2). 
In these multiple logistic regression analyses; age was included as a categoric varlable (i.e, the three strata 35-44,45-59, and 60-69), vital exhaustion as a continuous variable, and each SLE separately as a dichotomous variable. TABP, current smoking, and level of education were also included as dichotomous variables. As for the latter, included for the first time here, all subjects were categorized as having had either "Primary education only" (i.e., 7 years or less) or "More than primary education" (i.e. $>7$ years). In MI-cases, 67 patients (50\%) fell within the first category, whereas 55 NR (41\%) and 91 HR (47\%) had had seven years, or less, of formal education $\left(\mathrm{Chi}^{2}=2.28, \mathrm{df}=2, \mathrm{NS}\right)$. In addition to these variables, an interaction term between each separate SLE and age, as defined above, was included in all regression equations.

In computing each equation, both the forward and backward stepwise procedures were employed. In the former, age, current smoking, level of education, TABP, and vital exhaustion were all entered first. Then, each SLE and corresponding interaction term with respect to age were forced into the equation, provided the $\mathrm{Chi}^{2}$-improvement was significant at the 05 level. The backward procedure employs essentially the same strategy, but in reverse. That is, after including all of the above variables, as well as the above interaction term, it was determined whether the interaction term and each SLE constituted a significant $\mathrm{Chi}^{2}$-improvement with each equation. Both procedures were found to yield similar results.

Table 5.6. (p. 244) shows the relative risks and 95\% confidence intervals associated with those SLE that contribute significantly to the Chi ${ }^{2}$ - improvement in each equation. These relative risks were computed on the basis of the regression coefficients and the standard errors from the final step of each regression equation. Table 5.6. consists of three columns. The first column shows the relative risks and $95 \%$ confidence intervals that result when TABP is excluded from the equation, while the second column shows the same when vital exhaustion is excluded. The third column shows the relative risks and $95 \%$ confidence intervals when both TABP and vital exhaustion are included in the equations, together with age, current smoking, and level of education, and with the interaction term between each SLE and age. In this way, the three columns may be compared in order to identify those particular SLE that contribute to the development of first MI through their respective associations with either TABP or vital exhaustion. 
In the first series of these analyses, excluding TABP, 9 SLE (19\%) were assoclated with a significantly elevated risk for first MI. This was also true for the results in the third series, which included all independent variables. Thus, in these multiple logistic regression analyses, TABP did not constitute a confounder with regard to the associations of these SLE with first MI.

In the second series of analyses, excluding vital exhaustion, 12 SLE (26\%) were associated with a significantly elevated risk for first MI. Compared to the results from these analyses, those in the last column, which included all indlependent variables, showed that 9 SLE (19\%) were associated with significantly elevated risk for ML. Thus, 3 SLE - "Living away from home" ("Childhood \& Adolescence"), "Prolonged overtime" ("Work \& Career"), and "Prolonged/serious marital conflicts" ("Family \& Social Life") had been conducive to first MI through their respective associations with vital exhaustion as a precursor of first MI.

In the above computations, the possible interactions with age did not influence the associations of SLE with elevated risk for first MII. With some other SLE, however, this interaction term appear to contribute significantly to the improvement of the $\mathrm{Chi}^{2}$ in each of the three series of analyses. Thus, it may be said that an (age by) cohort effect was established with those SLE. In other words, certain SLE contributed to the development of first MI in a certain developmental phase, but not in other ones.

Table 5.7. (p. 245) shows the relative risks and 95\% confidence intervals associated with the latter SLE, again with TABP and vital exhaustion excluded from the analyses (first and second columns, respectively) and then with both these variables included, together with current smoking and level of education (third column).

In the first series of analyses, excluding TABP, an (age by) cohort effect was established with 4 SLE (9\%). That is, they were positively and significantly associated with risk of first $\mathrm{MI}$ in a certain developmental phase, but not in other ones. This applied to "Voluntary search for other job(s)" and "Increased responsibility at work" in "young adulthood", to "Prolonged/serious marital conflicts" in "middle age", and to "Prolonged/ serious illness of spouse" in "beginning old age", respectively. This was also true for the third series; all the same SLE were entered, with almost identical results. Thus, as in Table 5.6." TABP did not constitute a confounder. 
In the second series of analyses, excluding vital exhaustion, one SLE - "Increased responsibility at work" - constituted an elevated risk for first MI exclusively in "young adulthood". "Prolonged/serious marital conflicts" was not entered in the (age by) cohort analyses, although it figured in the previous series of analyses. "Voluntary search for other job(s)" failed to reach statistical significance in any developmental phase. "Prolonged/serious illness of spouse" played a role in "beginning old age". When these results are compared with those in the last column, it appears, once again, that all 4 SLE were included in the analyses with positive and significantly elevated risks in "young adulthood" ["Voluntary search for other job(s) and "Increased responsibility at work"] in "middle age" ("Prolonged/serious marital conflicts"), and in "beginning old age" ("Prolonged/serious illness of spouse").

\subsection{Summary.}

In summing up the results from this chapter, it can be said that about $30 \%$ of the SLE from the Structured Biographical Interview constituted substantially elevated risks for first $\mathrm{MI}$, in both univariate and multivariate analyses.

In univariate analyses, the HR-series yielded a far greater number of significant associations of SLE with first MI than the NR-series did. In the HR-series, SLE from both "Work \& Career" and "Family \& Social Life" were most manifest. In the NR-series, this occurred predominantly with events from "Family \& Social Life", specifically with probably longstanding conflicts with one's own children and other members of the family. Therefore, it may be concluded that, at least with respect to the analysis of SLE in the development of first $M$, the HR constitute a more appropriate referent group than the NR. That is, both HR and MI-cases had a prior illness history in common, although the impact of the respective diseases on life-span development may have been different in both groups.

In the multivariate analyses, these SLE appeared to be associated with substanthally higher risks for first MI, after simultaneously controlling for TABP, vital exhaustion, level of education and current smoking. Some SLE constituted elevated risks in one particular devellopmental phase only. 
$-106$

\section{.}




\section{Chapter 6: Discussion I: \\ Life-Span Development and First Myocardial Infarction: Some Epidemiological Considerations.}

This chapter will discuss the results already presented in Chapters 3 through 5 , beginning with the singular contributions of TABP, SLE, and manifestations of vital exhaustion to the development of first MI and followed by the interactions of these risk indicators. In Chapter 7, these results will then be discussed against the background of the life-span developmental theoretical framework presented in Chapter 1.

\subsection{The Type A Coronary-Prone Behavior Pattern and its Association with First Myocardial Infarction.}

\section{A. General Discussion.}

Table 3.1. showed that TABP, in general, occurred significantly more often in MI-cases than in either referent group. Table 3.3. showed that the overall age-adjusted estimated relative risks associated with TABP were significantly elevated (i.e, at least twofold) as compared to those of the Type B pattern. As such, these general results are in accordance with those of most case-referent studies (Siegel, 1984; Jenkins, 1988). Moreover, they are of the same magnitude as that found in most prospective studies (Matthews \& Haynes, 1986; Haynes \& Matthews, 1988). Thus, TABP was found to be a general risk indicator - not confounded by angina pectoris, current smoking, or coffee consumption - for first MI.

Although a generall risk indicator for first MI, Tables 3.1. and 3.2. also indicate that there was a strong association between TABP and age, or rather developmental phase, in MI-cases. That is, in the age stratum 35-39, representing the early phase of "young adulthood", 93\% of the 15 MI-cases were assessed as Type A. Of these, 60\% were designated as "fully developed" Type A1, the highest percentage in any of the seven age strata. By contrast, in the oldest stratum (65-69), marking the last phase of the transition to "beginning old age", only $50 \%$ of the MI-cases were designated as being Type A. In this particular stratum, and in the preceding stratum (60-64), TABP no longer constituted a risk indicator for first MI. This latter finding is in accordance with 
findings from some earlier American studies with comparable age ranges (e.g-, Mettlin, 1977; Zyzanski, 1978).

\section{B. I. Interviewer Bias.}

Is it possible that the previous results were influenced by interviewer bias? Perhaps. The fact is, the SI-assessment of TABP in MI-cases, NR and HR was carried out as part of the SBI. Prior to this, all interviewers were aware of the status of the MIcases and referents. This may have resilted in a more critical, or more precise, assessment of TABP in cases than in referents. Ideally, all SI-assessments should have been (video)taped and subsequently classified blindly by an independent expert. Since this taping procedure might have affected the trusting relationship between interviewee and interviewer that was thought necessary to properly conduct the SBI, this strategy was not adopted, with the result that interviewer bias may have influenced the findings to some extent.

\section{B.2. Retrospective Bias.}

Could the findings have been influenced by retrospective bias ? That is, should it be assumed that the relative risks actually represent an overestimation of the effect of TABP ? Not necessarily. The literature suggests that the opposite may, in fact, be trie, namely, that several factors may have contributed to an underestimation of this particular risk.

First, prospective studies have demonstrated that TABP is, in general, a stable behavioral disposition over the adult life-span (Matthews \& Haynes, 1986; Haynes \& Matthews, 1988).

Second, in male Type A cases who recently suffered an MI, the pathogenic characteristics of TABP were generally more manifest prior to their coronary events than immediately after them (Powell et al., 1984; Levenkron \& Moore, 1988). Since in the present study the factual assessment of current TABP occurred, on the average, about two months after discharge from the hospital, the actual prevalence of TABP, as measured in the MI-cases under study, may represent an underestimation of their characteristic behavior prior to their first MI. 
Third, it has been argued that surviving MI-cases who exhibit TABP to an extreme degree may be unwilling to cooperate or to comply at all with psychological testing after MI and may deny their disease and the behaviors they think are associated with it (Abbott et al, 1985; Halperin \& Littman, 1985, Oakes, 1985; Levenkron \& Moore, 1988). In other words, in the present study, extreme Type A cases may not lhave participated to the same extent as cases who exhibited this behavioral disposition to a lesser degree. In sum, since $55 \mathrm{MI}$-cases (25\%) initially agreed but later refused to participate in this study, possibly for the above-mentioned reason, the actual prevalence of TABP in the present study may have been underestimated (Falger et all, 1988).

\subsection{Reported Stressful Life Events and their Associations with First Myocardial Infarction.}

\section{A. General Discussion.}

Table 5.1. shows that SLE occurred more often with MI-cases than with either NR or HR, both in general and in the domain of "Family \& Social Life". In the HRseries only, MI-cases also reported more SLE in "Work \& Career" and in "Childhood \& Adolescence".

The quantitative results from both series together are in accordance with those from earlier case-referent research (Theorell \& Rahe, 1970; 1971; 1972; Thiel et al., 1973; Theorell, 1982; Byrne, 1987). The present results were also considered from a qualitative perspective, however. That is, in addition to the finding that MI-cases encountered more events than referents, the particular character of the reported SLE over the life-span of MI-cases was taken into account.

\section{A.1. Reported Events in Childhood \& Adolescence.}

Table 5.2.a. shows that in "Childhood \& Adolescence" 4 SLE occurred more often in the HR-series and one in the NR-series, namely, "Living away from home" (to a marginall extent), "Prolonged familial conflicts", "Prolonged unemployment (father)", and "Prolonged financial problems" (the latter event occurring in both referent series). It may be concluded that adverse living conditions in the formative years had a longlasting influence on the subsequent life-span development of future MI-cases. "Pro- 
longed financial problems" in particular was associated with a twofold risk for futture Mi in multivariate analyses.

A. Comparisons with Other Studies. These findings are comparable, to some extent, with those from another series of studies employing a different methodology. namely, an analysis of mortality statistics from consecutive historical time periods and the prevalence of conventional risk indicators for CHD (Forsdahil, 1977; 1978; Arnesen \& Forsdahl, 1985). The findings from these studies suggested that extreme poverty during childhood and adolescence, followed by prosperity in later developmental stages, resulted in higher serum cholesterol levels and, as such, was a risk indicator for the subsequent development of CHD (Forsdahl, 1977; 1978). Later analyses of the same data concluded that childhood poverty also operated, at least in part, as an indicator for CHD through other conventional risk indicators (Arnesen \& Forsdahl, 1985). In the present study, the SLE that were positively and significantly associated with adverse living conditions in childhood and adolescence may be thought to have also contributed to the onset of CHD in later developmental stages through the above-mentioned mechanisms.

\section{A.2. Reported Events in Work \& Career.}

Table 5.2.b. shows that in "Work \& Career" 8 SLE occurred more often in the HR-series and 2 in the NR-series. These particular SLE, in descending order of magnitude, were: "Prospects for promotion (unrealized)", "Prolonged overtime", "Work place closed down", "Prolonged/serious conflicts with supervisors", "Compulsory search for other job(s)", "Increased responsibility", "Prolonged/irregular working hours/shiftwork", and "Prolonged/serious conflicts with subordinates" (in the HR-series) and "Past unemployment" and "Prolonged overtime" (in the NR-series). These events are indicative both of an often disrupted career and of longstanding conflicts at work. Since those SLE are also associated with significantly elevated crude relative risks, which in most instances were more than twofold, it may be concluded that such obstacles in one's career are, in themselves, conducive to future first MI.

It should be mentioned here that only "Prolonged overtime" discriminated significantly in both referent series. Table $5.2 \mathrm{~b}$. shows, on the other hand, that the occupational careers of NR and HR may have differed in some important respects. That 
is, NR reported "Increased responsibility", "Important orgamizational/economic changes at work" , Prospects for promotion (unrealized)", and "Prolonged/serious conflicts with supervisors" significantly more often than HR. The latter, in turn, reported "Prolonged absenteeism" more often than NR. It might be lyypothesized that the occupational careers of HR, in general, were internupted by prolonged illness episodes that may have limited opportunities for career advancement. Yet, "Past disability" for medical reasons did not differ significantly in the two referent groups. From this perspective, it may be said that the occupational careers of future MI-cases and "healthy" NR show many more similarities than those of MI-cases and HR, who resemble each other more closely on almost all of the other psychosocial aspects studied.

The last two discriminating events mentioned above - "Prospects for promotion (unrealized)" and "Work place closed down" - also retained positive and significant associations with $\mathrm{MI}$ in multiple logistic regression analyses in which other risk indicators were controlled for (cf. Table 5.6.). The only event that occurred in both referent series - "Prolonged overtime" - was associated primarily with vital exhaustion and, thus; only appeared to lead to Mindirectly. In additional multiple logistic regression analyses, "Increased responsibility" and, to a lesser extent, "Voluntary search for other job(s) $)^{n}$ constituted other important occupational risk indicators for first MI in "young adulthood" only, through their respective positive interactions with age (cf. Table 5.7.).

A. Comparisons with Other Studies. As such, most of these results are in accordance with those from the series of retrospective and prospective studies by Theorell \& Rahe (1970; 1971; 1972), Lind \& Theorell (1973), Theorell et al., (1975), Theorell (1976), and Theorell \& Floderus-Myrhed (1977). In the retrospective studies, a significantly heavier "work load" index prior to MI distinguished consistently between different series of post-MI-patients and various referent groups. The single most important events from this index that are directly comparable with the present findings included "prollonged periods of overtime work" and "prolonged conflicts with superiors at work" (Theorell, 1982). In the prospective studies, "conflicts at work" and especially "increased responsibility" discriminated consistently between future MI-cases and referents (Theorell, 1982). However, in the present study, multivariate anallyses showed only the latter event to be a risk indicator for first MI in "young adulthood" only (ages $35-44$; cf. Table 5.7.). 
Since other major work and career-related events, such as "Work place closed down", were not included in the Theorell et al. studies, a direct comparison of their respective effects is impossible.

The fact that "Work place closed down" remained associated with risk for first MI over prollonged periods of time after controlling for confounders (cf. Table 5.6.) runs counter to the findings from an earlier American study (Kasll et al., 1975; Kasl \& Cobb, 1980). In this prospective investigation, the psychological and physical consequences of anticipated; one-time job loss were measured repeatedly. Changes in cardiovascular dysfunctioning were directly related to the consecutive phases of anticipation, plant closing, unemployment, and subsequent re-employment, with a gradual return to baseline values of previous cardiovascular performance at the end of the wo-year follow-up period.

By contrast, the fact that the present study was carried out in the South Limburg region of the Netherlands, where a tidal wave of unemployment due to the closing of all twelve regional coal mines had struck during the $1960^{*} \mathrm{~s}$, something which had a tremendous economic and psychological impact on the entire area (Falger, 1984), may have influenced the above finding to a considerable extent. Those former coal miners. who had worked for at least ten years in the mines before they were closed and who. formed a subgroup of the cases with first $\mathrm{MI}(27 \%)$, as compared to $16 \%$ in the combined referent groups (Falger, 1984), may have differed considerably with respect to risk indicators not included in the present study, such as pulmonary complications. That is; coal miners, in general, may be at elevated risk for respiratory hazards, pulmonary diseases, and arthritic conditions in later life (Smith, 1981). Those adverse health conditions may, in turn, have affected these coal miners' cardiovascular performance. Therefore, coal miners who already had certain health problems may have had fewer opportunities in the labor market during the ten years that the mines were being closed down, exposing them to greater job loss, than healthier and younger colleagues or colleagues who sought new jobs by themselves instead of waiting until new jobs had been found for them. Future stratified analyses may determine whether "Work place closed down" was, indeed, a risk indicator for future MI in former coal miners. 


\section{A.3. Reported Events in Fanily \& Social Life.}

Finally, Table 5.2.c. shows that 7 SLE in the HR-series and 5 in the NR-series occurred more often in MI-cases, reflecting three different categories:

(a) "ehronic" trouble or problems with children ("Prolonged/serious illness" longed/serious educational problems", and "Prolonged/serious conflicts with children away from home");

(b) "chronic" problems related to marital life ("Prolonged/serious financial problems" and "Prolonged/serious marital conflicts)"; and

(c) "Prolonged/serious illness and/or accident".

In the HR-series, another "chronic" event - "Living with extended family" - also occurred more often in the life histories of MI-cases. These SLE were associated with elevated and significant crude estimated relative risks for first MI. All but one of these events remained positively and significantly associated with first MI in multiple logistic regression analyses, with relative risks ranging from 3.65 for "Prolonged/serious conflicts with children away from home" to a marginal 1.63 for "Living with extended family" (cf. Table 5.6.). The one exception - "Prolonged/serious marital conflicts" - was associated with a significantly elevated relative risk in "middle age" (ages 45-59) only. "Prolonged/serious illness of spouse" appeared to be another marginally significant risk indicator for first MI that showed a positive interaction with age in "beginning old age" (ages 60-69; ef. Table 5.7.).

A. Comparisons with Other Studies. These results regarding the rolle of prolonged discord in the family and social life of future MI-cases have not been reported on a similar scale in previous studies. Most of the investigations by "Theorell et al. have focused primarily on events in "Work \& Career" although, in general, "dissatisfaction with family life" was reported to have occurred more often in MI-cases in one of the early retrospective studies (Theorell \& Rahe, 1972).

Yet, in a comparative cross-cultural study about the perceived importance of SLE in the development of CHD, including MI, it was found that, both in Stockholm and New York, middle-aged male CHD-patients were the least satisfied with their family lives, when compared to age-matched referents at risk for CHD and "healthy" controls (Orth-Gomér, 1979). However, in Stockholm, MI-cases most frequently rated work-related events as being the most important source of stress leading to their 
coronary event and not so much their familial problems. The male heart patients in New York most often blamed it on difficulities in family life, in particular prolonged problems with children. Indeed, almost one-third of these American men would have chosen a different kind of family life if they had been able to. The findings from the present study appear to corroborate the important role of child-related problems in the onset of MI.

In this respect, the rather "chronic" character of almost all events that occurred more often in MI-cases deserves extra attention. While the terms "life events" or "life changes" are often taken to mean one-time occurrences, the discriminating events in the present study imply that chronic or recurrent adverse situations constitute the major pathogenic psychosocial aspect of SLE associated with the development of first MI. Therefore, future research might explore the developmental relationships between "chronic adverse life situations", as these life events may more accurately be called, and "daily hassles", which have been postulated to serve as major mediators of psychosocial risk (Lazarus \& Folkman, 1984).

\section{B.1. Retrospective Bias.}

Could the reporting of SLE by the MI-cases in the present study have been brought about by retrospective bias? Again, this is possible. If, in fact, this is the case, "search for meaning" and/or "selective forgetting" may have played a role.

A. "Search for Meaning". As argued before, the retrospective assessment of the occurrence of SLE may have been seriously affected by the life-threatening event of first MI itself. That is, a patient who has survived a coronary event may look for explanations as to why it happened to him and, in doing so, may reappraise his antecedent life-span. He may reason that a number of past SLE must have had something to do with it. Consequently, he may report such events more often than referents and may attribute much more meaning to these events than they actually deserve (Lundberg et al., 1975; Lundberg \& Theorell, 1976). However, as argued before, a person-centered, structured interview like the SBI, in which the objectively-defined SLE are firmly anchored within the context of the individual life-span, may effectively reduce this "search for meaning" (Cohler, 1982; Laux \& Weber, 1987; Thomae, 1987). 
"Search for meaning" may, moreover, be associated with a fundamentally different recall of SLE, depending on how much time has elapsed between the occurrence of first MI and actual interviewing. This may imply that MI-cases who were interviewed relatively soon after their coronary event would report fewer SLE that they thought were associated with their MI than cases interviewed much later. Table 2.6. shows, however, that there were no significant differences whatsoever with respect to the total reporting of SLE, nor to the reporting of SLE in the three separate dornains, between MI-cases interviewed within one month, between one and three months, and more than three months after surviving first MI. Thus, "search for meaning" did not appear to influence the present results.

B. "Selective Forgetting". Although "search for meaning" did not inflate the present findings to a substantial extent, "selective forgetting" must also be considered. However, as argued previously, the fixed chronological arrangement of the SLE in the SBI resulted in each event being presented and discussed more than once, in different constellations, during the course of the interview. Thus, the chances of "selective forgetting" actually occurring were rather small.

\section{B.2. Interviewer Bias.}

Might interviewer bias have influenced the different reporting of SLE in MIcases and referents? Perhaps. As already mentioned, all interviewers were aware of the status of cases and referents. Moreover, some of them were also fully aware of the study hypotheses. Thus, interviewer bias may have influenced the results regarding the role of SLE in the biographies of MI-cases and referents to some extent.

Again, however, the chronological arrangement of the SBI and the unambiguous manner in which the occurrence of each SLE was first described in the interviewer instructions and later phrased by the interviewers makes it improbable that the SLE were misinterpreted by the interviewees. Of course, only a complete and, above all, blind replication of all 458 interviews conducted during this study by different interviewers would settle the issue of possible interviewer bias. 


\section{Manifestations of Vital Exhaustion and their Association with First Myocardial Infaretion.}

\section{A. General Discussion.}

Table 4.1. shows that vital exhaustion, as measured by the mean scores on the MQ, occurred significantly more often in MI-cases than in either HR or NR. It also shows that HR reported significantly more vital exhaustion than NR. The overall ageadjusted estimated relative risks associated with vital exhaustion in MI-cases was more than sevenfold in the NR-series and almost threefold in the HR-series. As such, these results are in accordance with those from earhier Dutch case-referent studies employing preliminary versions of the MQ (Appels, 1980; Verhagen et al., 1980). Also, as shown in Table 4.3, this association of vital exhaustion with first MI was not confounded to any substantial degree by age, angina pectoris, or current smoking. That is, after controlling for these risk indicators, vital exhaustion discriminated positively and significántly in both referent series.

Furthermore, Table 4.2. provides a detailed analysis of all items that, together, constitute the construct of vital exhaustion. In this analysis, the intermediate item pool of 58 items was scrutinized with respect to each separate association with first MI, in both referent series, after stratifying for the three life-span developmental phases used throughout the present study. This particular analysis yielded a number of interesting results, two of which will be discussed here.

B. More Items Discriminate in Retrospective than in Prospective Research.

First, in both referent series, $79 \%$ of the pool of 58 items were positively and significantly associated with an elevated, age-adjusted risk for first MI. This is more than twice the number of items that discriminated in the prospective RCSS, in which Form B of the MQ was established (Appels et al., 1987a). Thus, from a retrospective point of view, this quantitative analysis revealed that the construct of vital exhaustion contains many more items associated with first MI than was apparent in the prospective study. It was already noted, however, that the individual items that predicted MI in the RCSS yielded rate ratios that allow for a more precise estimate of the risk involved than the present odds ratios. 


\section{C. "Increased Irritability".}

Second, the best discriminating item from the intermediate 58 -item pool in the NR-series (MO 05), representing "increased irritability", was associated with the highly significant estimated relative risk of 8.66 . In the HR-series, it was associated with an estimated risk of 6.00 and constituted the second best discriminating item. MQ 19; the best discriminating of the 58 items in the HR-series and the third best discriminating one in the NR-series, showed this same tendency towards "increased irritability" in future MI-cases and was associated with an estimated relative risk of 7.42 and 7.66, respectively. Neither item, however, is included on Form B of the MQ since they did not discriminate in the prospective RCSS (Appels et al, 1987a). On the other hand; a third item denoting "increased irritability" (MQ 32) is among the 21 items on Form B and is associated with an estimated relative risk of 4.30 and 4.87 , respectively. Thus, from a retrospective point of view, "increased irritability" appears to constitute a crucial part of vital exhaustion and deserves further serutiny.

\section{D.1. Retrospective \& Recall Bias.}

To what extent could retrospective bias have influenced these particular findings? Did recall bias or "search for meaning" play a decisive role here?

A. Retrospective Bias. With respect to the first question, it is again conceivable that retrospective bias, due to sudden hospitalization or to sensitization to stress that they think contributed to their disease, may have led the MI-cases to report more manifestations of vital exhaustion than they actually experienced. The substantial difference in mean MQ scores in the HR-series, however, would seem to indicate that such reasons are, in themselves, not enough to account for the significantly elevated MQscores in MI-cases. That is, HR were included in this study primarily to demonstrate the possible effects of recent hospitalization on the perception and/or recall of vital exhaustion prior to admission. Yet, because their disorders were, in general, not related to stress, HR may have become less sensitized to it.

B. Recall Bias. Recall bias, or "search for meaning", may also have played a role. That is, having recently suffered an MI may have been instrumental in reappraising manifestations of vital exhaustion that occuirred during the last months prior to the coronary event. Both $\mathbb{N R}$ and HR may have noticed some of these manifestations but not 
reported them at the time they completed the MQ because they considered them to be of a transient nature. The indicators of "increased irritability" that were employed here may be particularly sensitive to such reappraisal. That is, many MI-cases asserted that their spouses had frequently noticed, and commented upon, their "in-creased irritability" shortly before their MIs. This may have led some of them to ex-aggerate the extent to which they experienced vital exhaustion, in general, and "in-creased irritability, in particular. Therefore, differential misclassification, based on these exaggerated reports of some of the MI-cases under study, may have influenced these results to some extent (Rothman, 1986).

There are, however, a number of arguments against substantial effects of both forms of bias. First, the present analysis included onlly the 21 items found in the RCSS to be predictive of future MI over the entire follow-up period of more than four years. In the RCSS, the shortest follow-up interval over which the risk associated with vital exhaustion was calculated was one year. The estimated age-adjusted relative risk associated with vital exhaustion for this first year was reported to be 10.05 , whereas those for the second, third, and fourth years were 2.23,3.04, and 0.68, respectively (Appels \& Mulder, 1988). Appels \& Mulder asserted that these data suggest that vital exhaustion is a "short-term" risk indicator. Thus, it may be concluded that the more than sevenfold risk estimate obtained in the NR-series is correct since it is lower than the former prospectively established risk, while that in the HR-series may represent an underestimation. Unlike prospective studies, retrospective ones generally tend to produce overestimations of conferred risk.

Following the same line of reasoning, the risk associated with vital exhaustion in the present HR-series may represent an underestimation. That is, HR were included to assess the effects of recent hospitalization on the perception and/or recall of vital exhaustion. The recall of one's mental and physical condition prior to hospitalization may be more similar between HR and MI-cases than between NR and the latter:

A third explanation for this strong association between vital exhaustion and first MI runs counter to the "search for meaning" argument. That is, since manifestations of vital exhaustion may be said, in principle, to have occurred "full blown" immediately prior to the coronary event, recollections of these manifestations are both very vivid and accurate. In the NR-series, the contrast with respect to vital exhaustion 
should be much larger than in the HR-series, since other, painful ailments may also lead to phenomena of vital exhaustion. In addition, HR may have had recollections about other manifestations of vital exhaustion that were associated with their ailments. Subjects who suffer from these manifestations may be more aware of their illness and may, as a result, be represented on a larger scale among the participating HR than subjects who do not. "This form of Berkson's bias could lead to an underestimation of the risk associated with vital exhaustion in future MI-cases (e.g., Kleinbaum et al., 1982).

If this reasoning is correct, a similar phenomenon should be observed, in general, in the prospective RCSS, namely, a relatively large estimated relative risk associated with vital exhaustion that occurs just before first $M I$ and that gradually decreases as the time prior to the coronary event increases. As mentioned earlier, this was, indeed, the case. It may, therefore, be concluded that the present findings regarding vital exhaustion have not been invallidated by retrospective or recall bias to any considerable extent.

\section{D.2. Selection Bias.}

If retrospective and recall bias did not influence the results with respect to vital exhaustion to any considerable extent; might selection bias have done so ? That is, could it be that only cases who were extremely "exhausted" or "irritable" prior to their MIs were included in the present study ? Or could it be that only extraordinarily "vital $^{\text {" }}$ referents were willing to participate?

A. MI-Cases. As discussed in detail earlier (cf. Table 2.1.), the 133 participating and 20 non-participating MI-cases did not differ significantly with regard to any of the comparisons made with regard to psychosocial risk indicators, including mean $\mathrm{MQ}$ scores. Given these results, it seems reasonable to assume that "vitally exhausted" MIcases were not the only ones who participated in this study.

B. Hospital Referents. Similarly, as shown in Table 2,2., the 192 participating and 41 non-participating HR did not differ with respect to mean age or primary reasons for hospitalization. Since only two of the latter HR returned a fully completed set of questionnaires, differences with respect to vital exhaustion could not meaningfully be established. 
C. Neighborhood Referents. It was previously conciuded that selection bias in the 133 participating NR cannot be ruled out since the 278 non-participants did not complete any of the questionnaires. Thus, there is no intormation available regarding the major variables of interest. However, those NR who gave reasons for their nonparticipation indicated that it was because they were either too busy or feeling too old. It may well be that older subjects were less willing to participate than younger, probably healthier, ones. It may be hypothesized; then, that the present results with respect to the MQ in the NR-series represent a slight overestimation of the true risk associated with vital exhaustion.

Finally, in the present study, of the 21 items on Form $B$ of the MQ, 2 in the NRseries and 3 in the $H R$-series did not discriminate, whereas they did in the prospective RCSS. These tems were. MQ 15 (During the last half year, did you believe that you thad come to a 'dead end ${ }^{*}$ ) and MQ 42 ["(..), did you sometimes want to be dead ?"] in the NR-series and MO 35 ["(...), I felt fine"], MQ 38 ["(...), did you sometimes feel that your body was like a battery that was losing its power ?"] and, once again, $\mathrm{MQ}$ 42 in the HR-series. Since a case-referent study like the present one by definition only includes those MI-cases who survived their events long enough to participate and who, thus; constitute a slightly different population than the one in the RCSS, it may be hypothesized that those non-discriminating items of the MQ are primarily associated with coronary death rather than with non-fatal MI.

\section{D.3. Confounding by Clinical Risk Indicators.}

As shown in Table 4.3., the association of vital exhaustion with first MI was not confounded by age, angina pectoris, or current smoking. However, vital exhaustion may be thought to be associated with other risk indicators, such as hypertension, or with subclinical manifestations of CHD, such as extent of atherosclerosis. Since the present study did not include a clinical assessment of those indicators, it is not known whether their possible associations influenced the present results to any extent.

Some of these factors (i.e, blood pressure and serum cholesterol), however, were simultaneously controlled for, together with current smoking, use of antiliypertensive drugs, and age, in multiple logistic regression analyses in the RCSS (Appels \& Mulder, 1988). Vital exhaustion remained predictive of future fatal or non-fatal MI 
after controlling for these factors in a large population free of $\mathrm{CHD}$. Thus, the risk indicators that could not be assessed in the present study probably did not influence the findings regarding vital exhaustion to a disproportionately large extent.

\section{D.4. "Neuroticism" and "Vital Exhaustion".}

Finally, the question arises of whether a general factor such as "neuroticism", which appears to be a common, basic psychometric component of many questionnaires that tap various aspects of personal dysunctioning (Luteijn \& Bouman, 1988), rather than "vital exhaustion", was responsible for the present findings. It has thas far been assumed that the particular mental and physical phenomena reported by the MIcases under study as having occurred prior to first MI actually did occur and were, in fact, manifestations of vital exhaustion. Moreover, it has been argued that the reporting of vital exhaustion most probably was neither influenced by retrospective, recall, or selection bias nor confounded by clinical risk indicators not included in the present study.

An alternative interpretation of these findings that should be mentioned here is that they may not result from some antecedent process of "vital exhaustion". Rather, the items on the MQ may reflect a stable, normal personality dimension - "neuroticism" $^{\prime}$. Based on a number of primarily retrospective studies, it was concluded that there are positive associations between trait measures of neuroticism and manifestations of CHD, in particular "soft events" such as angina pectoris (Jenkins, 1971; 1976; 1978a; Jenkins \& Zyzanski, 1980). These measures are thought to be indicative of a propensity in some adult subjects to regularly experience negative affect and, in general, to perceive and report adverse physiological experiences more often than adult subjects who are not characterized by this personality trait (Costa, 1986, 1987; Costa \& McRae; 1987; Costa et al, 1985; Luteijn \& Bouman, 1988).

In the present study, however, only cases with the clinically documented "hard"" event of first MI were included, whereas angina pectoris was adjusted for, when necessary, in the analyses involving the risk associated with vital exhaustion (e.g., Table 4.3.). Those analyses clearly demonstrated that vital exhaustion is a strong "short-term" risk indicator for first MI. Therefore, "vital exhaustion" may not reflect "neuroticism" but rather a particular psychosocial process that occurs in the last months prior to $\mathrm{MI}$. 


\section{E. Summary \& Conclusions.}

It may be concluded from the present case-referent study that vital exhaustion. as measured by Form $\mathrm{B}$ of the $\mathrm{MQ}$, constitutes a highly discriminating psychosocial risk indicator for first, non-fatal MI in adulthood and beginning old age. The overall more than sevenfold risk estimate found in the NR-series is less than the tenfold risk associated with one year of follow-up in the prospective RCSS and may, as such, be correct. On the other hand, the overall threefold risk that was calculated in the HRseries may represent an underestimation of the true effect of vital exhaustion. Those results were not influenced to any substantial extent by retrospective, recall, or selection bias and were not largely confounded by the other risk indicators (i.e., age, anglna pectoris, and current smoking) included in the present study. Nor were other risk indicators thought to have confounded these results.

Some of the 21 items on Form $\mathrm{B}$ of the $\mathrm{MQ}$ did not discriminate in the present study, but did so in the prospective RCSS. On the other hand, two items representing increased irritability" were among the best discriminating items in this study; these same items did not predict future MI in the RCSS. Therefore, it is suggested that those particular items be included in future research employing the MQ.

\subsection{The Type A Coronary-Prone Behavior Pattern, Reported Stressful Life Events, and their Associations with First Myocardial Infarction.}

\section{A. General Discussion.}

Tables 3.4.a through 3.4.c show that 6 of the 47 SLE (13\%) included in the SBI were reported significantly more often by Type A subjects when MI-cases, NR, and HR were combined. Four of those events denoted "chronic" conflicts in adulthood and/or beginning old age, specifically "Prolonged/serious conflicts with colleagues" and "Prolonged/serious conflicts with subordinates" ("Work \& Career") and "Prolonged/serious marital conflicts" and "Prolonged/serious conflicts with family members" ("Family \& Social Life"). The two other discriminating events were "Prospects for promotion (unrealized)" ("Work \& Career") and "Prolonged financial problems" ("Childhood d Adolescence"). 
A.1. Childhood Origins of the Type A Coronay-Prone Behavior Pattem, Reponed Stressful Life Events, and First Myocardial Infarction.

Prolonged financial problems ${ }^{\text {th }}$ raises the important issue of the hypothesized childhood origins of TABP and their associations with prevailing environmental factors, something which is increasingly receiving attention (e.g., Murray et al., 1986; Matthews \& Woodall, 1988). It was concluded earlier that the available evidence suggests that TABP has already become firmly established by the time a susceptible individual reaches early adulthood. Furthermore, it is thought that this behavior pattern is primarily induced and reinforced by specific mother-child interactions (e.g., Matthews, 1977). A recent review of the rapidly growing literature on this latter subject concluded that "...the data provide strong support for the validity of the Type A concept in children in that the behavioral correllates of Type $\mathrm{A}$ in children are consistent with those seen in Type A adults" (Matthews \& Woodall, 1988). Much less is known, as yet, about the environmental factors that induce and reinforce these interactions.

The "Prolonged financial problems" in childhood and/or adolescence that were reported significantly more often by adult Type A than Type B subjects may have been instrumental in modelling the parent-child interactions in such a way that the development of TABP was facilitated. This, together with other adwerse living conditions in the formative years, may have strongly influenced the subsequent life-span development of future MI-cases (Forsdahl, 1977, 1978; Arnesen \& Forsdahl, 1985).

Since TABP contributed significantly to first MI, the positive association of "Prolonged financial problems" and, from a broader perspective, of adverse living conditions with first MI may have been confounded by TABP. Table 5.6. shows, however, that in multiple logistic regression analyses that included TABP among other potential confounders, this event remained positively and significantly associated with first MI and represented a twofold risk. It may thus be concluded that "Prolonged finan" cial problems" in "Childhood \& Adolescence" constitutes both a current concomitant of TABP in adult men and, in the context of the present study, the earliest psychosocial precursor of first MI. 


\section{A.2. The Type A Coronary-Prone Behavior Pattem, "Irritability", Reported"}

Stressul Life Events, and First Myocardial Infarction.

In their review, Matthews \& Woodall (1988) concluded that Type A children may be significantly more irritable and, at the same time, socially less competent than their "Type B peers. [It should be noted bere that this aspect of "irritability" in children has been labeled "anger" and/or "hostility" in adults (Williams, 1987)]. If one assumes, as Matthews \& Woodall do, that those early behavioral traits become stable characteristics of TABP over the ensuing life-span, the present findings that adult Type A subjects, in general, were significantly more often involved in serious or longstanding conflicts at work and in family and social life may corroborate the previous assumptions regarding the stability of the "irritability" and "social incompetence" aspects of TABP:

These latter assumptions are generally supported by the "stability vs. change" debate in human development, in particular, with regard to personality development (e.g. Thomae, 1979; Costa \& McRae, 1980; Moss \& Sussman, 1980). That is, most of the recent longitudinal studies about the stability of personality in adulthood have demonstrated little or no change in personality traits with age. This may mean that adult Type $\mathrm{A}$ subjects perform poorly in social relationships and become easily involv-ed in conflicts in different personal domains, as hypothesized earlier in an analysis of the ecological context of TABP (Margolis et al., 1983).

Since Table 5.6. shows that in multiple logistic regression analyses certain conflict-related events in "Family \& Social Life" were also positively and significantly associated with elevated risk for first MI after controlling for TABP, it may be concluded that such conflicts are not only clear determinants with respect to perpetuating TABP but also instrumental in the development of first MI in adult men. This is in accordance with the central theme of the above-mentioned ecological analysis (Margolis et all., 1983).

Furthermore, it may be hypothesized that an event like "Prospects for promotion (unrealized)" is associated with a supposed "irritability" component of 'TABP. That is, it may be that an adult Type A subject's habitual "irritability" (or "hostility" and "anger") played an important role in his failure to achieve an expected promotion at work one or more times. In other words, in those subjects in whom "irritability" is a domi- 
nant characteristic of TABP, this trait may have had an adverse influence on their occupational career.

"Prospects for promotion (unrealized)" was not only positively and significantly associated with TABP but also with elevated risk for first MI. Thus, this event may have influenced the life-span developmental course of future MI-cases, independently of their behavioral status.

Finally "Prospects for promotion (unrealized)" may constitute a crucial marker in contemporary occupational careers. If this event did, in fact, represent a major interruption in a person"s "expected life history" (Bortner, 1979), it would be interesting to study whether it was associated with subsequently increased "anger" and "hostility", on the one hand, and with vital exhaustion at the same time or in a later developmental phase, on the other hand. Although the former aspect cannot be answered by the present results, it is possible that the latter can. However, attention will first be paid to the specific relationships between TABP and vital exhaustion and to their common association with first MI.

\subsection{The Type A Coronary-Prone Behavior Pattern, Manifestations of Vital Exhaustion, and their Common Association with First Myocardial Infarction.}

\section{A. General Discussion.}

Table 3.2. shows that the overall, age-adjusted estimated relative risk associated with TABP in MI-cases was significantly elevated, that is, at least twofold compared to the Type B pattern in both referent series. Furthermore, Table 4.1. indicates that a similar risk estimate associated with vital exhaustion in MI-cases was also significant$1 y$ elevated, that is, ranging from almost threefold in the HR-series to more than sev= enfold in the NR-series. Finally, Table 4.4. shows that Type A subjects who were free of angina pectoris generally reported significantly more symptoms of vital exhaustion than their counterparts.

The ensuing assumption that both risk indicators, when combined, represent a greater risk than the separate risk estimates for these indicators was supported by the findings in Table 4.5. On the basis of standardized relative risks, this particular table 
shows that when compared to "vital" Type B referents, "vitally exhausted" Type A cases were at a more than fivefold risk for first MI in the HR-series and at an almost elewenfold risk in the "healthy" NR-series. It was concluded that these results may indicate a modifying effect of vital exhaustion with respect to the established pathogenic influence of TABP.

This was, indeed, the case. Although "vitall" Type A subjects were at an almost twofold risk for first MI compared to "vital" Type B subjects, this risk was not significant in either referent series (cf. Table 4.5). However, "vitally exhausted" Type A subjects were at a significantly elevated, more than two-and-a-thalf-fold risk for first MI compared to "vital" Type A HR and at a five-and-a-half-fold risk compared to "vital" Type A NR. Thus, it was concluded that vital exhaustion may constitute a crucial modifier with respect to the risk generally thought to be associated with TABP, in that TABP may only predict future MI when the presence of vital exhaustion is considered simuitaneously. When this assertion was subsequently tested, the results in the HRseries corroborated it; that is, vital exhaustion was, in fact, a true modifier with respect to the risk conveyed by TABP. However, this was not the case in the NR-series.

Furthermore, in multiple logistic regression analyses, both TABP and vital exhaustion, as well as current smoking and angina pectoris, were positively and significantly associated with elevated risk for first $\mathrm{MI}_{3}$ although in both referent series the influence of TABP was rather marginal (cf. Table 4.6.). Thus, it may be concluded that the present data support, in part, the possibility of a synergistic relationship between TABP and vital exhaustion. In the present study, this possible interaction could not be tested statistically. It may be thought that "...the term 'synergism' can be characterized only in terms of experimentally verifiable biological models describing modes of action of substances at the cellular level" (Kleinbaum et al., 1982). Since the present study dealt with TABP and vital exhaustion on a conceptual level, the necessary, bas$\mathrm{ic}_{\mathrm{y}}$ biological information required to test a synergistic interaction pattern between the two constructs could not be obtained. However, in future psychophysiological studies, this possible synergistic relationship should be studied further and in more detail since the concurrent presence of TABP and vital exhaustion defines a particular subgroup that might be at highly elevated risk for a near-future coronary event. That is, 
it may be hypothesized that "vitally exhausted" Type A subjects respond with different physiological reaction patterns to recent SLE than do "vital" 'Type A subjects.

The above findings appear to be in accordance, at least in part, with the results from two recent meta-analyses, the first regarding the psychosocial and behavioral contexts of TABP and the second, the psychological determinants of "illmess-proneness" (Booth-Kewley \& Friedman, 1987; Friedman \& Booth-Kewley, 1987). These analyses indicate that, in general, "exhaustion" and "depression", among other psychosocial determinants, may be important predictors of CHD, independent of TABP.

Finally, the previous discussions about "increased irritability" as one of the most important constituents of vital exhaustion and about the role of "irritability" as a concomitant of TABP may contribute to a better understanding of the psychological meaning of the apparently synergistic relationship between TABP and vital exhaustion because of the central position of "irritability" in both constructs. Since the above reasoning was based primarily on global retrospective findings, more detailed casereferent studies and, above all, prospective investigations are necessary to determine the tenacity of this reasoning. In order to corroborate it, the component analysis of the SI should be incorporated into future studies: This will allow for a meaningful differentiation between the various components of TABP (Dembroski \& MacDougall, 1983; Dembroski \& Costa, 1988). A more extended version of the MQ should be included as well, incorporating all items about "increased irritability" that were found to be associated with substantially elevated estimated relative risks for first MI in both referent series (cf. Table 4.2.).

\section{B. Summary.}

In summing up the previous section, it may be said that there appears to be a symergistic relationship between TABP and vital exhaustion prior to first MI. This may be a promising first step towards unifying two rather different approaches to the study of psychosocial stress and CHD that have hitherto proceeded rather independently. By replicating the well-known finding that TABP, in general, is associated with a more than twofold overall estimated relative risk for first MI, the present results support the extensive retrospective evidence about the role of TABP in the pathogenesis of CHD. By demonstrating that vital exhaustion was associated with a relatively stronger risk 
for firs MI than TABP, the present study reinforces the conceptual appropriateness of previous studies indicating that psychosocial constructs similar to "vital exhaustion", namely, "emotional drain" (Wolf, 1969), "decreased human functioning" (Nixon, 1976), and "sadness coupled with loss of libido and exhaustion" (Crisp et al., 1984), may precede the onset of first MI in susceptible male adults.

\subsection{Manifestations of Vital Exhaustion, Reported Stressful Life Events, and} their Associations with First Myocardial Infaretion.

\section{A. General Discussion.}

Tables 4.7.a through 4.7.c show that, in all, 15 of the 47 SLE (32\%) induded in the SBI were reported significantly more often by subjects characterized as being "witally exhausted" when MI-cases, NR, and HR were combined. Contrary to the findings about TABP and the SLE associated with it, four events, rather than one, in "Childhood \& Adolescence" were found to be associated with vital exhaustion in adulthood and beginning old age. These SLE were: "Prolonged financial problems", which was also associated with TABP (cf. Table 3.4.a.) and with first MI, "Prolonged familial conflicts", "Prolong-ed unemployment (father)", and "Living away from home $\mathrm{e}^{n}(\mathrm{p}<.10)$.

In "Work \& Career" "6 SLE - compared to the 3 that were generally reported more often by Type A subjects - were positively associated with vital exhaustion. These SLE were: "Prolonged overtime", "Prolonged absenteeism", "Present unemployment/disability", "Past unemployment", "Prolonged/serious conflicts with supervisors", and "Prolonged/serious conflicts with subordinates". This last event was positively associated with TABP, as were "Prolonged/serious conflicts with colleagues" and "Prospects for promotion (unrealized)" (cf. Table 3.4.b.).

Finally, in "Family \& Social Life", 6 SLE, rather than the 2 reported more frequently by Type A subjects, were positively associated with vital exhaustion. These SLE were: "Prolonged/serious financial problems", "Prolonged/serious marital conflicts", "Prolonged/serious conflicts with family members", the latter two events being reported more often by Type A subjects (cf. Table 3.4.c), and "Prolonged/serious illness or accident", "Prolonged/serious educational problems with children" "and "Prolonged/serious illness/death of family members". To a lesser extent, "Prolonged/se- 
rious conflicts with friends/acquaintances" and "Prolonged/serious illiness of children" (both $\mathrm{p}<.10$ ) also contributed to the onset of vital exhaustion in adulthood.

When considered together, these events provide some interesting insight into the natural history of vital exhaustion in the several phases of adulthood discerned in the present study, as well as into the particular psychological contexts that appear to sustain TABP.

\section{A.1. Stressful Life Events as Early Developmental Origins of Vital Exhaustion} and Furst Myocardial Infarction.

The events in "Childhood \& Adolescence" that were positively associated with vital exhaustion were also the same events that were reported significantly more often by the MI-cases either in both referent series or in the HR-series only (cf. Table 5.2.a.). It may therefore be concluded that adverse living conditions relatively early in the lifespan may be conducive to vital exhaustion later on in life. These data do not shed direct light on the psychological processes underlying this intriguing finding. Further research into the particular appraisal and coping strategies for these early SLE leading to vital exhaustion is needed to clarify this issue. A possible first step to understanding these processes will be described in Chapter 7 .

One of these early events - "Prolonged financial problems" - deserves additional attention since it was also reported more often by Type A subjects in general. It may be hypothesized that Type A subjects who have experienced this particular event later develop a different, perhaps more pathogenic, attitude towards work, as a way of preventing the event from happening again in their adult lives, than Type A subjects who have not experienced this possibly traumatic event. The biographical analyses of three MI-cases that will be presented in Chapter 7 may provide preliminary evidence for this hypothesis. Future analyses should shed light on the intricate relationships between this early SLE and the development of TABP, vital exhaustion, and first MI.

The parallel role of certain early SLE that lead to two distinctly different endpoints over the life-span - vital exhaustion, in general, and first MI, in particular - once again raises the question of whether vital exhaustion is primarily a moderator - an effect modifier or a confounder - with respect to the risk for first Ml associated with those events. This was, indeed, the case with most of the events in "Childhood \& Adoles- 
cence". That is, in the first analysis, which controlled for vital exhaustion, only "Prolonged financial problems" (in both referent series) and "Prolonged familial conflicts" (in the HR-series) remained positively associated with a significantly elevated estimated relative risk for first MII (cf. Table 5.5.a). In multiple logistic regression analyses, however, in which vital exhaustion, TABP, age, current smoking, and educational level were controlled for simultaneously, only "Prolonged financial problems" remained positively associated with a significantly elevated risk for first MI (cf. Table 5.6.).

In sum, a number of conclusions can be drawn. First, "Prolonged familial conflicts" and "Living away from home" are primarily associated with vital exhaustion Second, "Prolonged familial conflicts", although associated with vital exhaustion over the adult life-span, may also be indirectly conducive to first MI. That is, this particular event predicts a future coronary event after controlling for vital exhaustion but not after controlling for vital exhaustion together with the other possible confounders included in the multivariate analyses. The association with first MI may perhaps be explained by a habitual propensity to exhibit "increased irritability" over the life-span after having been exposed to "chronic" familial conflicts in the formative years of one"s life, or by smoking. Third, "Prolonged financial problems" are associated positively and significantly with both endpoints, that is, both with wital exhaustion and with first MI in adulthood and/or beginning old age. Finally, someone who has experienced such adverse SLE during the formative years, when these events most likely appeared to be uncontrollable, might subsequently develop a coping strategy that renders him more vulnerable or helpless with regard to coping with similarly appraised SLE in later life.

A. Comparisons with Other Studies. It has been hypothesized and corroborated In a growing number of studies about the pathogenic impact, in general, of SLE over the life-span that undesirable and uncontrollable life events may lead to a state of "helplessness" and "depressed affect" (Silver \& Wortman, 1980; Hammen \& Mayol, $1982^{\text {; }}$ Snyder et al, 1987). However, this may only happen when the individual inwolly-ed feels that he was somehow responsible for those events occurring. In terms of the present study, these events may be thought to lead to vital exhaustion. When such an appraisal strategy is developed relatively early in life, it may be used for dealing with similarly perceived events in later developmental phases. Thus, appraising SLE 
in this manner may be thought to lead to one's becoming wulnerable to vital exhaustion.

This particular argument will be revisited when the SLE from "Work \& Career" and "Family \& Sacial Life" associated with vital exhaustion are discussed.

\section{A.2. Reported Stressful Life Events in Work \& Career, Manifestations of Vital}

Exhaustion, and First Myocardial Infarction.

Four of the six events in "Work \& Career" positively associlated with vital exhaustion were also reported significantly more often by MI-cases. These were: "Prolonged overtime" (in both referent series), "Past unemployment" (in the NR-series), and "Prolonged/serious conflicts with supervisors" and "Prolonged/serious conflicts with subordinates" (in the HR-series; cf. Table 5.2.b.). The latter event was also reported significantly more often by Type A subjects (cf. Table 3.4.b.). Thus, it may be concluded that certain SLE lead both to vital exhaustion in the adult phases of the lifespan and to first MI. It should be noted in this context that vital exhaustion tends to first appear during the adult phases of the life-span, whereas TABP most probably becomes established in childhood and/or adolescence.

This situation in "Work \& Career" raises the question of possible confounding by TABP or vital exhaustion with respect to these 4 SLE. Although all of these events were primarily associated with vital exhaustion, two may also lead to first MI indirectly through their link with vital exhaustion. That is, in the analysis that controlled for vital exhaustion, "Prolonged/serious conflicts with supervisors" and "Prolonged over-

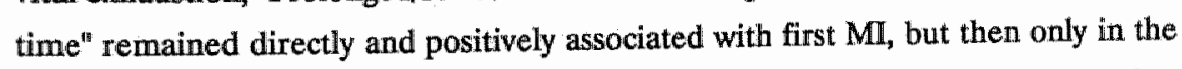
HR-series (cf. Table 5.5.b.). In multiple logistic regression analyses, however, after controlling simultaneously for vital exhaustion, TABP, educational level, and other risk indicators, neither event represented a significantly elevated risk for first MI any longer (cf. Table 5.6.).

In sum, it may be concluded, first, that "Past unemployment" and "Prolonged/serious conflicts with subordinates" are primarily determinants of vital exhaustion. As such, they deserve closer scrutiny with respect to those characteristics that are conducive to the signs and symptoms of vital exhaustion. Second, "Prolonged/serious conflicts with supervisors" and "Prolonged overtime" are associated with vital exhaustion, 
but may also lead indirectly to first MI. It may be thought that these particular events were instrumental in sustaining "increased irritability", as a component of vital exhaustion, in susceptible subjects.

A. Comparisons with Other Studies. When the above-mentioned arguments about the pathogenic consequences of "uncontrollable" SLE are revisited here, it appears that these SLE all constitute undesirable events over which the subject may not have been able to exert sufficient control. With "Prolonged/serious conflicts with supervisors" and "Prolonged/serious conflicts with subordinates", in particular, the subject may become "depressied" if he holds himself primarily responsible for their occurrence (Silver \& Wortman, 1980; Hammen \& Mayol, 1982; Snyder et al., 1987).

Interestingly enough, some case-referent studies have indicated that, contrary to the psychological reasoning that may lead to "depressed affect" in "healthy" subjects, adult MI-patients who recently suffered their coronary event, were inclined to hold others in their immediate social environment responsible for the occurrence of such events, rather than themselves. This is thought to result in the MI-case's maintaining, rather than losing, the threatened self-esteem (Byrne, 1980, 1983). This inclination might explain why the MI-cases from the present study became "vitally exhausted" instead of "depressed". That is, the efforts that were required to maintain their psychic equilibrium, which was perceived as being seriously threatened or cliallenged by certain "uncontrollable" SLE and by other individuals responsible for these SLE, may have depleted them of the vital energy necessary to cope with the extraordinary demands in their lives.

\section{A.3. Reported Stressful Life Events in Family \& Social Liff, Manifestations of}

Vital Exhaustion, and First Myocardial Infaretion.

Four of the 6 SLE in "Family \& Social Life" reported significantly more often by "vitally exhausted" subjects, in general, also occurred more frequently over the lifespan of MI-cases. That is, in both referent series, "Prolonged/serious financial problems " " "Prolonged/serious marital conflicts", "Prolonged/serious illness or accident", and "Prolonged/serious educational problems with children" showed a significantly higher prevalence in MI-cases (cf. Table 5.2.c.). The former 2 SLE were also positively associated, in general, with TABP (cf. Table 3.4.c). Thus, certain events in "Family 
3 Social Lfe $\mathrm{L}^{m}$ were also conduciwe both to vital exhaustion, in general, and to first MI, in particular.

Contrary to the findings in the previous two domains, in the analysis in which vital exhaustion was controlled for, all 4 SLE remained directly and positively associated with first MI in the HR-series; "Prolonged/serious educational problems with children $^{\text {"t }}$ and "Prolonged/serious marital conflicts" also retained significantly elevated, positive associations in the NR-series (cf. Table 5.5.c.). In multiple logistic regression analyses, in which wital exhaustion, TABP, educational level, and other risk indicators were all controlled for, all events remained associated with a significantly elevated estimated relative risk for first MI (cf. Table 5.6.). Thus, it may be concluded that these events have a direct influence upon the development of first MY in adulthood. This finding is quite different from that in "Work \& Career" and "Childhood \& Adolescence", where most events associated with both vital exhaustion and first MI contributed only indirectly to the latter through their primary association with the former.

It should, however, also be noted that with "Prolonged/serious marital conflicts" this positive association was significant only in "middle adulthood", due to a significant positive interaction with age in this cohor, while "Prolonged/serious illness of spouse" showed a positive interaction with age, which was only marginally significant, in "beginning old age" (ct. Table 5.7.).

A. Comparisons with Other Studies. When the above theoretical arguments about the possible associations of adverse "uncontrollable" events with subsequent "depressed affect", or with "vital exhaustion" in the particular case of MI-patients, are applied to the discriminating SLE in "Family \& Social Life", events such as "Prolonged/serious financial problems", "Prolonged/serious educational problems with children", and "Prolonged/serious marital conflicts" appear to have led to vital exhaustion. As argued previously, the MI-cases in the present study may have struggled in vain to cope with events and the consequences of events that they thought may have been brought about by others, including their spouse and/or children, in their immediate social environment. 
$-134$

\&

म : : बै 


\section{Chapter 7: Discussion II: \\ Life-Span Development and First Myocardial Infarction: Some Psychological Considerations.}

\subsection{Introduction.}

In the previous chapter, differences between MI-cases, HR and NR with respect to exposure patterns of behavioral and psychosocial risk indicators were described and discussed. Wherever appropriate, this happened in relation to the empirical findings from other studies. For the most part, these sections were devoted to the occurrence of significantly elevated relative risks for first. MI that were associated with these risk indicators. This primarily epidemiological approach, although necessary to unequivocally determine which of these manifold risk indicators contributed to the development of first MI and, moreover, in which particular phase or phases of the adult life-span, does not provide direct insight into the actual psychological meaning of those factors or into their significance with respect to life-span development.

Therefore, in this chapter, the psychosocial developmental contexts in which those events occurred will be described first. Second, the psychological impact of these events will be discussed, based on the biographical analysis of three cases who suffered their first MI in different phases of the adult life-span. Finally, in order to place the findings reported in the previous chapters within a life-span developmental perspective, the dynamics of these biographies will be commented upon, based on the work of Charlotte Bühler (1933; 1959; 1968).

7.2. The Psychological Impact of Reported Stressful Life Events over the LifeSpan of Three Selected Cases with First Myocardial Infarction.

All three interviews that will be discussed here were conducted by the author in October 1982, March 1981, and Octobet/November 1981. At the time of interviewing, all three participants consented to the details of their life histories being used in the present manner. However, in order to protect their privacy, initials, ages, and years of occurrence of SLE have sometimes been changed. 
There were a number of reasons for selecting these three particular cases. First, the life history of each case illustrates, and is representative of, at least one of the three different phases of life-span development distinguished in the present study.

Second, the three cases reflect both the actual distribution of TABP among heart patients from the present study and the different associated risks over the consecutive developmental phases. That is, two fully developed Type A1 cases represent "young adulthood" and "middle age", while a Type B case best represents "beginning old age".

Third, the SLE reported by those cases include most of the events that were positively and significantly associated with first MI in multiple logistic regression analyses (Tables 5.6. and 5.7.). It is therefore possible to gain insight into the meaning and impact of these SLE, as they pertain to the three cases. Their occurrence, impact, and meaning are summarized in Table 7.1. (p. 246). Other SLE, no doubt, may also have occurred in their biographies and, whether or not they discriminated between cases and referents, will be referred to on occasion.

Fourth, the SLE from "Work \& Career" reported by at least one case are associated with working in the coal mines for an extended period of time. Thus, this case is representative of about one-third of all participating MI-cases who reported such work. This particular type of work was unique to the South Limburg region of the Netherlands, where the vast majority of all participating subjects were born and raised.

Finally, all three cases are representative with regard to reported manifestations of vital exhaustion prior to their coronary events, since most of the MIl-cases were characterized by this prodrome.

First, each individual biography will be described and commented upon. Comparisons will subsequently be made between these life histories in order to discuss similarities and differences over the life-span. 


\section{A. Biography 1: Mr. A.}

1. General Information: Mr. A. suffered his first MI at age 38 . At the time, he was vice president of the rather large local branch of a major national bank in a small town. He had moved there a few months before his coronary event, after having commuted for three years. He was married and had a four-year-old daughter. He was assessed as Type A1 and his score on the MQ was 22 , half a standard deviation higher than the mean score for MI-cases.

2. Childhood \& Adolescence: Mr A., the older of two brothers, was born into a family in which all the men had, for generations, been coal miners. From early on, his parents, rather unconventionally, were against their sons' following in their footsteps. Because of a mining accident, his father became suddenly and severely disabled at age 45 , while Mr. A. was still attending high school. He was the only child in the whole mining community to do so, which met with strong disapproval from both sides of his parents' large families. The family's precarious financial situation after the accident was eased somewhat by his mother's working full-time and Mr. A.'s work in the coal mines during summer vacations. His father remained severely ill for seven years. Dur-ing this difficult time, Mr. A's parents encouraged him to complete high school at all costs, even after he had flunked his final exams. A year later, he graduated with very good grades.

Meanwhile, his younger brother, who was very much affected by his father's condition, dropped out of vocational training. He became emotionally disturbed and subsequently developed severe psychological problems for which he had to seek extensive treatment. Since that time, both brothers grew increasingly apart.

After graduating from high school at age $19, \mathrm{Mr}$. A. was drafted into the Dutch military. There, for the first time, he lacked the protective, supportive environment of home.

3. Work \& Career. After military service, Mr. A. began working for a small accountancy firm as an assistant controller at age 21 . While his career prospects were rather good, he did not particularly enjoy the predominantly administrative work. Therefore, after a year and a half, he looked for a different job with a major national bank. This would ultimately lead him to become senior executive, at a rather early age, 
although it meant beginming his career from scratch. His parents had both strongly encouraged him to make this career change.

From the beginning of this career until his first MI, 17 years later, be continuously took courses, both mandatory and voluntary, and studied almost every night. Every weekend before an exam, Mr. A would study constantly, smoking heavily and having trouble sleeping. His hard work resulted in his becoming bank president at different small branch offices, a position he held for almost 14 years. Three years before his MI, at age 34 , the was promoted to his present position of vice president at a much larger branch office. This latter promotion implied a substantial increase in responsibility and workload. Mr. A. currently still works regularly at home at night.

Because he and his wife are both very much attached to the area where they grew up together, and because Mr. A. does not want to leave under any circumstances to seek career advancement elsewhere, his present career opportunities are rather limited. According to $\mathrm{Mr}$. A, his wife has always supported his career moves and is rather proud of his present position.

From the time of his last promotion until his MI, Mr. A. had gradually become exhausted, increasingly listless, and very irritable. He was no longer satisfied with his leisure time activities and no longer went on vacation.

4. Family \& Social Life. Mr. A. got married at age 25 , a year and a half after he began working with the bank and a few months before his father died. From the very beginning of his marriage, his wife suffered from severe allergies and, occasionally, from anxiety attacks, which became more serious after their daughter was born. At that time, Mr. A was 34 years old. His wife worked part-time throughout their marriage until their daughter was three years old and Mrs. A. began to fear that her working might severely affect her daughter's health.

Before their daughter was born, after eight years of matrimony, $\mathrm{Mr}$. and $\mathrm{Mrs} . \mathrm{A}$. had consciously decided to have only one child. Once their daughter was born, it unexpectedly appeared that she suffered from the same allergies as her mother. She has been under permanent medical surveillance ever since, something which, according to Mr. A, puts an unbearable strain on the family. Mrs. A. still suffers periodically from anxiety attacks in which she re-experiences her very complicated pregnancy and delivery. 
Mr. and Mrs. A. do not maintain very close contact with his brother or with her siblings; on both sides, family members merely tolerate each other at family affairs.

After their marriage, Mr. and Mrs. A. lived in the same neighborhood they did not want to leave, After commuting for almost three years to his present office, Mr. A and his family were compelled to move since his substantial travel reimbursements would be terminated. After their move, a few months before the MI, they began to realize that their new house, located as it was in a quiet neighborhood, was a definite improvement over where they used to live.

\section{Discussion.}

A. Adverse Living Conditions in Childhood and Adoleseence. In the life history of Mr. A., the unexpected adverse living conditions of his adolescence were due to his father's suddenly becoming disabled after a mining accident. This occurred at the beginning of the most prosperous period ever in the history of the Netherlands, at a time when a unique social security system was being created. Thus, the psychological and physical consequences of this event for Mr. A. may not have been as serious as they might have, had the event occurred a decade earlier.

Because, throughout his formative years, Mr. A's parents had actively encouraged him to lay the foundations for a materially better and different life than theirs (Le., one outside the coal miner "milieu"), even after his father had become disabled, this stimulating psychosocial climate, which both facilitated the pursuit of his subsequent career with such perseverance and gave him and his younger brother little room for contrasting opinions, may have contributed to his becoming a fully developed Type A1. Thus, despite somewhat adverse living conditions during his formative years, a stimulating psychological climate at home prevented Mr. A's psychosocial development from being adversely affected.

B. Work \& Career. Both "Voluntary search for other job(s)" and "Increased responsibility" occurred in the course of Mr. A's career, the former when be decided to begin working for the bank and the latter when he was promoted to vice president of one of its large branch offices. Mr. A.'s being a fully developed Type A1, and the work attitude and job involvement that this construct implies, may have facilitated his achieving this latter goal. 
As noted earlier, both of the above-mentioned SLE are associated with a significantly elevated risk for first $\mathrm{MI}$, but only in the age group to which Mr. A. belongs. It is questionable, however, whether these particular events actually played a major role in the onset of his MI. While "Continuing education to improve one's position", as such, does not occur more often in MI-cases than in referents, it is perhaps more likely that the antecedent "chronic" burden of studying every night, and many weekends, for almost fourteen years contributed more directly and substantially to $\mathrm{Mr}$. A"s coronary event than the reported increase in responsibility.

One of the other two discriminating events in "Work \& Career" - "Prospects for promotion (unrealizedy" - might also have played an important role here. That is, due to his and his wife'semotional bonds with the area in which they had lived all of their lives, it would be very difficult, if not impossible, for Mr. A. to ever become bank president of a larger branch office in the same area, although he would certainly qualify for such a position. Mr. A.'s awareness of this, once he had reached his present position, mid have constantly overshadowed his past achievements.

Thus, Mr. A."s career was characterized by continuous striving for achievement, on the one hand, and by an apparent lack of future prospects once his present position had been realized, on the other.

C. Family \& Social Life. Mr. A. was 38 when he suffered his first MI. At that time, his onlly daughter was four years old. Thus, only a few of the SLE included in "Family \& Social Life" could have possibly occurred in the life of Mr. A. "Prolonged/serious illness of child" (i.e., his daughter's allergies) was one that did and constituted a burden for him and his wife from the moment his daughter was born. Having to cope with this chronic situation $\mathrm{w}_{\mathrm{w}}$ which, according to the physicians, would not likely improve, must have been difficult enough. This psychological burden was compounded by Mr. A. and his wife"s deliberately having postponed having their only child until such time as they felt they could really care for her (i.e., among other things, after Mr. A. had completed all of his studies). The only other family-related SLE that Mr. A. experienced was related to the first one, namely, his wife's unrelenting allergies and her periodic anxiety attacks primarily centering around her daughter. 
Thus, Mr. A.s family life was largely influenced by the double burden of chronic lliness of his wife and, in particular, of his only child. These events occurred in an early phase of adult development not normally characterized by such extraordinary occurrences. Having to constantly cope with a spouse"s illness in this phase of life may be said to represent an "off-time" event, whereas chronic illiness in a young child constitutes a rare, though not necessarily "off-time", event.

B. Biography 2: $M r . B$.

1. General Information: Mr. B. suffered his first Mr at age 53. At the time, he had been collecting disability compensation for almost two years. He was permanently overstrained, a condition for which he had to take rather heavy sedatives. Before his breakdown, he had been one of the chief operators in the electrocoating department of an automobile factory. He was married and had two sons. He was assessed as being Type A1, and his score on the MQ was 34 - two standard deviations higher than the mean score for MI-cases. .

2. Childhood \& Adolescence: Mr. B. was the fifth child in a family of thirteen and was born at the beginning of the Great Depression. At that time, his father had irregular work as a handyman and often became unemployed. During World War $\mathrm{H}$, hils father did forced labor in Germany and afterwards was employed as a bath house attendant in a coal mine. The family"s living conditions during Mr. B.'s childhood were very precarious, although he could not remember the effects on his personal life very clearly. He did vividly recall, however, that at ages 5 and 6 he had to be hospitalized a few times because of diphteria, a broken leg, and several eye operations. Those were the few occasions on which he was able to eat well and plentifully.

Beginning at age 12, while he was still in grade school, he worked two afternoons per week helping a greengrocer, which be enjoyed doing, in order to earn some desperately needed money to help support the family and to bring home free fresh vegetables. He would soon find himself spending most of his time there. About half a year before he would thave finished grade school, at age 13, he began working full-time. This coincided with the first year of the German occupation of the Netherlands during World War II, when the school hours that he was supposed to attend had become limited. 
3. Work \& Career: Mr. B.'s career was rather varied. During the war years, which, in the southern part of the Nietherlands ended in the fall of 1944 , he worked for the greengrocer and for other merchants. Immediately after the war had ended, he, like so many other adolescents, was called upon to help restore the many towns and villages in the South demolished during the skirmishes in the fall of that year. Then, after working a short time as a handyman at a building construction company, which he left after a conflict about social security premiums, and a score of other very shortlived jobs, he returned to his "old" job, where he also became repeatedly involved in several social conflicts. (During the interview, Mr. B. asserted that he always quit as soon as be could, once he found out that his rights as a laborer had been infringed upon).

When be got married five years later, at age $25, \mathrm{Mr}$. B. decided the time had come to become a coal miner, the best source of high and steady income from manual labor in the Netherlands at that time. There he worked for almost 14 years, following the regular career pattern, without any major conflicts with his superiors. The only exception was one time when he attacked, and injured; a supervisor who had slighted him.

In 1967, at age 39, Mr. B. was confronted with the most difficult decision of his career. Should he remain at the coal mine, which was scheduled to be closed in 1975, and then retire early with a good pension; or should he accept one of the three opportunities that would be offered to "young" miners to begin a different, well-paying career, on top of the basic income and social benefits that he had accumulated as a coal miner? He chose the latter, accepting the first opportunity offered. He was retrained to become an assembly-line worker at a new automobile factory that had been set up in the area in order to provide new jobs for former miners, using ample government subsidies. Mr. B., like every other former miner who accepted this offer, began working three shifts as he had been accustomed to doing in the mines. He was soon promoted to foreman on the day shift, which meant a considerable increase in responsibility.

In the beginning, Mr. B. had a very hard time adapting to this entirely new work enwironment. The close collaboration and comradeship he had so long experienced, and so much enjoyed, in the mines was replaced by fast-paced, independent, piece- 
meal work. When, in 1972, the originally Dutch factory was taken over by a foreign car manufacturer, several reorganizations were carried out in which most of the former coal miners were dismissed. Mr. B. resisted an attempt to be declared medically disabled and, soon after, at age 45 , became chief operator of the newly erected electrocoating department, where about twenty coats of primers and paints are applied to the car's body by very complicated electrochemical processes.

After this promotion, this highly responsible job kept Mr. B. on the go, day and night, seven days a week, for almost two years, until another chief operator was finally appointed to assist him. It took constant arguing with his superiors to finally persuade them that his work involved too much responsibility for one person alone. As he asserted during the interview, this had been the most difficult period in his life because he did not have a free moment for himself or for his family. For the entire six years he held this position, Mr. B. worked overtime during the week and worked irregular hours during the weekends because, as he asserted, he was considered to be the only able worker in the entire factory who really had any idea of how to properly and safely operate the equipment in his department. During that period, and until his MI; he was not able to sleep without a heavy dose of sleeping pills.

At age 51, Mr. B. became seriously overstrained and was temporarily declared work-disabled, a condition that lasted for almost two years. Three months before he would have received final confirmation of his $100 \%$ work-disabled status, which would have made it impossible for him to resume any kind of work at the factory, Mr. B suffered his first MI.

When he was interviewed, two months after his coronary event, he was still very much upset that none of his former supervisors had; in any way, acknowledged his plight. During the previous two years, he had only once received a birthday card from any of them.

4. Family \& Social Life: Mr. B. got married at age 25. His first son was born a year later and his second son, four years after the first. His family life had always been rather happy and very satisfying, according to Mr. B. There had been no major illnesses or educational problems with his children, except for his younger son's frequent absence from high school, which he later dropped out of completely. In order to keep 
close surveillance on this son, Mr. B. fownd him a job at the car factory, where his son still works.

Throughout his marriage, Mr. B. lived with an extended family, in one way or another, for prolonged periods of time. For the first five years of his marriage, until age 29 , he and his wife lived with her parents. When his wife's father died, her mother came to live with them for several years. During the last five years prior to his MI, after his oldest son had gotten married, his son and daughter-in-law came to live with Mr. B. and his wife. In order to facilitate this, Mr. B. almost single-handedly rebuilt his large house in such a manner that both families could live separately and yet spend as much time together as they wanted to. However, he had to raise his mortgage, some-

thing which Mr. B. did not consider a problem at all. He accomplished this on top of his already heavy workload and in spite of his sleeping problems.

The emotional bonds within his extended family had always been rather intense. It therefore came as a very severe blow to him when his mother died in 1969 and the regular family gatherings became less frequent. As Mr. B. asserted, his mother "...was the binding force in my life; after she died, the bottom fell out". During the

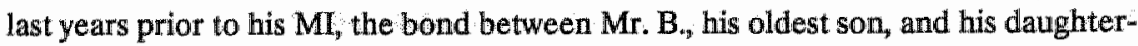
in-law had become very strong, sometimes too close for comfort. When his daughterin-law learned that he had suffered an MI, she was so shocked that she prematurely delivered the baby she was expecting.

From the time Mr. B. became disabled at age 50 and was forced to spend most of his time at home until his MI, many members of his family, former friends from the coal mines and the car factory, and neighbors became severely ill or developed severe health problems. He became more and more worried that the same things would happen to him.

\section{Discussion.}

A. Adverse Luing Conditions In Childhood And Adolescence. The physical and psychological hardships during the formative years of Mr. B.'s life were a result of his father's repeatedly becoming unemployed, like so many others, during the Great Depression. These adverse living conditions may, therefore, represent a particular cohort effect that influenced the life histories of $\mathrm{Mr}$. B. and most of his contemporaries 
to some extent, just as the booming economic conditions that prevalled during $\mathrm{Mr}$. A's formative years - another cohort effect - provided the background for his psychosocial development. A more direct, adverse personal consequence of these hardships may have been that $\mathrm{Mr}$. B. never got the chance to complete his primary education because he was needed to help support his large family when he was still a chill. Had he been able to complete primary school, his psychosocial development during adolescence and beyond may have prepared him to cope better with the hardships that were to follow in his career.

Thus, early exposure to hard work, which was necessary in order for him to survive, and the lack of a proper education in childhood and adolescence may have contributed both to his becoming a fully developed Type A1 and to the particular work ethos and sense of justice that would characterize Mr. B. in his many, and very different, jobs.

B. Work \& Career. "Voluntary search for other job(s)" and "Increased responsibility" occurred several times in very different phases of Mr. B.'s career. First, his constantly changing lines of work in the beginning of his career, when he was still single, was usually brought about by repeated conflicts at work. Whenever he felt betrayed by being underpaid for overwork or irregular working hours, something which would affect his social security compensation in case he would become ill, while he had put in more than his fair share of work, he would quit right away, provided he could find other employment. This happened quite a number of times, with the result that he often changed employers. It is conceivable that his being a fully developed Type A1 was instrumental in his becoming involved in these conflicts, on the one hand, and in his remaining faithful to his own high work morale, on the other.

Once $\mathrm{Mr}$. B. got married and began to feel responsible for providing his family with a decent, steady income, he no longer made these frequent, sudden occupational changes. Instead, Mr. B. learned to assert himself and to fight - and usually win - the same type of occupational battles he had walked out on in the past. This recently acquired behavior may have reinforced the "hostility" component of the everyday Type A behavior that he so often displayed during those conflicts. The only other time that Mr. B. changed to an entirely different line of work after his marriage, from being a coal miner to becoming an assembly-line worker in an automobile factory, occurred 
because of the impending shutdown of all the coal mines in the area. His concern about how he would be able to continue to provide his family with an ample income in a responsible way and still retain the social security benefits from his former job made him. decide to immediately accept the first job that was offered him.

Second, the considerable increase in responsibility that was passed on to $\mathrm{Mr}$. B. at a relatively late phase in his career was an almost immediate consequence of his transfer to the automobile factory, which he made of necessity rather than entirely of his own accord. There, he soon became chief operator of a newly established department. Mr. B. had an extremely difficult time dealing with this responsibility from the day he was promoted until he became disabled several years later. The perseverance he had always demonstrated in these matters, which was most probably associated with his TABP, may have helped him in what was a truly exhausting struggle with responsibility for such a long time. At the same time, however, Mr. B. developed chronic sleeping problems and became seriously overworked. During this most difficult period in his life, Mr. B. also had to fight almost continuously with his superiors to have his responsibility acknowledged as being too large, to have them finally appoint another chief operator to share his responsibilities, and to reduce his wrorking hours.

Finally, the ewent "Work place closed down" did not actually occur in the biography of Mr. B.. However, the impending shutdown of the mine in which he earned his living caused Mr. B. to make a rather sudden, though not totally unexpected, change in his career, one which was both unforeseen at the time he began working there and probably also conducive to the MI he suffered several years later. Thus, Mr. B.'s deliberate attempt to avoid a predictable event may still have influenced his subsequent life history.

In sum, Mr. B."s career was characterized by frequent job changes, both voluntarily, at the beginining of his career, and more or less involuntarilly, later on. In the latter instance, this crucial event was followed by a considerable increase in responsibility which, in retrospect, may have been too much of a psychologic and physical burden. Finally, after Mr. B. was declared no longer fit to work, he still identified very much with his last job and became very disappointed by his former superiors' and colleagues' almost total neglect prior to his MI. 
C. Family \& Social Life. One of the earliest SLE in Mr. B.'s family ife offers an interesting illustration of how one and the same prolonged situation can occur in different contexts and in different episodes of one's life-history.

First, right after getting married, Mr. B. and his wife, and later their first son, liwed with his in-laws for several years. This particular event represents another cohort effect since, in the post-w ar years, there was a severe housing shortage in the Netherlands and it was quite common for newlyweds to live with their parents. Second, after his father-in-law died, his mother-in-law came to live with them for several years. "Third, when his oldest son got married, his son and daughter-in-law came to live with them and deweloped a close emotional bond with Mr. $B_{\text {* }}$

Although Mr. B. asserted that he had always felt perfectly happy living with an extended family, this situation may have, nevertheless, been an additional burden for him. For example, in order to accommodate his son's family, he almost single-handedly rebuilt his large house. In order to do this, he had to raise his mortgage, which created some temporary financial problems for him but which he clearly did not mind.

Earlier in the history of his family, Mr. B. had to cope with his other son's serious educational problems that ultimately resulted in bis dropping out of vocational training. This event coincided with the thorough reorganization of the automobile factory where Mr. B. worked, brought on by its foreign takeover. In addition, it may be thought that Mr. B.'s repeatedly being overworked constituted another continual, and less easy to cope with, psychological burden, both for him and his family.

In sum, Mr. B.'s family and social life were always characterized by close emotional bonds with family members and by intense concern with their well-being. He may have felt that he did not receive as much emotional and social support as he had expected to get in return when Mr. B. needed it the most (i.e., when he had to cope with the inevitable prospect of becoming permanently work disabled). On the other hand, he may, in fact, have received adequate support but, being a fully developed Type A1, falled to perceive it as such. Instead, he may bave blamed himself primarily for not being able to gain this much-needed support (Glass \& Caryer, 1980; Matthews \& Glass, 1984). In either case, this may have lead to his becoming "vitally exhausted".

Although these particular events were all independently associated with elevated risk for first MI, in general, it may be thought that their apparent interconnec- 
tions, both at the time they actually occurred and long afterwards, brought about a much larger risik than that incurred with any single SLE in the family and social hife of Mr. B.

\section{Biography 3: Mr. C.}

1. General Information: Mr. C. suffered his first MI at age 63. Five years earlier, he had been declared work-disabled. Before that time, he had worked as chief administrator in one of the departments of the provincial head office of the national postal and telephone company. He had been a widower for twelve years and had a 19-year old son. He was assessed as Type B4 and his score on the MQ was the highest of all participating MI-cases (i.e., 41 , almost the maximum possible score).

2. Childhood \& Adolescence: Mr. C. was the youngest of three children. He grew up in a family that sometimes had severe problems making ends meet, but in which there was no real poverty. His mother died after being seriously ill for three years; $\mathrm{Mr}$. C. was 11 years old at the time. As Mr. C. himself asserted, he felt lonely ever since. His father, who worked abroad, was seldom home, with the result that he had become very attached to his mother. After this rather unexpected event, Mr. C.'s older sister tried to take over the mother's role in the household. Five years later, in 1934, his father became unemployed. It had become impossible for him, as a Dutch citizen, to carry on the business he conducted in neighboring Germany after the Nazi takeover of 1933. Two years later, when he was $18, \mathrm{Mr}$. C.'s father suddenly died, leaving the siblings in desperate financial circimstances.

Mr. C. was brought to the home of a childless relative of his father's, who was rather wealthy. He established a very close and lasting emotional bond with his uncle and aunt. However, this relationship was disrupted unexpectedly when both his uncle and aunt died shortly after each other when Mr. C. was 32 years old. Mr. C. had been living with them while commuting back and forth to the various offices in the area where he worked.

3. Work \& Career: Mr. C. graduated from high school at age 16, at the peak of the Great Depression. Since his father had recently become unemployed, he was very glad to find some work with an accountancy firm, even though it paid very poorly. Soon after, however, he was fired due to "poor performance", an ominous verdict he would 
bear quite often in the course of his career. After leaving another short-lived clerical job of his own accord, he was accepted by the national postal and telephone company as a trainee. For a number of years, he studied incessantly to obtain the necessary llcenses that would open up the higher hierarchical ranks for him. He finally became fully employed at age 22 , during the first year of the German occupation during World War II. During the war and afterwards, he worked in most of the local branch offices in and around his home town, where he lived with his uncle and aunt for 11 years until they died. After these sudden losses, he became severely overstrained, got serious stomach problems, and had to be operated on several times for gastric ulcers.

"...In order to begin a new life", Mr. C. requested to be transferred to a larger branch office elsewhere in the South. There, however, he "...would become crushed for the rest of his life" by ever-mounting conflicts with superiors about his allegedly poor performance and, later, mainly with colleagues and subordinates about his turbullent family life. Yet, Mr. C. continued working there until age 47 . Contrary to all the advice he had received, and mainly to prove to himself that he could accomplish something important; but also to spite his superiors and colleagues, he embarked upon a challenging five-year night course to further his career. He was told repeatedly that this would ultimately bring him atruly leading position. After seven years, at age 49 , Mr. C. passed the final qualifying examination. His studies were, however, interrupted by a transfer, requested by Mr. C., to the provincial head office because of serious problems in his marriage and because of his colleagues' reactions to these problems (see below). The long-awaited promotion, however, never materialized. As a result, Mr. C. became increasingly estranged from his colleagues and grew embittered because of the many petty battles fought over his rather substantial responsibilities. He became overworked for the first time at age 52 and again, but more seriously, three years later At age 58, he was declared $100 \%$ work-disabled and as a consequence, Mr. C. had to give up his job. Mr. C. asserted that he had never liked the work he did, although he had been a dedicated worker. He would much rather have become a journalist; however, he accomplished nothing more than writing a few columns in the organization's monthly newsletter. 
4. Family \& Social Life: After his uncle and aunt had died, Mr. C. came to rely solely on his older sister for emotional support. She, however, died quite unexpectedly five years llater, at the age of 40 . Mr. C. was 38 at the time. As be later asserted, in order to escape from loneliness and depression, $\mathrm{Mr}$. C. got married four years later and became father to his only son the following year.

Almost right from the beginning, the marriage proved to be disastrous, due to incessant petty arguments and major fights, mostly brought on by his wife. After two years of marriage, when his son was one year old, Mr. C. was told the reason for his wife's behavior: she was diagnosed as having an untreatable brain tumor and her physicians had completely given up on her. Mr. C.'s wife survived another seven years, but her behavior became increasingly aggressive, abusive towards herself and her family, and destructive. During these years, Mr. C. tried very hard to maintain his sense of integrity and sanity and to foster normal psychosocial and emotional development for his son as best he could. He also took his night studies very seriously.

During the last years of Mr. C.'s marriage, his family moved to a different city, in the hope that it might help his wife"s condition. It was there that Mr. C. finally passed his examination, but failed to get the promised promotion. As a result, Mr. C. became totally demoralized. About one year before his wife's death, Mr. C. considered filing for divorce, as his physician and the mental health counselors he had been consulting had been urging him to do, because he could no longer cope with his domestic situation. However, this posed such a serious moral dilemma that he decided to continue caring for his terminally ill wife for as long as he thought he could. Because of her rapidly deteriorating mental condition, his wife was finally admitted to a psychiatric hospital, where she died several months later. Unable to show any kind of enotion after this event, despite intensive psychotherapy, Mr. C. ultimately became overstrained. This occurred after first suffering a sudden nervous breakdown, about a year later, something which would occur again three years later.

In the years both prior to and following his wife's death, Mr. C. received professional help from a family home aide in order to care for bimself and for his son. The latter, although considered an "urgent" case, still had to wait several years before he could finally enter boarding school, about a month before his mother died. He remained there four years, until the end of grade school. Mr. C.'s son then began to develop 
severe emotional problems. Although his son's achievements in high school and vocational training were surprisingly good, $\mathrm{Mr} . \mathrm{C}_{\text {. }}$ was very concerned about his future. The reason was that just before $\mathrm{Mr}$. C." $\mathrm{M}$ M it was discovered that his son would most probably suffer from a similar form of brain damage as that which had afflicted his wife:

It comes as no surprise, then, that $\mathrm{Mr} . \mathrm{C}_{\text {, }}$ at the very beginning of the first interview, described himself as "...an absolute failure, trapped in perpetual social isolation, leading a life in which there is no hope, no future, no sun, but only a never-ending, uniform gray".

\section{Discussion.}

A. Adverse Living Conditions in Childhood and Adolescence. The Great Depression may have played a similar role in the life of $\mathrm{Mr}$. C. as it did in that of $\mathrm{Mr}_{\text {. }} \mathrm{B}$. since, in both cases, their fathers became unemployed. In Mr. C.'s case, his father was initially self-employed abroad and, thus, seldom home. He was brought up almost entirely by his mother, who died prematurely when he was in his early teens, and by his older sister. Three years later, his father also died unexpectedly. These events clearly occurred "off-time" and in a rather vulnerable phase of Mr. C.'s psychosocial development:

It is likely that these circumstances contributed to Mr. C.'s never having had an adequate male role model to identify with. Moreover, in his case, this accumulation of adverse living conditions may have resulted in his becoming Type $B$ (he was assessed as Type B4).

In sum, during Mr. C.'s formative years, a number of particularly adverse "offtime $e^{\text {"l }}$ events occurred, in addition to the more general cohort effect of parental unemployment that may have influenced his subsequent psychosocial development to a substantial extent, rendering him vulnerable to the consequences of unexpected and uncontrollable SLE in his future life history.

B. Work \& Career. In the biography of Mr. C., "Voluntary search for other job(s)" and "Increased responsibility" occurred several times and in different contexts.

First, after Mr. C. finally got married, he changed jobs, of his own accord, in order to preserve some kind of family life, something that had become impossible in the 
city where he, his wife, and their newborn son originally lived. His transfer to the provincial head office, however, did not work out at all the way he had expected it to.

Second, although he was promoted periodically, with some increase in respons-iblity, the major promotion that $\mathrm{Mr} . \mathrm{C}$. had been striving for so consciously and in which he had invested seven years of his life under wery difficult familial circumstances never materialized. Thus, in his case, the increasingly embittering and lasting consequences of another discriminating SLE in "Work \& Career", namely, "Prospects for promotion (unrealized)", also contributed to his $\mathrm{Mr}$ several years later.

Thus, the public service career of Mr. C., while not particularly outstanding, was characterized by a steady, conscious striving for promotions and increased responsibility. Yet, this goal was never fully achieved, leaving Mr. C. embittered and disillusioned before being declared work-disabled

C. Family \& Social Life. All of the discriminating events in "Family \& Social Lufe" occurred in the life history of Mr. C. (cf. Table 7.1.), most of them chronically. That 15, he lived with members of his extended family, (i.e., his uncle and aunt) during the last part of his adolescence and in early adulthood after both of his parents died; this occurred "off-time". He also had to cope with the chronic illness of his wife, something which posed insurmountable psychological problems.

After the rather unexpected deaths of his uncle and aunt and, later, of his sister, $\mathrm{Mr} . \mathrm{C}$, in order to escape loneliness and depression, got married, at age 42. This may have constituted another important "off-time" event that contributed to a disequilibrium between his work and family life. However, instead of the much longed-for emotional and social support, he "...got trapped inside an inferno".

Throughout his marriage, Mr. C. had serious, and mostly chronic, maritall conflicts which, over the years, increased in intensity. They became even more of a burden, and may have been experienced as inescapable, because of the fact that Mr. C.'s wife could not be held accountable for her aggressive behavior, due to her illness. It may be thought that, for $\mathrm{Mr}_{\text {, }} \mathrm{C}$, his wife's incurable illness, her gradually deteriorating condition, and their aggravating conflicts became inseparable. Although Mr. C. was, for his own well-being, urged by his physician and mental health counsellors to get a divorce, he felt that doing so would be a betrayal of his wifes and only chill's confidence. 
At the same time that he was struggling with these chronic conflicts, Mr. C. had to fulfill the domestic roles that a wife normally does. That is, he had to take primary responsibility for his son's education and for guiding hïs psychosociall and emotional development, while also working full-time during the day and studying as much as he could at night. Because of his wife's condition, which demanded constant medical care,

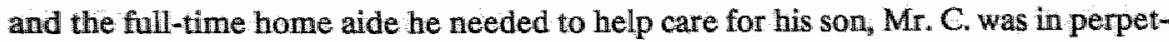
ual financial need. This latter circumstance also continued after his wife's tragic death, since Mr. C. had to partly finance his son's special education program in boarding. school.

$\mathrm{Mr}$. C. suffered at least one major nervous breakdown after his wife's death. Yet another source of aggravation, related to his $\mathrm{MI}$, was the fact that $\mathrm{Mr}$. C. had originally been diagnosed as suffering from acute stomach problems, most probably due to an acute gastric ulcer. According to his family physician, Mr. C. had been able to cope with all of his past stress so successfuilly that he could not conceivably have had an MI!.

In sum, the family and social life of Mr. C. was almost entirely determined by the adwerse and chronic events that occurred in his marriage. Moreover, it is apparent that those events are all intricately interconnected in such a way that it becomes almost impossible, in retrospect, to separate them or to say precisely which event may have lead to which other situation.

\section{Occurrence and Psychollogicall Impact of Reported Stressful Life Events} over the Life-Span of Three Cases with First Myocardial Infaretion: Some Similarities and Differences.

\section{A.t. Adverse Living Conditions in Childhaod and Adolescence.}

In all three biographies, adverse living conditions during childhood and/or adolescence, in particular "Prolonged financial problems", strongly influenced the course of these cases' future lives (cf. Table 7.1.).

It is difficult to compare the physical hardships that Mr. A. faced during his adolescence with those that occurred during Mr. B.'s formative years $s_{i}$ the latter being 15 years older. These, in turn, differ substantially from the prevailing conditions that caused the Depression hardships in the life of Mr. C., who is 25 years Mr. A.'s and 10 
years Mr. B.'s senior. However, in all three cases, the psychological climate during the formative years left quite lasting, albeit different, impressions on their subsequent lives. That is, the SLE referred to here under the general heading "adverse living conditions during childhood and adolescence" appeared to have different consequences for the three cases. For Mr. A. they seem to have stimulated his subsequent psychosocial development, for $\mathrm{Mr}$. B. they appeared not to be disadvantageous, while for Mr. C. they were probably harmful. Therefore, future research into the actual effects of such "adverse living conditions" should assess and appraise them rather carefully in terms of their effects on subsequent psychosocial development.

Finally, it should be mentioned that adverse living conditions during the formative years may influence future sex role orientation, which is an important aspect of TABP, in different manners (De Gregorio \& Carver, 1980). That is, both Mr. A. and B. were assessed as "fully developed Type A1", while Mr. C. was characterized as "Type B4". A similar finding, but without the explicit referral to TABP, has been reported from American longitudinal research about the psychological and social consequences of hardship during the Great Depression (Elder, 1979; Elder \& Rockwell, 1979). That is, it was demonstrated in this comparative study that adolescent boys found it more and more difficult to identify with their fathers' various roles the longer the latter had been unemployed and the more marital discord was associated with this event. This role uncertainty may also be characteristic of subsequent developmental phases.

\section{A.2. Work \& Career.}

Three of the four SLE that discriminated significantly between MI-cases and referents occurred in one way or another in the three biographies reported here (cf. Table 7.1.). Once again, however, they occurred in quite different psychosocial contexts with varying frequencies and in a different order.

First, in all bilograplies, "Voluntary search for other job(s)" occurred more than once, although in different contexts and at very different stages in their occupational careers.

Second, the three cases assumed "Increased responsibility" at vastly different moments in their careers and at different distances from MI. For example, in the career of $\mathrm{Mr}$. A., his formal responsibility at work increased considerably after he had be- 
come vice president. However, this occurred after he had been in banking for fourteen years with gradually increasing responsibilities similar to those in his new position. In the life of Mr. B., by contrast, this pattern was almost completely reversed. It took him years to have responsibilities that were once suddenly thrust upon him formally acknowledged.

Third, "Prospects for promotion (unrealized)" only actually occurred in the occupational life of $\mathrm{Mr}$. $\mathrm{C}$, although this particular event may also have influenced the career prospects of Mr. A.

Finally, it should be mentioned that "Work place closed down" never actually occurred in any of the three biographies. Yet, in the case of Mr. B, this impending event caused him to change his career.

In sum, future research should analyze in much more detail the intricate interconnections and the particular order of work and career-related events, which are independently associated with elevated risk for first $\mathrm{MI}$, in order to understand the actual impact of these events on a person"s life. In such analyses, the possible consequences of events that did not occur, like "Work place closed down", but that still may have influenced a person's subsequent career should not be excluded a priori. The equally important question of whether such events as "Voluntary search for other job(s) and "Increased responsibility", which showed a positive association within the youngest age group only, may have a different meaning and impact when they occur "on-time" or "off-time" will be discussed later.

\section{A.3. Events in Family \& Social Life.}

In contrast to the SLE reported in "Work \& Career", those in "Family \& Social Life" that were positively and significantly associated with first MI (cf. Table 7.1.) were reported more often as the cases grew older. The reason for this may be that events associated with starting and raising a family occur at relatively well-defined periods in adult development and generally follow patterns that are more fixed than those from the work and career trajectory that may be much more influenced by environmental factors. The latter was demonstrated by the life histories of $\mathrm{Mr}$. B. and Mr. C. Thus, the gradual accumulation of, and the increasingly complex interconnections between, family and social life-related events may be more readily observed. 
Mr. A. was 38 when he suffered his first MI; at that time, his only daughter was four years old. Thus, only a limited number of the events that confronted Mr. B. and Mr. C could have happened to Mr. A.

The discriminating events in the family life of Mr. B. were all different in nature from those in the life of Mr. A. Some of them were due to a particular cohort effect, namely, "Living with extended family". Furthermore, they were associated with "Prolonged educational problems" with one of his children, something that could not have occurred yet in the family life of Mr. A.

In the life history of Mr. C., all of the discriminating events in "Family \& Social Life $^{\mathrm{n}}$ occurred (cf. Table 7.1.) and most of them were chronic. Like Mr. B., he lived with members of his extended family (his uncle and aunt) during the last part of adolescence and early adultitood, but for entirely different reasons. Unlike Mr. B. but similar to Mr. A, Mr. C. had to cope with his wife's chronic illness, from which she eventually died; this illness may have influenced his marital life to a much more serious extent than that of Mr. A.

In sum, it is apparent that the events regarding family and social life in this last biography are even more intricately interconnected than those in the life of Mr. B., so much so that it is almost impossible, in retrospect, to separate them or to say which event may have led to what other situations.

\section{B. Summary \& Conclusions.}

When the results from these qualitative analyses, summarized in Table 7.1., are compared to the quantitative analyses on the aggregate data of Tables 5.6. and 5.7, several interesting differences become evident.

First the gradual accumulation over the life-span of SLE associated with first MI can be seen much more clearly in the individual biographies than in the aggregate data. This was depicted in Table 7.1, in which the accumulation, with age, of SLE in "Family \& Social Life" stands out.

Second, it is apparent from these three life histories that the psychosocial and environmental contexts in which these events occurred differ greatly between the three age groups. This may also be the case within these strata, although this could not be demonstrated here. 
Third, it has become clear that severall different sequences of the same events may lead to the same outcome, namely, first MI, in different phases of the adult lifespan. In other words, there is no single, wniversal constellation of SLE that leads to the endpoint under study, but there may be a wast array of different pathways, conditional upon age-group membership. It should be remembered in this context that in these biographical analyses only those ewents were included that discriminated positively in the multiple logistic regression analyses. This implies that the variety within these constellations of SLE may only become greater when the discriminating events from the untvariate analyses are also considered. For example, "Prollonged overtime" was reported to have occurred at least once in the careers of all three cases.

Fourth, the psychological impact of one and the same discriminating event proved, at times, to be rather different for the three cases. However, it is hard to infer from the reported biographies whether these differences in impact are associated in any systematic manner with age and/or TABP. In some instances (e.g., "Increased responsibility"', reported by Mr. A. and Mr. B.) this, most probably, was the case. This particular event did not, however, generally discriminate between Type A and Type B subjects.

Fifth, it was Hllustrated in the biography of Mr. B. that an event that did not actually occur but was in due time anticipated, acted upon, and, thereby, avoided (i.e., the impending closing of a coal mine), may still have played a crucial role in the individual's subsequent psychosocial development, ultimately leading to first $\mathrm{MI}$.

Finally, these biographies shed light on the role of particular age-related events in the various sequences that may lead to first MI. That is, some SLE in "Work \& Career" and, in particular, "Family \& Social Life", although positively associated with risk for first MI in only one of the age groups, also played an important role, sometimes with a much stronger impact, at other ages in the histories of subjects who suffered their MI at a later phase in their \ife.

One interpretation of this particular finding may be that because in the remaining age groups these events occurred about equally in cases and referents alike, the psychologicall impact and long-term consequences of these events proved to be more important than the actual occurrence of the events themselves, assuming that occurrence and impact of an event can be meaningfully distinguished. Such an analysis 
would, however, tequire other ways of examining and comparing the impact and consequences of SLE among MI-cases and referents.

A different interpretation of this "timing effect" might be that these particular events represent situations that may occur either "on-time" or "off-time" during the adult life-span, as opposed to other SLE that have no special association with age (Neugarten \& Datan, 1973). In the case of "off-time" occurrence, then, these events might represent an elevated risk, while with "on-time" occurrence they would not. Further analysis of this intrigung possibility would require taking into account the historical time at which these events occurred, as well as their chronological distance from the coronary event, something which was not included in the present analyses.

\subsection{The Life-Span Development of Cases with First Myocardial Infarction and Buhler's Theory of "Self-Determination".}

In Chapter 1 it was said that a continuous process of personal striving for psychic integration and fulfillment throughout the life-span constitutes the basic dimension of the teleological model propounded by Charlotte Bühler. In essence, the outcome should be that a healthy person experiences his or her entire life as a meaningful unit, as possessing a well-defined inner coherence that can be thought of as a normative developmental structure or, in other words, as a psychologically gratifying life structure that every individual continually strives for (Buihler, 1968). This personal striving is brought about by qualitatively different series of psychollogical patterns of "self-determination" that lead either to the aspired goal or to partial or complete failure, depending on the amount and types of conflicts an individual encounters throughout the life course and on the ways in which these idiosyncratic "developmental tasks" [Lebensaufgaben] are resolved (Büh]er, 1959; cf. also Havighurst, 1973).

According to Bulhler's theoretical model, "self-determination" throughout the life-span can be achieved by means of four different motivational and developmental processes: "creative expansion" [schöpferische Expansion] in the formative years, "selflimiting adaptation" [adaptive Selbstbeschränkung] in adulthood and old age, "upholding internal order" [Aufrechterhaltung der inneren Ordnung] throughout the life-span and, finally, "need satisfaction" [Bedurrnisbefriedigung] throughout one's life. In the 
final analysis, the psychological outcome of each developmental phase is largely dependent upon the particular constellation of psychological processes that determine whether "self-determination" may have been achieved in antecedent developmental phases. In other words, if, for example, "internal order" could not be sufficiently established in adolescence due to adverse SLE that occurred in childhood, it may be much harder to achieve - and maintain - an optimal, internal, mental and physical equilibrium, something which is necessary to cope successfully with the "developmental tasks" throughout the various stages of adulthood. It may no longer even be possible at all to achieve this necessary order. When this theoretical reasoning, which may provide an interesting and promising heuristic framework for interpreting the present results from a life-span developmental perspective, is applied to the individual dynamics that were discovered in the three life histories of MI-cases presented above, the following observations can be made.

\section{A. "Creative Expansion" and "Self-Determination".}

According to the Bühler model, "creative expansion" constitutes the governing developmental and motivational principle in the formative phases of childhood and adolescence. This is superseded by the principle of "self-limiting adaptation" when an individual enters the first phase of adulthood.

The adverse living conditions that prevailed during the child hood and/or adolescence of the three MI-cases, which were primarily associated with "Prolonged financial problems" as a consequence of "Prolonged unemployment (father)", may have influenced the cognitive and/or the emotional capabilities of these cases to fully achieve "creative expansion" to different extents during their formative years.

These conditions, virtually inescapable, may have had the most serious consequences on Mr. C.'s subsequent psychosocial development, due to his prolonged, intensive exposure to them and, most probably, to a lack of opportunities to properly identify with his father, who died at an early age. For Mr. B., the possibilities for achieving "creative expansion" may also have been severelly influenced by the stark living conditions in an otherwise well-adjusted family. For Mr. A., who experienced these adwerse conditions relatively late in his formative years and only to a moderate extent, 
the actual consequences for his subsequent development were comparatively few, due to a stimulating, compensatory familial environment.

In sum, adverse living conditions in the early phases of psychosocial development may have exerted a negative influence on the ability of these MI-cases to cope in a creative, meaningful, and satisfactory manner with the everyday demands of family, social, and working life that they were to encounter in adulthood.

To generalize from these case histories, it may be hypothesized that male subjects who, during their formative years, lack opportunities for "creative (self) expansion" with respect to the "developmental tasks" confronting them will find it difficult to achieve optimal psychosocial "self-determination" during adulthood, this impaired"creative (self) expansion" may be associated with an elevated risk for first MI in adulthood.

A preliminary test of this hypothesis may be found in the biographies presented here. In all three cases, it was observed that "Increased responsibility" in adulthood and the different constellations of events associated with it, either before or after its actual occurrence, posed major problems with respect to subsequent psychosocial adjustment. It may be thought, following the Bühler model, that in normative psychosocial development (ie, without the occurrence of prollonged adverse living conditions in the formative years), this particular event positively contributes to one's "self-determination", given the crucial role of work and achievement as the most intimate part of the identity of male adults in contemporary society (Miernyk, 1975; Jahoda, 1982). In these three cases, however, this event primarily engendered serious conflicts at work that were sometimes associated with persistent mental and physical health problems.

\section{B. "Self-Limiting Adaptation" and "Self-Determination".}

As noted above, the Bühler model considers "self-limiting adaptation" to be a necessary means for achieving "self-determination" and to be the guiding developmental and motivational principle in adulthood and old age. According to the model, a variety of behavioral strategies may be identified first with "creative expansion" and later with "self-limiting adaptation".

In the context of the present study; when referring to the notions of "creative expansion" and "self-limiting adaptation" as motivational principles, it must be acknow- 
ledged that in current, industrialized society TABP has become the primary behavioral strategy for successfully coping with the normative "developmental tasks" of childhood, adolescence, and adulthood. Thus, from a life-span developmental perspective, TABP may be thought of, in principle, as a primarily adaptive strategy as long as it enables an individual to carry out "developmental tasks" in ta successful and satisfactory manner. It is important to remember that only a small minority of all adult subjects exhibiting TABP actually develops CHD and MT (Matthews, 1982; Booth-Kewley \& Friedman, 1987).

The biographies of the two Type A MI-cases shed light, first, on the early psy chosocial origins of TABP as a governing motivational principle; second, on the individual manners in which this behavior pattern was subsequently employed throughout major segments of the life-span; and finally, on why TABP may have led to first MI. Thus, these case histories may illustrate why, in the final analysis, TABP was not an appropriate type of "self-limiting adaptation" for these MII-cases.

It may be hypothesized that in the case of Mr. A., TABP was induced and later reinforced by his parents" incessant striving to secure a better education for both their children than that which they had received. Later, when Mr. A. was building his career, his Type A behavior may have facilitated his ability to pursue his night studies with such perseverance and, finally, to complete them.

One may question whether TABP, to the extent that Mr. A. exhibited it until that time, was still the best adaptive behavioral strategy for him once he had reached his last position at work, knowing there was little room for further advancement. Moreover, TABP does not seem to have been the most adequate coping strategy for his permanent domestic troubles, especially his daughter's chronic ailment and his wife's poor health. Since it may be concluded from his biography that he was not exposed to many "developmental tasks" for which behavioral strategies other than TABP would have been more appropriate, Mr. A. may have repeatedly tried to cope with his most recent, chronic "tasks" with a behavioral strategy that had become inadequate.

In the case of Mr. B., TABP may have been brought about by the stark living conditions that prevailed during his childhood and adolescence. These may have made it necessary for him to act as an adult, starting at an early age, by assuming the responsibility of helping to support his family. As may be concluded from his biography, 
TABP was employed as a behavioral strategy throughout every new stage of his working life. During the two years before his $\mathrm{MI}$, at a time when $\mathrm{Mr}$. $\mathrm{B}$. was temporarily work-disabled but still hoped to resume working, this behavior did not change substantially. On the contrary, he was enraged that none of his superiors showed any interest in his predicament. In his case, too, TABP, once a fully adequate behavioral strategy, may have become inappropriate for coping successfully with the latest; uncontrollable circumstances that $\mathrm{Mr}$. B. found himself in.

To generalize from these two case histories, it may be thought that the efficacy of TABP, inasmuch as it represents "self-limiting adaptation" as a successful behavioral strategy in achieving "self-determination" throughout adulthood, should be constantly re-evaluated when used to carry out major "developmental tasks". Similar suggestions have been put forward in the literature about adult socialization (e.g, Albrecht \& Gift, 1975; Fiske \& Chiriboga, 1985).

In terms of a testable hypothesis that may be derived from this proposition, this means that male subjects who fail to regularly scrutinize the efficacy of the behavioral strategies they apply to carry out "developmental tasks" over the life-span will find it impossible to achieve optimal psychosocial "self-determination" throughout adulthood; this disposition may be associated with an elevated risk for first MI in adulthood.

\section{C. "Upholding Internal Order" and "Self-Determination".}

It may also be thought that an adult life-span characterized, first, by a lack of opportunities for "creative expansion" during the formative phases of childhood and adolescence and, second, by a predominantly improper mode of "self-limiting adaptation" to cope with the important and manifold "developmental tasks" of adulthood may eventually llead to an almost permanent inability to "uphold internal order", as formulated in the Bühler model. It may be said that this appropriate term bears some conceptuall resemblance to that used throughout the present study, namely, manifestations of "vital exhaustion", which, for a majority of the cases studied, was a precursor of impending first $\mathrm{MI}_{\text {. }}$

Interestingly, each of the three biographies illustrates a different pathway along which particular SLE may have been conducive both to vital exhaustion and to first MI. It is apparent in all three cases that adverse living conditions during the forma- 
tive years contributed to both vital exhaustion and first ML Some other SLE in later developmental phases may also have contributed to the process of becoming vitally exhausted prior to suffering an MI.

In the life of Mr. A, the prolonged studying for more than a decade and, later, the ever-present health problems of both his wife and daughter were most probably instrumental in his becoming exhausted after his promotion to vice president. During the interview, Mr. A asserted that in the course of those last few years he had gradually become increasingly listless and irritable, in particular with his wife and daughter. Finally, in the last months prior to his MI, he had become utterly exhausted.

In the case of Mr. B., vital exhaustion was most probably brought on by the incessant struggles for control over his workload in his last job as chief operator at the automobile factory. At about the same time, he was also doing heary physical labor at home, in order to provide appropriate living facilities for his oldest son and daughterin-law. It may further be concluded that Mr. B. was unable to "tuwind", both while he was still employed and once he had become temporarily disabled. At that time, while spending most of his days at home, he kept hoping he would be able to return to work soon. Thus, although vital exhaustion, in general, has been considered a "short-term" psychosocial precursor of first MI in the present study, in the case of Mr. B., manifestations of vital exhaustion may again have occurred for a prolonged period of time (i.e., four to five years) before he finally suffered his coronary event. More longitudinal analyses are needed to determine whether phases in the development of vital exhaustion may be discerned and; if so, which ones.

The fact that Mr. A. and Mr. B. were both fully developed Type A's may have contributed, on the one hand, to their demonstrated perseverance in pursuing their objectives and, on the other hand, to their becoming periodically, and severely, exhausted for substantial periods of time. Thus, both life histories illustrate, to some extent, the manner in which the synergistic relationship between TABP and vital exhaustion may take shape.

Mr. C's biography reflects his almost life-long tendency to become vitally exhausted in response to exposure to overwhelmingly negative SLE throughout all phases of the life-span. This was most evident after the death of his mother during his early adolescence, after the death of his father a few years later, after the death of both 
hils uncle and aunt during the first phase of his adulthood, and, finally; some time after the death of his wife, when Mr. C. was on the brink of early old age.

All three biographies suggest that vital exhaustion, when considered as an indicator of the inability to uphold "internal order", becomes established relatively early during one's psychosocial development as a pathogenic response to coping with particular adverse and predominantly uncontrollable "developmental tasks". In other words, at least in these three case histories, a propensity to habitually react with vital exhaustion emerges as a personality trait that will remain stable over subsequent phases of the life-span once it has become established. This reasoning, in general, is in accordance with the previously discussed "stability" model of behavioral and cognitive development over the life-span (Costa \& McRae, 1980; Horn \& Donaldson, 1980* Moss \& Susman, 1980), both with respect to dominant behavioral strategies, such as TABP, and emotional response patterns, such as vital exhaustion.

To generalize from these cases, it may be hypothesized that male subjects who are not able to maintain "internal order" with respect to the "developmental tasks" they have to carry out over the life-span will find it impossible to achieve optimal psychosocial "self-determination" during adulthood" this inability may be associated with an elevated risk for first MI in aululthood.

\section{D. "Need Satisfaction" and "Self-Determination".}

According to the Bühler model, the final motivational and developmental process by which "self-determination" in adulthood and beyond may be achieved is "need satisfaction", a process more widely referred to as "life satisfaction", which seems to be much more adequate here (Botwinick, 1984). It has been amply demonstrated that satisfactory health, adequate finances; job satisfaction, and someone to be with and confide in are all necessary basic conditions for "life satisfaction" in adulthood and old age. In the biographies of the MI-cases presented here, those basic conditions were, in one way or another, absent.

In the life of Mr. A, hard work occupied almostall of his waking time and brought him a well-deserved promotion to a respectable position. After this achievement, however, which was during the early phase of his adult development, he may have begun to realize that he had reached the peak of his career, and that it would be very hard 
for him to move further up the corporate ladder. At the same time, in his family life, his daughter's perpetual health problems and those of his wife, had become a major concern and a chronic source of vexation for him.

Mr. B. had also worked very hard during an even longer working life, but he felt that his devotion and extraordinary sense of responsibility, in particular in his last position, had never earned him the recognition he deserved from his superiors. When the finally began to realize that he would no longer be able to return to work, this grudge not only remained with him permanently but was reinforced by the total lack of empathy on the part of his former superiors. On the other hand, his admittedly happy family life, without any major problems in the last few years before his MI, may have compensated for this, although perhaps not enough.

The life history of Mr. C. provides by far the saddest illustration of how an almost uninterrupted series of virtually impossible to cope with chronic SLE over the life-span can finally bring about complete disillusionment with life at the time one has reached the brink of old age, with nothing left to look forward to or to hope for. For Mr. C., disillusionment with all domains of his entire life had become almost complete before he suffered his MI.

To generalize from these cases, it may be hypothesized that male subjects who are not able to obtain adequate "life satisfaction" with respect to the "developmental tasks" they have to cany out over the life-span will find it impossible to achieve optimal psychosocial "self-determination" during adulthood; this inability may be associated with an elevated risk for first MI in adulthood.

\section{E. Summary \& Conclusions.}

In sum, two of the terms from the Bühler model that served as a primarily heuristic framework here and the various processes associated with them appear to be appropriate terms to describe the dynamics characterizing the life-span developmental trajectories of adult male subjects who, at one point or another in their lives, will suffer a coronary event. That is, the motivational and developmental processes underlying "self-limiting adaptation" and "upholding internal order", in which the concepts of TABP and vital exhaustion are reflected, may represent promising terms for future consideration in behavioral and psychosocial CHD-research. 
First, "self-limiting adaptation", in the sease in which it was described above, implies a continuous process of anticipating, coping with, and evaluating the "developmental tasks" of adulthood. TABP constitutes a somewhat different process; in most of the literature about the development of TABP and its influence over the life-span, it is assumed that once TABP has become established as a dominant behavioral strategy in the formative years, its pathogenic impact on later developmental phases remains virtually unchanged (Matthews \& Woodall, 1988). The results from the present study cast some doubts on this assertion, as do the critical evaluations of the long-term follow-up findings from the original WCGS (Dimsdale, 1988; Ragland \& Brand, $1988 \mathrm{a}, \mathrm{b})$.

The process of "self-limiting adaptation" may represent a more accurate description of the cognitive and behavioral processes that are involved since the former implies continuous reappraisal of the efficacy of the behavioral strategies applied to cope with the "developmental tasks" over the adult life-span. It was already hypothesized that failing to regularly scrutinize this efficacy may be associated with an elevated risk for first MI in adulthood. This assumption about the necessity of continuous reappraisal is in accordance with the notions from life-span developmental theory that the actual occurrence and the consequences of major life crises ("developmental tasks") cannot be fully anticipated and, therefore, require a flexible behavioral and cognitive strategy to solve them successfully (Albrecht \& Gift, 1975; Riegel, 1975; Hultsch \& Plemons, 1979; Brim \& Ryff, 1980).

Second, the term "upholding internal order" implies that an established equilibrium with respect to a subject's prevailing mental and physical conditions may be continuously subject to change due to the processes of anticipating, coping with, and evaluating the "developmental tasks" of the entire adult life-span. In other words, having to cope with major SLE during the life-span may lead to temporary mental and physical disequilibrium as measured, for example, by the construct of "vital exhaustion", which may be associated with an elevated risk for first MI. This assumption is also in accordance with the above-mentioned life-span developmental literature on major life crises in adulthood. Thus, those terms and their underlying biological and psychological processes, which will require closer scrutiny in future studies, may be said to reflect the basic elements of constancy and change, the two fundamental proc- 
esses that form the necessary basis for understanding ontogenetic development (Ka$\operatorname{gan}, 1980)$.

The terms "self-limiting adaptation" and "upholding internal order" warrant further operationalization. They may be employed in behavioral and psychosocial research on CHD since they appear to be uniquely able to combine epidemiological rigor with the developmental insights that are necessary to fully understand why a certain, individual developmental trajectory over the life-span, which is unique in many respects, may lead to the life-threatening event of first MI. 
$-168$. 


\section{Chapter 8: Summary.}

Throughout this study, first myocardial infarction (MI) in adul thood is considered as the outcome of a developmental process that covers several stages of the human life-span. During this developmental process, a multitude of biological, behavioral, psychic, and social factors interact continuously in ever-changing configurations to bring about the life-threatening event of first MI in different phases of adulthood. It is argued that the biologically-oriented or contextualistic models that are currently employed to study the behavioral and psychosocial etiology of first MII may not be optimally suited to depicting the particular life-span developmental course that might be conducive to premature breakdown due to MI. Therefore, it is proposed that a lifespan developmental orientation may solve some of the problems that arise with respect to the developmental description and explanation of particular behawioral and psychosocial factors that lead to first MI.

Chapter 1 describes and discusses life-span developmental psychology as a theoretical and methodological orientation, and it reviews the current literature about the Type A coronary-prone behavior pattern (TABP), stressful life events (SLE), and manifestations of vital exhaustion from this particular point of view.

First, it is argued that a life-span developmental methodological perspective allows one to answer such questions as: Is the vast majority of MI-cases characterized by TABP, irrespective of the age at which they suffered their first ML, or is TABP most prominent in early adulthood? Does the same hold true for vital exhaustion prior to first MI, or does age play an entirely different role here ? Does every MI-case report the same SLE prior to first MI, despite vastly different childhood experiences, working conditions, career patterns, and family situations, or are such SLE clearly associated with age, TABP, vital exhaustion; or adverse life styles ?

Second, after reviewing some origins of life-span developmental psychology, it is argued that particular aspects of Charlotte Bühler's work on intra- and interindividual differences in life-span patterns of striving for "self-determination" that lead either to psychic integration and fulfillment or to partial or complete failure may provide a useful theoretical orientation for the present study. 
Third, after discussing the current epudemiological literature about TABP, SLE, and vital exhaustion, in which the often contradictory results from retrospective and prospective studies are compared and from which several questions may be raised with respect to developmental aspects of these risk indicators, an integration of this evidence from a life-span developmental perspective is attempted.

Chapter 2 describes the study design and the methods that are employed from a life-span developmental perspective.

First, the criteria, selection procedures, and selection biases with respect to the 458 male participants in the present case-referent study [i.e., 133 cases with a clinically documented first MI (MI-cases), 133 neighborhood referents (NR), and 192 hospital referents (HR)] are described. Both MI-cases and HR constituted, in principle, consecutive series from two major hospitals in the South Limburg region of the Netherlands. They were approached between June 1980 and September 1983, and March 1982 and March 1985, respectively. The final refusal rates were $25 \%$ and $16 \%$ for MIcases and $H R$, respectively, whereas $48 \%$ of the potential NR finally agreed to participate (Appendix I).

Analyses with respect to possible selection bias in participating and non-participating MI-cases ( $\mathrm{N}=20)$, based on completed and returned questionnaires (see below), showed that there were no significant differences between the two groups with respect to mean age, vital exhaustion, angina pectoris, current smoking, coffee consumption, use of sleeping pills, and sleep complaints within the last half year prior to first MI (Table 2.1., p.207). TABP could not be assessed in the non-participating cases because they were never interviewed (see below). Analyses with respect to mean age and primary reasons for hospitalization in participating and non-participating HR $(\mathrm{N}=41$ ) showed no differences between the two groups (Table 2.2., p.208). Thus, the present findings about MI-cases and HR may be said to be representative of the source population at large. The absence of selection bias in NR, however, could not be confirmed unequivocally; it is thought that older subjects were less willing to participate than younger, probably healthier, subjects. 
Second, the age distribution is described. The present study was designed to sample all participating subjects in such a way that MI-cases, $\mathrm{NR}_{\text {, }}$ and HR would be distributed more or less equally (at least $15 \mathrm{MI}$-cases, $15 \mathrm{NR}$, and $25 \mathrm{HR}$ ) among seven consecutive age strata, each spanning five years (i.e, 35-39, 40-44, etc. up to 65-69, Table 2.3., p.209). This particular time-consuming sampling strategy was adopted in order to deal with confounding with respect to age, cohort-membership, and time of measurement, a problem that is ever-present in life-span developmental psychology: As a result; the subsequent analyses could focus primarily on cohort-membership and on the various ways in which it may have influenced the individual developmental histories that lead to premature first $\mathrm{MI}$ in distinct phases of adulthood. In order to do this, age must be distributed as equally as possible over all three groups of participating subjects.

The mean age was 53.1 years $(S . D .=9.5$ years) for MI-cases, 51.1 years (S.D. $=9.7$ years) for HR, and 49.2 years $(S . D .=9.3$ years) for NR. In spite of the sampling procedure, NR were significantly younger than MI-cases. This may have been due, in large part, to a substantial refusal rate among older NR. Therefore, in most analyses, age was still controlled or adjusted for. Sometimes the data were also analyzed separately for the three different cohorts that, from a life-span developmental perspective, are thought to represent clearly distinct developmental phases in adulthood, namely, the group aged 35-44 ("young adulthood"), that aged 45-59 ("middie age"), and that aged 60-69 ("beginning old age").

Third, the various instruments (questionnaires and interviews) that were employed to assess the life-span developmental histories of MI-cases, NR, and HR are described. In the hospital, MI-cases and HR filled out the following questionnaires:

(a) the Maastricht Questionnaire (MO), assessing vital exhaustion prior to first MI;

(b) the London School of Hygiene Cardiovascular Questionnaire (LSHCO), assessing current angina pectoris; and

(c) the Life Styles Questionnaire (LSQ), assessing adverse life styles (i.e., cur rent smoking, alcohol use, and coffee consumption). NR completed the questionnaires prior to being interwiewed at home. 
The original MQ consisted of 37 items (Form A). In an independent follow-up study over more than four years, 21 of these items appeared to predict fatal or non-fatal MI, and these items constitute Form B. Below reference will be made to Forms A and $\mathrm{B}$ of the $\mathrm{MQ}$ and to an intermediate item pool of 58 items (including Form $\mathrm{A}$ ) that was employed in the present study.

About two months after discharge from the hospital, MI-cases and HR were interviewed at home. During this interview, TABP was assessed by means of the Structured Interview (SI). In addition, the actual occurrence and the appraisal and coping strategies with respect to SLE over the entire life-span prior to first MI or hospitalization were assessed by means of the Structured Biographical Interview (SBI). NR were also interviewed at home with the SI and the SBI.

The SBI, the major instrument for data collection in the present study, consists of 47 SLE from three different domains of the life-span, namely, "Childhood \& Adolescence" (11 SLE), "Work \& Career" (16 SLE), and "Family \& Social Life" (20 SLE; Appendix (I). These particular SLE, and the manner and order in which they were included in the SBI, were selected after reviewing the current literature and a pilot study with some $30 \mathrm{MI}$-cases.

The main reason for using a structured interview to assess SLE instead of such established questionnaires as the Social Readjustment Rating Scale was that an interview was considered:

(a) the best suited for assessing relevant SLE from earlier developmental phases that may have influenced physical and mental bealth in later life to a considerable extent, although at the actual time of occurrence these SLE may not have appeared to have such potential ("sleeper" effects);

(b) most efficient, in that the actual occurrence of a SLE in any developmental phase may be assessed as precisely as possible while, at the same time, the idiosyncratic anticipatory, appraisal, and coping strategies that were employed with respect to each SLE may also be assessed; and

(c) most likely to prevent retrospective bias, in that an interview situation enables the interviewer to directly check the replies given and to discuss important issues when necessary. 
Although, in all, mine interviewers performed these 458 SI and SBI, it was shown that there were no intra-interviewer differences with respect to the SBI-assessinents of SLE in MI-cases, NR, and HR, both in general and with respect to the three developmental domains (Table 2.5, p.211). Moreower, it was demonstrated that there was no retrospective bias ("search for meaning") in the SBI-data from the MI-cases, when the SLE reported by cases interviewed shortiy after their coronary event were compared with those from cases interviewed much later. Nor were there any significant differences with respect to mean age or TABP (Table 2.6., p.212).

Fourth, the various statistical procedures that were employed to analyze the questionnaire and interview data from MI-cases, NR, and HR are described.

In general, differences in overall and cohort-specific occurrences of TABP, vitall exhaustion, and SLE were tested, first, by computing uni-variate $\mathrm{Chi}^{2}{ }^{2}, \mathrm{~F}_{-}$, and $\mathrm{t}$ tests. Second, estimated relative risks for first MI (and the corresponding 95\% testbased confidence intervals) that are associated with TABP, vital exhaustion, and SLE were calculated using both crude and adjusted, as well as standardized, estimates of relative risk. In some instances, other risk indicators measured in this study (i.e., age angina pectoris, and current smoking) were also included in these analyses. Finally, some multiple logistic regression analyses were performed in which TABP, vital exhaustion, SLE, and other risk indicators, as well as their interactions with age, were included. Estimated relative risks and $95 \%$ confidence intervals were also calculated from these latter analyses.

Chapter 3 describes hypotheses and findings with respect to TABP. These hypotheses are that:

(1) TABP, in general, occurs more often in MI-cases than in referents; and that

(2) TABP constitutes an independent behavioral risk indicator for first MI when controlling separately for some other risk indicators for coronary heart disease (CHD):

Furthermore, the issue of whether TABP is associated with particular SLE over the life-span is explored. 
The major findings may be summarized as follows:

First, TABP occurred significantly more often in MI-cases than in both referent groups, thus corroborating hypothesis 1 (Table 3.1., p.213).

Second, Type A MI-cases suffered their first MIs at a significantly younger age than Type B cases.

Third, there were significant associations between TABP and cohort-membership. That is, although in each referent series the overall age-adjusted relative risks for first MI associated with TABP were significantly elevated (i.e., 2.37 in the NR-series and 2.29 in the HR-series), this risk declined with increasing age, from 4.04 and 3.44 , respectively, (age 35-44: "young adulthood"), to 2.14 and 2.98 (age 45-59: "middle age"), to non-significant associations, i.e., 1.66 and 1.12, after age 60 ("beginning old age ${ }^{\mathrm{A}_{*}}$ Table 3.3., p.215). These associations between TABP and elevated risk for first MI were not confounded by angina pectoris, current smoking, or excessive coffee consumption, thus corroborating hypothesis 2.

Finally, Type A subjects ( $N=247 ; 54 \%$ ), in general, reported more SLE [i.e., six in all (13\%)] in the SBI-domains of "Childhood \& Adolescence", "Work \& Career", and "Family \& Social Life" than Type B subjects $(\mathrm{N}=211$, 46\%; Table 3.4.a through 3.4.c, p.216-218). TABP in adult subjects was associated with financial hardships during the formative years and with major conflicts both at work and in family and social life. The question of whether TABP thus acts as a confounder with respect to the reporting of SLE over the life-span is analyzed and discussed in Chapter 5.

Chapter 4 describes hypotheses and findlings with respect to manifestations of vital exhaustion. These hypotheses are that:

(1) vital exhaustion, in general, occurs more often in MI-cases than in referents; that

(2) vital exhaustion, in general, constitutes an independent psychosocial risk indicator for first MI when controlling separately for other risk indicators for $\mathrm{CHD}$; that

(3) subjects who are assessed as being Type A are at an elevated risk of becoming "witally exhausted"; that 
(4) Type A subjects who are "vitally exhausted" are at a more elevated risk of suffering first MI than Type A subjects who are not; and that

(5) when controlling for vital exhaustion, Type A subjects are at a more elevated risk of suffering first MI than Type B subjects.

Furthermore, the issue of whether vital exhaustion is associated with particular SLE over the life-span is explored.

The major findings may be summarized as follows:

First, MI-cases scored significantly higher on Form B of the MQ, used to assess vital exhaustion, than both referent groups, thus corroborating hypothesis 1 . Unlike the findings with respect to TABP, HR scored significantly higher on this Form than NR.

Second, the significant overall age-adjusted relative risks for first MI associated with vital exhaustion (Form B) were 7.35 in the NR-series and 2.90 in the HR-series (Table 4.1., p.219).

Third, analyses of each of the 58 items from the intermediate item pool demonstrated that, in both referent series, 46 items $(79 \%)$ constituted significantly elevated estimated relative risks for first $\mathrm{MI}$, although not all discriminating items were similar in each series (Table 4.2., p.220-223). In neither of the referent series were all 21 items of Form $B$ associated with such risks. Some items from the intermediate item pool constituted relative risks that were at least as high as those associated with the items of Form B. This applied, in particular, to two items about "Increased irritability ${ }^{\prime \prime}$ prior to first MI, with associated estimated relative risks of 8.66 and 7.66 (NR-series) and of 7.42 and 6.00 (HR-series), respectively (Table 4.2.).

Fourth, after dividing the MQ scores (Form B) into tertiles, the intermediate and high degrees of vital exhaustion - expressed both as unadjusted standardized relative risks and as standardized risks after adjusting separately for age (i.e., the three cohorts $35-44,45-59$, and $60-69$ ), angina pectoris, and current smoking - remained positively and significantly associated with first MI in both referent series, thus corroborating hypothesis 2 (Table 4.3., p.224). In the NR-series, for the highest tertile, the unadjusted standardized relative risk was 11.96 ; the separately adjusted risks were 14.08 for age (thus indicating that age might exert a modifying influence), 9.41 for an- 
gina pectoris, and 10.10 for current smoking. In the HR-series, the unadjusted risk was 5.03; the adjusted ones were $5.31,4.29$, and 4.69, respectively. Thus, in general, the association of vital exhaustion with first MI was not confounded by these other risk indicators. Since these findings were based on the prospectively validated Form $B$ of the $\mathrm{MQ}_{1}$ it is argued that it is unlikely that these particular findings were strongly influenced by retrospective bias.

Fifth, "healthy" Type A subjects (i,e., those who were free of angina pectoris, $\mathrm{N}=220$ ) generally scored higher on Form $\mathrm{B}$ of the $\mathrm{MQ}$ than likewise categorized Type B subjects ( $\mathrm{N}=193$ ), thus corroborating hypothesis 3 (Table 4.4., p.225).

Sixth, "vitally exhausted" Type A subjects were at a significantly elevated risk of suffering first MI. That is, when all subjects were categorized both as being either Type A or Type B and as being either "vital" or "vitally exhausted" (based on the median score of the combined referent groups), and when "vital" Type B subjects were employed as the reference category, the standardized estimated relative risks for first $\mathrm{MI}$ associated with being a "vitally exhausted" Type A were 11.02 in the NR-series and 5.20 in the HR-series, thus corroborating hypothesis 4 (Table 4.5., p.226). These substantially elevated risks in both referent series suggest a modifying effect of vital exhaustion with respect to the actual influence of TABP. This, in pairwise analyses, appeared in fact to be the case.

Seventh, it was demonstrated that when the estimated relative risk associated with TABP was standardized for vital exhaustion, this risk estimate still reached significance in the HR-series but not in the NR-series (i.e., 1.98 and 1.62, respectively). Thus, hypothesis 5 was only corroborated in part.

Finally, "vitally exhausted" subjects $(\mathrm{N}=280 ; 61 \%)$, in general, reported more SLEE [i.e., 15 in all (32\%)] in the SBI-domains of "Childhood \& Adolescence", "Work \& Career", and "Family \& Social Life" than "vital" subjects $(\mathrm{N}=178 ; 39 \%)$ (Table 4.7.a through 4.7.c p.228-230). Only one SIE was reported more often by "vital" subjects. Vital exhaustion in adult subjects was associated, in general, with adverse living conditions during the formative years, with the disruption of one's working pattern and career opportunities, and with prolonged or serious educational problems and familial conflicts. Some of these SLE were also reported significantly more often by Type A subjects. The question of whether vital exhaustion thus acts as a confounder with 
respect to the reporting of SLE over the life-span is analyzed and discussed in Chapter 5 .

Chapter 5 describes hypotheses and findings with respect to the occurrence of SLE over the life-span. These hypotheses are that:

(1) SLE associated with "Childhood \& Adolescence", "Work \& Career", and "Family \& Social Life", in general, occur more often in MI-cases than in referents; and that

(2) SLE associated with "Childhood \& Adolescence", "Work \& Career", and "Family \& Social Life", in general, constitute independent psychosocial risk indicators for first MI.

Furthermore, the issues of whether TABP exerts a moderating influence on the associations of SLE in the above-mentioned domains with first MI, and whether SLE in these domains exert a moderating influence on the association of vital exhaustion with first MI are explored.

The major findings may be summarized as follows:

First, MI-cases reported a significantly higher mean occurrence of SLE over the life-spain, in general, than both referent groups, thus corroborating hypothesis 1 (Table 5.1., p.231). The findings regarding the three separate domains indicate that "Family \& Social Life", in particular, was characterized by a significantly higher mean occurrence of SLE in MI-cases in both referent series. With "Work \& Career" and "Childhood \& Adolescence", only the HR-series showed significantly higher mean occurrence rates of SLE.

Second, in the HR-series, 18 SLE (38\%) were reported significantly more often by MI-cases; in the NR-series this was true for eight SLE (17\%; Table 5.2.a through 5.2.c, p.232-234). Two SLE (4\%) were reported significantly more often by HR than by MI-cases; four SLE ( $9 \%$ ) were reported more often by NR. Eight SLE (17\%) were reported more often by NR than by HR, while two SLE (4\%) were reported more often by HR than by NR. After demonstrating that seven of the latter ten SLE only distinguished between both referent groups, and not between these groups and MI-cases, 
the data from both referent groups were combined in some analyses in order to enhance statistical power.

Third, in the HR-series, 19 SLE (40\%) were associated with significantly ellevated crude estimated relative risks for first $\mathrm{MI}_{;}^{*}$ in the NR-series this was true for eight SLE (17\%), thus corroborating hypothesis 2 (Table 5.3.a through 5.3.c, p.235-237). Some of these crude risks appeared to be rather "high", in particular in "Family \& Social Life" [e.g., "Prolonged/serious conflicts with children away from home": 6.78 (NRseries), and 2.96 (HR-series); "Prolonged/serious educational problems with children":" 4.27 , and 2.60 , respectively).

Fourth, in the combined referent series, 14 SLE (30\%) were associated with significantly elevated crude relative risks for first MI (Table 5.4.a through 5.4.c, p.238240). After adjusting for cohort-membership (i.e., ages 35-44, 45-59, and 60-69) and after simultaneously controlling for TABP, $12 \operatorname{SLE}(25 \%)$ retained a positive and significant association with first MI. Thus, the associations of two SLE (4\%) with first MI were confounded by TABP and/or age. Furthermore, particular cohort effects were identified with respect to nine SLE (19\%) on the basis of a significant heterogeneity $\mathrm{Chi}^{2}$. These effects applied mostly to "young" Type A MI-cases (e.g., "Voluntary search for other job(s)": crude estimated relative risk: 8.00 ; "Increased responsibility at wor $k^{\mathrm{n} \text { " }}$ 6.83; and "Divorce": 5.14) or to "middle aged" Type A cases (e.g., "Prolonged/serious marital conflicts"': 2.96 ).

Fifth, when, as with TAB $P$, the issue of whether vital exhaustion may have served as a moderator was explored, it was found that, in the HR-series, the associations of five SLE (10\%) with first MI were confounded by vital exhaustion and/or age(Table 5.5.a through 5.5.c, p.241-243). In the NR-series, this occurred with respect to four SLE ( $8 \%$ ). Furthermore, cohort effects were observed with respect to seven SLE $(14 \%)$ in the HR-series and three SLE (6\%) in the NR-series. These effects applied mostly to "young" MI-cases who were "vitally exhausted" [e.g., "Increased responsibility at work": crude estimated relative risk: 5.13 (NR-series), and "Past unemployment": 3.59 (HR-series)].

Finally, in three series of multiple logistic regression analyses, in which the data from both referent groups were combined and in which each SLE was entered separately while controlling simultaneously for age (i.e., the three cohorts $35-44_{n} 45-59$, and 
60-69), current smoking; TABP, vital exhaustion, and educational level, nine SLE (19\%) retained positive and significant associations with first MI (Table 5.6, p.244). Six of these SLE occurred in "Family \& Social Life". The most important ones were "Prolonged/serious conflicts with children away from home", estimated relative risk: 3.65 and "Prolonged/serious financial problems": 237 . The two SLE that discriminated with respect to "Work \& Career" were "Prospects for promotion (unrealized)": estimated relative risk" 1.97 and "Work place closed down": 1.70. Finally, "Prolonged financial problems" during the formative years retained a twofold relative risk for first MI. Furthermore, in the same analyses, significant positive interactions with age (1.e., cohort effects) were found with respect to four SLE (9\%), namely, "Voluntary search for other job(s)": estimated relative risk: 4.99 and "Increased responsibility at work": 4.93 , in "young adulthood" (age 35-44); "Prolonged/serious marital conflicts": 3.57 , in "middle age" (age 45-59); and "Prolonged/serious illness (spouse)": 2.40 in "beginning old age" (age 60-69) (Table 5.7, p.245).

Chapters 6 and 7 discuss the findings presented in Chapters 3 through 5 . The former pertains to the findings about all MI-cases and the latter describes the lifespan developmental patterns of three MI-cases, one from each cohort, who are thought to be representative of the entire study base. These biographies are discussed against the background of the life-span developmental notions about "self-determination" that were proposed by Charlotte Bühler and discussed in Chapter 1.

First, in Chapter 6, the associations of TABP with first MI are discussed. It is reasoned that they are, in general, in accordance with the associations reported in most case-referent studies and, moreover, that they are of the same magnitude as found in most prospective studies. In other words, the present study confirms that TABP constitutes a behavioral risk indicator for first MI that is not confounded by angina pectoris, current smoking, and coffee consumption. The strong association of TABP with risk for first MI in the earliest developmental phase in adulthood, but much less so in the later ones, is a finding that deserves particular attention. Finally, it is argued that these findings may have been influenced to some extent by interviewer bias. It is much less likely that they were influenced by retrospective bias. That is, on the basis of several empirical arguments (i.e., stabillity over the life-span, differen- 
ces in outspokennes of TABP-characteristics before and after $M \mathrm{M}_{\text {, }}$ and refusal rates among extreme Type A subjects) it appears as though the actual prevalence of TABP in the participating MI-cases has been underestinated.

Second, the associations of SLE with first MI are discussed. It is argued that these findings are, in general, in accordance with those from most case-referent studies. Thus, the present study also confirms that SLE constitute psychosocial risk indicators for first MI which, moreover, exert their influence over the entire life-span. That is, when the three developmental domains are considered separately, one finds that adverse living conditions during childhood and adolescence may very well contribute to the development of first MI in adulthood. It is also argued that disruptions in one's career (in particular "Unrealized prospects for promotion" and "Work place closed down') and longstanding conflicts at work are characteristic of future MI-cases. It is, above all, noteworthy that prolonged discord in the family and in social lifesomething which has not been reported on a similar scale in previous studies - appears to play the most important role in the life histories of future MI-cases. Attention is focused on the "chronic" character of most of these SLE and their probable longlasting influence on life-span development. Finally, it is reasoned that retrospective bias reflecting either a "search for meaning" or "selective forgetting" most likely did not influence the present findings to any substantial degree. On the other hand, it is possible that interviewer bias may have influenced them to some extent.

Third, the associations of vital exhaustion with first MI are discussed. It is argued that these findings are, in general, in accordance with those from previous retrospective studies that employed a preliminary version of the MQ. In this respect it is noteworthy that some $79 \%$ of the intermediate pool of MO-items were positively and significantly associated with first MI. Of these, the items denoting "Increased irritability" deserve particular attention. Furthermore, it is reasoned that the risk estimate associated with vital exhaustion in the NR-series of the present study (i.e., more than sevenfold) is comparable to that obtained in the prospective study in which the MQ was validated, whereas the threefold estimate from the HR-series may represent an underestimation of the actual risk. It is argued in detail that it is unlikely that retrospective, recall, or selection bias (or "neuroticism") influenced these findings about vi- 
tal exhaustion to a substantial extent, or that these findings were largely confounded by the other risk indicators that were included in the present study.

Fourth, the relationships between TABP, SLE, and first MI are discussed. With respect to the possible childhood origins of TABP, it is reasoned that Trolonged financial problems", which may be representative of adxerse living conditions during the formative years, contributed to the subsequent development of TABP. Furthermore, it is reasoned that the many conflict situations at work and in family and social life that adult Type A subjects confront may constitute major determinants both with respect to perpetuating TABP in adulthood and to developing first MI. It is thought in this respect that "irritability" may be central to both the construct of TABP and that of vital exhaustion.

Fifth, the relationships between TABP and vital exhaustion and their common association with first MI is discussed. On the basis of the modifying effect of vital exhaustion on TABP, which was established in the present study, it is proposed that this apparently synergistic relationship be inwestigated further. The concurrent presence of TABP and vital exhaustion appears to define a particular subgroup of subjects who may be at a highly elevated risk for a near-future coronary event.

Sixth, the relationships between SLE, vital exhaustion, and first MI are discussed. It is concluded, first, that a substantial number of SLE, which in previous studies appeared to be directly associated with first MI, may, in fact, only lead indirectly to this event, that is, through their primary association with vital exhaustion. Furthermore, it is reasoned that adverse living conditions in the formative years may be conducive to both vital exhaustion and first MI in adulthood. This reasoning also applies to the majority of reported SLE from "Work \& Career" and "Family \& Social Life". Thus, in future research, the pathways along which SLE develop and eventually lead to vital exhaustion and first MI should be studied in more detail. Finally, it is argued that these particular findings may be in accordance with current theoretical notions about "helplessness" as a result of continuous exposure to undesirable and uncontrollable SLE. 
In Chapter 7, three life-span dewelopmental histories of M-cases representative of the three different cohorts are described in detail in order to illustrate the psychosocial, developmental contexts from which the above-mentioned SLE emerged (Table 7.1. p.246). This was thought necessary since the primarily epidemiological approach taken in Chapters 3 through 5 may not provide immediate insight into the psychological meaning of the behavioral and psychosocial risk indicators reported there.

First, it is concluded that the gradual accumulation of SLE over the life-span is more evident in these individual biographies than in the aggregate data presented before them.

Second, it becomes apparent that the psychosocial and environmental contexts in which the discriminating SLE occur differ widely between the three cohorts.

Third, the psychological impact of one and the same discriminating SLE may be different in different cohorts.

Eourth, most importantly, however, it is illustrated that there may not be one single universal constellation of SLE leading to first MI but rather a vast array of different pathways. The same SLE may be combined in unique configurations, conditional upon cohort-membership. It is also lliustrated that events that do not actually occur may still play crucial roles in subsequent psychosocial development.

Finally, these three biographies are scrutinized against the background of Charlotte Bühler's notions of "self-determination" across the life-span. It is argued that two of the four concepts (i.e., "Self-limiting adaptation" and "Upholding internal order") which are used to describe the life-long striving for "self-determination" and the developmental processes that these concepts imply, may be useful heuristic terms to be employed in future research. These concepts appear to be able to combine epidemiological principles with the developmental insights thought necessary to understand why a certain individual developmental trajectory over the life-span, which is unique in many respects, may lead to the life-threatening event of first MI. 


\section{List of Abbreviations:}

CHD:

FHS:

HR:

IMIR:

KRIS:

LSHCO:

LSQ:

MI:

MO:

NR:

RCSS:

SBI:

SCD:

SI:

SLE:

TABP:

WCGS:
Coronary heart disease

Framingham Heart Study

Hospital referents

Imminent Moycardial Infarction Rotterdam (Study)

Kaunas/Rotterdam Intervention Study

"London School of Hygiene Cardiovascular Questionnaire"

("Rose" Questionnaire) (assessment of angina pectoris)

"Life Styles Questionnaire" (assessment of current smoking, etc.)

Myocardial infarction

"Maastricht Questionnaire" (assessment of vital exhaustion)

Neighborhood referents

Rotterdam Civil Servants Study

Structured Biographical Interview" (assessment of SLE)

Sudden cardiac death

"Structured Interview" (assessment of TABP)

Stressful life ewents

Type A coronary-prone behavior pattern

Western Collaborative Group Study. 


\section{Notes to Chapter 1}

1. My own free English translation of this crucial paragraph (p. 15) would read:

"Man as such is conducting his life through unconscious as well as conscious regulatory acts. While never ceasing to reconsider - within his umique idiosyncratic context - his past, present, and presupposed future, he tries to steer his own course while mastering external events. He will experience the results of his strivings at different times in his life as satisfactory or unfulfilling, depending on his commitment, circumstances, and objectives".

2. In this section, reference will be made to the 1968 English paper, and to the thoroughly revised second edition of the book, in German, published in 1959. It appeared rather impossible to obtain the original 1933 edition.

3. O. Miettinen, personal communication, September 1983.

\section{Note to Chapter 2}

1. Grant 31.010h/1981, Dutch Heart Foundation 


\section{References}

Abbott, A., Peters, R. \& Vogel, M. (1985) Type A behavior and survival after myocardial infarction (Correspondence). New England Jaumal of Medicine, 313, 450-451.

Abramson, L., Garber, J. \& Seligman, M. (1980) Learned helplessness in humans: An attributional analysis.

In J. Garber \& M. Seligman (Eds.), Human helplessness: Theory and applications. New York, NY: Academic Press, 3-34.

Abramson, L., Metalsky, G. \& Alloy, L. (1989) Hopelessness depression: A theorybased subtype of depression. Psychological Review, 96, 358-372.

Albee; $\mathrm{G}$. (1980) A competency model must replace the defect model.

In L. Bond \& J. Rosen (Eds.), Competence and coping during adulthood. Hanover, NH: University Press of New England, 75-104.

Albrecht, G. \& Gift, H. (1975) Adult socialization: Ambiguity and adult life crises. In N. Datan \& L. Ginsberg (Eds.), Life-span developmental psychology: Normative life crises. New York, NY: Academic Press; 237-251.

Alonzo, A., Simon, A. \& Feinleib, M. (1975) Prodromata of myocardial infarction and sudden death. Circulation, 52, 1056-1062.

Antonovsky, A. \& Kats, R. (1967) The life crisis history as a tool in epidemiological research. Journal of Health and Social Behavior, 8, 15-21.

Appels, A. (1980) Psychological prodromata of myocardial infarction and sudden death. Psychotherapy \& Psychosomatics, 34, 187-195.

Appels, A. \& Mulder, P. (1984) Imminent myocardial infarction: A psychological study. Jotumal of Human Stress, 10, 129-134.

Appels, A. \& Mulder, P. (1985) Type A behavior and myocardial infarction. A.9.5 year follow-up of a small cohort. International Journal of Cardiology, 8, 465-470. Appels, A \& Mulder, P. (1988) Excess fatigue as a precursor of myocardial infarction. European Heart Joumal, 9, 758-764.

Appels, A. Jenkins, C.D. \& Rosenman, R. (1982) Coronary-prone behavior in the Netherlands: A cross-cultural validation study, Joumal of Behavioral Medicine, 5 , $83-90$. 
Appels, A., Höppener, P. \& Mulder, P. (1987a) A questionnaire to assess premonitory symptoms of myocardial infarction. International Joumal of Cardiology, 17, 15-24.

Appels, A. Mulder, P. \& Höppener, P. (1989) Een prospectieve studie over vitale uitputting als woorloper van het hartinfarct en andere ernstige aandoeningen. [A prospective study about vital exhaustion as precursor of myocardial infarction and other serious diseases.] Nederlands Tijdschrift voor de Psychologie, 44, 122128.

Appels, A., Mulder, P., Van 't Hof, M., Jenkins, C.D., Van Houtem, J. \& Tan, F. (1986) The predictive power of the A/B Typology in Holland: Results of a 9.5 year follow-up study.

In T. Schmidt, T. Dembroski \& G. Blümchen (Eds.), Biological and psychological factors in cardiovascular disease. Berlin: Springer Verlag, 56-62.

Appels, A., Mulder, P., Van 't Hof, M., Jenkins, C.D., Van Houtem, J. \& Tan, F. (1987b) A prospective study of the Jenkins Activity Survey as a risk indicator for coronary heart disease in the Netherlands. Joumal of Chronic Diseases, 40, 959. 965.

Arnesen, E. Forsdahl, A. (1985) The Tromso heart study: Coronary risk factors and their association with living conditions during childhood. Journal of Epidemiology and Community Health, 39, 210-214.

Baker, L., Dearborn, M., Haskings, J. \& Hamberger, K. (1984) Type A behavior in women: A review. Health Psychology, 3, 477-497.

Baltes, P. (1968) Longitudinal and cross-sectional sequences in the study of age and generation effects. Human Development, 11, 145-171.

Baltes, P. (1979) Life-span developmental psychology: Some converging observations on history and theory.

In P. Baltes \& O. Brim Jr, (Eds.), Life-span development and behavior, Vol. 2. New York, NY: Academic Press, 255-279.

Baltes, P. \& Goulet, L. (1970) Status and issues of a life-span developmental psychology.

In L. Goulet \& P. Baltes (Eds.), Life-span developmental psychology: Research and theory. New York, NY: Academic Press, 3-21. 
Baltes, P. \& Schaie, K.W. (1973) On life-span developmental research paradigms: Retrospects and prospects:

In P. Baltes \& KW. Schaie (Eds.), Life-span developmental psychology. Personalaty and socialization. New York, NY: Academic Press, 365-395.

Baltes, P. Cornelius, S. \& Nesselroade, J. (1978) Cohort effects in behavioral development: Theoretical and methodological perspectives.

In W. Collins (Ed.), Minnesota symposia on child psychology, Vol 11. Hillsdale, NI: Erlbaum, 1-63.

Baltes, P., Reese, H. \& Lipsitt, L. (1980) Life-span developmental psychology. Annual Review of Psychology, 31, 65-110.

Baltes, P., Reese, H. \& Nesselroade, J. (1977) Life-span developmental psychology: Introduction to research methods. Monterey, CA: Brooks/Cole.

Berkman, L. (1982) Social network analysis and coronary heart disease. Advances in Cardiology, 29, 37-49.

Berkman, L. (1986) Social networks, support, and health: Taking the next step forward. American Journal of Epidemiology, 123, 559-562.

BMDP Statistical Software. (1985) Los Angeles, CA: University of California Press. Booth-Kewley, S. \& Friedman, H. (1987) Psychological predictors of heart disease: A quantitative review. Psychological Bulletin, 101, 343-362.

Botwinick, J. (1984) Aging and behavior. New York, NY: Springer Publishing Co. (3rd ed.)

Bortner, R. (1969) A short rating scale as a potential measure of pattern A behavior. Journal of Chronic Diseases, 22, 87-91.

Bortner, R. (1979) Notes on expected life history. International Journal of Aging and Human Development, 9, 291-294.

Bortner, R. \& Rosenman, R. (1967) The measurement of pattern A behavior. Journal of Chronic Diseases, 20, 525-533.

Brand, R. (1978) Coronary-prone behavior as an independent risk factor for coronary heart disease.

In T. Dembroski, S. Weiss, J. Shields, S. Haynes \& M. Feinleib (Eds.), Coronaryprone behavior. New York, NY: Springer Verlag, 11-24. 
Brand, R, Rosenman, R., Sholtz, R. \& Friedman, M. (1976) Multivariate prediction of coronary heart disease in the Western Collaborative Group Study compared to the findings of the Framingham study. Circulation, 53, 348-355.

Brim, Jr, O. \& Ryff, C. (1980) On the properties of life events.

In P. Baltes \& O. Brim Jr. (Eds.), Life-span dewelopment and behavior, VoL 3. New York, NY: Academic Press, 367-388.

Brown, G. (1974) Meaning, measurement, and stress of life events.

In B.S. Dohrenwend \& B.P. Dohrenwend (Eds.), Stressful life events: Their nature and effects. New York, NY: Wiley, 217-243.

Brown, G. (1984) Contextual measures of life events.

In B.S. Dohrenwend \& B.P. Dohrenwend (Eds.), Stressful life events and their contexts. New Brunswick, NJ: Rutgers University Press, 187-201.

Brozek, J., Keys, A. \& Blackburn, H. (1966) Personality differences between potential coronary and non-coronary subjects. Annals of the New York Academy of Siciences, 134, 1057-1064.

Brunson, B. \& Matthews, K. (1981) The Type A coronary-prone behavior pattern and reactions to uncontrollable stress: An analysis of performance strategies, affect, and attributions during failure. Joumal of Personality and Social Psychology, 40, 906-918.

Bühler, C. (1933) Der menschliche Lebenslauf als psychologisches Problem. Leipzig: Hirschel.

Bühler, C. (1959) Der menschliche Lebenslauf als psychologisches Problem. Göttingen: Hogrefe. (2nd. rev. ed.)

Bühler, C. (1968) The course of human life as a psychological problem. Human Development, 11, 184-200.

Burke, R. \& Weir, T. (1980) The Type A experience: Occupational and life demands, satisfaction and well-being. Joumal of Human Stress, 6, (4), 28-38.

Burnam, A., Pennebakèr, J. \& Glass, D. (1975) Time consciousness, achievement striving, and the Type A coronary-prone behavior pattern. Joumal of Abnormal Psychology, 84, 76-79. 
Butensky, A. Faralli, V., Heebner, D. \& Waldron, I. (1976) Elements of the coronary-prone behavior pattern in children and teenagers. Joumal of Psychosomatic Research, 20, 439-444.

Byrne, D. (1980) Attributed responsibility for life events in survivors of myocardial infarction. Psychotherapy \& Psychasomatics, 33, 7-13.

Byrne, D. (1981) Type A behaviour, life-events and myocardial infarction: Independent or related risk factors? British Joumal of Medical Psychology, 54, 371-377.

Byme, D. (1983) Personal determinants of life event stress and myocardiall infarotion. Psychotherapy \& Psychosomatics, 40, 105-114.

Byrne, D. (1987) Invited review: Personality, life events and cardiowascular disease. Journal of Psychosomatic Research, 31, 661-671.

Byrne, D. \& Rosenman, R. (1986) The Type A behaviour pattern as a precursor to stressful life events: A confluence of coronary risks. British Joumal of Medical Psychology, 59, 75-82.

Byrne, D. \& Whyte, H. (1980) Life events and myocardial infarction revisited: The role of measure of individual impact. Psychosomatic Medicine, 42, 1-10.

Carver, C. \& Glass, D. (1978) Coronary-prone behavior and interpersonal aggression. Jourmal of Personality and Social Psychology, 36, 361-366.

Carver, C., Coleman, E. \& Glass, D. (1976) The coronary-prone behavior pattern and the suppression of fatigue on a treadmill test. Joumal of Personality and Sacial Psychology, 33, 460-466.

Cassel, J. (1976) The contribution of the social environment to host resistance. American Journal of Epidemiolagy, 104, 107-122.

Charles, D. (1970) Historical antecedents of life-span developmental psychology. In L. Goulet \& P. Baltes (Eds.), Life-span developmental psychology" Research and theory. New York, NY: Academic Press, 23-52.

Chesney, M. Roserman, R. (1980) Type A behaviour in the work setting. In C. Cooper \& R. Paine (Eds.), Current concerns in occupational stress. New York, NY: Wiley, 187-212.

Cobb, S. (1976) Social support as a moderator of life stress. Psychosomatic Medi* cine, $38,300-314$. 
Cohler, B. (1982) Personal narrative and the life course.

In P. Baltes \& O. Brim, Jr. (Eds.), Life-span development and behavior, VoL 4. New York, NY: Academic Press, $205-241$.

Connoly, J. (1976) Life events before myocardial infarction. Joumal of Human Stress, 2, (4), 2-17.

Cooper, T, Detre, T. \& Weiss, S. (1981) Coronary-prone behavior and coronary heart disease: A critical rewiew. Curculation, 63, 1199-1215.

Costa, P., Jr. (1986) Is neuroticism a risk factor for CAD? Is Type A a measure of neuroticism?

In T. Schmidt, T. Dembroski \& G. Blümchen (Eds.), Biological and psychological factors in cardiovascular disease. Berlin: Springer Verlag, 85-95.

Costa, P., Jr. (1987) Influence of the normal personality dimension of neuroticism on chest pain symptoms and coronary artery disease. American Joumal of Cardiology, 60, 20J-26J.

Costa, P., Jr. \& McRae, R. (1980) Still stable after all these years: Personality as a key to some issues in adulthood and old age.

In P. Baltes \& O. Brim, Jr. (Eds.), Life-span development and behavior, VoL 3. New York, NY: Academic Press, 65-102.

Costa, P. Jr. \& McRae, R. (1987) Neuroticism, somatic complaints, and disease: Is the bark worse than the bite? Journal of Personality, 55, 299-316.

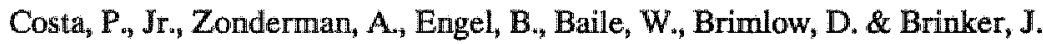
(1985) The relation of chest pain symptoms to angiographic findings of coronary artery stenosis and neuroticism. Psychosomatic Medicine, 47, 285-293.

Crisp, A., Queenan, M. \& D'Souza, M. (1984) Myocardial infarction and the emotional climate. The Lancet, March 17,616-619.

De Faire, U. \& Theorell, T. (1976) Life changes and myocardial infarction: How useful are life change measurements? Scandinavian Joumal of Social Medicine, 4, 115-122.

De Gregorio, E. \& Carver, C. (1980) Type A behavior pattern, sex role orientation, and psychological adjustment. Journal of Personality and Social Psychology, 39, 286-293. 
Dembroski, T. \& Costa, P. Jr. (1988) Assessment of coronary-prone behavior: A current overview. Annals of Behowional Medicine, 10, 60-63.

Dembroski, T. \& MacDougall, J. (1983) Behavioral and psychophysiological perspectives on coronary-prone behavior.

In T. Dembroski, T. Schmidt \& G. Blümchen (Eds.), Biobehavioral bases of caronary heart disease. Basel: Karger, 106-129.

Dimsdale, J. (1988) A perspective on Type A behavior and coronary disease. New England Joumal of Medicine, 318, 110-112.

Dorreboom, G. \& Snel, J. (1988) Type A/B gedrag in relatie met persoonlijkheidskenmerken, coping style en levensgebeurtenissen bij jonge mannen en vrouwen. [Type $A / B$ behavior and its relationship to personality, coping style and life events in young men and women]. Gedrag \& Gezondheid; 16, 68-76.

Elder, G., Jr. (1975) Age differentiation and the life course. Annual Review of Socio$\log y_{\|}, 1,165-190$.

Elder, G., Jr. (1979) Historical change in life patterns and personality. In P. Baltes \&. O. Brim, Jr. (Eds.) Life-span development and behavior, Vol. 2. New York, NY: Academic Press, 117-159.

Elder, G., Jr. \& Caspi, A. (1986) Life satisfaction in old age: Linking social psychology and history. Psychology \& Aging, 1, 18-26.

Elder, G., Jr. \& Rockwell, R. (1979) The life course and human development: An ecological perspective. International Journal of Behavioral Development, 2, 1-21. Elder, G., Jr. \& Seligman, M. (1986) Learned helplessness and life-span development.

In A. Sorensen, F. Weinert \& L. Sherrod (Eds.), Human development: Multidisciplinary perspectives. Hillsdale, NJ: Erlbaum.

Emmelkamp, P. \& Karsdorp, E. (1987) The effects of perceived parental rearing style on the development of Type A pattern. European Journal of Personality, 1, 223-230.

Eyer, J. (1977a) Prosperity as a cause of death. International Journal of Health Services, $7,125-148$. 
Byer, J. (1977b) Does unemployment cause the death rate peak in each business cycle? A multifactorial model of death rate change. International Joumal of Healith Services, 7, 625-662.

Eyer, J. (1980) Social causes of coronary heart disease. Psychotherapy \& Psychosomatics, 34, 75-87.

Falger, P. (1983a) Pathogenic life changes in middle adulthood and coronary heart disease: A life-span developmental perspective. International Joumal of Aging and Human Development, 16, 7-27.

Falger, P. (1983b) Behavioral factors, life changes, and the development of vital exhaustion and depression in myocardial infarction patients. International Joumal of Behavioral Development, 6, 405-425.

Falger, P. (1984) Mijnsluiting, psychische en sociale aanpassing, en hartinfarct. [The closing of coal mines, psychological and social adaptation, and myocardial infarction].

In K. Soudijn \& R.J. Takens (Red.), Psychologie en economische recessie. Amsterdam; Nederlands Instituut van Psychologen, 140-152.

Falger, P. (1987) Biografische analyse en hartinfarct op middelbare leeftijd. [Biographical analysis and myocardial infarction in middle adulthood]. Nederlands Tijdschrift voor de Psychologie, 42, 11-20.

Falger, P. (1988) Life changes in middle adulthood, coronary-prone behavior, and vital exhaustion: Some retrospective findings.

In C. Spielberger, I. Sarason \& P. Defares (Eds.), Stress and anxiety, Vol. 11. Washington, DC: Hemisphere, 151-161.

Falger, P., Schouten, E., Appels, A. \& De Vos, Y. (1988) Sleep complaints, behavioral characteristics and vital exhaustion in myocardial infarction cases. Psychology \& Health, 2, 231-258.

Fiske, M. Chiriboga, D. (1985) The interweaving of societal and personal change in adulthood.

In J. Munnichs, P. Mussen, E. Olbrich \& P. Coleman (Eds), Life-span and change in a gerontological perspective. Orlando, FL: Academic Press, 177-209. 
Forsdahl; A. (1977) Are poor living conditions in childhood and adolescence an immportant risk factor for arteriosclerotic heart disease? British Joumal of Preventive and Social Medicine, 31, 91-95.

Forsdahl, A. (1978) Living conditions in childhood and subsequent development of risk factors for arteriosclerotic heart disease. Journal of Epidemology and Community Health, 32, 34-37.

Friedman, H. \& Booth-Kewley, S. (1987) The "disease-prone personality": A metaanalytic view of the construct. American Psychologist, 42, 539-555.

Friedman, M. \& Rosenman, R. (1959) Association of specific overt behavior pattern with blood and cardiovascular findings: Blood cholesterol level, blood clotting time, incidence of arcis senilis and clinical coronary artery disease. Joumal of the American Medical Association, 169, 1286-1296.

Friedman, M. \& Rosenman, R. (1974) The key cause - Type A behavior pattern. In J. Monat \& R. Lazanus (Eds.) (1977), Stress and coping. New York, NY: Columbia University Press.

Gastorf, J., Suls, J. \& Sanders, G. (1980) Type A coronary-prone behavior pattern and social facilitation. Joumal of Personality and Social Psychology, 38, 773-780. Glass, D. (1977) Behavior patterns, stress, and coronary disease. Hillsdale, NJ: Erlbaum.

Glass, D. \& Carver, C. (1980) Helplessness and the coronary-prone personality. In J. Garber \& M. Seligman (Eds.), Human helplessness: Theory and applications. New York, NY: Academic Press, 223-243.

Glass, D., Snyder, M. \& Hollis, J. (1974) Time urgency and the Type A coronaryprone behavior pattern. Joumal of Applied Social Psychology, 4, 125-140.

Glasunov, I., Dowd, J., Baubiniene, A., Grabauskas, V., Sturmans, F. \& Schuurman, J. (Eds.) (1981) The Kaumas-Rotterdam Intervention Study. Amsterdam: Elsevier/North-Holland.

Gould, R. (1972) The phases of adult life: A study in developmental psychology. American Joumal of Psychiatry, 129, 521-531.

Gould, R. (1978) Transitions: Growth and change in adult life. New York, NY: Simon \& Schuster. 
Greene, W.; Goldstein, S. \& Moss, A (1972) Psychosocial aspects of sudden death: A preliminary repoirt. Archives of Intemal Medicine, 129, 725-731.

Groffmann, K. (1970) Life-span developmental psychology in Europe: Past and present.

In L. Goulet \& P. Baltes (Eds.), Life-span developmental psychology: Reseanch and theory. New York, NY: Academic Press, 53-68.

Halperin, P. \& Littman, A. (1985) Type A behavior and survival after myocardial infarction (Correspondence). New England Journal of Medicine, 313, 450.

Hammen, C. \& Mayol, A (1982) Depression and cognitive characteristics of stressful life event types. Joumal of Abnomal Psychology, 91, 165-174.

Havighurst, R. (1973) History of developmental psychology: Socialization and personality development through the life-span.

In P. Baltes \& K.W. Schaie (Eds.), Life-span developmental psychology: Personality and socialization. New York, NY: Academic Press, 3-24.

Haynes, S. \& Matthews, K. (1988) Review and methodological critique of recent studies on Type A behavior and cardiovascular disease. Annols of Behavional Medicine, 10, 47-59.

Haynes, S., Feinleib, M. \& Kannel, W. (1980) The relationship of psychosocial factors to coronary heart disease in the Framingham Study. III. Eight-year incidence of coronary heart disease. American Joumal of Epidemiology, 111, 3758.

Haynes, S. Feinleib, M., Levine, S., Scotch, N. \& Kannell, W. (1978a) The relationship of psychosocial factors to coronary heart disease in the Framingham Study. II. Prevalence of coronary heart disease. American Joumal of Epidemiology, 107, 384 402 .

Haynes, S., Levine, S., Scotch, N., Feinleib, M. \& Kannel, W. (1978b) The relationship of psychosocial factors to coronary heart disease in the Framingham Study. I. Methods and risk factors. American Joumal of Epidemiology, 107, 362-383. Heyden, S., Bartel, A., Tabesh, E., Cassel, J., Tyroler, H., Cornoni, J. \& Hames, C. (1971) Angina pectoris and the Rose questionnaire. Archives of Intemal Medicine, $128,961-964$. 
Hinkle, L., Ir. (1974) The effects of exposure to cultural change, social change, and changes in interpersonall relationships on health.

In B.S. Dohrenwend \& B.P. Dohrenwend (Eds.), Stressful tife events. Their nature and effects. New York, NY: Wiley, 9-44.

Holmes, T. \& Rahe, R. (1967) The Social Readjustment Rating Scale. Joumal of Psychosomatic Research, 11, 213-218.

Horn, J. \& Donaldson, G. (1980) Cognitive development in adulthood. In O. Brim, $\mathrm{J}_{\mathrm{r} .}$ \& J. Kagan (Eds.), Constancy and change in human development. Cambridge, MA: Harvard University Press, 445-529.

Hultsch, D. \& Plemons, J. (1979) Life events and life-span development.

In P. Baltes \& O. Brim, Ir. (Eds.), Life-span development and behavior, Vol. 2. New York, NY: Academic Press, 1-36.

Jahoda, M. (1982) Employment and unemployment: A social-psychological analysis. Cambridge: Cambridge University Press.

Jenkins, C.D. (1971) Psychologic and social precursors of coronary disease. New England Journal of Medicine, 284, 244-255 (pt. 1); 307-317 (pt. 2).

Jenkins, C.D. (1976) Recent evidence supporting psychologic and social risk factors for coronary disease. New England Joumal of Medicine, 294, $987-994$ (pt. 1); 1033-1038 (pt. 2).

Jenkins, C.D. (1978a) Behavioral risk factors in coronary artery disease Annual Review of Medicine, $29,543-562$.

Jenkins, C.D. (1978b) A comparative review of the interview and questionnaire methods in the assessment of the coronary-prone behavior pattern.

In T. Dembroski, S. Weiss, J. Shields, S. Haynes \& M. Feinleib (Eds.), Coronayprone behavior. New York, NY: Springer Verlag, 71-88.

Jenkinis, C.D. (1988) Epidemiology of cardiovascular diseases. Journal of Consulting and Clinical Psychology, 56, 324-332.

Jenkins; C.D. \& Zyzanski, S. (1980) Behavioral risk factors and coronary heart disease. Psychotherapy \& Psychosomatics, 34, 149-177.

Jenkins, C.D., Hurst, M. \& Rose, R. (1979) Life changes: Do people really remember? Archives of General Psychiatry, 36, 379-384. 
Kagan, J. (1980) Perspectives on continuity.

In O. Brim, Jr. \& J. Kagan (Eds.), Constancy and change in human development. Cambridge, MA: Harvard University Press, 1-25.

Karasek, R., Baker, D., Marxer, F., Ahlbom, A. \& Theorell, T. (1981) Job decision latitude, job demands, and cardiovascular disease. American Joumal of Public Health, 71, 694-705.

Kasl, S. \& Cobb, S. (1980) The experience of losing a job: Some effects on cardiovascular functioning. Psychotherapy \& Psychosomatics, 34, 88-109.

Kasl, S., Gore, S. \& Cobb, S. (1975) The experience of losing a job: Reported changes in health, symptoms, and illness behavior. Psychosomatic Medicine, 37, 106-122.

Kittel, F. (1984) Approache psychosocial de la prévalence et de l'incidence des affections coronairiennes. Brussels: Free University, unpublished Ph.D. thesis.

Kleinbaum, D., Kupper, L. \& Morgenstern, H. (1982) Epudemiologic research: Principles and quantitative methods. New York, NY: Van Nostrand Reinhold.

Krantz, D., Glass, D. \& Snyder, M. (1974) Helplessness, stress level, and the coronary-prone behavior pattern. Joumal of Experimental Social Psychology, 10, 284-300.

Kuller, L. (1978) Prodromata of sudden death and myocardial infarction. Advances in Cardiology, 25, 61-72.

Kuller, L., Cooper, M. \& Perper, J. (1972) Epidemiology of sudden death. Archives of Internal Medicine, 129, 714-719.

Laux, L. \& Weber, H. (1987) Person-centered coping research. European Joumal of Personality, 1, 193-214.

Lazarus, R. \& Folkman, S. (1984) Stress, appraisal, and coping. New York, NY: Springer Publishing Co.

Lehr, U. (1976) Zur Frage der Gliederung des menschlichen Lebensablaufs. Aktuelle Gerontologie, 6, 357-345.

Levenkron, J. \& Moore, L. (1988) The Type A behavior pattern: Issues for intervention research. Annals of Behowioral Medicine, 10, 78-83.

Levinson, D. (1977) The mid-life transition: A period in adult psychosocial development. Psychiairy, 40, 99-112. 
Lewinson, D., Darrow, C., Klein, E., Levinson, M. McKee, B. (1979) The seasions of a man's life. New York, NY: Ballantine Books:

Lind, E. \& Theorell, T. (1973) Sociological characteristics and myocardial infarctions. Joumal of Psychosomatic Research, 17, 59-73.

Lundberg, U. \& Theorell, T. (1976) Sealing of life changes: Differences between three diagnostic groups and between recently experienced and non-experienced events. Joumal of Human Stress, 2, 7-17.

Lundberg, U., Theorell, T. \& Lind, E. (1975) Life changes and myocardial infarction: Individual differences in life change scaling. Joumal of Psychosomatic Research, 19, 27-32.

Lundman, $T$., Liljeförs, $\mathbb{I}_{\text {, }}$ Cederlof, R. \& Friberg, L. (1971) The validity of the questionnaire diagnosis "Angina pectoris". Archives of Environmental Healch, 22, 597-599.

Luteijn, F. \& Bouman, T. (1988) The concepts of depression, anxiety, and neuroticism in questionnaires. European Journal of Personality, 2, 113-120.

Mantel, N. (1963) Chi-square tests with one degree of freedom: Extensions of the Mantel-Haenszel procedure. Joumal of the American Statistical Association, 58, $690-700$.

Mantel, N. \& Haenszel, W. (1959) Statistical aspects of the analysis of data from retrospective studies of disease. Joumal of the National Cancer Institute, 22, 719-748.

Mantel, N., Brown, C.\& Byar, D. (1977) Test for homogeneity of effect in an epidemiologic investigation. American Joumal of Epidemiology, 106, 125-129.

Margolis, L.y McLeroy, K., Runyan, C. \& Kaplan, B. (1983) Type A behavior: An ecological approach. Journal of Behavioral Medicine; $6,245-258$.

Marmot, M. (1982) Socio-economic and cultural factors in ischaemic heart disease. Advances in Cardiology, 29, 68-76.

Matteson, M. \& Ivancevich, J. (1980) The coronary-prone behavior pattern: A review and appraisal. Sacial Science \& Medicine, 14A, 337-351.

Matthews, K (1977) Caregiver-child interactions and the Type A coronary-prone behavior pattern. Child Development, 48, 1752-1756. 
Matthews, K (1979) Efforts to control by children and adults with the Type A coronary-prone behavior patterm. Child Development, 50, 842-847.

Matthews, K (1982) Psychological perspectives on the Type A behavior pattern. Psychological Bulletin, 91, 293-323.

Matthews, K \& Angulo, J. (1980) Measurement of the Type A behavior pattern in children:-Assessment of children's competitiveness, impatience-anger, and aggression. Child Development, $51,466-475$.

Matthews, K \& Brunson, B. (1979) Allocation of attention and the Type A coronary-prone behavior pattern. Journal of Personality and Social Psychology, 37, 2081-2090.

Matthews, K. Q Glass, D. (1984) Type A behavior, stressful life events, and coronary heart disease.

In B.S. Dohrenwend \& B.P. Dohrenwend (Eds.), Stressful life events and their contents. New: Brunswick, NJ: Rutgers University Press, 167-185.

Matthews, K. \& Haynes, S. (1986) Type A behavior pattern and coronary disease risk: Update and critical evaluation. American Joumal of Epidemiology, 123, 923 960 .

Matthews, K \& Valkin, J. (1981) Efforts to excel and the Type A behavior pattern in children. Child Development, 52, 1283-1289.

Matthews, K. \& Woodall, K. (1988) Childhood origins of overt Type A behaviors and cardiowascular reactivity to behavioral stressors. Annals of Behavioral Medicine, 10, 71-77.

Matthews, K, Glass, D., Rosenman, R. \& Bortner, R. (1977) Competitive drive, pattern $A$, and coronary heart disease: A further analysis of some data from the Western Collaborative Group Study, Journal of Chronic Disecuses, 30, 489-498.

Matthews, K., Krantz, D., Dembroski, T. \& MacDougall, J. (1982) Unique and common variance in Structured Interview and Jenkins Activity Survey measures of the Type A behavior pattern. Joumal of Personality and Social Psychology, 42, 303-313.

McCranie, E. \& Simpson, M. (1987) Parental child-rearing antecedents of Type A behavior. Personality and Social Psychology Bulletin, 12, 493-501. 
Mettlin, C. (1976) Occupational careers and the prevention of coronary-prone behavior "Social Science \& Medicine, 10, 367-372.

Miernyk, W. (1975) The changing life cycle of work.

In N. Datan \& L. Ginsberg (Eds.), Life-span developmental psychology Normatwe Iffe crises. New York, NY: Academic Press, 279-285.

Miettinen, O. (1972) Standardization of risk ratios. American Joumal of Epidemiolo$8 y, 96,383-388$.

Miettinen, O. (1976) Estimability and estimation in case-referent series. American Joumal of Epidemiology, 103, 225-235.

Miettinen, O. (1985a) The "case-control" study: Valid selection of subjects. Joumal of Chronic Diseases, 38, 543-548.

Miettinen, O. (1985b) Theoretical epidemiology: Principles of occurrence research in medicine. New York, NY: Wiley.

Moss, H. \& Susman, E. (1980) Longitudinal study of personality development.

In O. Brim Jr. \& J, Kagan ( $\mathrm{Eds}_{4}$ ), Constancy and change in human development: Cambridge, MA: Harvard University Press, 530-595.

Munnichs, J. \& Olbrich, E. (1985) Life-span and change in a gerontological perspective.

In J. Munnichs, P. Mussen, E. Olbrich \& P. Coleman (Eds.), Life-span and change in a gerontological perspective. Orlando, FL: Academic Press, 3-11. Murray, D, Matthews, K., Blake, S., Prineas, R. \& Gillum, R. (1986) Type A behavior in children: Demographic, physiological and behavioral correlates. Health Psychology, 5, 159-170.

Neugarten, B. \& Datan, N. (1973) Sociological perspectives on the life cycle.

In P. Baltes \& K.W. Schaie (Eds.), Life-span developmental psychology: Personality and socialization. New York, NY: Academic Press, 53-69.

Nixon, P. (1976) The human function curve. The Practitioner, 217, 765-770; 935-944.

Oakes, T. (1985) Type A behavior and survival after myocardial infarction (Corréspondence). New England Journal of Medicine, 313, 451.

Orth-Gomer, C. (1979) Ischaemic heart disease and psychological stress in Stockholm and New York. Joumal of Psychosomatic Research, 23, $165-173$. 
Overton, W. \& Reese, H. (1973) Models of dewelopment: Methodological inalicathons.

In I: Nesselroade \& H. Reese (Eds.), Life-spon developmental psychology: Methodological ussues, New Yor

Pearce, $N$, \& Checkoway, $H$, (1988) Case-control studies usimg other diseases as controls: Problems of excluding exposure-related diseases. American Joumal of Epidemiology, 127, 851-856.

Pitner, M. \& Houston, B. (1980) Response to stress, cognitive coping strategies and the Type A behavior pattern. Journal of Personality and Social Psychology, $39,147-157$.

Powell, L., Friedman, M., Thoresen, C., Gill, J. \& Ulmer, D. (1984) Can the Type A behavior pattern be altered after myocardial infarction? A second-year report from the Recurrent Coronary Prevention Project. Psychosamatic Medicine, 46, 293-313.

Ragland; D. \& Brand, R. (1988a) Coronary heart disease mortality in the Western Collaborative Group Study. Follow-up experience of 22 years. American Joumal of Epidemiology; 127, 462-475.

Ragland, D. \& Brand, R. (1988b) Type A behavior and mortality from coronary heart disease. New England Joumal of Medicine, 318, 65-69.

Rahe, R., Bennett, L., Romo, M., Siltanen, T. \& Arthur, R. (1973) Subjects' recent life changes and coronary theart clisease in Finland. American Journal of Psychiatry, 130, 1222-1226.

Rahe, R., Romo, M., Bennett, L. \& Siltanen, P. (1974) Recent life changes, myocardial infarction, and abrupt coronary death. Archives of Internal Medicine, 133, $221-228$.

Reese, H. \& Overton, W. (1970) Models of development and theories of development.

In L. Goulet \& P. Baltes (Edsw), Life-span developmental psychology: Research and theory. New York, NY: Academic Press, 114-145.

Reinert, G. (1979) Prolegomena to a history of life-span developmental psychology. In P. Baltes \& O. Brim Jr. (Eds.), Life-span development and behavior, VoL 2. New York, NY: Academic Press, 205-254. 
Riegel, K (1975) Adult life crises: A dialectic interpretation of development: In N. Datan \& L. Ginsberg (Eds), Life-span developmental psychology Normative life crises. New York, NY: Academic Press, 99-128.

Riegel, K. (1979a) The dialectics of lnuman development.

In K. Riegel, Foundations of dialectical psychology. New York, NY: Academic Press, 1-16.

Riegel, K. (1979b) Historical introduction.

In K. Riegel, Foundations of dialectical psychology. New York, NY: Academic Press, 17-34.

Rissanen, V., Romo, M. \& Siltanen, P. (1978) Premonitory symptoms and stress factors preceding sudden death from ischaemic heart disease. Acta Medica Scandinavica, 204, 389-396.

Romo, M., Siltanen, P., Theorell, T. \& Rahe, R. (1974) Work behavior, time urgency, and life dissatisfactions in subjects with myocardial infarction: A crosscultural study. Journal of Psychosomatic Research, 18, $1-8$.

Rose, G., Blackburn, H., Gillum, R. \& Prineas, R. (1982) Cardiovascular survey methods. Geneva: World Health Organization Monograph Series, No. 56. (2nd. ed.)

Rosenman, R. (1978) The interview method of assessment of the coronary-prone behavior pattern.

In T. Dembroski, S. Weiss, J. Shields, S. Haynes \& M. Feinleib (Eds.), Coronaryprone behavior. New York, NY: Springer Verlag, 55-69.

Rosenman, R. \& Chesney, M. (1980) The relationship of Type A behavior pattern to coronary heart disease. Activitas Nervosa Superior (Praha), 22, 1-45.

Rosenman, R. \& Friedman, M. (1961) Association of specific behavior pattern in women with blood and cardiovascular findings. Circulation, 24, 1173-1184.

Rosenman, R., Friedman, M., Straus, R, Wurm, M., Kositchek, R., Hahn, W. \& Werthessen, N. (1964) A predictive study of coronary heart disease: The Western Collaborative Group Study. Joumal of the American Medical Association, $189,15-26$. 
Rosenman, R, Brand, R., Jenkins, C.D., Friedman, M., Straus, R. \& Wurm, M. (1975) Coronary heart disease in the Western Collaborative Group Study: Final follow-up experience of 8,5 years. Joumal of the American Medical Association, 233, 872-877.

Rothman, K. (1986) Modem epidemiology. Boston, MA: Little, Brown \& Company. Rothman, K. \& Bolce, J. (1982) Epidemiologic analysis with a programmable calculator. Boston, MA: Epidemiological Resources. (New ed.)

Sands, J. \& Parker, J. (1979) A cross-sectional study of the perceived stressfullness of several life events. International Joumal of Aging and Human Development, $10,335-341$.

Schaie, K.W. (1965) A general model for the study of human dewelopment. Psychological Bulletin, 64, 92-107.

Schaie, KW. (1973) Methodological problems in descriptive developmental research on adulthood and aging.

Ih J. Nesselroade \& H. Reese (Eds.), Life-span developmental psychology: Methodological issues. New York, NY: Academic Press, 253-280.

Schaie, KW. (1977) Toward a stage theory of adult cognitive devellopment. Joumal of Aging and Human Development, 8, 129-138.

Schaie, K.W. \& Gribbin, K. (1975) Adult development and aging. Anmual Review of Psychology, 26, 65-96.

Schroots, J. (1982) Ontogenetische psychologie: Een eerste kennismaking. [Ontogenetic psychology: An introduction]. De Psycholoog, 17, 68-81.

Shekelle, R., Hulley, S., Neaton, J., Billings, J., Borbani, N., Gerace, T., Jacobs, D., Lasser, N., Mittlemark, M. \& Stamler, J. (1985) The MRFIT behavior pattern study. II. Type A behavior and incidence of coronary heart disease. American Joumal of Epidemiology, 122, 559-570.

Siegel, J. (1984) Type A behavior: Epidemiologic foundations and public health implications. Annual Review of Public Health, 5, 343-367.

Siegel, J. \& Leitch, C. (1981) Assessment of the Type A behavior pattern in adolescents. Psychosomatic Medicine, 43, 45-56. 
Siegrist, J. \& Weber, K. (1983) Statusbedrohung in mittleren Erwachsenen-alter und ihre gesundheitlichen Folgen. Medizin-soziologische Befunde zu koronaren Herzkrankheiten. Zeitschrift für Gerontologie, 16, 100-106.

Silver, R. \& Wortman, C. (1980) Coping with undesirable life events.

In J. Garber \& M. Seligman (Eds.), Human helplessness: Theory and applications. New York, NY: Academic Press, 279-340.

Smith, $B_{w}$ (1981) Black lung: The social production of disease. International Joumal of Health Senvices, 11, 343-359.

Smith, T. \& Brehm, S. (1981) Person perception and the Type A coronary-prone behavior pattern. Journal of Personality and Social Psychology, 40, 1137-1149.

Snyder, C., Ford, C. \& Harris, R. (1987) The effects of theoretical perspective on the analysis of coping with negative life events.

In C. Snyder \& C. Ford (Eds.), Coping with negative life events: Clinical and psychological perspectives. New York, NY: Plenum Press, 3-13.

SPPS-X (1986) New York, NY: McGraw-Hill. (2nd. ed.)

Steinberg, L. (1985) Early temperamental antecedents of adult Type A behaviors. Developmental Psychology, 21, 1171-1180.

Theorell, T. (1976) Selected illnesses and somatic factors in relation to two psychosocial stress indices. A prospective study on middle-aged building construction workers. Joumal of Psychosomatic Research, 20, 7-20.

Theorell, T. (1980) Life events and manifestations of ischaemic heart disease: Epidemiological and psychophysiological aspects. Psychotherapy \& Psychosomatics, 34, 135-148.

Theorell, T. (1982) Review of research on life events and cardiovascular illness. Advances in Cardiology, 29, 140-147.

Theorell, T. \& Flodérus-Myrhed, B. (1977) "Workload" and risk of myocardial infarction - A prospective psychosocial analysis. Intemational Joumal of Epidemiology, 6, 17:21.

Theorell, T. \& Rahe, R. (1970) Psykosocialla faktorer i tidsmässig relation till hjärtinfarkt. Nordisk Medicin, 84, 850-857.

Theorell, T. \& Rahe, R. (1971) Psychosocial factors and myocardial infarction. I. An inpatient study in Sweden. Journal of Psychasomatic Research, 15, 25-31. 
Theorell, T. \& Rahe, R. (1972) Behavior and life satisfactions characteristics of Swedish subjects with myocardial infarction. Joumal of Chronic Diseawes, 25, 139-147.

Theorell, T., Lind, E. \& Floderus, B. (1975) The relationship of disturbing life changes and emotions to the early development of myocardial infarction and other serious illnesses. Intemational Joumal of Epidemiology, 4, 281-293.

Theorell, T, Olsson, A \& Engholm, E. (1977a) Concrete work and myocardial infarction. Scandinavian Joumal of Work \& Environmental Health, 3, 144-153. Theorell, T, Schalling, D. \& Akerstedt; T. (1977b) Circulatory reactions in coronary patients during interview. A noninvasive study. Biological Psychology, 5, 233-243.

Theorell, T, Lind, E., Fröberg, J., Karlsson, C. \& Levi, L. (1972) A longitudinal study of 21 subjects with coronary heart disease: Life changes, catecholamine excretion and related biochemical reactions. Psychosomatic Medicine, 34, 505516.

Thiel, H., Parker, D. \& Bruce, T. (1973) Stress factors and the risk of myocardial infarction. Journal of Psychosomatic Research, 17, 43-57.

Thomae, H. (1979) The concept of development and life-span developmental psychology.

In P. Baltes \& O. Brim, Jr. (Eds.), Life-span development and behavior, VoL 2. New York, NY: Academic Press, 281-312.

Thomae, H. (1987) Conceptualizations of responses to stress. European Joumal of Personality, 1, 171-192.

Thomas, C.B. (1976) Precursors of premature disease and death: The predictive potential of habits and family attitudes. Annals of Intemal Medicine, 85, 653-658.

Thomas, C.B. \& Greenstreet, R. (1973) Psychobiological characteristics in youth as predictors of five disease states: Suicide, mental illness, hypertension, coronary heart disease and tumor. Johns Hopkins Medical Joumal, 132, 16-43.

Totman, R. (1979) What makes "Life Events" stressful? A retrospective study of patients who have survived a first myocardial infarction. Joumal of Psychosomatic Research, 23, 193-201. 
Vaillant, G. (1974) Natural history of male psychological health. II. Some antecedents of heal thy adult adjustment. Archives of General Psychiatry, 31, 15-22.

Vaillant, G. (1977) Adaptation to life: How the best and the brightest cane of age. Boston, MA: Little, Brown \& Co.

Vega-Lahr, N. \& Field, T. (1986) Type A behawior in preschool children. Child Development, 57, 1333-1348.

Verhagen, F., Nass, C., Appels, A., Van Bastelaer, A. \& Winnubst, J. (1980) Crossvalidation of the A/B Typology in the Netherlands. Psychotherapy \& Psychosomatics, 34, 178-186.

Vossel, G. (1987) Stress conceptions in life ewent research: Towards a person-centered perspective. European Joumal of Personality, 1, 123-140.

Williams, R. (1987) Psychological factors in coronary artery disease: Epidemiologic evidence. Circulation, 76, Monograph 6, I 117-123.

Wolf, S. (1969) Psychosocial factors in myocardial infarction and sudden death. Circulation, 40, Suppl. IV, 74-83.

Zyzanski, S. (1978) Coronary-prone behavior pattern and coronary heart disease:

Epidemiological evidence.

In T. Dembroski, S. Weiss, J. Shields, S. Haynes \& M. Feinleib (Eds.), Coronaryprone behavior. New York, NY: Springer Verlag, 25-40. 
$-206-$ 
Table 2.1.:

Selection Bias

in Participating (Part) and Non-Participating (Non-Part)

Cases with First Myocardial Infaretion.

Pant Non-Pant Statistics

Number of cases

133

20

Mean age/standard deviation $53.1(9.5)$

$54.5(8.9)$

$\mathrm{t}=0.63 ; \mathrm{NS}$

Behavioral \& clinical characteristics:

Mean MQ-scores/standard deviation

Angina pectoris

Current smoking

Coffee consumption ${ }^{\mathrm{a}}$

Use of sleeping pills
$18.0(10.8)$

$30(23 \%)$

111. $(84 \%)$

$67(50 \%)$

$12(9 \%)$
$15.9(11.5)$

$5(25 \%)$

$15(75 \%)$

$9(45 \%)$

$0(0 \%)$ $t=0.78 ;$ NS

$\mathrm{Chi}^{2}=0.06$; NS

$\mathrm{Chi}^{2}=0.86 ; \mathrm{NS}$

$\mathrm{Chi}^{2}=0.20 * \mathrm{NS}$

$\mathrm{Chi}^{2}=1.96 ; \mathrm{NS}$

Current sleep complaints: "Over the last half year, $[. .$.$] ?"$

did you often have trouble falling asleep ${ }^{b}$

(MO-item)

$62(47 \%)$

$10(50 \%)$

$\mathrm{Chi}^{2}=0,08 ; \mathrm{NS}$

did you often wake up at night ${ }^{b}$

(MQ-item)

$56(42 \%)$

$10(50 \%)$

$\mathrm{Chi}^{2}=0.44 ; \mathrm{NS}$ did you sometimes wake up in the morning feeling tired and exhausted ${ }^{b}$ $\begin{array}{llll}\text { (MQ-item) } & 45(34 \%) & 6(30 \%) & \mathrm{Chi}^{2}=0.11 \text {; NS }\end{array}$ did you sleep poorly in general ${ }^{b}$

(LSQ-item)

\section{$55(41 \%)$}

$8(47 \%)$

$\mathrm{Chi}^{2}=0.47 ; \mathrm{NS}$

did you often get out of bed at night ${ }^{\text {b }}$ (LSQ-item)

$7(35 \%)$

$\mathrm{Chi}^{2}=1.46 ; \mathrm{NS}$ did you wake up in the morning feeling refreshed ${ }^{c}$ (LSQ-item) 45 (44\%)

$6(32 \%)$

$\mathrm{Chi}^{2}=0.05 ; \mathrm{NS}$ did you often take naps during the day ${ }^{d}$ (LSQ-ïtem)

${ }^{a} 6$ or more cups/day only.

b" "yes" only.

$c$ "no" only.

d. "often, light and short" and "often, in deep sleep" only. 
Table 2.2:

Sellection Blas

in Participating (Part) and Non-Participating (Non-Part)

Hospital Referents

as Assessed by Means of the Primary Reasons for Hospitalization.

A) Surgical \& newrological:

Hypertrophic tendinitis

Inguinal hernia

Hemorrhoids

26

10

(Acute) appendicitis

22

6

Varices

16

3

Cataract

14

3

TOTAL

B) Urological:

Papilloma vesicae

Prostate hypertrophia

Ureter stones

Hydrocele

Pyeloplication

$\begin{array}{rr}9 & 1 \\ 9 & 1 \\ 9 & 1 \\ 5 & 1 \\ 5 & 0 \\ 5 & 0 \\ 5 & 0 \\ 4 & 0 \\ 3 & 0 \\ 2 & 0 \\ 22 & 6 \\ 78 & 10\end{array}$

Spermatocele 0

Ureter stricture

Kidney colics 0

Vasectomy 0

Urine retention

Other single urological diagnostic categories TOTAL

$\mathrm{Chi}^{2}=11.77, \mathrm{df}=7 ; \mathrm{NS}$. ( $\mathrm{df}=7$, because the six "surgical \& neurological" categories, "other single urological diagnostic categories", and the remaining urological categories were collapsed in order to avoid cell frequencies that would be too smalli). 


\section{Table 23:}

Distribution of Cases with First Myocardial Infarction (MI), Neighborhood Referents (NR), and Hospital Referents (HR)

in Seven Age Strata.

\begin{tabular}{|c|c|c|c|c|}
\hline & $M T(N=133)$ & $N R(N=133)$ & $H R(N=192)$ & $\operatorname{Total}(N=458)$ \\
\hline Age & $N \%$ & $N \%$ & $N \%$ & $N \%$ \\
\hline $35-39$ & $15(11.3)$ & $26(19.6)$ & $24(12.5)$ & $65(14.2)$ \\
\hline $40-44$ & $16(12.0)$ & $21(15.8)$ & $35(18.2)$ & $72(15.7)$ \\
\hline $45-49$ & $19(14.3)$ & $21(15.8)$ & $30(15.6)$ & $70(15.3)$ \\
\hline $50-54$ & $18(13.5)$ & $23(17.3)$ & $24(12.5)$ & $65(14.2)$ \\
\hline $55-59$ & $26(19.6)$ & $18(13.5)$ & $29(15.1)$ & $73(15.9)$ \\
\hline $60-64$ & $23(17.3)$ & $17(12.8)$ & $32(16.7)$ & $72(15.7)$ \\
\hline $65-69$ & $16(12.0)$ & $7(5.2)$ & $18(9.4)$ & $41(9.0)$ \\
\hline & & $\ldots \ldots$ & 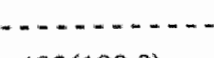 & - \\
\hline & $133(100.0)$ & $133(100.0)$ & $192(100.0)$ & $458(100.0)$ \\
\hline
\end{tabular}

$\mathrm{Chi}^{2} \mathrm{MIXNR}=10.22, \mathrm{df}=6 ;$ NS.

$\mathrm{CHi}^{2} \mathrm{MLXHR}=3.65, \mathrm{df}=6$; NS. 
Table 2.4.:

Distribution of Cases with First Myocardial Infarction (MI), Neighborhood Referents (NR), and Hospital Referents (HR) by Nine Interviewrers .

\begin{tabular}{|c|c|c|c|c|}
\hline \multirow[t]{2}{*}{ Interviewer } & $M I(N=133)$ & $N R(N=133)$ & $H R(N=192)$ & Total $(N=458)$ \\
\hline & $N \%$ & $N \%$ & $N \%$ & $N \quad \%$ \\
\hline $\mathrm{A}$ & $46(34.6)$ & $9(6.8)$ & $0(0.0)$ & $55(12.0)$ \\
\hline $\mathrm{B}$ & $26(19.5)$ & $30(22.6)$ & $4(2.1)$ & $60(13.1)$ \\
\hline $\mathrm{C}$ & $24(18.0)$ & $6(4.5)$ & $5(2.6)$ & $35(7.6)$ \\
\hline D & $6(4.5)$ & $18(13.5)$ & $34(17.7)$ & $58(12.7)$ \\
\hline E & $2(1.5)$ & $11(8.3)$ & $57(29.8)$ & $70(15.2)$ \\
\hline F & $9(6.8)$ & $25(18.8)$ & $31(16.1)$ & $65(14.2)$ \\
\hline $\mathrm{G}$ & $5(3.8)$ & $20(15.0)$ & $22(11.4)$ & $47(10.3)$ \\
\hline $\mathrm{H}$ & $2(1.5)$ & $14(10.5)$ & $31(16.1)$ & $47(10.3)$ \\
\hline$I^{\prime \prime}$ & $13(9.8)$ & $0(0.0)$ & $8(4.2)$ & $21(46)$ \\
\hline & $133(100.0)$ & $133(100.0)$ & $192(100.0)$ & $458(100.0)$ \\
\hline
\end{tabular}


Table 2.5.:

Mean Numbers and Standard Deviations

of Reported Stressful Life Events

in Cases with First Myocardial Infarction (MI),

Neighborhood Referents (NR), and Hospital Referents (HR)

as Recorded by Nine Interviewers .

Inteniewer $M I(N=133) \quad N R(N=133) . H R(N=192) \quad$ Statistics

$\begin{array}{lllll}\text { A } & 22.4(4.4) & 21.3(2.5) & 0.0(0.0) & \mathrm{t}=0.68 ; \mathrm{NS} \\ \text { B } & 18.9(4.8) & 19.2(4.8) & 19.2(4.3) & \mathrm{F}=0.22 ; \mathrm{NS} \\ \text { C } & 19.8(5.2) & 20.5(3.7) & 18.8(3.7) & \mathrm{F}=0.17 ; \mathrm{NS} \\ \text { D } & 16.2(2.8) & 17.3(5.5) & 16.8(4.0) & \mathrm{F}=0.18 ; \mathrm{NS} \\ \mathrm{E} & 24.5(3.5) & 19.3(4.8) & 17.4(4.4) & \mathrm{F}=3.03^{*} \\ \text { F } & 16.0(2.6) & 16.6(3.3) & 16.1(4.0) & \mathrm{F}=0.17 ; \mathrm{NS} \\ \mathrm{G} & 18.6(1.7) & 19.9(2.9) & 19.1(3.9) & \mathrm{F}=0.40 ; \mathrm{NS} \\ \text { H } & 16.0(1.4) & 19.1(3.0) & 18.1(4.6) & \mathrm{F}=0.61 ; \mathrm{NS} \\ \text { I } & 19.0(4.8) & 0.0(0.0) & 14.6(6.0) & \mathrm{t}=1.88 ; \mathrm{NS}\end{array}$

$* \mathrm{p}<.05$ 


\section{Table 2.6.:}

Number, Mean Age and Standard Deviation, Type A Coronary-Prone Behavior Pattern, and Mean Numbers and Standard Deviations

of Reported Stressful Life Events in Cases with First Myocardial Infarction who were Interviewed at Different Times after Discharge from the Hospital.

< 1Month 1-3Months > 3 Months Statistics

Number of cases

$24(18 \%) \quad 90(68 \%) \quad 19(14 \%)$

Mean age/standard deviation
$53.0(8.6)$
$53.8(9.2)$
$51.3(11.0)$
$\mathrm{F}=0.41 ; \mathrm{NS}$

Type A coronary-prone behavior pattern
$17(71 \%)$
$56(62 \%)$
$16(84 \%)$
$\mathrm{Chi}^{2}=3.63 ; \mathrm{NS}$

Number of reported stressful life events:

Childhood \& Adolescence
$4.3(1.8)$
$4.0(1.7)$
$4.2(1.8)$
$F=0.30 ;$ NS

Work \& Career
$8.0(2.2)$
$8.4(2.3)$
$7.3(2.7)$
$\mathrm{F}=1.60 ; \mathrm{NS}$

Family \& Social Life
$8.2(2.8)$
$7.6(2.8)$
$7.8(2.5)$
$\mathrm{F}=0.49 ; \mathrm{NS}$

Total

$20.5(5.3) \quad 20.0(4.7) \quad 19.4(5.3) \quad F=0.31 ; N S$

$F: \mathrm{df}=2,130$.

$\mathrm{Chi}^{2}: \mathrm{df}=2$. 
Table 3.1.:

Occurrence of Type A Coronary-Prone Behavior Pattern in Cases with First Myoeardial Infarction (MI),

Neighborhood Referents (NR), and Hospital Referents (MR), in Seven Age Strata.

\begin{tabular}{|c|c|c|c|c|c|c|}
\hline \multirow[b]{2}{*}{ Age Stratum } & \multicolumn{2}{|c|}{$M I(N=133)$} & \multicolumn{2}{|c|}{$N R(N=133)$} & \multicolumn{2}{|c|}{$H R(N=192)$} \\
\hline & Type A & Type B & Type A & Type B & TypeA & Type B \\
\hline & . & & & & & \\
\hline $35-39$ & $14(93 \%)$ & $1(7 \%)$ & $12(46 \%)$ & $14(54 \%)$ & $14(58 \%)$ & $10(42 \%)$ \\
\hline $40-44$ & $11(69 \%)$ & $5(31 \%)$ & $12(57 \%)$ & $9(43$ & $18(51 \%)$ & $17(49 \%)$ \\
\hline $45-49$ & $13(68 \%)$ & $6(32 \%)$ & $10(48 \%)$ & $11(48$ & $14(47 \%)$ & $16(53 \%)$ \\
\hline $50-54$ & $12(67 \%)$ & $6(33 \%)$ & $12(52 \%)$ & $11(48$ & $7(29 \%)$ & $17(71 \%)$ \\
\hline $55-59$ & $18(69 \%)$ & $8(31 \%)$ & $9(50 \%)$ & $9(50 \%)$ & $14(48 \%)$ & $15(52 \%)$ \\
\hline $60-64$ & $13(57 \%)$ & $10(43 \%)$ & $7(41$ & $10(59 \%)$ & $20(63 \%)$ & $12(37 \%)$ \\
\hline $65-69$ & $8(50 \%)$ & $8(50 \%)$ & $3(43 \%)$ & $4(57 \%)$ & $6(33 \%)$ & $12(67 \%)$ \\
\hline & & & & & $\ldots$ & $\ldots \ldots$ \\
\hline $35-69$ & $39(67 \%)$ & $44(33 \%)$ & $65(49 \%)$ & $68(51 \%)$ & $93(48 \%)$ & $99(52 \%)$ \\
\hline
\end{tabular}


Table 32:

Ratios of Type A to Type B Coronary-Prone Behavior Pattern, in Cases with First Myocardial Infarction (MI),

Neighborhood Referents (NR), and Hospital Referents (HR), In Seven Age Strata.

\begin{tabular}{lccc} 
Age Stratum & $M I(N=133)$ & $N R(N=133)$ & $H R(N=192)$ \\
$35-39$ & 14.00 & 0.86 & 1.40 \\
$40-44$ & 2.20 & 1.33 & 1.06 \\
$45-49$ & 2.17 & 0.91 & 0.88 \\
$50-54$ & 2.00 & 1.09 & 0.41 \\
$55-59$ & 2.25 & 1.00 & 0.93 \\
$60-64$ & 1.30 & 0.70 & 1.67 \\
$65-69$ & 1.00 & 0.75 & 0.50 \\
$\ldots$ & 2.02 & 0.96 & 0.94 \\
\hline $35-69$ & $\ldots$ & &
\end{tabular}


Table 33.:

Age-Adjusted Relative Risks and 95\% Confidence Intervals Associated with Type A Coronary-Prone Behavior Pattern, in Cases with First Myocardial Infarction (MI), Compared to Neighborhood Referents (NR) and Hospital Referents (HR), in Three Age Strata.

Age Stratum

$$
M I(N=133) \times N R(N=133) \quad M I(N=133) \times H R(N=192)
$$


Table 3.4.:

Occurrence of Reported Stressful Life Rvents over the Life-Span in Type A and Type B Subjects,

Including Cases with First Myocardial infaretion, Neighborhood Referents, and Hospital Referents.

A. Childhood \& Adolescence

$$
\begin{array}{ll}
\text { Type A } & \text { Type B } \\
(N=247) & (N=211)
\end{array}
$$

01) Being raised by one parent

$$
\begin{array}{lll}
39(16 \%) & 34(16 \%) & 0.01 \\
65(26 \%) & 64(30 \%) & 0.91 \\
55(22 \%) & 38(18 \%) & 1.27 \\
43(17 \%) & 27(13 \%) & 1.87 \\
28(11 \%) & 25(12 \%) & 0.03 \\
137(56 \%) & 119(56 \%) & 0.04 \\
63(26 \%) & 37(18 \%) & 4.24 * \\
50(20 \%) & 33(16 \%) & 1.68 \\
80(32 \%) & 69(33 \%) & 0.01 \\
77(31 \%) & 64(30 \%) & 0.04
\end{array}
$$$$
\text { 02) Prolonged parental illness }
$$$$
\text { 04) Prolonged familial conflicts }
$$$$
\text { 05) Prolonged unemployment (father) }
$$$$
\text { 06) Relocations }
$$

07) Prolonged financial problems$$
\text { 08) Prolonged illness (respondent) }
$$

09) Hospital admissions (respondent)

10) Working after school

11) Military service

$117(47 \%) \quad 88(42 \%) \quad 1.48$

$0: p<.10 ; *: p<.05 ; * *: p<.01 ; * * * p, 001$ 
B. Work \& Career

$$
\begin{array}{ll}
\text { Type A } & \text { Type B } \\
(N=247) & (N=211)
\end{array}
$$

01) Present unemployment/disability

$107(43 \%) \quad 98(47 \%) \quad 0.51$

02) Past unemployment

$59(24 \%) \quad 48(23 \%) \quad 0.08$

03) Past disability

$26(11 \%) \quad 33(16 \%) \quad 2.65$

04) Voluntary search for other job(s)

$191(77 \%) \quad 150(71 \%) 2.33$

05) Compulsory search for other job(s)

$95(39 \%) \quad 69(33 \%) \quad 1.64$

06) Work place closed down

$71(29 \%) \quad 48(23 \%) \quad 2.13$

07) Important organizational/economic changes at work

$75(30 \%) \quad 51(24 \%) \quad 2.19$

08) Prospects for promotion (unrealized) 147(60\%) 103(49\%) $5.25 *$

$\begin{array}{llll}09) \text { Increased responsibility at work } \quad 156(63 \%) & 120(57 \%) & 1.88\end{array}$

10) Prolonged/serious conflicts with colleagues

$38(15 \%) \quad 17(8 \%) \quad 5.78^{*}$

11) Prolonged/serious conflicts with supervisors

$$
78(32 \%) \quad 60(28 \%) \quad 0.53
$$

12) Prolonged/serious conflicts with subordinates

$$
23(9 \%) \quad 7(3 \%) \quad 6.68^{* *}
$$

13) Prolonged/irregular working hours/shiftwork

$$
\begin{array}{lll}
168(68 \%) & 147(70 \%) & 0.14 \\
138(56 \%) & 113(54 \%) & 0.25 \\
175(71 \%) & 158(75 \%) & 0.93 \\
\text { position } & & \\
137(56 \%) & 106(50 \%) & 1.25
\end{array}
$$

14) Prollonged overtime

15) Prolonged absentieeism

16) Continuing education to improve one's position

$0: \mathrm{p}<.10 ; *: \mathrm{p}<.05 ; * * \mathrm{p}<.01 ; * * * \mathrm{p}<.001$. 
C. Family \& Social Life

$$
\begin{array}{ll}
\text { Type A } & \text { Type B } \\
(N=247) & (N=211)
\end{array}
$$

01) Divorce

$$
\begin{array}{lll}
13(5 \%) & 11(5 \%) & 0.00 \\
30(12 \%) & 33(16 \%) & 1.17
\end{array}
$$

02) Childlessness

03) Prolonged/serious illness of children ${ }^{\text {a }}$

04) Death of children ${ }^{a}$

$$
60(28 \%) \quad 50(28 \%) \quad 0.00
$$

$17(8 \%) \quad 21(12 \%) \quad 1.75$

05) Prolonged/serious educational problems with children ${ }^{\text {a }}$

06) Children leaving home $e^{a}$

$$
28(13 \%) \quad 18(10 \%) \quad 0.71
$$

07) Prolonged/serious conflicts with children away from home ${ }^{\text {a }}$

$125(58 \%) \quad 112(63 \%) \quad 1.04$

$18(8 \%) \quad 11(6 \%) \quad 0.62$

08) Prolonged/serious marital conflicts $\quad 71(29 \%) \quad 27(13 \%) \quad 17.21 * * *$

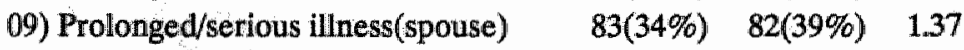

10) Prolonged/serious illness or accident (respondent)

11) Living with extended family

$119(48 \%) \quad 86(41 \%) \quad 2.53$

12) Prolonged/serious illness/death of family members ${ }^{b}$

$132(53 \%) \quad 119(56 \%) \quad 0.40$

$$
140(57 \%) \quad 125(59 \%) \quad 0.31
$$

13) Prolonged/serious illness/death of friends/acquaintances ${ }^{b}$

$$
64(25 \%) \quad 45(21 \%) \quad 1.32
$$

14) Prolonged/serious conflicts with family members

15) Prolonged/serious conflicts with friends/acquaintances

$$
65(26 \%) \quad 34(16 \%) \quad 6.99 * *
$$

16) Relocations

17) Spouse working

18) Prolonged/serious financial problems

19) Substantial loans/mortgages

20) Being summoned to court
$37(15 \%) \quad 23(11 \%) \quad 1.66$

$214(87 \%) \quad 180(85 \%) \quad 0.17$

$110(45 \%) \quad 92(44 \%) \quad 0.04$

$69(28 \%) \quad 44(21 \%) \quad 3.07 \mathrm{o}$

$123(50 \%) \quad 104(50 \%) \quad 0.00$

$62(25 \%) \quad 45(21 \%) \quad 0.85$

\footnotetext{
${ }^{a}$ Calcullated for subjects with children only.

${ }^{b}$ Calculated over the last 5 years only.

o: $p<.10 ;{ }^{*}: \mathrm{p}<.05 ; * *$; $<<.01 ;{ }^{* * * *}$ : $<<.001$.
} 


\section{Table 4.1.:}

Age-Adjusted Relative Risks and 95\% Confidence Intervals Associated with Vital Exhaustion

in Cases with First Myocardial Infarction (MD), Compared to Neighborhood Referents (NR) and Hospital Referents (HR).

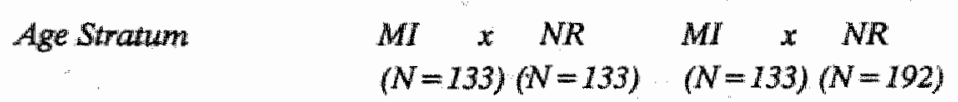


Table 4.2.:

Age-Adjusted Relatíve Risks and 95\% Confidence Intervals Associated with Each Single Item of the Maastricht Questionnaire

(Form B)

In Cases with First Myocardial Infarction (MI), Compared to

Nelighborhood Referents (NR) and Hospital Referents (HR).

\begin{tabular}{|c|c|c|}
\hline Item & $\begin{array}{l}M I \quad x \quad N R \\
(N=133)(N=133)\end{array}$ & $\begin{array}{l}R O^{a} M I \quad x \quad H R \\
\quad(N=133)(N=192)\end{array}$ \\
\hline
\end{tabular}

"Over the last half year, $[\ldots$.$] "$

01) Did you often feel tired?

$\begin{array}{llll}7.85(4.53-13.62) & 2 & 4.42(2.72-7.19) & 4\end{array}$

02) Did you often have trouble falling asleep ?
$3.77(2.20-6.44)$
$10 \quad \mathbf{2 . 0 3}(1.29-3.21)$
36

03) Did you wake up repeatedly during the night?

2.52(1.50-4.23)

32

$1.78(1.12-2.81)$

43

04) Did you feel less confident lately?

$4.87(2.87-8.26)$

$6 \quad 4.80(2.97-7.76)$

05) I seemed to blow up easily at times.

$$
\text { 8.66(4.95-15.14) } \quad 1 \quad 6.00(3.73-9.65)
$$

06) Did you sometimes have the feeling you had problems that you couldn't work out?

07) Did you often feel weak?

$$
\text { 2.15(1.28-3.61) }
$$

$37 \quad 2.71(1.68-4.36)$

21

$$
5.48(3.18-9.43) \quad 5 \quad 2.89(1.82-4.59)
$$

08) I clearly felt that I was in the prime of my life.

$$
1.38(0.81-2.36) \quad 1.21(0.74-1.98)
$$

09) Were you no longer able to bear loud noises ?

$$
1.94(1.18-3.17) \quad 42 \quad 3.02(1.91-4.76)
$$

10) Did you have the feeling that you hadn't been accomplishing much lately?

$$
\begin{array}{llll}
2.72(1.60-4.62) & 26 & 1.95(1.23-3.10 & 37
\end{array}
$$

11) Did you have the feeling that you couldn't cope with everyday problems as well as you used to?

$$
3.64(2.18-6.05) \quad 12 \quad 2.74(1.74-4.32)
$$

12) I seemed to criticize my own behavior quite often.

$$
3.49(1.98-6.13) \quad 15 \quad 3.47(2.11-5.69)
$$

13) Did you have the feeling that the future was becoming less and less certain ? 
Item

$$
\begin{aligned}
& M I \quad x \quad N R \\
& R O^{a} M I \quad x \quad N R
\end{aligned}
$$

14) Did you think more often about friends or relatives who were deceased?

$$
1.13(0.66-1.92) \quad 1.20(0.74-1.95)
$$

15) Did you believe that you had come to a "dead end" ?

$$
\begin{aligned}
& \text { 1) } 1.95(0.66-5.75) \\
& \text { 2) } 0.43(0.20-0.95) \\
& \text { 3) } 0.29(0.07-1.17)
\end{aligned} \quad \mathbf{1 . 9 3}(\mathbf{1 1 . 1 4 - 3 . 2 6})
$$

16) Were you in a good mood most of the time ?*

$$
1.69(1.00-2.87)
$$

17) Were you constantly worrying about your health ?

$$
\begin{aligned}
& \text { 1) } 2.13(0.79-5.72) \\
& \text { 2) } 0.54(0.25-1.19) \\
& \text { 3) } 0.26(0.07-0.96)
\end{aligned} \quad 1.13(0.70-1.83)
$$

18) Had there been demands made on you that you couldn't cope with?

$$
3.41(1.81-6.42) \quad 16 \quad 2.77(1.60-4.79)
$$

19) Did minor hassles irritate you easily ?

$$
\text { 7.66(4.33-13.53) }
$$$$
3 \quad 7.42(4.51-12.21)
$$

20) Did you feel more listless than before?

$$
\text { 7.04(4.11-12.05) }
$$$$
4 \quad 2.79(1.76-4.41)
$$

21) Did you feel like you were losing your self-restraint?

$$
3.31(1.89-5.80) \quad 18(2.76(1.69-4.52)
$$

22) Did you have the feeling that nobody could help you with problems deep inside you?

$$
\text { 2.68(1.56-4.59) } \quad 28 \quad 2.12(1.32-3.40)
$$

23) Had there been demands made on you that you could only meet with extra effort?

$$
\begin{array}{lll}
\begin{array}{l}
2.00(1.16-3.44) \\
\text { about death ? }
\end{array} & 41 & \mathbf{2 . 1 7}(1.32-3.56) \\
1.23(0.68-2.22) & & 1.46(0.85-2.50)
\end{array}
$$

24) Did you often think about death ?

25) I enjoyed sex as much as ever. *

$$
2.68(1.61-4.47) \quad 27
$$

$$
\begin{array}{lll}
3.02(1.67-5.47) & 23 & 2.33(1.41-3.87)
\end{array}
$$

27) I often became annoyed with things at work.

$$
1.84(1.09-3.12) \quad 45 \quad 2.16(1.34-3.48)
$$

28) Did you often worry about your health ? 
Jtem

$$
\begin{aligned}
& M I \quad x \quad N R \\
& R O^{f} M T \quad x \quad N R
\end{aligned}
$$

29) Did it take longer to grasp a difficult problem than it used to?
$3.03(1.74-5.28)$
$22 \quad 3.17(1.93-5.22)$

30) Did you sometimes wonder whether you would still be alive the next day?

$$
1.17(0.60-2.29)
$$

$1.10(0.60-1.99)$

31) Did you suddenly get the feeling you had failed in life?

$$
1.89(1.01-3.54) \quad 44 \quad 1.59(0.92-2.76)
$$

32) Did little things begin to irritate you more than they used to ?

$$
\text { 4.87(2.87-8.28) } \quad 7 \quad 4.30(2.69-6.86)
$$

33) Did you feel you wanted to give up trying ?

$$
\text { 2.08(1.23-3.51) } \quad 38 \quad \mathbf{2 . 4 0}(1.48-3.89)
$$

34) Did you become less satisfied with yourself ?

35) I felt fine. " $\quad \mathbf{3 . 4 0}(\mathbf{2 . 0 4 - 5 . 6 8 )} \quad 17 \quad 1.41(0.88-2.28)$

$$
2.85(1.65-4.90) \quad 24 \quad 2.34(1.46-3.77)
$$

36) Did you ever have the feeling "you hadn't achieved enough, and that you could have achieved more if only you were healthier, not so weak, not so limp" ?

$$
\begin{array}{llll}
5.24(3.03-9.07) & 6 & 2.37(1.50-3.75) & 24
\end{array}
$$

37) Did you feel cast down?

$$
\text { 2.02(1.18-3.45) } \quad 40 \quad 1.93(1.19-3.11)
$$

38) Did you sometimes feel that your body was like a battery that was losing its
power?
$2.54(1.52-4.24)$
$31 \quad 1.53(0.97-2.40)$

39) Did you sometimes have the feeling you didn't know exactly where you stood ?
3.03(1.80-5.11)
$21 \quad 2.15(1.36-3.38)$
32

40) Did you feel less capable of doing something useful ?

$$
\text { 4.12(2.29-7.43) } \quad 9 \quad 2.19(1.35-3.53)
$$

41) Did you have the feeling your family didn't understand you very well ?

$$
2.20(1.19-4.05) \quad 35 \quad 1.63(0.96-2.74)
$$

42) Did you sometimes want to be dead?

$$
2.33(0.97-5.63) \quad 2.03(0.96-4.29)
$$

43) Did you feel quaint bodily sensations ?

$$
\text { 3.70(2.21-6.20) } \quad 11 \quad 3.55(2.24-5.65)
$$

44) Did you have the feeling you just didn't have what it takes any more?

$$
2.15(1.30-3.54) \quad 36 \quad 1.68(1.06-2.67)
$$

45) Was it harder and harder to get yourself to leave the house and go somewhere for a visit ?

46) Did you feel dejected? 
Item

$$
\begin{array}{lrl}
M I & \times \quad N R & R O^{a} M I \quad x \quad N R \\
(N=133)(N=133) & & (N=133 \quad(N=192
\end{array}
$$$$
\mathrm{RO}^{\mathrm{b}}
$$

47) Did you ever tremble and quiver all ower?

$$
\text { 2.67(1.47-4.93) }
$$

48) Did you sometimes feel like cying?

$$
\text { 3.07(1.55-6.10) }
$$

$20 \quad 1.75(1.00-3.05)$

44

49) Were there moments when you felt completely exhausted?

$$
3.56(2.09-6.05) \quad 14 \quad 2.29(1.45-3.61)
$$

28

50) Did you ever wake up feeling exhausted and fatigued ?

$$
4.39(2.45-7.89) \quad 8 \quad 2.80(1.72-4.56)
$$

51) Did it get harder and harder for you to concentrate on a single subject for a long time?

$$
\text { 1.92(1.16-3.19) } \quad 43 \quad 2.15(1.36-3.42)
$$

52) Did you ever feel unhappy because of ill health ?

$$
2.62(1.51-4.54) \quad 30 \quad 1.42(0.89-2.26)
$$

53) I would shrink from my regular work as if it were a mountain to climb.

$3.59(2.11-6.10)$

$13 \quad 2.82(1.77-4.49)$

54) Did you become forgetful ?

$$
\begin{aligned}
& \text { 1) } 0.21(0.08-0.55) \\
& \text { 2)0.91(0.45-1.86) } \\
& \text { 3) } 0.17(0.06-0.50)
\end{aligned}
$$

55) After doing something, did you check more often than before whether you had done it right?

$$
1.36(0.82-2.24) \quad 1.11(0.71-1.75)
$$

56) Did you become quieter?

$$
\text { 2.72(1.65-4.50) } 25 \quad 2.45(1.55-3.85)
$$

57) Did you need more time to get started than you did in earlier times?

$$
\begin{aligned}
& \text { 1) } 0.10(0.04-0.27) \\
& \text { 2) } 0.50(0.24-1.02) \\
& \text { 3) } 0.31(0.11-0.90)
\end{aligned} \quad \text { 3.10(1.96-4.91) }
$$

58) Did you prefer to withdraw from company ?

$$
\text { 2.32(1.39-3.85) }
$$

Rank order of respective MQ-item in the neighborhood series.

${ }^{b}$ Rank order of respective $\mathrm{MQ}$-item in the hospital series.

* Reversed scoring. 
Table 4.3.:

Standardlized Relative Risks Associated with Different Degrees of Vital Exhaustion (First, Second, and Third Tertiles of MQ Scores), Adjusted Separately for Age, Current Smoking, and Angina Pectoris, in Cases with First Myocardial Infarction (MI), Compared to Neighborhood Referent (NR), and Hospital Referents (HR).

MI Compared to NR

$(N=133) \quad(N=133)$

$M Q$-Tertiles

12

Unadjusted SRR:

$\begin{array}{lll}1.00 & 4.38 & 11.96\end{array}$

MI Compared to HR $(N=133) \quad(N=192)$ MQ-Tertiles

$\begin{array}{lll}1 & 2 & 3\end{array}$

SSR Adjusted for:

Age: $\quad \begin{array}{llll}1.00 & 4.40 & 14.08\end{array}$

$\begin{array}{ll}1.00 \quad 2.07 & 5.31 \\ \mathrm{Ch}^{2} \mathrm{MH}=22.75^{* * *}\end{array}$

$\mathrm{Chi}^{2} \mathrm{MH}=52.75^{* * *}$

$1.00 \quad 2.26 \quad 5.03$

Angina Pectoris:
$\begin{array}{lll}1.00 & 3.32 & 9.41\end{array}$
$\begin{array}{lll}1.00 & 2.33 & 4.29\end{array}$
$\mathrm{Chi}^{2} \mathrm{MH}=39.16^{* * *}$
$\mathrm{Chi}^{2} \mathrm{MH}=17.66^{* * *}$

Current Smoking:
$\begin{array}{lll}1.00 & 3.93 & 10.10\end{array}$
$1.00 \quad 2.20 \quad 4.69$
$\mathrm{Chi}^{2} \mathrm{MH}=42.39$
$\mathrm{Chi}^{2} \mathrm{MH}=19.82^{* * *}$

***: $\mathrm{p}<.001$, two-sided. 
Table 4.4*:

Vital Exhaustion (Mean MQ Scores)

in Type A and Type B Subjeets without Angina Pectoris.

$\begin{array}{ll}\text { Type } A^{a} & \text { Type } B^{\circ} \\ (N=220) & (N=193)\end{array}$

Mean MQ/Stand.ard deviation 13.3(10.2)

${ }^{a}$ Combined MI, NR, and HR without angina pectoris.

b d.f. $=1,411$.

$* *: \mathrm{p}<.001$, two-sided. 
Table 4.5.:

Standardized Relative Risks for

First Myocardial Infaretion in "Vital" and "Vitally Exhausted"

Type A and Type B Subjects,

Including Cases with First Myocardial infarction (M),

Neighborhood Referents (NR), and Hospital Referents (HR).

MI compared to $N R$

MI compared to $H R$

$(N=133)$

$(N=133)$

$(N=133)(N=192)$

Vit $B^{a} \quad$ Vit $A^{b}$ Exh $B^{C}$ Exh $A^{d "}$ Vit $B^{e}$ Vit $A^{f}$ Exh $B^{g}$ Exh $A^{h}$

\begin{tabular}{|c|c|c|c|c|c|c|c|c|}
\hline Casses & 10 & 14 & 34 & 75 & 10 & 14 & 34 & 75 \\
\hline Referents & 47 & 33 & 21 & 32 & 43 & 31 & 56 & 62 \\
\hline Total & 57 & 47 & 55 & 107 & 53 & 45 & 90 & 137 \\
\hline$S R R$ & 1.00 & 1.99 & 7.61 & 11.02 & 1.00 & 1.94 & 2.61 & 5.20 \\
\hline & \multicolumn{4}{|c|}{$\begin{array}{l}\text { ChiExt }=7.05^{* * *} \\
\mathrm{Chi}^{2}=52.05^{* * *}\end{array}$} & \multicolumn{4}{|c|}{$\begin{array}{l}\text { ChiExt }=4.78^{* * *} \\
\text { Chi }^{2}=23.65^{* * *}\end{array}$} \\
\hline
\end{tabular}

a "Vital" Type B subjects in the neighborhood series.

b "Vital" Type A subjects in the neighborhood series.

c "Vitally exhausted" Type B subjects in the neighborhood series.

d"Vitally exhausted" Type A subjects in the neighborhood series.

" "Vital" Type B subjects in the hospital series.

" "Vital" Type A subjects in the hospital series.

(I) "Vitally exhausted" Type B subjects in the hospital series.

to "Vitally exhausted" Type A subjects in the hospital series"

**": $p<.001$. 
Table 4.6.:

Estimated Relative Risks and 95\% Confidence Intervals Assocliated with Current Smoking, Angina Pectoris, Type A Coronary-Prone Behavior Pattern, and Vital Exhaustion, when Simultaneously Controlling for Age, in Cases with First Myocardial Infarction (MI), Compared to Neighborhood Referents (NR), and Hospital Referents (HR) (Muitiple Logistic Regression).
A. $M I(N=133) \times N R(N=133)$
$R R \& 95 \% \mathrm{Cls}^{a}$

1) Vital exhaustion

$5.35(2.91-9.83)$

2) Current smoking

$3.11(1.61-6.01)$

3) Angina pectoris

$3.03(1.13-8.11)$

4) Type A coronary-prone behavior pattern

$1.93(1.07-3.47)$

B. $M I(N=133) \times H R(N=192)$

$R R \& 95 \% \mathrm{Cls}^{a}$

1) Angina pectoris

$5.18(2.23-12.03)$

2) Current smoking

$3.88(2.16-6.97)$

3) Type A coronary-prone behavior pattern

$2.22(1.33-3.70)$

4) Vital exhaustion

$2.13(1.20-3.79)$

astimated relative risks and $95 \%$ confidence intervalls. 
Tabile 4.7.:

Occurrence of Reported Stressful Life Events over the Life-Span in Subjects Who Are "Vitally Exhausted" (Exh)

and in Subjects Who Are Not (Vit),

Including Cases with First Myocardial infarction,

Neighborhood Referents, and Hospital Referents.

A. Childhood \& Adolescence

$$
\begin{array}{ll}
\text { Exh } & \text { Vit } \\
(N=280) & (N=178)
\end{array}
$$

01) Being raised by one parent

$\begin{array}{rrl}45(16 \%) & 28(16 \%) & 0.92 \\ 82(29 \%) & 47(26 \%) & 0.50 \\ 64(23 \%) & 29(16 \%) & 2.900 \\ 53(19 \%) & 17(10 \%) & 7.39 \% \\ 39(14 \%) & 14(8 \%) & 3.91^{*} \\ 153(55 \%) & 103(58 \%) & 0.46 \\ 73(26 \%) & 27(15 \%) & 7.58 * \\ 55(20 \%) & 28(16 \%) & 1.16 \\ 99(35 \%) & 50(28 \%) & 2.62 \\ 90(32 \%) & 51(29 \%) & 0.62 \\ 114(41 \%) & 91(51 \%) & 4.77\end{array}$

02) Prolonged parental illness

03) Living away from home $64(23 \%) \quad 29(16 \%)-2.900$

04) Prolonged familial conflicts $39(14 \%) \quad 14(8 \%) \quad 3.91^{*}$

06) Relocations

07) Prolonged financial problems

08) Prolonged illness (respondent) 0.46

09) Hospital admissions (respondent) $114(41 \%) \quad 91(51 \%)$

$0: \mathrm{p}<.10 ; * \mathrm{p}<.05 ; * * \mathrm{p}<.01 ; * * * \mathrm{p}<.001$. 
B. Work \& Career

$$
\begin{array}{lll}
\text { Exh } & V i t & \mathrm{Chi}^{2} \\
(N=280) & (N=178)
\end{array}
$$

01) Present unemployment/disability

$\begin{array}{rrl}139(50 \%) & 66(37 \%) & 7.13^{*} \\ 75(27 \%) & 32(18 \%) & 4.72 * \\ 41(15 \%) & 18(10 \%) & 1.99 \\ 213(76 \%) & 128(72 \%) & 0.99 \\ 109(39 \%) & 55(31 \%) & 3.050 \\ 77(28 \%) & 42(24 \%) & 0.86\end{array}$

02) Past unemployment

03) Past disability

04) Voluntary search for other job(s)

05) Compulsory search for other job(s)

06) Work place closed down

07) Important organizational/economic changes at work

$\begin{array}{rrc}71(25 \%) & 55(31 \%) & 1.68 \\ 151(54 \%) & 99(56 \%) & 0.13 \\ 164(59 \%) & 112(63 \%) & 0.86 \\ 39(14 \%) & 16(9 \%) & 2.51 \\ 94(34 \%) & 44(25 \%) & 4.05 \%\end{array}$

08) Prospects for promotion (unrealized)

$24(9 \%) \quad 6(3 \%) \quad 4.81 \%$

13) Prolonged/irregular working hours/shiftwork

09) Increased responsibility at work

10) Prolonged/serious conflicts with colleagues

11) Prolonged/serious conflicts with supervisors

$200(71 \%) \quad 115(65 \%) \quad 2.36$

14) Prolonged overtime

$171(61 \%) \quad 80(45 \%)$

15) Prolonged absenteeism

16) Continuing education to improve one's position

$$
151(54 \%) \quad 92(52 \%) \quad 0.22
$$

$0 * \mathrm{p}<.10 ; * \mathrm{p}<.05, * * \mathrm{p}<.01 ; * * * \mathrm{p}<.001$. 
C. Fomily \& Social Life

$$
\begin{array}{ll}
\text { Exh } & \text { Vit } \\
(N=280) & (N=178)
\end{array}
$$

01) Divorce

$16(6 \%) \quad 8(5 \%) \quad 0.33$

02) Childlessness

$39(14 \%) \quad 24(14 \%) \quad 0.02$

03) Prolonged/serious illness of children ${ }^{\text {a }}$

$74(31 \%) \quad 36(24 \%) \quad 2.72^{\circ}$

04) Death of children ${ }^{a}$

$21(9 \%) \quad 17(11 \%) \quad 0.54$

05) Prolonged/serious educational problems with children ${ }^{\text {a }}$

06) Children leaving home $\mathrm{a}^{\mathrm{a}}$

$36(15 \%) \quad 10(7 \%) \quad 6.58 \%$

07) Prolonged/serious conflicts with children away from home ${ }^{\text {a }}$

08) Prolonged/serious marital conflicts

$21(9 \%) \quad 8(5 \%) \quad 1.74$

09) Prolonged/serious illness (spouse)

$71(25 \%) \quad 27(15 \%) \quad 6.72 * *$

10) Prolonged/serious iliness or accident (respondent)

11) Living with extended family

12) Prolonged/serious illness/death of family members ${ }^{b}$

13) Prolonged/serious illness/death of friends/acquaintances $b$

$$
175(63 \%) \quad 90(51 \%) \quad 6.36 *
$$$$
73(26 \%) \quad 36(20 \%) \quad 2.05
$$

14) Prolonged/serious conflicts with family members

$$
69(25 \%) \quad 30(17 \%) \quad 3.90 *
$$

15) Prolonged/serious conflicts with friends/acquaintances

16) Relocations

17) Spouse working

18) Prolonged/serious financial problems

19) Substantial loans/mortgages

20) Being summoned to court

$\begin{array}{rrl}43(15 \%) & 17(10 \%) & 3.220 \\ 246(88 \%) & 148(83 \%) & 2.01 \\ 119(43 \%) & 83(47 \%) & 0.75 \\ 83(30 \%) & 30(17 \%) & 9.58 * * \\ 136(49 \%) & 91(51 \%) & 0.35 \\ 70(25 \%) & 37(21 \%) & 1.01\end{array}$

${ }^{a}$ Callculeted for subjects with children only.

${ }^{b}$ Calculated over last five years only.

$0: \mathrm{p}<.10 ;: \mathrm{p}<.05 ; * \mathrm{p}<.01 ; *: \mathrm{p}<.=001$ 
Table 5.1.:

Mean Numbers and Standard Deviations

of Reported Stressful Life Events over the Life-Span

in Cases with First Myocardial Infaretion (MI),

Neighborhood Referents (NR), and Hospital Referents (HR).

\begin{tabular}{|c|c|c|c|c|}
\hline Domain & $\begin{array}{l}M I \\
(N=133)\end{array}$ & $\begin{array}{l}N R \\
(N=133)\end{array}$ & $\begin{array}{l}H R \\
(N=192)\end{array}$ & Statistics \\
\hline $\begin{array}{l}\text { Childhood \& } \\
\text { Adolescence }\end{array}$ & $3.1(1.7)$ & $3.0(1.6)$ & $2.8(1.4)$ & $\begin{array}{l}\mathrm{F}=2.39 ; \mathrm{NS} \\
\mathrm{M} \mathrm{MxNR}=0.38 ; \mathrm{NS} \\
\mathrm{t}_{\mathrm{MLXHR}}=1.96^{\circ}\end{array}$ \\
\hline Work \& Career & $7.1(2.3)$ & $6.9(2.3)$ & $6.0(2.2)$ & $\begin{array}{l}\mathrm{F}=11.18 * \\
\mathrm{t}_{\mathrm{MLxNR}}=0.98 ; \mathrm{NS} \\
\mathrm{MIxHR}=4.45 * *\end{array}$ \\
\hline $\begin{array}{l}\text { Family \& } \\
\text { Social Life }\end{array}$ & $7.7(2.8)$ & $6.9(2.2)$ & $6.6(2.4)$ & $\begin{array}{l}F=8.43^{* *} \\
\text { tMIXNR }=2.84^{*} \\
\text { tMIxHR }=3.87^{*}\end{array}$ \\
\hline Total & $18.0(4.8)$ & $16.8(4.1)$ & $15.4(4.4)$ & $\begin{array}{l}F=13.74 * * \\
t M I x N R=2.23^{*} \\
\text { MIXHR }=5.04^{*}\end{array}$ \\
\hline
\end{tabular}

$\mathrm{F}: \mathrm{df}=2,455$.

tMIxNR: $\mathrm{df}=1,264$.

tMIxHR: $\mathrm{df}=1,323$.

$*: \mathrm{p}<.05 ; *: \mathrm{p}<.01 ; * *: \mathrm{p}<.001$. 
Table 5.2.:

Occurrence of Reported Stressful Life Events over the Life-Span

in Cases with First Myocardial Infarction (MI),

Neighborhood Referents (NR), and Hospital Referents (HR).

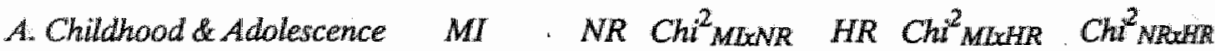

$$
(N=133)(N=133) \quad(N=192)
$$

01) Being raised by one parent

02) Prolonged parental illness

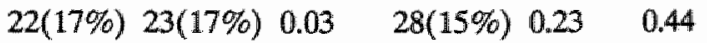

03) Living away from home $36(27 \%) 23(17 \%) 3.680$

$43(22 \%) 2.44 \quad 5.87 *$

04) Prolonged familial conflicts $27(20 \%) \quad 24(18 \%) \quad 0.22 \quad 19(10 \%) \quad 7.00 * * 4.55^{*}$

05) Prolonged unemployment (father)

$23(17 \%) \quad 13(10 \%) \quad 3.210 \quad 17(9 \%) \quad 5.18^{*} \quad 0.08$

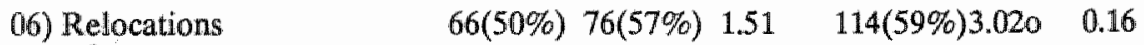

07) Prolonged financial problems

$44(33 \%) 22(17 \%) \quad 9.75 * * 34(18 \%) \quad 10.18 * 0.08$

08) Prolonged illness (respondent)

$24(18 \%) 32(24 \%) 1.45 \quad 27(14 \%) 0.90 \quad 5.18^{*}$

09) Hospital admissions (respondent)

\begin{tabular}{|c|c|c|c|c|c|}
\hline & $44(33 \%)$ & $42(32 \%)$ & 0.07 & $63(33 \%)$ & 0.00 \\
\hline & $44(33 \%)$ & $35(26 \%)$ & 1.46 & $62(32 \%)$ & 0.02 \\
\hline $\mathrm{N}$ & $45(34 \%)$ & $69(52 \%)$ & $8.84 * *$ & $91(47 \% 0)$ & $5.94 *$ \\
\hline
\end{tabular}

o: $\mathrm{p}<.10 ; * \mathrm{p}<.05 ; * * \mathrm{p}<.01 ; * * \mathrm{*}<<.001$. 
W. Work \& Career

$$
\begin{array}{ll}
M I \quad N R \quad C h i^{2} M L N R & H R \quad C h i^{2} M H_{R} C h i^{2} N R x H R \\
(N=133)(N=133) & (N=133)
\end{array}
$$

01) Present unemployment/disability

$\begin{array}{lllllll} & 68(51 \%) & 54(41 \%) & 2.97 \% & 83(44 \%) & 1.85 & 0.26 \\ \text { 02) Past unemployment } & 39(29 \%) & 24(18 \%) & 4.68 * & 44(23 \%) & 1.70 & 1.13 \\ \text { 03) Past disability } & 14(11 \%) & 18(14 \%) & 0.57 & 27(14 \%) & 0.89 & 0.02\end{array}$

04) Voluntary search for other job(s)

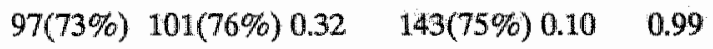

05) Compulsory search for other job(s)

$$
58(44 \%) 50(38 \%) 1.00 \quad 56(29 \%) 7.20 * 2.54
$$

06) Work place closed down $47(35 \%) \quad 35(26 \%) 2.54$

$37(19 \%) \quad 10.53 * 2.26$

07) Important organizational/economic changes at work

$$
32(24 \%) 51(38 \%) 6.32 * \quad 43(22 \%) \quad 0.12 \quad 9.72 *
$$

08) Prospects for promotion (unrealized)

$$
87(65 \%) 77(58 \%) \quad 1.59 \quad 86(45 \%) \quad 13.42 * * * 5.40 *
$$

(09) Increased responsibility at work

$85(64 \%) \quad 92(69 \%) \quad 0.83 \quad 99(52 \%) 4.88 * \quad 10.06 *$

10) Prolonged/serious conflicts with colleagues

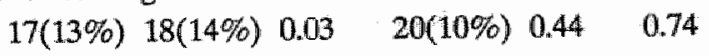

11) Prolonged/serious conflicts with supervisors

$$
50(38 \%) \quad 45(34 \%) \quad 0.41 \quad 43(22 \%) 8.88 * * 5.21 *
$$

12) Prollonged/serious conflicts with subordinates

$$
\begin{array}{llllll}
13(10 \%) & 9(7 \%) & 0.79 & 8(4 \%) & 4.09 * & 1.07
\end{array}
$$

13) Prolonged/irregular working hours/shiftwork

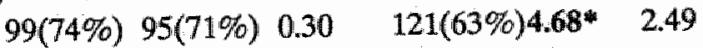

$$
\begin{aligned}
& 88(66 \%) 72(54 \%) 4.02 * \quad 91(47 \%) 11.19 * * 1.43 \\
& 93(70 \%) \quad 89(67 \%) \quad 0.28 \quad 151(79 \%) 3.190 \quad 5.60 * \\
& 62(47 \%) \quad 82(62 \%) \quad 6.06 * \quad 99(52 \%) \quad 0.77 \quad 3.240
\end{aligned}
$$

14) Prolonged overtime

15) Prolonged absenteeism

16) Continuing education to improve one's position

$0 * \mathrm{p}<.10 ; * \mathrm{p}<.05 ; * * \mathrm{p}<.01 ; * * * \mathrm{p}<.001$. 
C. Family \& Social Life

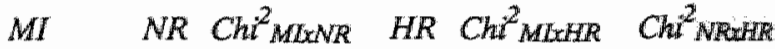

$$
\begin{aligned}
& (N=133)(N=133) \quad(N=192)
\end{aligned}
$$

01) Divorce

$\begin{array}{llllll}9(7 \%) & 7(5 \%) & 0.27 & 8(4 \%) & 1.07 & 0.21 \\ 19(14 \%) & 13(10 \%) & 1.28 & 31(16 \%) & 0.21 & 2.720\end{array}$

02) Childlessness

$19(14 \%) 13(10 \%) 1.28$

$31(16 \%) 0.21$

2.720

03) Prolonged/serious illness of children ${ }^{\text {a }}$

04) Death of children ${ }^{\text {a }}$

$$
43(38 \%) 32(27 \%) 3.17 \mathrm{o} \quad 35(22 \%) 8.98 * 1.17
$$

05) Prolonged/serious educational problems with childre ${ }^{\text {a }}$

$13(8 \%) \quad 0.96 \quad 0.39$

$$
24(21 \%) 7(6 \%) 11.62 * 15(9 \%) 7.55 * 1.11
$$

$\begin{array}{llllll}06) \text { children leaving home } e^{\text {at. }} \quad 74(66 \%) & 67(56 \%) & 2.27 & 96(60 \%) & 0.97 & 0.41\end{array}$

07) Prolonged/serious conflicts with children away from home ${ }^{\text {a }}$

$$
17(15 \%) \quad 3(3 \%) \quad 11.39 * * * 9(6 \%) \quad 6.78 * * \quad 1.57
$$

08) Prolonged/serious marital conflicts

$$
44(39 \%) 21(16 \%) 10.77 * * * 33(17 \%) \quad 10.98 * * * 0.11
$$

09) Prolonged/serious illmess (spouse)

$$
\begin{array}{llllll}
52(39 \%) & 49(37 \%) & 0.14 & 64(33 \%) & 1.14 & 0.43
\end{array}
$$

10) Prolonged/serious illness or accident (respondent)

$$
75(56 \%) 57(43 \%) 4.87 * \quad 73(38 \%) 10.69 * * 0.77
$$

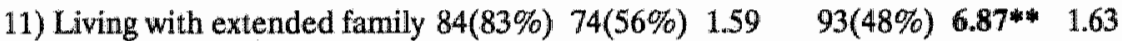

12) Prolonged/serious illness/death of family members ${ }^{b}$

$$
79(59 \%) 66(50 \%) 2.56 \quad 120(63 \%) 0.32 \quad 5.32 *
$$

13) Prolonged/serious illness/death of friends/acquaintances ${ }^{b}$

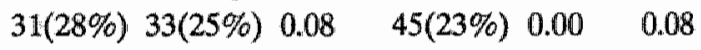

14) Prolonged/serious conflicts with family members

$$
33(25 \%) 34(26 \%) \quad 0.02 \quad 32(17 \%) 3.250 \quad 3.84 *
$$

15) Prolonged/serious conflicts with friends/acquaintances

16) Relocations

17) Spouse working

18) Prolonged/serious financial problems

$$
16(12 \%) 20(15 \%) 0.51
$$$$
118(89 \%) 116(87 \%) 0.14
$$$$
24(13 \%) 0.02
$$$$
44(33 \%) 62(47 \%) 5.08 *
$$$$
160(83 \%) 1.84
$$

$96(55 \%) 9.17 * 0.36$

$$
52(39 \%) 28(21 \%) 10.30 * 33(17 \%) \quad 19.33 * * 0.77
$$

19) Substantial loans/mortgages $63(47 \%) 67(51 \%) 0.30$ $97(51 \%) \quad 0.31 \quad 0.00$ $\begin{array}{llllll}20) \text { Being summoned to court } 30(23 \%) & 29(22 \%) & 0.01 & 48(25 \%) & 0.25 & 0.40\end{array}$

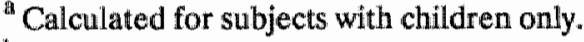

${ }^{b}$ Calculated over last 5 years only.

$0: p<.110 ; *$ p $<.05 ; * *: p<.01 ; * * * p<.001$.
} 
Table 5.:

Crude Relative Risks and $95 \%$ Confidence Intervals

Associated with Reported Stressful Life Lvents over the Life-Span

in Cases with First Myocardial Infaretion (MD),

Compared to Neighborhood Referents (NR) and Hospital Referents (HR).

A. Childhood \& Adolescence

$M I \times N R \quad M I \times H R$

$$
(N=133)(N=133) \quad(N=133)(N=192)
$$

01) Being raised by one parent

$0.95(0.50-1.80)$

$1.16(0.63-2.13)$

02) Prolonged parental illness

$0.81(0.49-1.36)$

$1.49(0.90-2.46)$

03) Living away from home

$1.78(0.99-3.19)$

$1.72(1.01-2.93)$

04) Prolonged familial conflicts

$1.16(0.63-2.13)$

2.32(1.24-4.33)

05) Prolonged unemployment (father)

$1.93(0.94-3.97)$

2.15(1.11-4.17)

06) Relocations

$0.74(0.45-1.20)$

$0.67(0.43-1.05)$

07) Prolonged financial problems

$2.49(1.40-4.43)$

2.30(1.38-3.83)

08) Prolonged illness (respondent)

$0.70(0.38-1.25)$

$1.34(0.73-2.44)$

09) Hospital admissions (respondent)

$1.07(0.64-1.79)$

$1.01(0.63-1.62)$

10) Working after school

$1.38(0.32-2.35)$

$1.04(0.65-1.66)$

11) Military service

$0.47(0.29-0.78)$

$0.57(0.36-0.90)$ 
B. Work \& Career

$$
M I \times N R \quad M I \times H R
$$

$$
(N=133)(N=133) \quad(N=133)(N=192)
$$

01) Present unemployment/disability

$1.53(0.94-2,49)$

$1.36(0.87-2.12)$

02) Past unemployment

1.88(1.06-3.35)

$1.40(0.84-2.31)$

03) Past disability

$0.75(0.36-1.58)$

$0.72(0.36-1.43)$

04) Voluntary search for other job(s)

$0.85(0.49-1.48)$

$0.92(0.56-1.53)$

05) Compulsory search for other job(s) 1.28(0.79-2.10)

$1.88(1.18-2.98)$

06) Work place closed down

$1.53(0.91-2.59)$

$2.29(1.39-3.77)$

07) Important organizational/economic changes at work

$1.10(0.65-1.85)$

08) Prospects for promotion (unrealized)

$$
0.51(0.30-0.86)
$$

$2.33(1.48-3.67)$

09) Increased responsibility at work

10) Prolonged/serious conflicts with colleagues

$1.26(0.63-2.51)$

11) Prọlonged/serious conflicts with supervisors

$$
0.94(0.46-1.91)
$$

$2.09(1.29-3.39)$

12) Prolonged/serious conflicts with subordinates

$$
1.18(0.71-1.95)
$$

$1.49(0.62-3.61)$

13) Prolonged/irregular working hours/shiftwork

$2.49(1.03-6.05)$

$1.16(0.68-2.00)$

1.71(1.05-2.78)

14) Prolonged overtime

1.66(1.01-2.72)

2.17(1.38-3.42)

15) Prolonged absenteeism

$1.15(0.68-1.93)$

16) Continuing education to improve one's position

$0.63(0.38-1.05)$ 
C. Family \& Social Life

$$
\begin{array}{cc}
M I \times N R & M T \times H R \\
(N=133)(N=133) & (N=133)(N=192)
\end{array}
$$

01) Diworce

$1.31(0.47-3.62)$

$1.54(0.73-3.25)$

$1.67(0.63-4.41)$

02) Childlessness

$1.66(0.95-2.89)$

$0.87(0.47-1.61)$

03) Prolonged/serious illness of children ${ }^{\text {a }}$

$1.15(0.50-2.64)$

04) Demth of children ${ }^{2}$

05) Prolonged/serious educational problems with children ${ }^{a}$

06) Children leaving home ${ }^{a}$

$4.27(1.85-9.84)$

$1.50(0.88-2.55)$

07) Prolonged/serious conflicts with children away from home $\mathrm{e}^{\mathrm{a}}$

6.78(2.23-20.64)

08) Prolonged/serious marital conflicts $2.64(1.48-4.71)$

$2.96(1.311-6.71)$

2.38(1.42-3.98)

09) Prolonged/serious illness (spouse)

$1.10(0.67-1.81)$

10) Prolonged/serious illness or accident (respondent)

$$
1.72(1.06-2.80)
$$

11) Living with extended family

$1.37(0.84-2.23)$

12) Prolonged/serious illness/death of family members ${ }^{b}$

$$
1.49(0.91-2.41)
$$

13) Prolonged/serious illness/death of friends/acquaintances ${ }^{b}$

$$
0.92(0.52-1.62)
$$

2.60(1.31-5.13)

$1.28(0.78-2.12)$
$1.49(0.67-3.35)$

$1.28(0.81-2.03)$

2.11.(1.35-3.30)

$1.82(1.16-2.86)$

$0.88(0.56-1.38)$

$1.00(0.59-1.66)$

14) Prolonged/serious conflicts with family members

$$
0.96(0.55-1.67) \quad 1.65(0.96-2.84)
$$

15) Prolonged/serious conflicts with friends/acquaintances

$\begin{array}{lll} & 0.77(0.38-1.57) & 0.96(0.49-1.88) \\ \text { 16) Relocations } & 1.15(0.55-2.42) & 1.57(0.82-3.03) \\ \text { 17) Spouse working } & 0.57(0.34-0.93) & 0.49(0.31-0.78) \\ \text { 18) Prolonged/serious financial problems } & 2.41(1.41-4.12) & 3.09(1.87-5.11) \\ \text { 19) Substantial loans/mortgages } & 0.87(0.54-1.42) & 0.88(0.57-1.37) \\ \text { 20) Being summoned to court } & 1.03(0.58-1.85) & 0.87(0.52-1.47)\end{array}$

${ }^{a}$ Calculated for subjects with children only.

${ }^{b}$ Calculated over last five years only. 


\section{Table 5.4.:}

Crude and Age-Adjusted Relative Risks and 95\% Confidence Intervals Associated with Reported Stressfull Life Events over the Life-Span, Simultaneously Controlled for Type A Coronary-Prone Behavior Pattern, in Cases with First Myocardial Infarction, Compared to the Combined Referents.

A. Childhood \& Adolescence Crude $^{a}$

Age-Adjusted \& HeteroSimultaneously geneity

Controlled for $\mathrm{Ch}^{2}$

$T A B P$

01) Being raised by one parent

$1.06(0.62-1.84)$

$0.98(0.56-1.73)$

4.85

02) Prolonged parental illness

$1.14(0.73-1.78)$

$1.26(0.80-2.00)$

10.540

03) Living away from home

1.75(1.09-2.81)

$1.56(0.95-2.56)$

2.76

04) Prolonged familial conflicts

$1.16(0.63-2.13)^{b}$

$1.11(0.58-2.13) b$

$10.09 \mathrm{o}$

$2.32(1.24-4.33)^{c}$

\begin{tabular}{l:l}
$2.45(1.25-4.80) \mathrm{c}$ & 2.22 \\
\hline
\end{tabular}

05) Prolonged unemployment (father)

2.06(1.15-3.66)

$1.92(1.05-3.51)$

7.45

06) Relocations

$0.70(0.47-1.05)$

$0.69(0.46-1.05)$

6.21

07) Prolonged financial problems

2.37(1.51-3.74)

2.20(1.37-3.53)

9.13

08) Prolonged illness (respondent)

$0.99(0.59-1.67)$

$0.94(0.55-1.61)$

6.33

09) Hospital admissions(respondent)

$1.04(0.67-1.59)$

$1.12(0.71-1.75)$

3.31

10) Working after school

$1.16(0.75-1.79)$

$1.13(0.72-1.77)$

5.52

11) Military service

$0.53(0.35-0.80)$

$0.53(0.34-0.81)$

9.450

$0: \mathrm{p}<.10 ; * \mathrm{p}<.05$. 
B. Work \& Career

Crude $^{a}$

Age-Adjusted \&

Hettero-

Simultaneously

geneity

Controlled for

$\mathrm{Ch}^{2}$

TABP

01) Present unemployment/disability

$1.43(0.95-2.14)$

$1.20(0.73-1.98)$

13.94*

02) Past unemployment

$1.57(0.99-2.48)$

$1.56(0.97-2.52)$

2.07

03) Past disability

$0.73(0.39-1.38)$

$0.73(0.38-1.40)$

1.40

04) Voluntary search for other job(s) $0.89(0.57-1.41)$

$0.87(0.54-1.41)$

9.380

05) Compulsory search for other job(s) $1.60(1.06-2.41)$

$1.46(0.95-2.25)$

6.68

06) Work place closed down

$1.92(1.24-2.98)$

1.75(1.11-2.76)

2.85

07) Important organizational/economic changes at work

$0.78(0.49-1.24)$

$0.76(0.47-1.23)$

2.07

08) Prospects for promotion (unrealized)

09) Increased responsibility at work

$$
1.88(1.24-2.85)
$$

$1.80(1.17-2.76)$

1.38

$0.79(0.47-1.32)^{b}$

$0.76(0.45-1.28) \mathrm{b}$

$11.50^{*}$

$1.66(1.06-2.62)^{\mathrm{c}}$

$1.68(1.04-2.69) \mathrm{c}$

8.14

10) Prolonged/serious conflicts with colleagues

$$
1.11(0.60-2.04)
$$

$1.07(0.56-2.05)$

3.91

11) Prolonged/serious conflïcts with supervisors

$$
\begin{array}{lll}
1.18(0.71-1.95)^{b} & 1.27(0.74-2.17) b & 7.38 \\
\mathbf{2 . 0 9}(1.29-3.39)^{c} & 2.11(1.27-3.52) c & 4.15
\end{array}
$$

12) Prolonged/serious conflicts with subordinates

$$
1.96(0.93-4.12) \quad 1.77(0.80-3.91) \quad 4.77
$$

13) Prolonged/irregular working hours/shiftwork

14) Prolonged overtime

$$
1.47(0.94-2.31)
$$

$1.42(0.89-2.27)$

15) Prolonged absenteeism

$1.94(1.28-2.95)$

1.87(1.21-2.87)

0.98

16) Continuing education to improve one's position

$0: \mathrm{p}<.10^{*} * \mathrm{p}<.05$. 
C. Family \& Social Life

Crude $^{a}$

Age-Adjusted \&

Hetero-

Simultaneousty geneify

Controlled for

$\mathrm{Chi}^{2}$

$T A B P$
a1) Divorce
$1.50(0.64-3.50)$
$1.51(0.62-3.72)$
10.250
02) Childlessness
$1.21(0.60-2.24)$
$1.18(0.64-2.16)$
0.40
03) Prolonged/serious illness of children ${ }^{d}$

8.95

04) Death of children ${ }^{d}$

1.96(1.21-3.13)

$1.96(1.20-3.18)$

$12.48^{*}$

05) Prollonged/serious educational problems with children ${ }^{\text {d }}$

$1.39(0.66-2.92)$

2.15

3.13(1.71-5.73)

3.01(1.59-5.69)

8.31

06) Children leaving home ${ }^{d}$

1.37(0.87-2.16)

$1.12(0.61-2.04)$

07) Prolonged/serious conflicts with children away from bome ${ }^{d}$

3.91(1.88-8.13)

$3.38(1.56-7.35)$

2.40

08) Prolonged/serious marital conflicts, $2.48(1.57-3.92)$

2.22(1.37-3.58)

10.720

09) Prólonged/serious illness (spouse) $1.20(0.79-1.83$ )

$1.18(0.77-11.83)$

8.83

10) Prolonged/serious illness or accident (respondent)

$1.78(1.16-2.71) \quad 8.35$

11) Living with extended family

1.94(1.29-2.91)

$1.61(1.05-2.47)$

3.04

12) Prolonged/serious illness/death of family members ${ }^{e}$

$1.09(0.73-1.65)$

$1.11(0.73-1.70)$

13) Prolonged/serious illness/death of friends/acquaintances ${ }^{e}$

$$
0.96(0.60-1.55)
$$

$0.88(0.54-1.43)$

2.72

14) Prolonged/serious conflicts with family members

$$
1.30(0.80-2.09)
$$

$1.20(0.73-1.98)$

3.29

15) Prolonged/serious conflicts with friends/acquaintances

16) Relocations $0.87(0.47-1.61)$

$0.85(0.45-1.60)$

17) Spouse working

$1.40(0.75-2.59)$

$1.31(0.69 \cdot 2.48)$

3.31

18) Prolonged/serious financial problems

$0.54(0.34-0.86) \quad 3.88$

19) Substantial loans/mortgages

$2.78(1.79-4.30)$

$2.58(1.64-4.06)$

20) Being summoned to court

$0.88(0.59-1.32)$

$0.96(0.63-1.46)$

1.46

$0.93(0.58-1.51)$

$0.91(0.56-1.48)$

3.13

Total number of cases with first $\mathrm{MI}(\mathrm{N}=133)$ compared to total number of referents from both series $(\mathrm{N}=325)$; ${ }^{\mathrm{b}}$ Neighborhood series only.: ${ }^{\mathrm{c}}$ Hospital series only; ${ }^{4}$ Calculated for subjects with children only; ${ }^{e}$ Calculated ower last five years only. o: $\mathrm{p}<.10 ; 0^{*}: \mathrm{p}<.05$. 
Table 5.5.:

Age-Adjusted Relative Rusks and $95 \%$ Confidence Intervals Associated with Reported Stressful Life Events over the LIfe-Span, Sümultaneously Controlled for Manifestations of Vital Exhanstion, in Cases with Furst Myocardial Infaretion, Compared to Neighborhood Referents and Hospital Referents.

A. Childhood \& Adolescence

$M I \times N R$ Heterogeneity $M I x H R$ Heterogenety $(N=133)(N=133) \mathrm{Chi}^{2} \quad(N=133)(N=192) \mathrm{Chi}^{2}$

01) Being raised by one parent

$0.95(0.47-19.5) \quad 4.36 \quad 1.14(0.60-2.15) \quad 5.33$

a) Prolonged parental illness

$0.73(0.41-1.32)$

3.16

$1.47(0.87-2.59) 3.03$

Bi) Living away from home

$1.47(0.75-2.88)$

2.17

$1.60(0.92-2.77) \quad 1.45$

04) Prolonged familial conflicts

$0.81(0.40-1.63)$

3.48

$2.30(1.17-4.49) \quad 6.05$

b) Prolonged unemployment (father)

$1.39(0.61-3.16)$

0.71

$1.94(0.97-3.87) \quad 6.82$

10) Relocations

$0.77(0.45-1.33)$

4.47

$0.71(0.44-1.12) \quad 4.38$

Di) Prolonged financial problems

$2.34(1.20-4.55)$

2.75

2.01(1.18-3.42) 7.41

08) Prolonged illness (respondent)

$0.62(0.32-1.18)$

8.56

$1.18(0.63-2.21) \quad 3.50$

09) Hospital admissions (respondent)

$0.96(0.54-1.73) \quad 2.53$

$0.91(0.56-1.48) \quad 5.68$

10) Working after school

$1.34(0.73-2.43) \quad 5.18$

$1.05(0.64-1.72) 2.77$

11) Millitary serwice

$0.62(0.35-1.09)$

3.11

0.61(0.39-0.97) 12.1.7*

$0: \mathrm{p}<.10 ;: \mathrm{p}<.05$ 
B. Work \& Career

$M I x$ NR Heterogeneity $M I x$ HR Heterogeneity $(N=133)(N=133) \quad C h i^{2} \quad(N=133)(N=192) C h i^{2}$

01) Present unemployment/disability

$0.83(0.44-1.55)$

3.26

$1.19(0.69-2.05) \quad 3.51$

02) Past unemployment

$1.65(0.86-3.19) \quad 8.20$

$1.34(0.79-2.27) \quad 10.550$

03) Past disability

$0.47(0.20-1.08) \quad 0.61$

$0.66(0.33-1.35) \quad 6.24$

04) Voluntary search for other job(s) $1.00(0.52-1.91) \quad 4.25$

$0.87(0.51-1.47) \quad 8.59$

05) Compulsory search for other job(s)

$0.98(0.57-1.69) \quad 5.70 \quad 1.91(1.18-3.11) \quad 3.42$

06) Work place closed down

$1.61(0.88-2.92)$

$11.29 * 2.23(1.32-3.75) \quad 10.820$

07) Important organizational/economic changes at work

08) Prospects for promotion (unrealized)

$$
\begin{array}{llll}
0.52(0.29-0.95) & 2.37 & 1.18(0.67-2.05) & 5.37
\end{array}
$$

$1.75(1.00-3.10) \quad 3.00 \quad 2.34(1.46-3.75) \quad 1.26$

09) Increased responsibility at work $\quad 0.88(0.51-1.53) \quad 12.67 * 1.74(1.08-2.79) \quad 8.19$

10) Prolonged/serious conflicts with colleagues

$$
0.96(0.42-2.21) \quad 4.99 \quad 1.16(0.57-2.39) \quad 0.63
$$

11) Prolonged/serious conflicts with supervisors

$$
0.93(0.52-1.65) \quad 6.61 \quad 1.99(1.20-3.31) \quad 5.03
$$

12) Prolonged/serious conflicts with subordinates

$$
1.39(0.52-3.69) \quad 5.24 \quad 2.09(0.83-5.22) \quad 6.17
$$

13) Prolonged/irregular working hours/shift work

14) Prolonged overtime

$0.82(0.45-1.49)$

11.85* $1.59(0.96-2.64) \quad 12.49 *$

15) Prolonged absenteeism

$1.13(0.63-2.01)$

5.98

1.94(1.21-3.12) 5.90

16) Continuing education to improve one's position

$0.89(0.49-1.62) \quad 1.55 \quad 0.55(0.32-0.94) \quad 3.39$

$0.52(0.30-0.91)$

$4.15 \quad 0.78(0.49-1.25) \quad 2.91$

$0: p<.10 ; *: p<.05$. 
C. Fanily \& Social Life

MI $x$ NR Heterogeneity MI $x$ HR Heterogeneity $(N=133)(N=133) \quad \mathrm{Chi}^{2}(N=133)(N=192) \mathrm{Ch}^{2}$

(01) Diworce

$1.47(0.47-4.60)$

4.97

$1.71(0.62-4.77) 12.7 *$

02) Childlessness

$1.63(0.68-3.89) \quad 4.34$

$0.87(0.46-1.67) \quad 1.92$

(B) Prolonged/serious illness of children ${ }^{\text {a }}$

04) Death of children ${ }^{a}$

$1.62(0.86-3.07) \quad 3.47$

2.08(1.19-3.62) 5.60

$1.00(0.37-2.69) \quad 5.58$

$1.56(0.65-3.72) \quad 5.37$

$05)$ Prolonged/serious educational problems with children ${ }^{\text {a }}$

106) Children leaving home ${ }^{\mathrm{a}}$

3.15(1.21-8.23) 7.71

$2.40(1.18-4.86) \quad 5.47$

DD) Prolonged/serious conflicts with children away from home

$1.08(0.56-2.07) \quad 6.15$

6.01(1.65-21.85) $\quad 5.40$

2.94(1.25-6.96) 1.84

08) Prolonged/serious marital conflicts $2.24(1.17-4.30)$

7.75

$2.33(1.37-3.99) \quad 9.660$

09) Prolonged/serious illness (spouse) $0.82(0.47-1.45)$

4.83

$1.21(0.74-1.96) \quad 6.56$

10) Prolonged/serious illness or accident (respondent)

$$
1.43(0.82-2.49)
$$

6.50

1.86(1.16-2.98) 2.12

11) Living with extended family

$1.45(0.83-2.54) \quad 1.09$

$1.70(1.06-2.73) \quad 6.98$

12) Prolonged/serious illness/death of family members ${ }^{b}$

$1.27(0.73-2.20) \quad 0.63$

$0.79(0.49-1.27) 2.36$

13) Prolonged/serious illness/death of friends/acquaintances ${ }^{b}$

$$
0.92(0.52-1.63)
$$

$14.74 *$

$0.94(0.57-1.56) \quad 12.29^{*}$

14) Prolonged/serious conflicts with family members

$$
0.86(0.47-1.58) \quad 7.67 \quad 1.53(0.87-2.71) \quad 1.63
$$

15) Prolonged/serious conflicts with friends/acquaintances

16) Relocations

$$
0.63(0.30-1.35)
$$

5.68

$0.89(0.45-1.77) \quad 1.50$

17) Spouse working

$0.68(0.37-1.99)$

6.00

$1.44(0.73-2.87) \quad 3.90$

18) Prolonged/serious financial problems

$0.71(0.39-1.29) \quad 3.57$

$0.48(0.29-0.80) \div 7.56$

19) Substantial loans/mortgages

$1.77(0.96-3.25) \quad 6.38$

$2.95(1.74-4.99) \cdot 5.87$

$0.86(0.50-1.51)$

1.89

$0.94(0.59-1.49) \quad 4.86$

20) Being summoned to court

$1.02(0.53-1.99) \quad 5.08$

Calculated for subjects with children only.

${ }^{b}$ Calculated over last five years only.

a: $\mathrm{p}<.10 ; * \mathrm{p}<.05$ 
Table 5.6:

Estimated Relative Risks and 95\% Confidence Intervals Assoclated with Keported Stressful Life Events over the Lufe-Span, When Simultaneously Controlling for Age,

Current Smoking, Type A Coronary-Prone Behavior Pattern, Manifestations of Vital Exhaustion, and Edicational Level, un Cases with First Myocardial Infarction, Compared to the Combined Referents (Multuple Logistic Regression).

$R R \& 95 \% \mathrm{Cl}^{a} \quad \mathrm{RR} \& 95 \% \mathrm{Cl}^{b} \quad \mathrm{RR} \& 95 \% \mathrm{Cl}^{\mathrm{C}}$

03) Living away from home

Not entered

$1.69(1.02-2.82)$

Not entered

06) Relocations

Not entered $0.65(0.42-0.99)$ Not entered

07) Prolonged financial problems

2.14(1.28-3.58)

2.11(1.28-3.47)

2.02(1.20-3.40)

RR\& $95 \% \mathrm{Cls}^{a} \quad$ RR\&95\% Cls ${ }^{b} \quad$ RR\&95\% Cls

06) Work place closed down

$1.78(1.09-2.89)$

$1.83(1.14-2.93)$

$1.70(1.04 .2 .78)$

08) Prospects for promotion (unrealized)

2.10(1.32-3.33)

$1.89(1.20-2.95)$

1.97(1.24.3.15)

14) Prolonged overtime

Not entered

1.85(1.19-2.88)

Not entered

C. Family \& Social Life

RR\& $95 \% \mathrm{CI}^{a}$

$R R \& 95 \% \mathrm{CIS}^{b} \quad R R \& 95 \% \mathrm{Cls}^{c}$

03) Prolonged/serious illness of children ${ }^{\text {d }}$

1.78(1.07-2.97) $1.87(1.14-3.06)$

$1.80(1.08-3.02)$

05) Prolonged/serious educational problems with children ${ }^{d}$

$$
2.05(1.04-4.04) \quad 2.43(1.25-4.70)
$$

07) Prolonged/serious conflicts with children away from home ${ }^{d}$

$$
3.74(1.55-8.99) \quad 4.00(1.68-9.54)
$$

$3.65(1.49-8.92)$

08) Prolonged/serious marital conflicts Not entered $2.24(1.36-3.70)$

Not entered

10) Prolonged/serious illness or accident (respondent)

$$
1.75(1.11-2.75)
$$

$1.65(1.04-2.61)$

11) Living with extended family

$1.63(1.04-2.57)$

$1.58(1.02-2.46)$

$1.63(1.03-2.59)$

18) Prolonged/serious financial problems

$$
2.47(1.51-4.04) \quad 2.75(1.70-4.45)
$$

${ }^{a}$ Multiple logistic regression analyses excluding TABP;

${ }^{b}$ Multiple logistic regression analyses excluding manifestations of vital exhaustion.

${ }^{c}$ Multiple logistic regression analyses including both TABP and manifestation of vital exhaustion. ${ }^{d}$ Calculated for subjects with children only. 
Table 5.7.:

Estimated Relatiwe Risks and 95\% Confidence Intervals Associated with Reported Stressful Life Events over the Life-Span, Which Show an Interaction with Age, when Simultaneously Controlling for Current Smoking, Type A Coronary-Prone Behavior Pattern, Manifestations of Vital Exhaustion, and Educational Level, in Cases with First Myocardial Infarction, Compared to the Combined Referents (Multiple Logistic Regression). $R R \& 95 \% \mathrm{Cl}^{a} \quad \mathrm{RR} \& 95 \% \mathrm{Cls}^{b} \quad \mathrm{RR} \& 95 \% \mathrm{Cls}^{c}$

04) Voluntary search for other job(s)

Age 35-44:

Age 45-59:

Age 60-69:

09) Increased responsibility at work

Age 35-44:

Age 45-59:

Age 60-69:

$\begin{array}{lll}\mathbf{5 . 0 2}(1.03-24.48) & 3.66(0.79-16.89) & \mathbf{4 . 9 9 ( 1 . 0 1 - 2 4 . 7 8 )} \\ 0.47(0.22-1.02) & 0.44(0.21-0.95) & 0.40(0.18-0.89) \\ 0.75(0.31-1.79) & 1.00(0.43-2.32) & 0.76(0.32-1.84)\end{array}$

$4.97(1.75-14.13) \quad 3.66(1.34-9.98)$

4.93(1.73-14.09)

$0.87(0.44-1.71) \quad 0.96(0.50-1.84) \quad 0.86(0.43-1.70)$

$0.80(0.33-1.92) \quad 0.73(0.31-1.69) \quad 0.75(0.31-1.82)$

C. Family \& Social Life

$R R \& 95 \% C_{C} s^{a} \quad R R \& 95 \% C l s^{b} \quad R R \& 95 \% C l s^{c}$

08) Prolonged/serious marital conflicts

Age 35-44:

Age 45-59:

Age 60-69:

09) Prolonged/serious illness (spouse)

Age 35-44:

Age 45-59:

Age 60-69:
0.88(0.33-2.35) Not entered

4.07(1.95-8.48) Not entered

$1.81(0.59-5.50) \quad$ Not entered
$0.79(0.29-2.15)$

3.57(1.69-7.51)

$1.65(0.54-5.04)$

$\begin{array}{lll}0.37(0.12-1.10) & 0.36(0.12-1.06) & 0.32(0.11-0.99) \\ 1.16(0.60-2.23) & 1.20(0.63-2.28) & 1.21(0.62-2.37) \\ 2.29(0.96-5.49) & \mathbf{2 . 3 9}(1.03-5.58) & \mathbf{2 . 4 0 ( 1 . 0 0 - 5 . 8 0 )}\end{array}$

Multiple logistic regression analyses excluding Type A coronary-prone behavior pattern. ${ }^{b}$ Multiple logistic regression analyses excluding manifestations of vital exhaustion. Multiple logistic regression analyses including both Type A coronary-prone behavior pattern and manifestations of vital exhaustion. 
Table 7.1.:

Prevalence of Discriminating Reported Stressful Life Events, Type A Coronary-Prone Behavior Pattern, and Manifestations Of Vital Exhaustion in Three Selected Life Histories of Cases with First Myocardiall Infarction.

Case:

Age

A $\quad B \quad C$

$38 \quad 53 \quad 63$

TABP

A1 A1

B4

Discriminating SLE and Their Estimated Impact on The Life-Span

A) Childhood \& Adolescence:

- Prolonged Financial Problems

B) Work \& Career:

- Work place closed down

- Prospects for promotion (unrealized)

- Voluntary search for other job(s)

(Age 35-44)

- Increased responsibility

(Age 35-44)

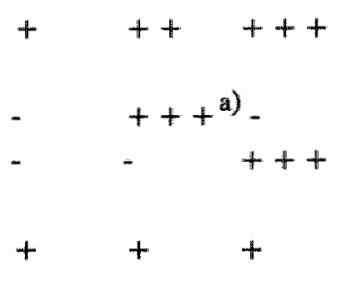

C) Family \& Social Life:

$+++++$

- Prolonged/serious illness of children

$$
+++++
$$

- Prolonged/serious educational problems with children

- Prolonged/serious conflicts with children away from home

$$
+++
$$

- Prolonged/serious illness/accident (respondent)

- Living with extended family

- Prolonged/serious financial problems

- Prolonged/serious marital conflicts

\section{(Age 45-59)}

- Prolonged/serious illness (spouse)

(Age 60-69)

Manifestations of Vital Exhaustion (MQ-Score)

$\begin{array}{lll}- & - & ++ \\ - & +++ & +++ \\ - & ++ & + \\ & +t & +++ \\ - & - & +++ \\ + & - & +++ \\ 22 & 34 & 41\end{array}$

- : Not Reported.; + No/Moderate Impach, as judged from the SBI.; + + : Substantial Impact, as judged from the SBI; +++ : (Very) Severe Impact, as judged from the SB.I $_{*}^{\text {a) }}$ : This event did not actually occur, but influenced subsequent life-span development to a very substantial extent. 
Figure 3.1.:

Ratios of Type A to Type B Coronary-Prone Behavior Pattern, in Cases with First Myocardial Infarction (MI),

Neighborhood Referents (NR), and Hospital Referents (HR), in Seven Age Strata.

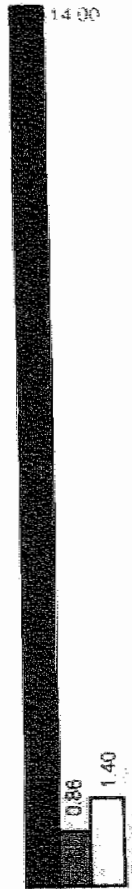

Age: $35-39$

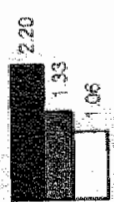

$40-44$

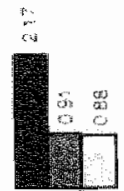

$45-49$

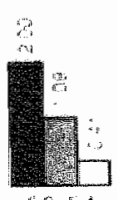

$50-54$

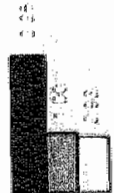

5559

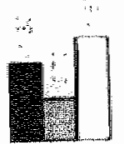

(3) 1,4

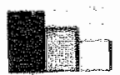

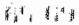

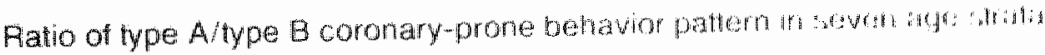


Figure 4.1.:

Standardized Relative Risks Associated with Different Degrees of Vital Exhaustion (First, Second, and Third Tertiles of MQ Scores), Adjusted Separately for Angina Pectoris, Current Smoling, and Age, in Cases with First Myocardial Infarction (MI), Compared to Neighbortiood Referents (NR), and Hospital Referents (HR).

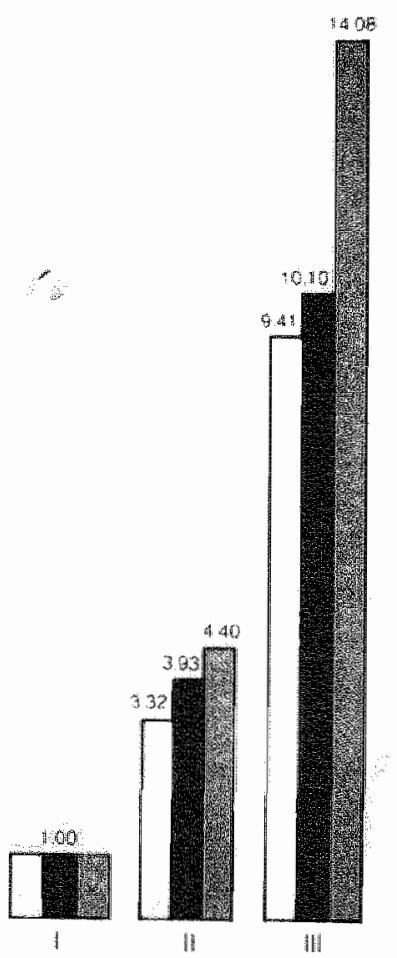

Tartilles of wital exhaustion: M." Caser $(173)$ compared to NBHD (133)
Adusted for

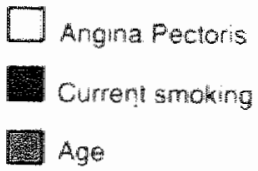

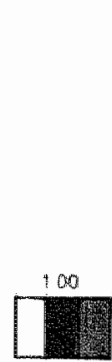

1

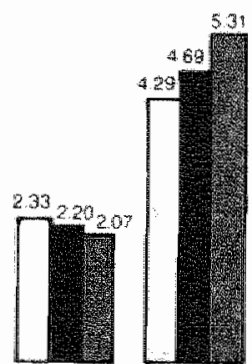

II ilil
Tertles of vital extrasition:

Mi-cases (133) compared to HPTL 1192

Standardized relative risks associated with different degrees of vital exhaustion and adjusted for angina pectoris, current smoking, and age. 
Figure 4.2.:

Standardized Relative Risks Associated with First Myocardial Infarction in "Vital" and "Vitally Exhausted" Type A and Type B Subjects, Including cases with first Myacardial Infarction (MD), Neighborhood Referents (NR), and Hospital Referents (HR).
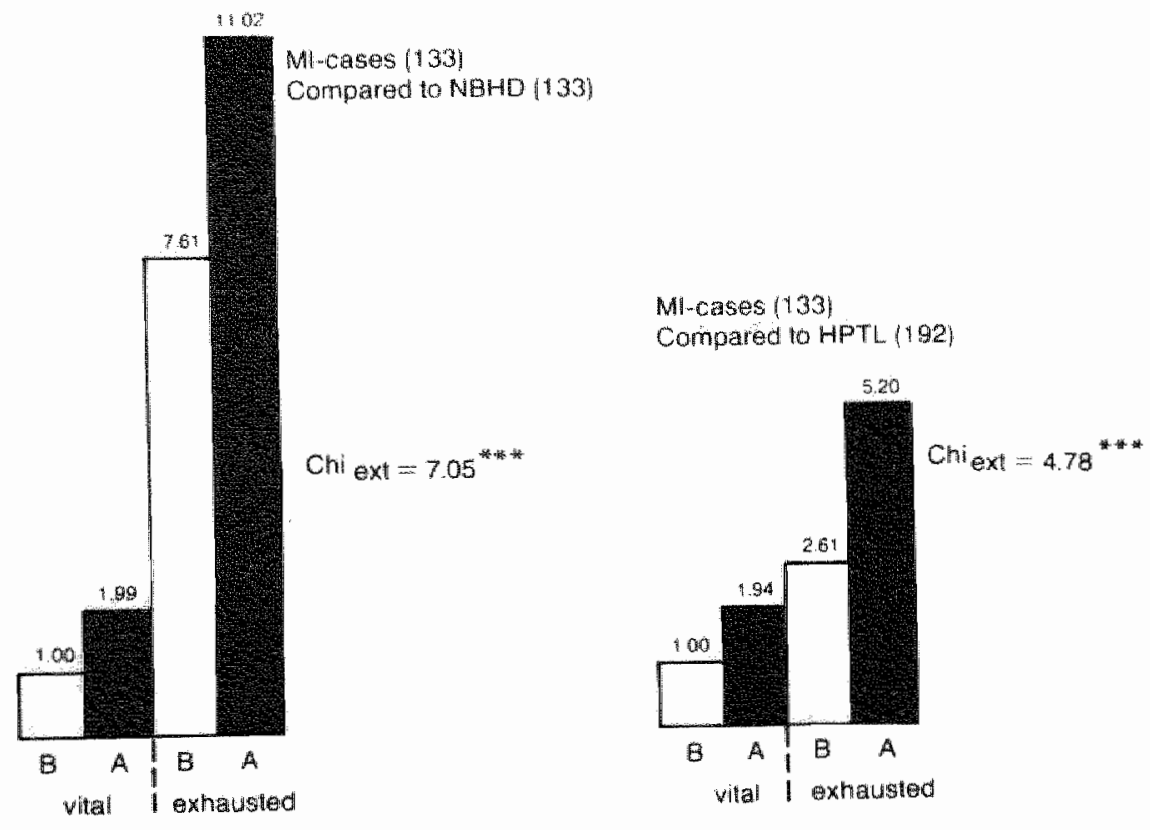

Standardized relative risks associated with first myocardial infarction in "Vitall" and "Vitally exhausted" type A and Type B subjects. 
-250 - 
Appendix I: Composition of Participating and Non-Participating Subjects.

1. Cases with first $M I$ inwited to participate:

Inteniewed:

Total $N=220$

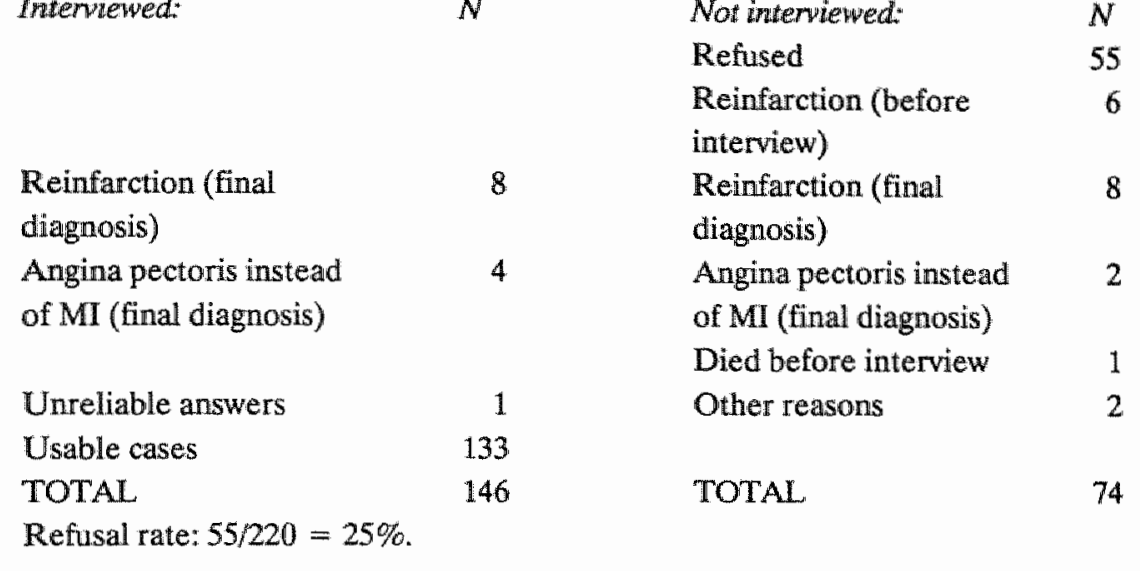

2. Neighborhood referents invited to participate:

Total $N=532$

Interviewed: $N$

Not interviewed: $\quad N$

Refused 278

Unsuitable due to age $\quad 112$

Other reasons

Usable referents

133

TOTAL

133

TOTAL

399

Refusal rate: $278 / 532=52 \%$.

3. Hospital referents invited to participate:

$\operatorname{Total} N=252$

Interviewed: N

Not interviewed: $\quad N$

Refused 41

Died before interview 2

Other reasons $\quad 17$

Usable referents

192

TOTAL

Refusal rate: $41 / 252=16 \%$. 
$-252$ 


\section{Rijksuniversiteit Limburg}

Fakuteit der geneeskunde

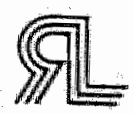

Capaciteitsgroep Medische Psychologie

Appendix II: Structured Riographical

LEUENSLOOP INTERUIEU

Respondentmumer:

Geboorteda tum:

Burgerlijke staat:

$\begin{array}{ll}\text { Ongehuwd } & 1 \\ \text { Gehuwd/Santenwonend } & 2 \\ \text { Weduwnaar } & 3 \\ \text { Gescheiden } & 4\end{array}$

Hoonplats:

Waan Huisarts:

Interview

Gescheiden

Geschikt voor werwerking:

Echtgenote bij gesprek aanwezig:

Datum afmame interview:

Dutur interview: begin: ainde: ja

men

3의

he 


\section{LICHAMELIJKE KLACHTEN}

Za dadel ijk noen ik enkele Thamelijke klachten. Ik wil u vragen on aan te geven of er pertoden in uw leven zijn geweest, warin u gedurende langere tijd ển of meerdere van deze klachten heeft gehad. Indien dat het geval is; will $t$ dan angeven wanneer dat ongeveer was. en ook of u toen in verband met deze klachten een arts heeft geraadpleegd.

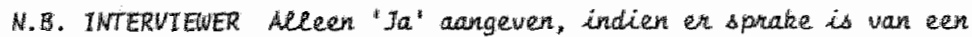
poychosomatische blacht. Indien dit niet duidelijh is, het uhargterent angeven. Indien et en duiderij somatische oonzark voor de blacht

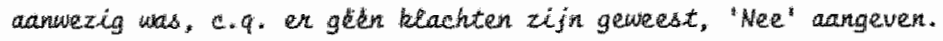

1. Heeft $u$ wel eens gedurende langere tijd last gehad van hoofdpithen/duzeligheid? Ja? Nee arts 19...

2. Heeft 4 wel eens gedurende langere tijd last gehad wan madglk lachten? da: ? Nee arts 19...

3. Heeft u wel eens een magzweer gehad? da? Nee arts 19...

4. Heeftu well eens gedurende langere tijd last gehad wan darmistoonis is sen?

Ja ? Nee arts $19 .$.

5. Heeft ul wel eens gedurende langere tijd last gehad wan kortademigheid/benauwdheid ?

Ja ? Nee arts $19 \ldots$

6. Heeft $₫$ wel eens last gehad van hartkloppingen? Ja ? Nee arts $19 \ldots$

7. Heeft $u$ wel eens gedurende langere tijd last gehad wan rugklachten?

8. Heeft $u$ wel eens gedurende langere tijd last gehad wan huidaandoeningen ? 


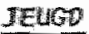

Hieronder volgen een eerste reeks vragen ower de tuja warin u bent opgegroeid, en: over gebeurtenissen die zich eventueel in uw jeugd hebben vorgedaan.

1. Wat is uw geboorteplats?

2 . Hoevel kinderen waren er bij u thuis?

Jongens:

Meisjes:

3. Welke plats nam un ?

$\begin{array}{ll}\text { Oudste } & 1 \\ \text { Tweede } & 2 \\ \text { Derde } & 3 \\ \text { Vierde } & 4 \\ \text { Nee } & - \\ \text { Ja } * \text { yrg } 5\end{array}$

4. Werd a door uw beide ouders opgevoed?

-- Indien 'Nee":

- a. Warom niet?

$\begin{array}{ll}\text { Vader overleden } & 1-b / c \\ \text { Moeder overleden } & 2+b / d \\ \text { Ouders gescheiden } & 3+b / c / d \\ \text { Modder ongehuwd } & 4+c \\ \text { Anders } & 5+c\end{array}$

-D. Hoe oud was u toen?

- c. Indien opgevoed door moeder:

Nam iemand de kostwinnerstaak over?

Ja Nee

- Indien " Ja": Whe?

- d. Indien opgevoed door vader:

Mam iemand de zorg voor het hutshoudan over?

\begin{tabular}{ll} 
Moeder & 1 \\
Respondent zelf & 2 \\
Broer/zus & 3 \\
Familieleden & 4 \\
Anders & 5 \\
\hline
\end{tabular}

-- Indien 'Ja': Wie?

$\begin{array}{ll}\text { Vadieps } & 1 \\ \text { Respondent zelf } & 2 \\ \text { Broer/zus } & 3 \\ \text { Familieledien } & 4 \\ \text { Anders } & 5\end{array}$


- Welke direkte gevolgen had dit voor u persoonlijk?

\section{Heguallen yan waden/moader/apvoedes}

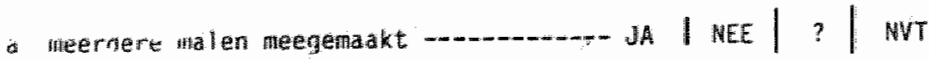

b) wordereid (aktief) _........... JE $\mid$ NEE | | NVT

c) verwacht rop dat moment) -

d) destijds overwegend erwaren als -..... POS | NEG $|?|$ NWT I POS/NEG

e) op lange termijn ervaren als -....... POS | NEG | ? | NWT | POS/HEG

f) 'social sunoort' -..................... JA $\mid$ NEE $\mid$ ? NWT POS/NEG van welke personen: kort ma gebeurtenis op lange termijn

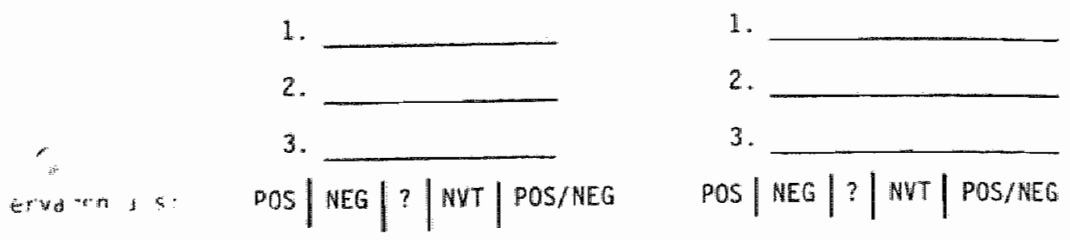

5. Is ển van uw ouders, of zijn liw belde ouders gedurende uw jeugd langdurig en/of erristig ziek geweest? Ja Nee + vrg 6 Langdurige ziekte auder(s)
a) meerdere malen meegemakt _........... JA I NEE ? IVT

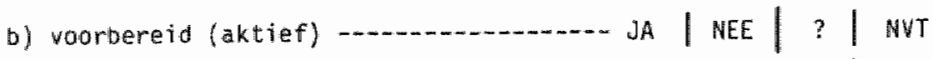
c) verwacht (op dat moment) -.............. JA INEE | ? NVT
d) destijds overwegend ervaren als ..... POS | NEG ? I NVT | POS/NEG
e) on lange termijn ervaren als -......... POS | NEG |? | NVT | POS/NEG

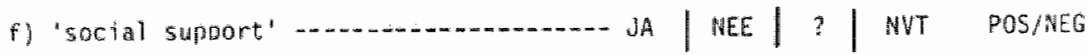 van welke personen: kort na gebeurtenis op lange temijn
1.
1.
2.
2.
3
3.

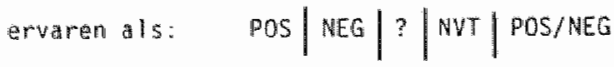
POS | NEG | ? | MVT | POS/AEG 
6. Heeft u tijodens wa jeugd butenshuis gewoond? -. Indien "da":

Kostschool/Internat 1

Gez insvervangend

tehuis

Fanilie

Intern bij werkgever 4

Anders 5

\section{Buitenshuis wonen}

a) meerdere miden meegemakt -........... JA I NEE $|?|$ NVT

b) voorbereid (aktief)

JA $\mid$ NEE | ? | NVT

c) verwacht (op dat moment)

JA $\mid$ NEE $|?|$ NVT

d) destijds overwegend ervaren ats \begin{tabular}{l|l|l|l|l} 
POS & NEG & ? & NVI & POS/NEG
\end{tabular}

e) op lange termijn ervaren als -....... POS \begin{tabular}{l|l|l|l|l|l|l|l|l|} 
NEG & $?$ & NVT & POS NEG
\end{tabular}

f) 'social suipurt' JA van welke gerronen: kort na gebeurtenis

1.

2.

3.

erwaren $:$ POS $\mid$ NEG $\mid$ ? $\mid$ NVT | POS/NEG \begin{tabular}{l|l|ll} 
NAEE & $?$ NVT
\end{tabular} op lange termijn

7. Waren er tijdens uw jeugd vaak ruzies of langdurige konflikten in het gezin?
Ja
Nee $\rightarrow$ yrg 8

\section{RuzLes/konflikten in het gezin}

d) meerders malen meegemaakt $\ldots \ldots \ldots \ldots$ JA I NEE

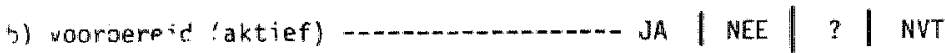

C, warke ht ;00 dat moment) -.............. JA | NEE | | NVT

$\rightarrow$ se 3 idk overwegend ervaren als -...- POS | NEG | ? | NVT | POS/NEG

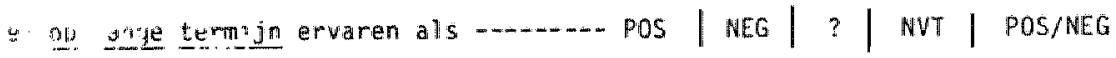

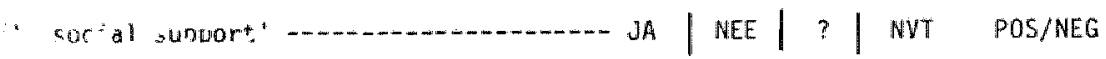
$v$ *lke gpronen: kort na gebeurtenis op lange termijn
1.
1.
2.
2.
3.
3.

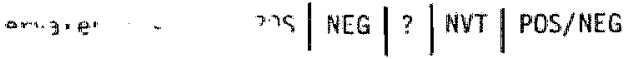
POS | NEG | ? | NWT | POS/NEG 
a. Waren er tijdens uk jeugd ển of meerdere pertodes van langdurige werkeloosheid van het hoofd van het gezin?

Ja

Nee $\rightarrow$ re 9

- a. In hoeverre drukte dit op thet gezinsleven?

- b. Had dit gevolgen voor u persoonlijk ?

\section{Wentheoashed van het hoofd van het gezin}
a) meerdere alen meegemakt
JA $\mid$ NEE $|?|$ NWT
D) voorbereid (aktief)
MA | NEE
? I MTT
c) iverwacht (op dat moment)
JA $\mid$ NEE $?$ ? NWT
d) destijds overwegend ervarem als _...... POS
\begin{tabular}{l|l|l|l|l|} 
NEG & $?$ NVT 1 POS/NEG
\end{tabular}
e) op lange termijn ervaren alls POS NEG
NVT | POS/NEG
f) 'social supoort'
34
NAEE $|7|$ NVT POS/NEG van welke perconen: kart na gebeurtenis
1.
2.
3.
Q" rar. als: POS NEG $\mid$ ? $\mid$ NVT $/$ POS/NEG
ap lange termijn
1.
2.
3.
POS NEG $|?|$ NVT | POS/NEG 
9. Bent u tijdens uw jeugd met het gezin verhuisd? Ja Nee - vrg 10 - a. Dp hoeveel adressen heeft u toen gewoond?

-b. Hoe oud was u ten tijde van deze verhuizing(en)?

-c. Bleef $u$ in dezelfde ongeving ?

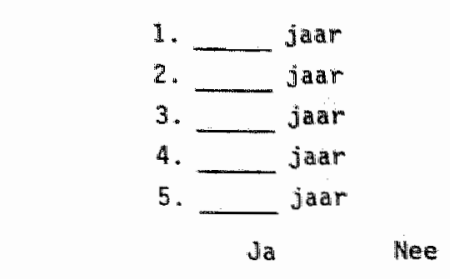

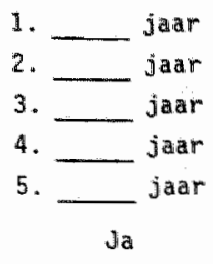

M.B. INTERVIEUER Hier moteren var welke plaats naar welke plaats de respondent is verhuisa, of belangrifke verschicten/veranderingen in de woonsituatie(s).

-1 .

-2 .

$-3$.

--4 .

-5 .

\section{Venhuizing (en)}
a) meerdere malen meegemaakt ............ JA I NEE | ? NVT
b) voorbereid (aktief)
JA. $\mid$ NEE | ? | NWT
$\therefore$ verwacht lop dat moment) -........... JA | NEE | | NWT
d) destijas overwegend ervaren als -..... POS | NEG
e) Op lange termijn erwaren als _....... POS | NEG
op lange termijn wan welke versonen: kort ma gebeurtenis
1.
2.
2 .
3.
3.
ervaren als: $\quad$ POS NEG $/$ ?NT $\|$ POS/NEG
$\operatorname{POS} \mid$ NEG $|?|$ NVT | POS/NEG
1. 
10. Was het tijdens uw jeugd 20 , dat .......... U luke heeft gekend

Er voldoende geld was om de gewone dingen te kunnen doen 2 Het ledere keer weer een probleem was de eindjes a an elkar te knopen

- a. Hefft u destijds oolt persoonlifk iets ondervonden van financiele problemen?

Ja

Hee + vrg 11

\section{Financele phoblemen}
a) meardere malen meegiemal t
IA $\|$ NEE $|?|$ NVT
0; voorbereid (aktief)
IA $\mid$ NEE $|?|$ NVT
4) verwacht (op dat moment)
JA $\mid$ NEE $|?|$ NVT
d. dest jos overwegend ervaren als -...-. pOS
\begin{tabular}{l|l|l|l} 
NEG & $?$ & NVT & POS/NEG
\end{tabular}
e! op lange termijn ervaren als -.......- pos
\begin{tabular}{l|l|l|l|l|l|l|l|} 
NEG & $?$ & NVT
\end{tabular}
f) 'socilal support'
\begin{tabular}{l|l|l|l} 
NEE & $?$ & NVT & POS/NEG
\end{tabular}

var welke pexsonen: kart nia gebeurtenis

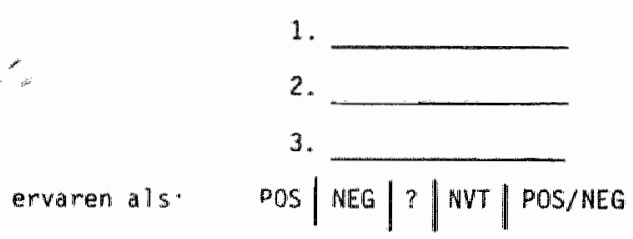

op lange termijn

1.

2 .

3.

POS | NEG |? | NWT | POS/NEG

11. Has u in uw jeugd vaak ziek ?

Ja:

Nee $\rightarrow$ vrg 12

-a. Hoe oud was u toen?

jaar

-. b. Welke ziekte(n)?

Ziekte(n) in de jeugd

: meerdere malien meegemaakt -........... JA I NEE ? INT

b) voorbereid (aktiof) -......... JA |NET

c) Werwiticht (op dat moment) ............... JA | NEE | ? NVT

d) destijds overwegend erwaren als -...- POS | NEG $|?|$ NVT I POS/NEG

e) ap lainge termijn ervaren als -......- POS | NEG | ? NVT | POS/NEG

f) 'social support' van welke personen: kort na gebeurtenis

op lange termitin

1.

2.

3.

ervaren als
,
1.

2.

3.

POS | NEG $|?|$ NWT $\mid$ POS/NEG 
12. Bent u tijdens uw jeugd oo it opgenonen in een riekenhis ?

-- a. Hoe oud was u toen?

Ua

Hee 19

- b. Warvoor?

jaar

\section{Zielemperso pname $(n)$}

a) meerdere malen meegemaakt -........ NA I NEE |

b) roarbereid itarief! -

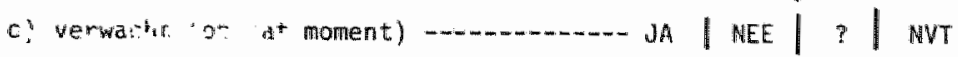

d) destijde rvarivegend ervaren als -....- POS | NEG

" DD iange termijn erwaren als -......... POS | NEG | ? | NVT || POS/NEG

fh a supeort:

$\therefore$ wark parsonen: kort na gebeurtenis lange termion

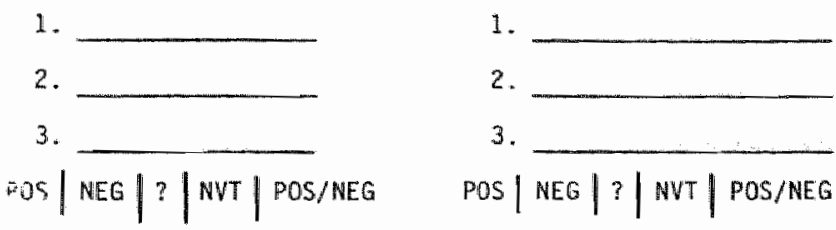

13. Welke scholen heeft U (vŏor u ging werken) doorlopen, en hoe oud was u toen?

-- a. Bent u aoit van school veranderd (zelfide opleiding) ? Ja Nee Indien 'Ja', warom?

-- b. Heeft $u$ scholen niet afgemakkt/woortijdig verlaten ? Ja Nee Indien "Ja" "waron?

- c. Zijn er nog bijzondere ervaringen met school die voor u destijds van groot beliang waren? 

a) meerdere mialen meegenaakt -........... JA I REE | ? MVT
b) voorbereid (aktief)
JA $\mid$ HEE | ? | WUT
c) verwacht (op dat moment)
JA | MEE | ? IVT
d) destifds overwegend ervaren als POS AEG ?
NVT | POS/HEG
e) op lange termijn erwaren als POS $\|$ NEG |?
NVT POS/MEG
f) 'social support" JA | NEE | ?
MVT PDS/KEG van welke personen: kort ma gebeurtenis

\section{- op lange termijn}
1.
1.
2.
2 .
3.
3.
erwaren als: $\quad$ POS $\mid$ NEG $|?|$ WWT $\mid$ POS/NEG
POS $\mid$ NEG $|?|$ NVT $\mid$ POS, /NEG

14. Heeft u buiten schooltijd am nog moeten werken? Ja Nee + wrg 15

-- a. Bij wie/war?

- b. Hoe oud was u toen? jaar

-- c. Wat voor werk was dat ?

Werken buiten schooltid om
a) inee-tive ma en meegemakt
JA $\mid$ NEE $|?|$ MVT
$\therefore$ waorcereid aktief)
JA $\mid$ NEE $|?|$ NVT
$c$. orwacht (wD dat moment)
JA I NEE | ? N NVT
d) destijds overwegend ervaren als ......- Pas \begin{tabular}{l|l|l|l|l|l|} 
NEG & $?$ & NVT & POS/NEG
\end{tabular}
e) op lange termijn ervamen als -........- pos NEG $?$ I NVT I POS/AEG
f) "social sumpora". JA | HEE | ? | NVT POS/MEG Jan welke persomen: kort na gebeurtenis
op lange termijn

1.

2 .

3.

envaltema.s
1.

2.

3.

POS | NEG |? | NVT | POS/NAEG 
$-263$

15. Bent u in militare diemst geweest?

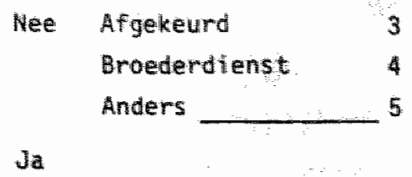

- a. Hoe oud was u toen?

jatro

- b. Waar bent k in dienst geweest?

\section{Mulitaine diensutpeleht}
a) meerdere malen meegemaakt $\ldots$ INT
b) woorbereid (aktief) JA $\mid$ NEE $|?|$ NVT
c) verwacht (ap dat moment)
JA $\mid$ NEE $|?| \mathrm{NVT}$
d) destijds overwegend erwaren als -.... POS | NEG |? | NVT | POS/NEG
e) op lange termijn ervarem a1s _........ POS I NEG
f) "social support"
JA | NEE $|?|$ NUT
van welke personen: kort na gebeurtenis
op lange termijn
1.
1.
2.
2.
3.
3.
erwaren als: $\quad$ POS $\mid$ MEG $|?|$ WVT $\mid$ POS/NEG $\operatorname{POS}|\mathrm{NEG}| ? \mid$ NVT $\mid$ POS/NEG 


\section{OPLENOTNG}

1. Wat is wh hoogte dagschoolopleiding ?

- Lager andeniljs

-- Middelbaar onderwíjs (MULO/HBS/Gymnasiua) 2

-- Lager beroepsonderwijs 3

-- Middelbaar beroepsonderwijs 4

- Hoger beroepsonderwijs $5+\operatorname{vrg} 3$

- Uniwersitair anderwijs $6+\underline{\operatorname{vrg}} 3$

2. Hilde u destijds nog een verdere opleiding volgen? da Nee $\rightarrow$ wrg 3

-- Welke opleiding(en) ?

- b. Wa rom?

3. Heeft u ná uw dagschoolopleiding nog andere kursussen gewoigd, of verder gestudeerd? Ja Nee $\rightarrow$ Wrg 4

- a. We1ke kursussen/studie(s) ?

- b. Heeft u deze opleiding(en) voltooid? Ja Nee

4. Heeft u in vergelijking met uw broer(s)/zuster(s) duidelijk mër, duidelijk minder, of ongeveer dezelfde opleiding genoten?

$\begin{array}{ll}\text { Duidelijk meer } & 1 \\ \text { Duidelijk minder } & 2 \\ \text { Hetzelffe niveau } & 3\end{array}$

5. Wat is/was thet beroep en de schoolopleiding van LW vader?

6. Wat is/was het beroep en de schoolopleiding van uw moeder ?

N.B. INTERVIEUER De volgende vragen wits kuitend vaor gehuwden/samenwonenden.

7. Wat is/was thet beroep en de schoolopleiding van uw echtgenate?

B. Wat is/was het beroep en de schoolopleiding wan uw schoonwader? 
UER

Wheronder valgen enkele vragen over wherksituatie van vroager en watin de latste tija.

1. Was $u$ in de periode dat $u$ het hartinfarct kreeg/wốr dit gesprek:

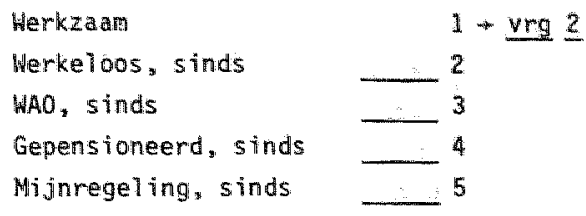

Deze wenteloosheid/wAo/penstonerung/mijnegeling
a) meerdere malen meegemaakt _.......... JA I NEE | ? NVT
b) voorbereid (aktief)
JA $\mid$ NEE $|?|$ NVT
c) werwacht (op dat moment)
JA NEE $\mid$ ? $\|$ NVT
d) destijds overwegend erwaren als -....-- pas
NEG
$?$ NVT $1 \mathrm{POS} / \mathrm{NEG}$
e) on lange termijn ervaren als -.......- pos
\begin{tabular}{l|l|l|l} 
NEG & $?$ & NVT & POS/NEG
\end{tabular}
f) "social support"
JA $\mid$ NEE $|?|$ NVIT POS/NEG
van welke personen: kort na gebeurtents
op lange termin

1.

2.

3.

elvaren 5 POS $\mid$ NEG | | | WVT | POS/NEG

2. Bent u weleens (eerder) werkeloos geweest?
1 .

2.

3.

- a. Van wanneer tot wanneer?

werkeloosheid

a) meerdere mal len meegemaakt .......... JA I NEE | ? NVT

2) Wophereid (aktief) JA $\mid$ NEE $|?|$ NVT

c) veructit (op dat moment) JA $\mid$ NEE $|?|$ NVT

d. destijos overwegend ervaren als pos

e) op lange termin ervaren als pos

f) "soctal suspor"' JA van welke versoner: kort na gebeurtenis NEG $|?|$ NWT I POS/NEG

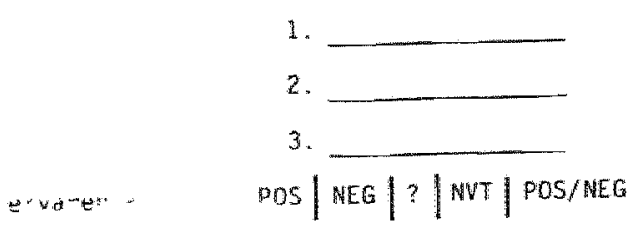
\begin{tabular}{l|l|l|l|l|l|l|l|l|} 
NES & $?$
\end{tabular} NEE $?$ | WVT POS/NEG op lange terminn

I.

2.

3.

POS $\mid$ NEG $|?|$ WVT $\mid$ POS/NEG 
3. Bert u ooft (eerder) arlyeldsongeschikt verklatard ?a

Nee $+\operatorname{mrg}$ I

- a. Van wanneer tot wanneer?"

WAO

a) meerdere malen neegenaakt -.......... JA | WEE |? | NVT

b) worbereid (aktief) ……............ IA I REE |? IVT

c) werwacht (op dat moment) -............. JA | MEE |? NVT

d) destijds owerwegend erwaren als -...- POS $\mid$ NEE $|?|$ NVT $\mid$ POS/WEG

e) op lange temijn erwaren als -........ POS $\mid$ MEG

f) "social support"

van welke personen: kort na gebeurtenis op lange temijn

1.

2 .

3.

erwaren als: $\quad$ POS $\mid$ NEG / ? | NVT $\mid$ POS/MEG
1.

2.

3.

POS $\mid$ NEG |? | NWT |POS/NEG

4. Hoe oud was u toen u ging werken? jaar

\section{Begin van het arbeidsproces}

a) meerdere malen neegenaakt -......... JA I MEE |? MVT

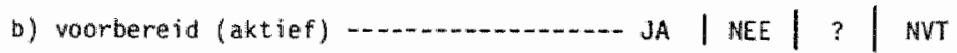

c) verwacht (op dat moment) $\ldots \ldots \ldots$ A $\mid$ NEE |? NWT

d) destijds overwegend ervaren als-..-- POS | NEG | ? | WVT | POS/NEG

e) op lange temijn erwaren als -........ POS | MEG | ? | NWT | POS/NEG

f) "social support" van welke personen: kort na gebeurtenis op lange termijn

1.

2 .

3.

ervaren als: POS/NEG I / WVT / POS/NEC
1.

2.

3.

POS $\mid$ NEE $|7|$ NWT $/$ POS/NEG

5. Welke funktie heeft uhet latste uitgedefend? 
c. Kunt u angeven welke beroepen/funkties u zoal heeft uitgeoefend, en wanneer dat was?

Beroep/Funktie

Bedrijf/lnstelling

Periode

in

2.

3.

4.

5.

W. B. INTERUTEWER Bij de volgende whagen steeds awgeven op welke werkbring het antwoond bethelking heeft d.m.v. het cijber, dat overeenhamit met bovenstaande werkbringen.

7. Heeft $u$ ooit uit eigen beweging naar een andere werkkring uitgekeken, dus zonder druk var bulitenaf ?

Ja $\quad \mathrm{Nee}+\underline{\mathrm{vrg}} \underline{\mathrm{B}}$

-- a. Helke werkkring wilde u toen verlaten?

- b. Wamneer?

- c. Heeft u toen BINNEN / BUITEN het bedrijf gezocht?

- d. Kunt u een redien aangeven waram u ander werk willde?

- e. Heeft u ook een andere werkkring gewandem? Ja Nee

Lit eigen berveging naar anded werk gezacht
a) meerdere malen neegemaakt
JA I NEE | ? NWT
b) voorbereid (aktief)
JA I NEE | ? | NWT
c) verwacht (on dat moment)
JA $\mid$ NEE $|?|$ NVT
d) destijids overwenend ervaren als -.....- pos
\begin{tabular}{|l|l|l|l|} 
NEG & $?$ NWT $\mid$ POS/NEG
\end{tabular}
e) op lange teraijn ervaren als -........ POS |NEG I | NWT | POS/NEG
f) "social support"
JA $|\mathrm{NEE}| ? \mid \mathrm{NWT}$
van welke persomen: kort na gebeurtenis
op lange termijt
1.
2.
3.
erraren als: POS $\|$ NEG $\|$ ?'NVT POS/NEG
1.:
2.
3.
POS $\mid$ NEG $|?|$ NVT | POS/NEG 
0. Heeft u oolt noodgedwongen ander werk gezocht ?

-- a. Welke werkkring noest u verlaten?

-- b. Wanneer?

- c. Waarom?

\section{Noodordwonger ander werk moeten zoeben}
a) meerdere malem meenemakt
JA | NEE | ? NVT
b) woorbereid (aktief)
JA $\mid$ NEE $|?|$ NVT
c) werwacht (op dat moment)
JA I NEE | ? NVT
d) destijds overwegend ervaren als P0s
e) op lange tertijn ervaren als POS \begin{tabular}{l|l|l} 
NEG & $?$ & NVT
\end{tabular}
POS/NEG
f) "social support"
JA. \begin{tabular}{l|l|l|l|l} 
NEG & $?$ & NVT & POS/NEG
\end{tabular} \begin{tabular}{l|l|l} 
NEE & $?$ MVT
\end{tabular} van welke personem: kart na gebeurtenis

1 .

2.

3 .

ervaren alis: $\quad$ POS $\mid$ NEG $|?|$ NVT $\mid$ POS/NEC op lange termijn

1.

2.

3. POS $\longdiv { \text { NEG } | ? | \text { NNT } | \text { POS/NEG } }$ I. Ia
Nee $\rightarrow$ vrg 10

9. Heeft $u$ oojt een bedrijfssluiting meggemakt ?

- a. In welke werkkring ?

-- b. Wanneer ?

Bedrij6sskuting
a) meerdere malen rueegemakt
JA $\mid$ NEE $|?|$ NWT
b) voorbereid (aktief) MA | NEE | ? | NWT
c) verwacht (on dat monent) MA | MEE | ? | NWT
d) destijds overwegend ervaren als -..... pos \begin{tabular}{l|l|l|l} 
NEG & $?$ NWT & POS/NEG
\end{tabular}
e) op lange termijn ervaren als POS
f) "social support" JA van welke personen: kort na gebeurtenis NEG I ? | WWT I POS/MEG NEE | ? | NVT
1.
2.
3.
ervaren als
POS NEG I I NWT | POS/NEG
op lange termijn
1.
2 .
3.
POS | NEG | ? NWT | POS/NES 
10. Heeft a ooit belangrijke veranderingen meegemakt wat betreft de economische situatie op uw werk, zoals fusie, reorganisatie e.d.?

Ja wee $-\underline{\operatorname{urg}} 11$

-w. We lke werkkring ?

- b. Wanneer ?

Belangrijhe economische veranderingen in de werts futuatie
a) meerdere malen neegemakt
JA $1 \mathrm{NEE}$
$?$ NUT
b) woorbere, " $A \times i$ ief)
JA $\mid$ NEE $|?|$ NVT
c) verwach: (op dat moment)
IA $\mid$ NEE $|?|$ NVT
d) destijdš averwegend ervaren als _....- POS IN
NEG | 1 NVT | POS/NEG
e) op ange tum: in ervaren als -........-. Pos
\begin{tabular}{l|l|l|l|l|l|} 
NEG & $?$ MUT & POS/NEG
\end{tabular}
f) "social suorent.
JA $\mid$ NEE $|?|$ NVT
van we"ka pe-sonen: kort na gebeurtenis
op lange terming
1.
1.
2.
2.
3.
3.
exvaren als
POS | NEG |? | NVT | POS/MEG
POS $\overline{\text { NEG }}$ ? $\mid$ NVT $\mid$ POS/NEG

11. Heeft $u$ in uw werk ooit duidelijke vooruitzichten op een verbetering van uw funktie gehad?

Ja

$\mathrm{Nee}+\mathrm{wrg} 12$

- a. Welke werkkring ?

-- b. Wanneer ?

-- c. Is uw positie toen daadwerkelijk verbeterd? Ja

Nee

vooruitzichten op verbetering van funktie
a) meerdere mallen reegemaakt
JA NEE $\|$ ? NTT
b) voorbereid (aktief)
JA | NEE | ? | NWT
c) verwacht (on dat moment) JA | NEE | ? | NVT
d) destijds overwegend ervaren als POS
e) op lange termijn ervaren als Pos
fi) "social support" JA $\mid$ NEE | ? | NVT
van welke personen: kort na gebeurtenis
op lange termijn
1 .
2.
3.
ervaren als.
.
.
POS | NEG $\mid$ ? NVT | POS/ HAE
1.
2.
3.
POS $\mid$ NEG $|?|$ NVT $\mid$ POS/NEG 
12. Heeft o in wherk weleens een anzienlijke toename van verantwoordelijkheid meegernalat ? Ia

情e $\rightarrow$ wra 13

--a. Welke werking ?

- b. Wannegr?

Toenume wein werantwoordelifheid
a) meerdere malen neegemakt
JA | NEE | ? | NVT
b) waombereld (aktief)
NEE $?$ | NVT
c) verwatht (op dat moment)
MEE $|?|$ NVT
d) destijds overwetend ervaren als -...-. POS
\begin{tabular}{l|l|l|l} 
MEG & $?$ & WVT & POS/NEG
\end{tabular}
e) op lange termijn ervaren als
f) 'social support'
JA $\mid$ NEE | ? | NVT
van welke personen: kort ma gebeurtenis
op lange termijn
1.
2.
3.
E.varen als: POS/ NEG / ? NWT | POS/MEC
1.
2.
3.
POS | NEG |? | WVT $\mid$ POS/NEG

13. Heeft w ooit ernstige moejlijkheden in de dagelijkse omgang met kallega's gehad?

Ja. $\quad \mathrm{Nee}+\operatorname{vrg} 14$

- a. Welke werkkring ?

- b. Wanneer ?

\section{Ernstige modeijheden met kollega's}

a) meerdiere malen neegemaakt $\ldots \ldots \ldots \ldots$ JA | NEE | ? NVT

b) voorbereid (aktief) $\ldots \ldots$

c) wemacht (on dat moment) -........... JA | NEE | ? NVT

d) destijds overwegend ervarem als -..... POS $\mid$ NEG $?$ ? NVT $\mid$ FOS/NEG

e) op lange termijn ervaren als -........ POS I NEG I ? NWT | POS/NEG

f) "social support" a wan welke personen: kort na gebeurtenis og lange termijn

1.

2.

3.

arwaren a's:: POS|NEG|?|NWT|PQS/NEG
1.

2.

3.

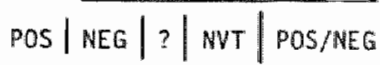


14. Waren er opit ernstige problemen/spanningem met un direkte chef?

$\mathrm{Ja} \quad \mathrm{Nee}+\mathrm{vrg} \mathbb{1 5}$

-- Welke werkkring?

- b. Wanneer?

\section{Probeemen/spanningen met direkte ché}
a) meerdere malen meegemakt
JA $\mid$ NEE $|?|$ WVT
b) voorbereid (aktief)
JA $\mid$ MEE $|?|$ NVT
c) verwacht (op dat moment)
JA | NEE | ? | NVT
d) destijds overwegend ervaren als -..... POS
$\mid$ NEG $|?|$ NVT $\mid$ POS/NEG
e) op lange teraijn ervaren als -........ POS
NEG | ? NWT | POS/NEG
f) 'social support'
JA $\mid$ MEE $|?|$ NVT
van welke personen: kort na gebeurtienis
op lange termijn
1 .
2.
3.
ervarerials: $\quad$ POS / NEG |? | NVT | POS/NEG
1.
2.
3.
$\operatorname{POS} \|$ NEG $\|$ ? NVT $\mid$ POS/NEG

M.B. INTERVTEWER Volgende whag witsiluitend bij Reidinggevende funktie

15. Waren er ooit ernstige problemen/spanningen met uw ondergeschikten ?

Ja Nee $\rightarrow$ vrg 16

-- a. Welke werkkring ?

-- b. Wanneer?

Problemen/spanningen met ondergeschikten
a) meerdere malen neegenakt
JA | NEE | ? | NVT
D) voorbereid (aktief)
JA | NEE | ? | NVT
c) verwacht (on dat moment)
JA | NEE | ? NVT
d) destijds ovarwegend ervaren als pas MEG
NVT | POS/NEG
e) op lange temijn ervaren als pos
f) "social support:"
JA $\mid$ MEE | $\mid$ NVT van we Tke cersonen: kort na gebeurten is
op lange tertition
1.
2.
3.
ervaren a
.
1.
2.
3.
POS $\mid \overline{\text { MEG }|?| \mid \text { NWT } \mid \text { POS/AEG }}$ 
16. Heeft $u$ in ww loophan walt ....... Onregelmatige werktijuden gehad I

$\begin{array}{ll}\text { Plloegendiensteri gehad } & 2 \\ \text { Gëen van beide } \rightarrow \text { vrg } 17 & 3\end{array}$

-w. Welke werkkring ?

- b. Wanneer?

Onnegelmatige wertitiden/ Poegendiensten
a) meerdere malen neegema $k$ t
JA $\mid$ NEE $\mid$ ? HVT
b) voorbereid (aktief)
\begin{tabular}{l|l|l|l|l|} 
NEE & $*$ NVT
\end{tabular}
c) verwacht lop dat moment)
NEE ? INT
d) destijds overwegend erwaren als ......- POS I
NEG $\mid$ " NVT | POS/MEG
e) op lange teraign ervaren als wa...... pos | van welke personen: kort na gebeurtenis
HEG $\mid$ ? INT | POS/MEG
NEE $|?|$ NWT
1.
op lange termijin

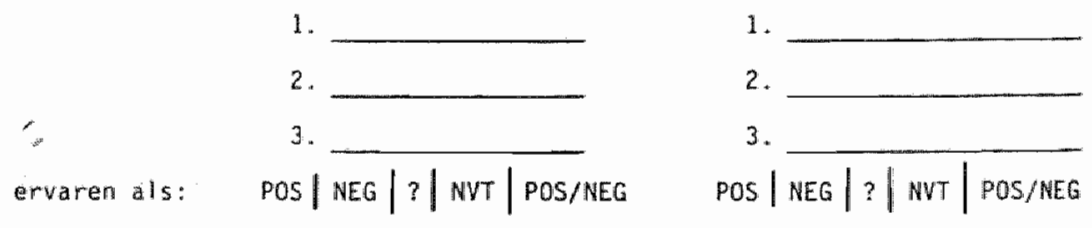

17. Heeft $w$ oott gedurende langere tijd (half jaar of langer) oweruren gemalkt ?

- a. Welke werktoring ?

Ja Hee $* \underline{\operatorname{vrg}} 18$

- b. Wanneer?

- c. Gebeurde dit .............. Wrijwillig onvrijuitrig

overuien
a) meerdere malem neegemaakt

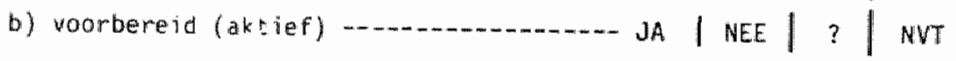
c) verwacht 1 ald dat moment) ............ JA | NEE | ? NWT
d) dastijds overwegend ervaren als ...... POS I NEG | ? NWT | POS/NEG
e) op lange termign erwaren als -........ POS | NEG |
f) "social suoport"
JA | MEE | $\mid$ NVT
van welke personen: kort na gebeurtenis

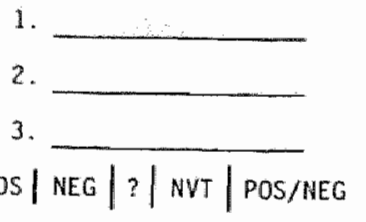
op larige termijn
1.
2 .
3.
ervaren a
POS $\mid$ NEG $|?|$ NWT $\mid$ POS/NEG 
18. Bent w welleens gedurende een lange periode (Tanger dan bern mand) ziek thuts gebleven van uwerk?

ha

New $\rightarrow \operatorname{vrg} 19$

-.- a. Helke werkkring ?

- b. Hanneer?

\section{Langdurig ziektevenzuin}

a) meerdere malen meegemaakt …........ JA I NEE | ? WVT

b) voorbereid (aktief) - N I NEE | ? NVT

c) verwacht (ap diat moment) -........... WA $\mid$ NEE $\mid$ ? WVT

d) destijes ovemegend ervaren als-...-POS | NEG |? | NVT | POS/NEG

e) op lange temijn ervaren als -......- POS | NEG |? | NVT | POS/NEG

f) "social support" van welke personen: kort na gebeurtenis

op lange termijn

1.

2.

3.

erwaren als: $\quad$ POS $\mid$ NEG $|?|$ NVT $\mid$ POS/NEG
II.

2.

3.

POS $\mid$ NEG $|?|$ WNT $\mid$ POS/NEG

19. Heeft u - naast uw werk - ooit nog gestudeerd/kursussen gevolgd in de avonduren?

Ja

Nee + vrg 20

- a. Helke werkkring ?

- b. Wanneer?

\section{studiebelasting naast het werk}
a) meerdere malen meenemakt
JA | NEE |? | NVT
b) voorbereid (aktief)
JA I NEE | ? NNT
c) venwacht (on dat moment)
\begin{tabular}{l|l|l} 
NEE & 7 & NVT
\end{tabular}
d) destijds overwegend ervaren als
Pos
NEG $?$
NWT $\mid$ POS/NEG
e) op lange temijn ervaren als POS MEG ?
NVT | POS/NEG
f) 'social support"
NA | NEE | ? | NVT yan wellke personen: kort na gebeurtenis
op lange temijn
1.
2 .
3.
ervaren als:
POS | NEG $\mid$ ? | NVT | POS/NEG
1.
2.
3.
POS |NEG | | | NVT | POS/NEG 


$$
-274
$$

20. Kunt wangeven of de gebeurtenissen zoals die nu zijn besproken m.b.t.

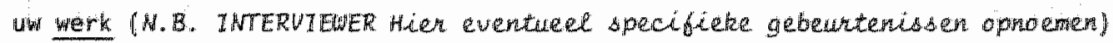
destijos wan invloed zijn geweest op uw leefgewoonten, zoals roken, drinken w eten, slapen, of op hoe u zich toen voelde?

GEBEURTENIS (SEN)

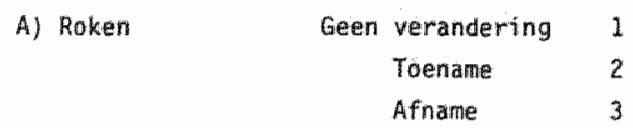

B) Drinkem (Allcohol) Geen verandering 1

Toename 2

Afname 3

c) Koffite Geen verandering 1

Toename 2

D) Eten Geen verandering 1

$\begin{array}{ll}\text { Toename } & 2 \\ \text { Afmame } & 3 \\ \text { Overslaan } & 4\end{array}$

E) Slapen

$\begin{array}{cc}\text { Geen verandering } & 1 \\ \text { Toename } & 2 \\ \text { Afname } & 3 \\ \text { Moeilijk inslapen } & 4 \\ \text { Moeilijk doorslapen } & 5\end{array}$

F) Perioden van Neerslachtigheid 1

vệ] piekeren 2

Lusteloosheid 3

Humeurig zijn/

Prikkelbaartheid 4 


\section{GEZN}

Hieronder volgen enkele wragen over uw eventwele gezinssituatie van vroeger en wan de latste tijd.

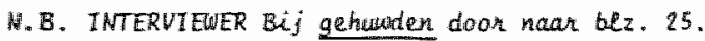

\section{A.LEENSTAAMDEN (URT JGEZEL/GESCHEIDEN/UEOUUWAAR)}

1. Woonde $u$ in de periode vốr uw hartinfarct/vór dit gesprek alleen ?

2. Hoont/woonde $u$ bij $\ldots \ldots \ldots \ldots \ldots$....... Ouders 1

Familie 2

Kennissen $\quad 3$

Anders 4

3. Sinds wanneer woont/woonde 4 daar ?

4. Zijn er weleens ernstige problemen/konflikten met uw huisgenoten geweest?

Ja Nee $\rightarrow$ vrg $5 / 6$

- a. Wanneer was dat?

Eurstige problemen/kanflikten met huisgenoten

a) meerdere malen neegemaakt …........... JA NEE ? NVT

b) woorbereid (aktief) -

c) verwacht (op dat moment) -.......... JA $\|$ NEE | | NVT

d) destijds owerwegend ervaren als -..... POS $\mid$ NEG $\mid ? \|$ INVT | POS/NEG

e) QP lange termijn ervaren als -....... POS $\mid$ NEG $\mid$ ? INVT | POS.NEG

f) "sociall support" -

van welke personen: kort na gebeurtenis op lange termign

1.

2.

3.

ervaren als:
POS | NEG $|?|$ NVT | POS/NEG
1.

2.

3.

POS $\mid$ NEG $|?|$ WNT $\mid$ POS/NEG

H.B. INTERVTEUER Indien respondent urijgezel is, doongaan met vraag y? GEHUUDEN/GEZTN. 


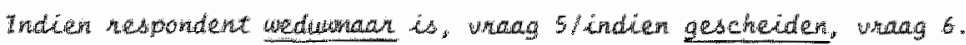

5. hameer werd wh huthis gesloten?

- a. In well jar is w echtgerote overleden?

\section{Dueveriden tehtgente}

a) medrdere miden neegemakt -............. JA I REE

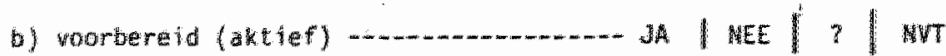

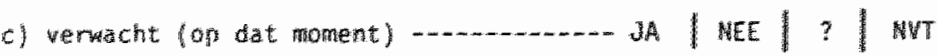

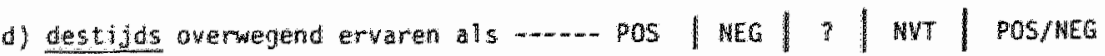

e) op ange tertisin ervaren als .......... POS $\mid$ WEG $\mid$ ? WVT I POS/WEG

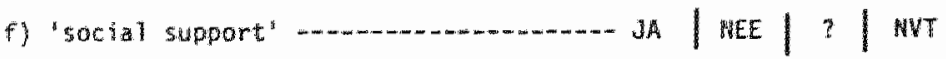
yan welke personem: kort na gebeurtenis op lange teming

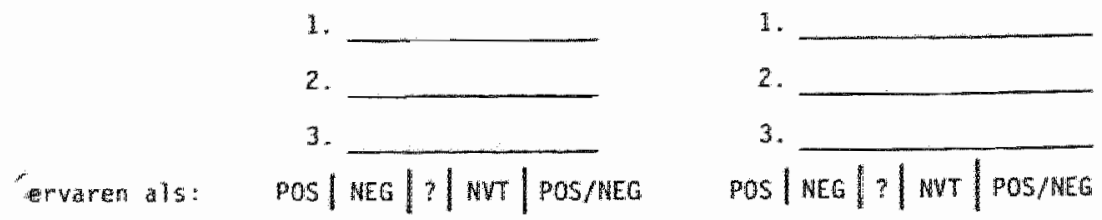

W. B. TNTERTEUER Doongaan naW whata 3 GEHUWDEN/GEZIN.

6. Wanneer werd ww hwelik gesloten ?

- a. In welk jaar werd uw buwelijk ontbonden?

Echescheiding
a) meerdere malen neegemakt
IA $\mid$ NEE $? ?$ NUT
b) woorbereid (aktief)
JA $\mid$ NEE $\mid ?$ WUT
c) verwacht (an 'at monent)
NEE $? 7$ NWT
d) destijos overwenend ervaren als ...... Pos
NEG ? INT POS/ NEG
e) Op lange termijun ervaren als -........ POS NEG ? : NWT POS/REG
f) "social suaport" WEE $\mid ?$ NWT van welke personen: komt na gebeurtenis
op lange termign
1.
2.
3.

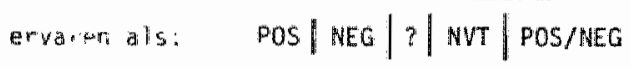
1.
2.
3.
POS | NEG |?|NVT| POS/WEG

N. B. TNTERVIEUER Doorgaan Maan Uhang 3 GEHUtWOEN/GEZIN. 
HUDEU GEZIN

Wanneer werd uw huwelijk gesloten?

Bent u ooit eerder getrouwd geweest ?

- a. Bent u gescheĩden ?

Nee

Ja

Nee $-\operatorname{yrg} 3$

- b. Is uw echtgenote overleden? Mee

Ja + Welk jar ?

seheiding/overtidem eerste echtgenote
a) meerdere malen meegemakt
JA $\mid$ NEE | $\mid$ NVT
b) voorbereid (aktief)
JA $\mid$ NEE $|7|$ NVT
c) verwacht (op dat moment)
JA $\mid$ NEE $|\geqslant|$ NVT
d) destijds owerwegend ervaren als POS $\mid$ MEG |?
WVT
POS/NEG
e) op lange termijn ervaren ats POS
f) "social support" JA $\mid$ NEG | ?
NVT | POS/NEG van wellke personen: kart na gebeurtenis NEE $|?|$ NVT
1.
1.
2.
2.
3.
3.
ervarem als: $\quad$ POS $\overline{\text { NEG }|?| \text { WUT } \mid \text { POS/NEG }}$ POS|NEG $|?|$ NVT $\mid$ POS/NEG op lange temign

3. Wat is het geboortejaar van uw (huidige) echtgenote?

1. Heeft u kinderen? (0ok uit ev. eerder huwelijk) sa Nee * vrg 10

- a. Hoeveel kinderen heeft $u ?$

-b. Wat zijn de geboortejaren ? 1 .

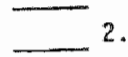
2. 3. 4. 5.

\section{Gezinswitbreiding/Gezinsomuang}
a) meerdere malen meegemakt
JA $\mid$ NEE $|?|$ NVT
b) voorbereid (aktief) JA | NEE | ? N NVT
c) verwacht (ap dat moment) JA | NEE | ? NVT
d) destijds overwegend ervaren als pos
e) op lange termijn ervaren als: POS | NEG |? | NVT | POS/NEG
f) 'soctal support' JA NEE van welke personen: kort na gebeurtenis op lange termijn
1.
2.
3.
erwaren als: $\quad$ POS $\mid$ NEG $\mid$ ? $\mid$ NVT $\mid$ POS/NEG
1.
2.
3.
POS $\overline{\text { NEG }|?| \text { NVT } \mid \text { POS/NEG }}$ 
5. Zijn een/meerdere hind(eren) onit emstig af langdurig ziek geweest?

$$
\text { Ja } \quad \text { Wee } \rightarrow \text { yrg } 5
$$

- a. Weik(e) kind(eren) ?

$\therefore$ b. Hanneer $?$

- c. Welke ziekte(n) ? (Kinderziekten niĕt meetellen)

\section{Enstige/Langdurige zelekte tind(eren)}

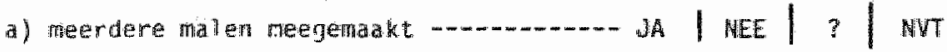
b) voorbereid (aktief) …................. IAEE | | NVT
c) verwacht (on dat moment) -....... J I NEE INT
d) destijds averwegend ervaren als..... POS I NEG $?$ ? NVT POS/NEG
e) op lange termijn ervaren als -......- POS | NEG | ? NVT | POS/NEG
f) 'sacial support' -................ JWE wan welke personen: kort na gebeurtents

op iange termijn

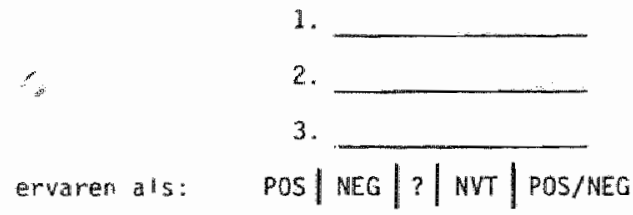

1.

2.

3.

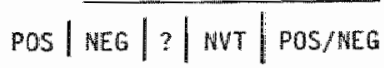

6. Zijn al uw kinderen nog in leven?

Nee

da $+4 \pi$ I

-- a. Welk(e) kindieren) is/zijn overteden?

- b. Warneer?

-- c. Helke oorzak ?

\section{overeijden kind(eren)}
a) meerdere malen reegemakt
JA | NEE ? | NVT
b) vourbereid (aktief) JA $\mid$ NEE | ? | NVT
c) Verwacht (on dat monert) JA | NEE | ? NUT
d) destijds overwegend ervaren als Pos
e) op lange termijn ervarem als ......... pos $\mid$ NEG $~ ? ~ N W T$ POS/NEG
f) 'sociall support. JA $\mid$ NEE | ? | NWT wan welke personen: kort na gebeurtenis op lange terming

1.

2.

3.

ervaren a's:
1.

2.

3.

POS $\mid$ NEG $|?|$ NUT $\mid$ POS/NEG 


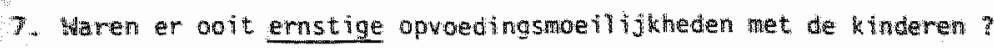

$$
\text { Ja } \quad \text { was }
$$

- a wantweer ?

\section{Opvoedingsmoeili jheden}

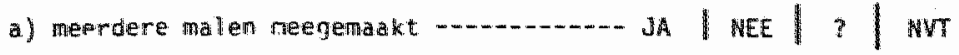
b) voorbereid (aktief) -
c) verwacht (op dat moment) - N I NEE I ? WT
d) destijds overwegend ervaren als -....-POS / REG I I WT I POS/NEG
e) op lange temijn ervaren als _........ POS | NEG I? NUT | POS/WEG
f) 'social support" -......... WEE van welke personen: kort na gebeurtenis

op lange termin

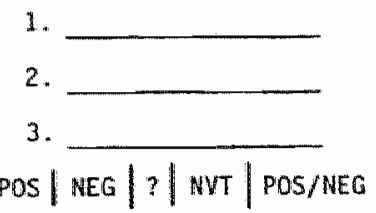

1.

2.

3.

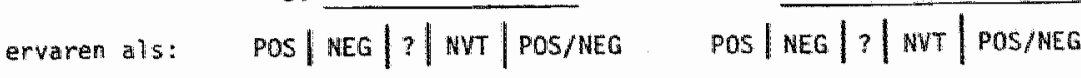

B. Zijin er al kinderen het huis uit gegaan?

Ja Nee $+\underline{w g} \underline{9}$

-- a. Helke kinderen?

- b. Wanneer?

- c. Waaron? (Trouwen, studie e.d.)

Wit huld gaan van de kinderent
a) meerdere malen meegemaakt
JA I NEE | ? WVT
b) voorbereid (aktief)
JA $\mid$ NEE $|?|$ NVT
c) verwacht (op dat moment)
JA NEE | $\mid$ NVT
d) destijds overwegend ervaren als - POS
$\mid \mathrm{NEG}$
e) OP lange termijn ervaren als _......... POS \begin{tabular}{|l|l|l|l|}
$\mid$ NEG & $?$ & NWT & PAS/NEG
\end{tabular}
f) 'soctial support"
JA $\mid$ NEE | ? | NVT van welke personen: kort na gebeurtenis
op lange terminn
1.
2 .
3.
erwaren als:
.
POS | MEG |? NWT | POS/MEG
1.
2.
3.
POS $\mid$ NEG $|?|$ AVT $\mid$ POS/NEG 
9. Zun er colt problemen gewest met (aangetrouwde) binderen die al

$$
\text { het huts uit waren? Ja Wee }- \text { yra } 10
$$

- a. Warneer ?

\section{Problenen met zelfotandig wonende (aangetrowade) bindoren}
a) meerdere malem reegenadkt
WA $\mid$ MEE $|?|$ WVT
b) woorbereid (aktief)
JA $\mid$ NEE | $2 \mid$ NVT
c) verwacht (op dat moment)
JA $\mid$ NEE $|?|$ NVT
d) destijds overwegend ervaren als - -..- Pos
$\mid$ NEG $|?|$ NVT | POS/NEG
e) op lange termijn ervaren als -........ po $\mid$ NEG | ? | NVT | POS/NEG
f) "social support" JA $\|$ NEE $|?|$ NVT wan welke personen: Kart na gebeurtenis
op lange temijn

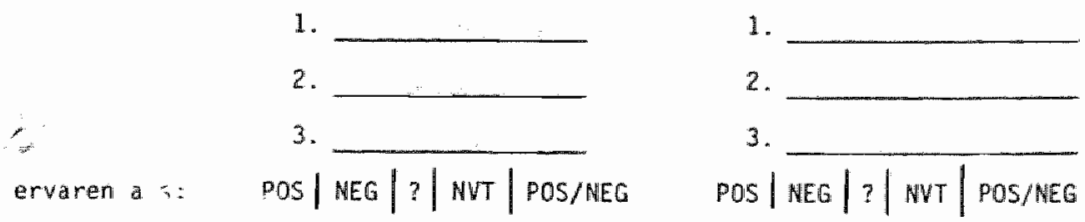

10. Kunt $u$ zeggen of er tussen $u$ en uw vrouw ooit langdurige perioden van spanningen of ernstige problemen zijn geweest? Ja Nee $+\underline{y r g} 11$

-- a. Wanneer ?

- b. Kunt u iets zeggen over de aard ervan ?

Spanningen/Problemen in het huwelijk
a) meerdere malen neegenaakt
JA $\mid$ NEE $|?|$ NVT
b) woorbereid (aktief)
JA $\mid$ NEE $|?|$ NVT
c) verwacht (on dat moment?
JA $\mid$ NEE $|?|$ NVT
d) destijds owerwengend ervaren als ...... pas
\begin{tabular}{l|l|l|l|l|l|l|} 
& NEG
\end{tabular}
- op lange Lemijn ervaren alls pos
f) "social support" IA $\mid$ NEE $|?|$ NUT wan welke personen: kort na gebeurtenis

ap lange temonijn

1.

2.

3.

erwaren als
1.

2.

3.

POS $\mid$ NEG $|?|$ NVT $\mid$ POS/NEG 
11. Is uw vroum ooit langdurig of emstig ziek geweest ? Ja

Nee $-1 \mathrm{rg} 12$

- a. Wanneer?

- b. Helke ziekte(n)?

\section{Lietute echigenate}

a) meerdere malen neegemaakt $\ldots \ldots \ldots \ldots$

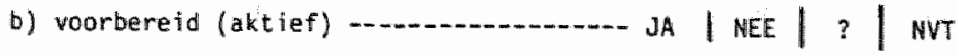

c) verwacht (OP dat moment) -............. JA \NEE I? NVT

d) destijids overwegend ervaren als -....-POS | NEG I? | NVT | POS/NEG

e) op lange termijn ervaren als -....... POS | NEG $\mid$ ? | NVT | POS/NEG

f) 'social support'

van welke personen: kort na gebeurtenis op lange termijn

1.

2.

3.

ervaren als: $\quad$ POS | NEG $\mid ? \|$ NVT $\mid$ POS/NEG
1.

2.

3.

POS $\mid$ NEE $|?|$ NVT $\mid$ POS/NEG

12. Heeft $u$ vóór het hartinfarct/vöor dit gesprek wel eens een ongeval gehad, of bent $u$ oovt enstig ziek geweest?

$\mathrm{Ja}$

Nee + vrg 13

N.B. INTERUIEWER op pag. 2 en 8 zijn reeds eerder whagen over zietete gesteld.

- a. Wanneer?

-b. Welke ziekte $(n)$ ?

\section{Ziekte/Ongeval}

a) meerdere malen meegemaakt -........ JA | NEE |

b) woorbereid (aktief) $\ldots \ldots \ldots \ldots \ldots$ JA $\|$ NEE | $\mid$ WVT

c) verwacht (op dat monent) .............. JA | MEE | ? NWT

d) destijds avemwegend ervaren alis _.... POS | NEG | $\mid$ NWT | POS/NEG

ef op lange ternijn ervaren als-....... POS | NEG | | NVT | POS/NEG

f) "soc val subport' van we:ke personen: kort na gebeurtenis op lange termijn

1.

2 .

3.

eruaren als: POS NNEG $\mid$ ? NWT $\mid$ POS/NEG
1.

2.

3 .

POS I NEG I P N $\mid$ POS/NEG 
13. Hebber (schoon) ouders of anderen blj u ingewoond? Ja Nee $\rightarrow$ vrg

-.m. Manneer?

- b. We?

\section{InHoning UAN anderen}
a) meerdere malen neegendakt …n.......... JA | NEE
b) woorbereid (aktief) -.................. JA $\|$ NEE $\|$ | WVT
c) werwacht (on dat moment) _............. JA $\mid$ NEE $|7|$ NVT
d) destijds overwegend emaren als -..... POS |NEG
e) op lange termign ervarer als -....... POS $\mid$ NEG
f) "social silpport" - wan welke personen: kort na gebeurtents
op lange termijn
1.
2
3.

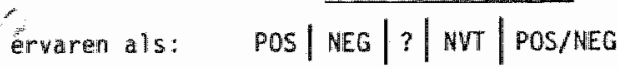
1.
2.
3.
POS | NEG $\mid$ INT | POS/NEG

N.B. IHTERTEWER Indien hespondent urijgezel is, doongaan met unaag $14 a$.

14. Hebben $\mathrm{s}$ en wh vrouw (eventueel mèt kind(eren)) bij anderen ingewoond?

14a. Heeft $u$ ooit bij anderen ingewoond?
Ja

Ja
Nee + vrg 15

Nee + vrg 15

- a. Hanneer ?

- b. Bij wie?

\section{Inuoning BIJ anderen}
a) meerdere mallen meegemaakt
JA $\mid$ MEE $|?|$ NVT
b) worberafd (aktiaf)
\$A $\mid$ KEE | $\mid$ NVT
c) werwath (on dat moment)
MA $\mid$ NEE $|?|$ WV
d) destidds owerwegend ervaren als ........ pos
POS $\mid$ NEG $|7|$ NUT $\mid$ POS/NEG
e) og lange termijn erwaren als POS
f) "social support" IA wan welk personen: kort na gebeurtenis |NEG $7 \mid$ NWT $\mid$ POS/NEG A A IEE $|?|$ WVT
op lange temijn

1.

2.

3.

ervaren is: pOS/NEG/?/NVT/POS/NEG
1.

2.

3.

POS 
15. Zijn in de latste yof jar famlieleden langdurig ziek geweest. of overleden ?

- A. wanneer?

-. b. Wie?

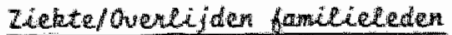
a) meerdere malen meegemakt
MA $\mid$ NEE $|?|$ NVT
b) voorbereid (aktief)
JA $\mid$ NEE $\mid ?$ NWT
c) werwacht lop dat moment)
JA $\mid \mathrm{NEE}$ ? NVT
d) destijas overwegend ervaren a is -...-. Pos

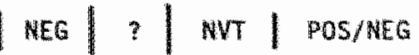

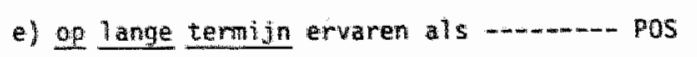
$\mid$ NEG $|7|$ NVT $\mid$ POS/NEG
f) "social support"
\begin{tabular}{l|l|ll} 
NEE & $?$ AVT & POS/NEG
\end{tabular}
van welke persomen: kort na gebeurtenis
op lange termijn
1.
2.
3.
ervaren $a^{2}$
.
NOS | NEG $|?|$ NVT $\mid$ POS/NEG
1.
2.
3.
POS |NEG |? |NVT | POS/NEG

16. Zijm er in de laatste wif jaar wrienden of goede kennissen langdurig Ilek geweest, of overleden ?

Ja

Nee $-\underline{\operatorname{vrg}} \pm 17$

-- a. Wanneer?

-b. Whe?

\section{Ziekte/overelfden vrienden/goede kennisten}

a) meerdere malen meegemalkt_......... JA I NEE | I NVT

b) woorbere t, aktief) -......... IA I NEE ? IVT

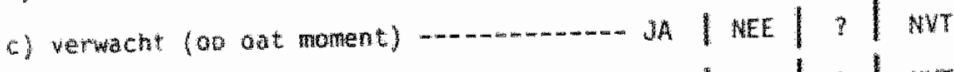

d) destijos averwegend ervarem as an-...- pos I NEG $|?|$ NVT I POS/NEG

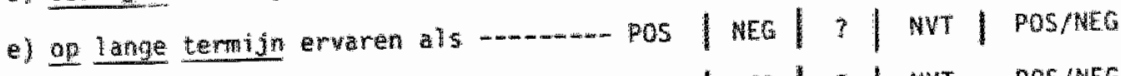

f) "SOCial support" yol we personen: kont na gebeurtents

op lange ternijn

1.

2.

3.

erwaren $3^{*}:$ DOS $\mid$ NEG $/ ? \mid$ HNT $/$ POS/NEG
1.

2.

3.

POS | NEG |? | NVT | POS/NEG 
17. Zijn er wot ermstige problemen of konflikten geweest net w (angetrouwde) familie?

I:

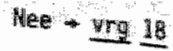

-- a. Wanneer?

- b. Met wie ?

\section{Problemen/Konflikten fanidieleden}
a) meerdere mal ien meegemalkt
JA $\mid$ NEE | $\$$ NVT:
b) wootbereid (aktief)
JA NEE | $\mid$ NVT
c) werwacht (op dat moment)
JA | MEE | ? NHT
d) destijes overwegend ervaren als -..... pos
\begin{tabular}{|l|l|l|l|l|l|l|} 
NEG & $*$ & NVT & POSHEC
\end{tabular}
e) op lange tiermijn ervaren als ........- POS
MEG | $7 \mid$ NVT | POS/NEG
f) 'social support' $J A$ wan welke personen:" kort na gebeurtenis MEE $|?|$ WWT POS/KEG

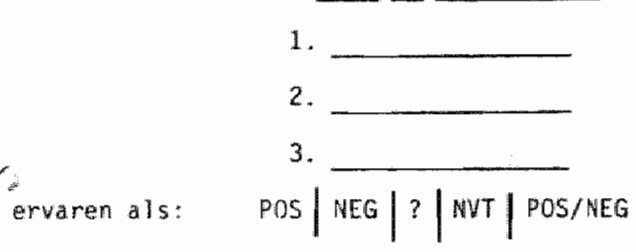

\section{op lange termijn}

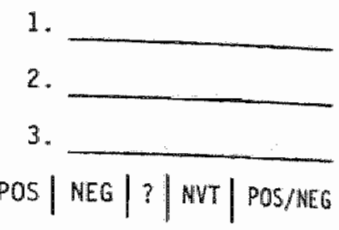

18. Zijn er ooit emstige problemem of konflikten geweest met buren,

$$
\begin{aligned}
& \text { vrienden, goede kennissen, of anderen? Ja Nee }+ \text { urg } 19 \\
& \text { - a. Wanneer? } \\
& \text {-- b. Met wite? }
\end{aligned}
$$

\section{Problenen/Konflikten buren, whienden, goede kenmissen}
a) meendere malen meegemaakt
MEE $|?|$ NVT
b) Woorbereid (aktief)
c) werwacht (op dat monient)
d) destijids overwegend ervaren als ....... POS
$\|$ NEE $|?| N Y$
e) op lange termijn ervaren als _......... POS
f) "social supoort"
\begin{tabular}{|l|l|l|l|l|l|l|} 
INEG & $?$ & NVT & POS/NEG
\end{tabular}

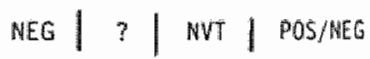 van welke personen: kort na gebeurtenis NEE ?

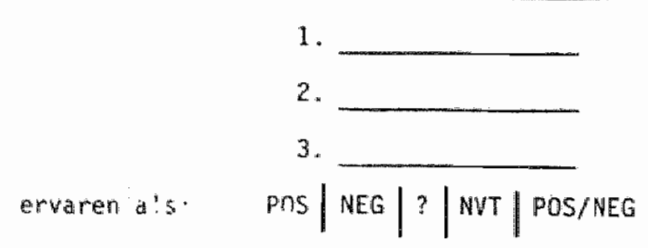 op lange termijn
1.
2.
3.
POS | NEG $|?|$ NVT $\mid$ POS/NEG 


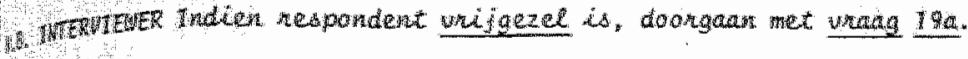

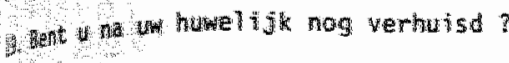

3a $\operatorname{targ} 20$

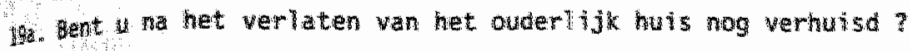

Ja Nee yra 21
- a. Wanneer ?
1.
4.
2.
5.
3.
6.

- . Op hoewel adressen heeft u gewoond?

- c. Blefef In dezelfo angeving ?

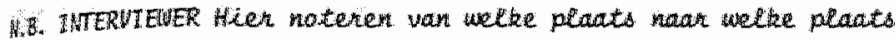

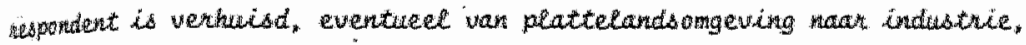

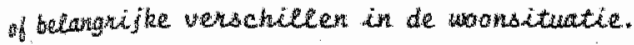

I.

2.

3.

4.

5.

\$.

Nehturizing(en)
d) Jutereme malen meeqemakt
JA $|\mathrm{NEE}| ? \mid \mathrm{WNT}$
3) worbereid (aktief)
JA $\mid$ NEE $|?|$ NUT
c) weruacht (op dat moment)
JA I NEE I ? NVT
d) destijes werwegend ervaren als
POS KEG
$?$
NVT POS/NEG
e) dange termijn evaren als -........- pos
| HEG ? I NVT POS/NEG

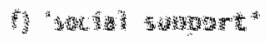

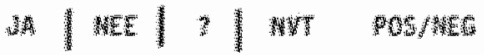

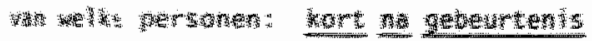

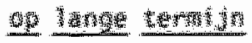

畒.

2

3.

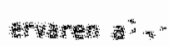

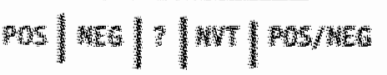

s.

2

管

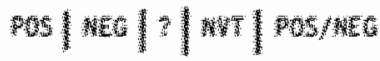




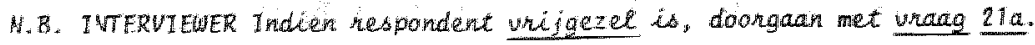

20. Heeft w echtgenote oolit buitenshuis gewerkt?

I

Nee $+\operatorname{vrg} 21$

- a. Wanneer

- b. Welke werkkring?

\section{Buitenshuis werken echtgenate}

a) meerdere malen meégemakt -.......... JA $\mid$ MEE | ? WVT

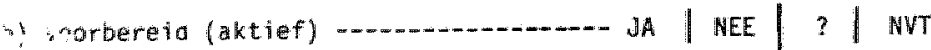

c: verwacht lop dat moment) -............. JA I NHEE | ? | NVT

d) destijds overwegend erwaren als -..-- POS | NEG

e) op lange termijn ervaren als -.......- POS | NEG |? | NVT I POS/NEG

f) "social support" -.................. IA $\mid$ NEE $|?|$ NVT POS/NEG van welke personen: kort na gebeurtenis op lange termign

1.

2.

3.

ervaren al: POS $\mid$ MEG $|?|$ NVT $\mid$ POS/NEG
1.

2.

3.

POS | NEG |? | NVT | POS/NEG

21. Zijn er binnen het gezin ernstige of langdurige financięle problemen gewerest?

$\mathrm{Ja} \quad \mathrm{Nee} \rightarrow \underline{\mathrm{urg}} 22$

21. Heeft u ernstige of langdurige fimanciele problemen gehad?

a. Wanneer?

Ja $\quad$ Nee $\rightarrow \underline{\operatorname{mrg}} \underline{22}$

\section{Ernstige/Langdurige financiele problemen}
a) meerdere malen meegemalkt
JA I NEE $|?|$ NVT
b) woorbereid (aktief)
NEE ? I NVT
c) verwacht (00 dat moment)
MEE | ? | NVT
d) destijds awerwegend ervaren als _..... pos
NEG | ? NWT | POS/NEG
e) op lange termign erwaren als POS | NEG | ? NWT | POS/NEG
f) 'sactall support.'
\begin{tabular}{l|l|ll} 
MUEE & $?$ & NVT & POS/NEG
\end{tabular}

van welke personer: kort na gebeurtenis

1.

2.

3.

ervarem $4: \cdots$
POS $\mid$ NEG |? NWT | POS/NEG op lange termijn

1.

2.

3.

POS || NEG | ? | NVT | POS/NEG 
22. Heeft u oolt een anzienlijke geldlening (bijw, hypotheek) afgesloten?

Ja. Nee $-\underline{\operatorname{urg} 23}$

-- a. Wanneer?

Afowiten acnzienlije geldkening

a) meerdere malen meegemakt -

b) voorbereid (aktief) -.... I I NEE

c) verwacht (op dat moment) -............. IA | NEE | IVT

d) destijds averwegend ervaren als -....- POS | MEG

e) OP lange termijn erwaren als -....... POS | NEG | ? IVT | POS/NEG

f) "social support" -....... JA | NEE | | NVT POS/NEG wan welke personen: kort na gebeurtenis op lange termijin

1.

2.

3.

ervaren alls: $\quad$ POS $\mid$ NEG $\mid$ ? | NWT | POS/NEG
1 .

2.

3.

POS | NEG |? | WNT | POS/NEG

23. Bent u ooit betrokken geweest bij een gerechterlijke procedure?

N.B. IWTFRUTEWER Bij een gescheiden respondent echtscheidingsprocedwe noemen, indien respondent dit vergeet.

$$
\mathrm{Ja} \quad \mathrm{Nee}+\underline{\mathrm{vrg}} 24
$$

-- a. Wanneer?

- b. Waarower?

\section{Gerechterkijke procedure}

a) meerdere malen meegemaakt _........ JA I NEE

b) voorbereid (aktief) -

c) verwacht (op dat moment) -............ JA I NEE | ? NVT

d) destijos overwegend ervaren als -..... POS I NEG $|?|$ NWT I POS/WEG

e) op lange temijn ervaren als -........ POS | NEG $\mid$ ? NVT | POS/NEG

1) 'socta support' van welke personen: kort na gebeurtents op lange termijn

1.

Z.

3.

ervarer a's: $\quad$ POS $\mid$ NEG $\mid$ ? NNT $\mid$ POS/NEG
1.

2 .

3.

POS $\mid$ NEG $|?|$ NVT $\mid$ POS/NEG 
24. Kunt u a angeven of de gebeurtentssen zods die mu zijo besproken m. b.t.

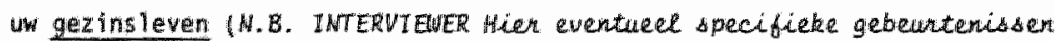
opwoemen) destijds van invloed zijn geweest op uw leefgewoonten, zod:s roken, drinken, eten, slapen, of op hoe uzich toen voelde?

\section{GEBEURTEHIS(SEH)}

$\begin{array}{cc}\text { A) Hoken Geen verandering } & 1 \\ \text { Toename } & 2 \\ \text { Afmame } & 3\end{array}$

B) Drinken (Allcohol) Geen verandering 1

Toename 2

Afname 3

c) Koffle

Geen verandering 1

Toename 2

Afname: 3

D) Eten

$\begin{array}{ll}\text { Geerl werandering } & 1 \\ \text { Toaname } & 2 \\ \text { Afname } & 3 \\ \text { Dverslaan } & 4\end{array}$

E) Slapen

$\begin{array}{cc}\text { Geen verandering } & 1 \\ \text { Toemane } & 2 \\ \text { Afname } & 3 \\ \text { Moeilijk inslapen } & 4 \\ \text { Moetilijk doorstapen } & 5\end{array}$

F) Perioden wan Neerslachtigheid

1

Vẹ

2

Lustelloosheid

3

Humeurig zijn/

Prikkel baa rhe id 
SOCIALE AKTIVTETTEN

1. Vrijetijusbesteding/iefhebberijen?

2. Aktiviteiten in het werenigingsleven ?

3. Ongang urienden/kenmissen ?

4. Politieke interesse ?

5. Kerkelijke interesse?

6. Andere aktututeiten? 


\section{HSTORTE}

1. Ervaren criststjo vốr Tweede Wereldoorlog?

2. Tweede Wereldoorlog:?

3. Hederopbouwtijd nå de oor $\log$ ?

4. Huldige ontwikkelingen van de laatste jaren, op het gebied van kerk, politfek en morad? 


\section{AD TYPOLOGTE}

\begin{tabular}{|c|c|}
\hline Respondent is Type & $A-1$ \\
\hline & $A-2$ \\
\hline & $x$ \\
\hline & $B-3$ \\
\hline & $B-4$ \\
\hline
\end{tabular}

Weet niet/ kan

niet zeggen $6+$ N.8. INTERUIEUER in dit gewal het gestuctureende interviow afnemen.

Op grond van het afgenomen gestructureerde interview is de respondent in te delen als:

Type A-1
\[ \begin{array}{cc}A-2 & 2 \\ X & 3 \\ B-3 & 4 \\ B-4 & 5\end{array} \]
Weet miet/kan
niet zeggen

Het is gewenst de respondent alsnag de JAS (Jenkins Activity Survey) te sturen: Ja Nere

- a. JAS verzonden d.d.

- b. JAS ontvangen d.d.

- c. JAS score 
$-292$ 


\section{List of Publications and Abstracts about Life-Span Development and Myocardial Infarction.}

01. Falger, P.R.J. (1978) Psychosociale risicofiactoren en coronaire hartziekte: Aantekeningen bij een symposium.

De Psycholoog, 13, 459-467.

02. Falger, P.R.J. (1979) Changes in "Work Load" as potential risk constellation for myocardial infarction: A review.

Gedrag, Tijdschrift voor PSychologie, 7, 96-114.

03. Falger, P.R.J. (1979) Pathogenic life changes in middle adulthood and coronary heart disease: A life-span developmental perspective.

Proceedings Jahrestagung Deutsche Gesellschaft fur Gerontologie, Sektion Psychologie und Sozialwissenschaften. Nürnberg (BRD), october.

04. Falger, P.R.J. (1980) Lebenslauf und Herzinfarkt: Proceedings Jahrestagung Deutsche Gesellschaft fur Gerontologie, Sektion Klinische Geriatrie. Berlin (BRD), september.

05. Falger, P.R.J., Bressers, I. \& Dijkstra, P. (1980) Levenslooppatronen van hartinfarctpatienten en van controlegroepen: Enkele overeenkomsten en verschillen.

Gerontologie, 11, 240-257.

06. Appels, A. \& Falger, P. (Eds.) (1980), The role of psychosocial factors in the pathogenesis of coronary heart disease.

Psychotherapy \& Psychosomatics, 34, (2-3), 73-223.

07. Falger, P.R.J. (1981) Behavioral factors, life changes, and the development of vital exhaustion and depression in myocardial infarction patients. 
Proceedings Sixth Biennial Meetings Intemational Society for the Study of Behavioural Development, symposium: Developmental Issues in Health Behavior. Toronto (CDN), augustus.

08. Falger., P.R.J. (1982) Factors contributing to the devellopment of vital exhaustion and depression in male myocardial infarction patients. Activitas Nervosa Superior (Praha), Suppl. 3, 151-156.

09. Falger, P.R.J. \& Appels, A.P.W.M. (1982) Psychosocial risk factors over the life course of myocardial infarction patients.

In H. Denolin (ed.), Psychological problems before and after myocardial infarction. Serie: Advances in Cardiology, Vol. 29. Basel: Karger, 132-139.

10. Falger, P.R.J. \& Bressers, I. (1982) Psychosoziale Belastung, Krisen und Verarbeitufigsstrategien im Lebenslauf von Herzinfarktpatienten.

Proceedings Jahrestagung Deutsche Gesellschaft für Gerontologie, Plenarsitzung. Bamberg (BRD), 23-25 september.

11. Falger, P.R.J. (1983) Pathogenic life changes in middle adulthood and coronary heart disease: Alife-span developmental perspective.

Intemational Journal of Aging and Human Development, 16, 7-27.

12. Falger, P.R.J. (1983) Behavioral factors, life changes, and the development of vital exhaustion and depression in myocardial infarction patients.

International Journal of Behavioural Development, 6, 405-425.

13. Falger, P.R.J. (1983) Psychosoziale Belastung, Krisen, Vitalitătsverlust und Depression im Lebenslauf von Herzinfarktpatienten. Zeitschrift für Gerontologie, 16, 121-129. 
14. Falger, P.R.J. (1983) Belastende levensgebeurtenissen en myocardinfarct: In A. Appels (red.), Psychologische risicofactoren voor het hartinfarct. Serie: Nederlandse Bibliotheek der Geneeskunde, d. 165. Alphen a/d Rijn: Stafleu, 89115.

15. Falger, P.R.J. (1983) Behavioral factors, stress and health in heart patients and controls: The South-Limburg Life History and Myocardial Infarction Study. Proceedings Seventh Biennial Meetings Intemational Society for the Study of Behovioural Development, symposium: Health and Self Concept in Adulthood and Old Age. München (BRD), 31 juli-4 augustus.

16. Appels, A.P.W.M. \& Falger, P.R.J. (1984) Ontwikkelingen in het psychosomatisch onderzoek over het hartinfarct.

The Practitioner, 1, 923-929.

17. Falger, P.R.J. (1984) Mijnsluiting, psychische en sociale aanpassing, en hartinfarct.

In K. Soudijn \& R.J. Takens (Red.), Psychologie en economische recessie. Ansterdam/Lisse, Nederlands Instituut van Psychologen/Swets \& Zeitlinger, 140-152.

18. Falger, P.R.J. (1984) Behavioral factors, stressful life changes, and depression in heart patients: Some results from the South-Limburg Life History \& Myocardial Infarction Study.

In R. Schwarzer (Ed.), The self in anxiety, stress and depression. Serie:Advances in Psychology, Vol. 21. Amsterdam: North Holland/Elsevier Science, 283-295.

19. Falger, P.R.J., Appels, A.P.W.M. \& Lulofs, R. (1984) Ontogenetic development and breakdown in adaptation: A review of psychosocial factors contributing to the development of myocardial infarction, and a description of a research program.

In J. Cullen \& J. Siegrist (Eds.), Breakdown in human adaptation to "stress": Towards a multidisciplinary approach, Vol. 1. Den Haag: Martinus Nijholf/ Commission of the European Communities, 159-187. 
20. Falger, P.R.J. \& Belkers, J. (1984) Psychosocial prodromall symptoms in myocardial infarction patients, surgical patients, and healthy referents. Proceedings Jahrestagung Deutsche Gesellschaff fur Gerontologie, Sektion Psychologie und Sozialwissenschaften. Frankfurt/Main, 22-24 september.

21. Falger, P.R.J. (1985) Levensloop, continuiteit en hartinfarct. In J. Schroots (Red.), Levenslooppsychologie. Lisse: Swets \& Zeitlinger, 53-58.

22. Falger, P.R.J. (1985) Life-span development and myocardial infarction: A casereferent study on 420 men.

Proceedings Sixth Annual Scientific Sessions Society of Behavioral Medicine, poster session: Behayioral Medicine Across the Life Cycle. New Orleans, LA (USA), 2730 maart.

23. Falger, P.R,J. (1985) Life course and myocardial infarction. Proceedings Thirteenth International Congress of Gerontology, paper session: Atherosclerosis: Clinical Aspects. New York, NY (USA), $12-17$ juli.

24. Falger, P.R.J. (1985) Biographische Amalyse und Herzinfarkt: Eine FallReferenzuntersuchung. Proceedings Siebente Tagung Entwicklungspsychologie, paper session: Klinische Psychogerontologie. Trier (BRD), 22-25 september.

25. Falger, P.R.J. (1986) Vital exhaustion and depression and Type A behaviour in myocardial infarction cases.

European Heart Journal, 7, Abstr. Suppl. 1, 5.

26. Falger, P.R.J., Appels, A.P.W.M. \& Bekkers, J. (1986) Biographische Analyse und Herzinfarkt: Eine Untersuchung an Herzinfarktpatienten und zwei Referenzgruppen.

Zeitschrift fiur Gerontologie, 19, 276-285. 
27. Falger, P.R.J. (1987) Biografische analyse en hartinfarct op middelbare leeftijd. Nederlands Tijdschrift voor de Psychologie, 42, 11-20.

28. Falger, P.R.J. (1987) Vitale uitputting en Type A gedrag alls risicofactor voor het hartinfarct.

Proceedings 13 e Bijeenkomst Werkgroep Epidemiologisch Onderzoek. Nederland, paper session: Howt- en vaatziektent, I. Maastricht (NL), 23-24 april.

29. Falger, P.R.J, Schouten, E.G.W. \& Appels, A.P.W.M. (1987) Sleep complaints, behaviorall characteristics and vital exhaustion in myocardial infaretion cases. Proceedings Eighth Annual Scientific Sessions Society of Behovioral Medicine, paper session: Biobehavioral Mechanisms of Coranary Heart Disease. Washington, DC (USA), 18-22 maart.

30. Falger, P.R.J. (1988) Life changes in middle adulthood, coronary-prone behavior, and vital exhaustion: Some retrospective findings.

In C. Spielberger, I. Sarason \& P. Defares (Eds.), Stress and Anxiety, Vol. 11. Washington, DC: Hemisphere, 151-161.

31. Falger, P.R.J. \& Schouten, E.G.W. (1988) Welke mensen krijgen een hartinfarct? Gedragsfactoren in de etiologie en bij de revalidatie. Gedrag \& Gezondheid, 15, 155-164.

32. Falger, P.R.J I, Schouten, E.G.W., Appels, A.P.W.M. \& De Vos, Y.C.M. (1988) Sleep complaints, behavioral characteristics, and vital exhaustion in myocardial infarction cases.

Psychology \& Health, 2, 231-258.

33. Falger, P.R.J., Schouten, E.G.W. \& Appels, A.P.W.M. (1988) Relationships be tween age, Type A coronary-prone behavior pattern, stressful life changes, and vital exhaustion in myocardial infarction cases: A case-referent study. 
Proceedings Ninth Annual Scientific Sessions Society of Behavioral Medicine, paper session: Behavioral Medicine Research on Aging and the Aged Boston, MA (USA), 27-30 april.

34. Falger, P.R.J. (1989) Levensgebeurtenissen en hartinfarct. The Practitioner, 6, 248-252.

35. Falger, P.R.J. (1989) Interactions of stressful life changes, cognitive factors, and vital exhaustion in myocardial infarction patients: A life-span developmental study.

In C. Spielberger, I. Sarason \& J. Strelau (Eds.), Stress and Anxiety, Vol. 12. Washington, DC: Hemisphere, 329-341.

36. Falger, P.R.J. \& Schouten, E.G.W. (1989) Levensioop en hartinfarct: Een epidemiologische studie in een ontogenetisch kader. Proceedings Comgres Psychon werkgemeenschap Ontwikkelingspsychologie, postersession. Amsterdam (NL), 14 april. 


\section{Curriculum Vitae}

De auteur van dit proefschrift werd geboren te Utrecht, op 23 september 1944. In 1964 behaalde hij er het eindexamen HBS-A aan het Thorbecke Lyceum. Van december 1965 tot juli 1974 studeerde hij aan de Rijksuniversiteit in zijn geboorteplaats, met als hoofdrichting sociale psychologie, en als nevenrichting algemene wetenschapsfilosofie en methodologie.

Van juli 1974 tot en met juni 1976 was hij als onderzoeksmedewerker verbonden aan de Stichting Sociaal Geriatrisch Gerontologisch Centrum te Rotterdam. Sedert 1 juli 1976 is hij werkzaam als wetenschappelijk medewerker/universitair docent bij de vakgroep Medische Psychologie van de Rijksuniwersiteit Limburg te Maastricht (hoofd: Prof.Dr. J.J.C.B. Bremer).

Het onderzoek, waarover in dit proefschrift verslag wordt gedaan, werd uitgevoerd binnen deelproject/divisie VII "Psychosociale factoren hart-yaatziekten" van het Hoofdproject Hart- en Vaatziekten (deelprojectleider: Prof.Dr. A.P.W.M. Appels).

De auteur is gehuwd, en heeft drie kinderen. 